\title{
Exploring the diagnostic pathway of symptomatic \\ cancer patients in the Netherlands
}



Exploring the diagnostic pathway of symptomatic cancer patients in the

Netherlands

Nicole van Erp 
Exploring the diagnostic pathway of symptomatic cancer patients in the Netherlands PhD dissertation, Utrecht University, The Netherlands

\section{(C) Nicole van Erp, 2020}

The copyright of the published articles has been transferred to the respective publishers. No part of this thesis may be reproduced, stored or transmitted, in any form or by any means, without prior permission of the author.

Cover design and layout Printing ISBN
Nicole van Erp

Ridderprint | www.ridderprint.nl

978-94-64I6-097-0

Financial support by 'Stichting beroepsopleiding Huisartsen (SBOH)', employer of GP trainees and Non Papa B.V. for the publication of this thesis is gratefully acknowledged. 


\title{
Exploring the diagnostic pathway of symptomatic cancer patients in the Netherlands
}

\author{
Een verkenning van het diagnostisch traject van \\ symptomatische kankerpatienten in Nederland \\ (met een samenvatting in het Nederlands)
}

\begin{abstract}
Proefschrift
ter verkrijging van de graad van doctor aan de Universiteit Utrecht op gezag van de rector magnificus, prof. dr. H.R.B.M.

Kummeling, ingevolge het besluit van het college voor promoties in het openbaar te verdedigen op donderdag 29 oktober des middags te 12:45 uur

door

Nicole Felice van Erp

geboren op I 2 januari 1988 te Huizen
\end{abstract}


Promotoren

Copromotor
Prof. dr. N.J. de Wit

Prof. dr. P.H.M. Peeters

Dr. C.W. Helsper 


\section{TABLE OF CONTENTS}

Chapter I General introduction

7

PART I The diagnostic pathway of symptomatic cancer patients in the Netherlands

Chapter 2 Time to diagnosis and treatment for cancer patients in the Netherlands: room for improvement?

Chapter 3 Time to diagnosis of symptomatic gastric- and oesophageal cancer in the Netherlands

Chapter 4 The diagnostic pathway of symptomatic kidney and bladder cancer

Chapter 5 Can we improve the diagnostic pathway of symptomatic ovarian cancer?

\section{PART II Exploring reasons for long duration to referral from primary care}

Chapter 6 Potential for reducing time to referral for colorectal cancer patients in primary care

Chapter 7 Reasons for long time to referral for nine cancer types: a thematic analysis

Chapter $8 \quad$ General discussion

Appendices

Abbreviations

General appendices

Summary

Nederlandse samenvatting

Dankwoord

About the author 
General Introduction 


\section{Cancer: a leading health problem}

One in three persons will be diagnosed with cancer at a point in their life. Due to population growth, changes in lifestyle and ageing, the annual number of patients newly diagnosed with cancer is rising. In 2018, over II6.000 patients were diagnosed with cancer in the Netherlands. For Dutch men, the most common cancer types currently are prostate cancer, skin cancer and lung cancer as compared to breast cancer, skin cancer and colorectal cancer for women.' Despite significantly improved therapeutic interventions, leading to increasing survival rates for most cancer types, cancer has been the leading cause of death in the Netherlands since 2007.

\section{Importance of a timely diagnosis}

Early detection of cancer is widely pursued. Main driver for this is to optimize disease outcomes. For almost all cancer types, prognosis is highly dependent on disease stage at diagnosis. For the four most common cancer types in the Netherlands (which are, besides skin cancer, colorectal cancer, breast cancer, lung cancer and prostate cancer), the five-year survival rate ranges from only I to $31 \%$ for patients with stage IV disease to 37 to $94 \%$ for patients with stage I disease.' Ensuring timely detection of cancer, at an early stage, is therefore a prime focus to improve the management and outcomes of cancer. There is growing evidence that prolonging the intervals between first symptom, presentation and diagnosis increases the risk of stage progression. ${ }^{2-5}$ This suggests that 'delay' should be avoided to attain the most optimal outcomes.

Another important reason for early detection of cancer is the patient experience. An inadequate or delayed diagnostic pathway in case of cancer suspicion negatively affects the perceived quality of life and patient satisfaction. ${ }^{6,7}$

\section{How to detect cancer early}

There are different strategies in the pursuit of early cancer diagnosis. One cornerstone of early cancer detection is screening of the asymptomatic population for certain types of cancer. The Netherlands has implemented population screening programmes for breast cancer, cervical cancer and, since 2014, for colorectal cancer. These cancer types meet the pre-set criteria to be eligible for population screening. ${ }^{8}$ Still, even for cancer types that are subject to screening programs, the majority of patients - up to $85 \%$ - is diagnosed after symptomatic presentation. ${ }^{9,10}$ Therefore, screening is not a guarantee for timely detection. Adequate recognition of cancer related symptoms by both patients and healthcare providers and prompt action where needed lie at the heart of early cancer detection. 
In healthcare systems where the general practitioner (GP) acts as a gatekeeper, patients are only referred to secondary healthcare services in case of relevant risk of serious disease. Therefore, the GP has a key role in the early recognition of symptomatic cancer. Healthcare systems with a strict gatekeeper role for the GP have significantly lower I-year relative cancer survival than systems without such gatekeeper functions." Although heavily debated, it was suggested that the gatekeeping role of GPs may have caused an adverse effect on cancer survival.

\section{The cancer diagnostic pathway}

The diagnostic pathway of cancer is divided in different time intervals, each encompassing a sequential phase from initial symptoms towards a cancer diagnosis. Figure I shows these intervals of the cancer diagnostic pathway for symptomatic patients in the Netherlands. These milestones and intervals are based on the definitions provided in the Aarhus statement, which promotes consistency in methods and measurements used in cancer diagnostic research. ${ }^{2}$ Timeliness of the route to diagnosis depends on the efficiency of all these intervals, in which delays may occur.

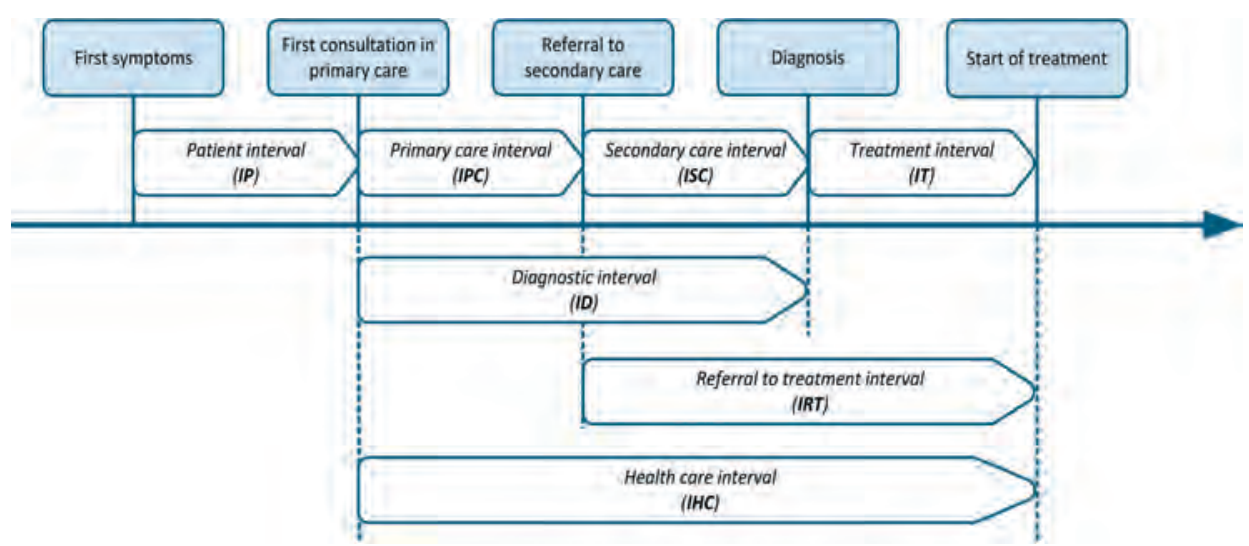

Figure I. Milestones and time intervals in the route from symptom onset to diagnosis and start of treatment.

\section{Differences in cancer survival across Europe: room for improvement?}

When compared to other countries in central and northern Europe, cancer survival rates in the Netherlands are mediocre and for some cancer types, such as gastric cancer, even significantly worse. ${ }^{13,14}$ Differences in cancer outcomes between countries are thought to at least partly reflect differences in diagnostic timeliness, and have led to international research exploring the cancer diagnostic process and factors influencing its efficiency. ${ }^{10,15-20}$ 
Most of the work in this field derives from Denmark and the United Kingdom (UK), both gatekeeper healthcare systems with relatively poor survival rates in European comparison. ${ }^{14}$ More recently, the International Cancer Benchmarking Partnership (ICBP) was initiated, with the aim to understand how and why cancer survival varies between participating countries. ${ }^{21}$ These studies show variation in duration of the diagnostic pathway and its intervals between cancer types, time periods and countries and suggest unrealised potential for improved pathways for several cancer types.

To be able to assess whether there is room for improvement in the diagnostic pathway of cancer in the Netherlands, knowledge is needed on the current variation in duration within and between the different intervals. This would demonstrate potential for reducing time to diagnosis and allow international comparison to determine best practices. Next, a thorough exploration of the reasons for delayed diagnostic intervals of individual patients would provide understanding of the background of delay or relatively long duration in the diagnostic pathway. This would enable targeted efforts to improve the diagnostic process. Since the GP plays a central role in the identification of symptomatic cancer in the Netherlands, the duration and reasons for long duration of the primary care interval are in particular need of detailed exploration.

\section{Aims and outline of this thesis}

In this thesis, we aim to explore the diagnostic pathway of symptomatic cancer patients in the Netherlands and to identify room for improvement.

Therefore, for symptomatic patients with ten types of cancer we:

I. Chart the duration of the different phases of the diagnostic pathway;

2. Identify patient- and presentation characteristics associated with 'long duration', with a focus on the primary care interval;

3. Perform an in depth analysis of the mechanisms explaining the longest durations to referral in primary care.

The ten types of cancer included in the research of this thesis are: cancer of the breast, colon, lung, prostate, oesophagus, stomach, kidney, bladder, ovaries and melanoma. This selection is based on the incidence of these cancers and the unfavourable balance between disease stage at detection and stage related survival. Together, these cancers are responsible for around $70 \%$ of total cancer incidence and two thirds of total cancer related mortality in the Netherlands.' 
In PART I of this thesis we present the duration of the different intervals of the diagnostic pathway for all ten cancer types, including characteristics associated with 'long duration' for a selection of cancer types.

Chapter 2 demonstrates the duration of the different intervals of the diagnostic pathway for the five most common cancer types in the Netherlands; breast cancer, colorectal cancer, prostate cancer, lung cancer and melanoma.

In chapter 3, we describe the diagnostic pathway of oesophageal- and gastric cancer, including characteristics associated with 'long duration' and the association between duration and tumour stage at diagnosis. Chapter $\mathbf{4}$ provides this information for kidneyand bladder cancer and chapter $\mathbf{5}$ for ovarian cancer.

In PART II of this thesis we explore reasons for long duration to referral in primary care.

In chapter $\mathbf{6}$ we focus on the potential for reducing time to referral from primary care for colorectal cancer patients.

Chapter 7 presents a thematic analysis of reasons for longest durations from presentation in primary care to referral for nine cancer types.

Finally, in chapter $\mathbf{8}$, the main findings and conclusions of this thesis are discussed. 


\section{REFERENCES}

I. Data from the Netherlands Cancer Registry, managed by The Netherlands Comprehensive Cancer Organisation [Internet].Available from: https://www.iknl.nl/nkr-cijfers. Accessed June 27, 2020.

2. Neal RD, Tharmanathan P, France B, Din NU, Cotton S, Fallon-Ferguson J, et al. Is increased time to diagnosis and treatment in symptomatic cancer associated with poorer outcomes? Systematic review. Br J Cancer 2015; I 12:S92-SI07.

3. Tørring ML, Murchie P, Hamilton W,Vedsted P, Esteva M, Lautrup M, et al. Evidence of advanced stage colorectal cancer with longer diagnostic intervals: a pooled analysis of seven primary care cohorts comprising II 720 patients in five countries. Br J Cancer 20 I 7; I I 7:888-897.

4. Tørring ML, Falborg AZ, Jensen H, Neal RD, Weller D, Reguilon I, et al.Advanced-stage cancer and time to diagnosis:An International Cancer Benchmarking Partnership (ICBP) cross-sectional study. Eur J Cancer Care 2019;28.

5. Arhi CS, Markar S, Burns EM, Bouras G, Bottle A, Hanna G, et al. Delays in referral from primary care are associated with a worse survival in patients with esophagogastric cancer. Dis Esophagus 2019;32:I-II.

6. Booij JC, Zegers M, Evers PMPJ, Hendriks M, Delnoij DMJ, Rademakers JJDJM. Improving cancer patient care: Development of a generic cancer consumer quality index questionnaire for cancer patients. BMC Cancer 2013;13.

7. Montgomery M, McCrone SH. Psychological distress associated with the diagnostic phase for suspected breast cancer: Systematic review. J Adv Nurs 2010;66:2372-2390.

8. Wilson J, Jungner G. Principles and practice of screening for disease [Internet]. Geneva; 1968. Available from: http://www.who.int/bulletin/volumes/86/4/07-050 I I2BP.pdf. Accessed May I2, 2020.

9. Elliss-Brookes L, McPhail S, Ives A, Greenslade M, Shelton J, Hiom S, et al. Routes to diagnosis for cancer - Determining the patient journey using multiple routine data sets. $\mathrm{Br} J$ Cancer 2012;107:1220-1226.

10. Hansen RP,Vedsted P, Sokolowski I, Søndergaard J, Olesen F.Time intervals from first symptom to treatment of cancer: a cohort study of 2,212 newly diagnosed cancer patients. BMC Health Serv Res 201।;। I:284.

II. Vedsted P, Olesen F.Are the serious problems in cancer survival partly rooted in gatekeeper principles? Br J Gen Pract 2011;61:661.

12. Weller D,Vedsted P, Rubin G,Walter FM, Emery J, Scott S, et al. The Aarhus statement: improving design and reporting of studies on early cancer diagnosis. Br J Cancer 2012; 106:1262-1267.

13. Eurostat Cancer Statistics [Internet].Available from: https://ec.europa.eu/eurostat/statisticsexplained/index.php?title=Cancer_statistics.Accessed February 10, 2020.

14. De Angelis R, Sant M, Coleman MP, Francisci S, Baili P, Pierannunzio D, et al. Cancer survival in Europe 1999-2007 by country and age: results of EUROCARE-5-a population-based study. Lancet Oncol 2013;2045:1-12. 
15. Lyratzopoulos G, Saunders CL, Abel GA, McPhail S, Neal RD,Wardle J, et al. The relative length of the patient and the primary care interval in patients with 28 common and rarer cancers. $\mathrm{Br} J$ Cancer 2015; I 12:S35-S40.

16. Swann R, McPhail S, Shand B, Rashbass J,Witt J,Abel GA, et al. Diagnosing cancer in primary care: Results from the National Cancer Diagnosis Audit. Br J Gen Pract 2018;68:e63-e72.

17. Menon U,Vedsted P, Zalounina Falborg A, Jensen H, Harrison S, Reguilon I, et al. Time intervals and routes to diagnosis for lung cancer in 10 jurisdictions: Cross-sectional study findings from the International Cancer Benchmarking Partnership (ICBP). BMJ Open 2019;9:e025895.

18. Weller D, Menon U, Zalounina Falborg A, Jensen H, Barisic A, Knudsen AK, et al. Diagnostic routes and time intervals for patients with colorectal cancer in 10 international jurisdictions; Findings from a cross-sectional study from the International Cancer Benchmarking Partnership (ICBP). BMJ Open 2018;8: e023870.

19. Jensen H,Tørring ML, Olesen F, Overgaard J, Fenger-Grøn M, Vedsted P. Diagnostic intervals before and after implementation of cancer patient pathways - a GP survey and registry based comparison of three cohorts of cancer patients. BMC Cancer 2015; 15:308.

20. Din NU, Ukoumunne OC, Rubin G, Hamilton W, Carter B, Stapley S, et al. Age and Gender Variations in Cancer Diagnostic Intervals in 15 Cancers:Analysis of Data from the UK Clinical Practice Research Datalink. PLoS One 2015;10:e0127717.

21. Butler J, Foot C, Bomb M, Hiom S, Coleman M, Bryant H, et al. The International Cancer Benchmarking Partnership:An international collaboration to inform cancer policy in Australia, Canada, Denmark, Norway, Sweden and the United Kingdom. Health Policy 20 I3; I I2: I48-155. 



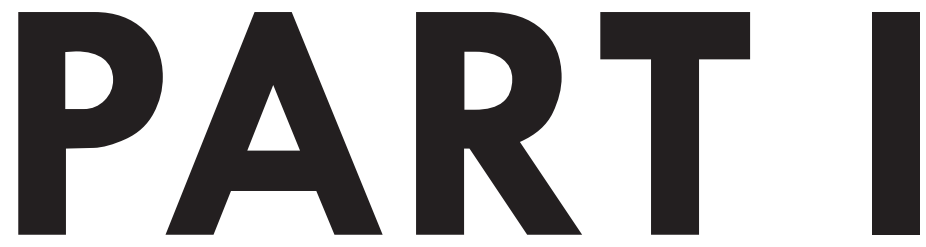

The diagnostic pathway of symptomatic cancer patients in the Netherlands

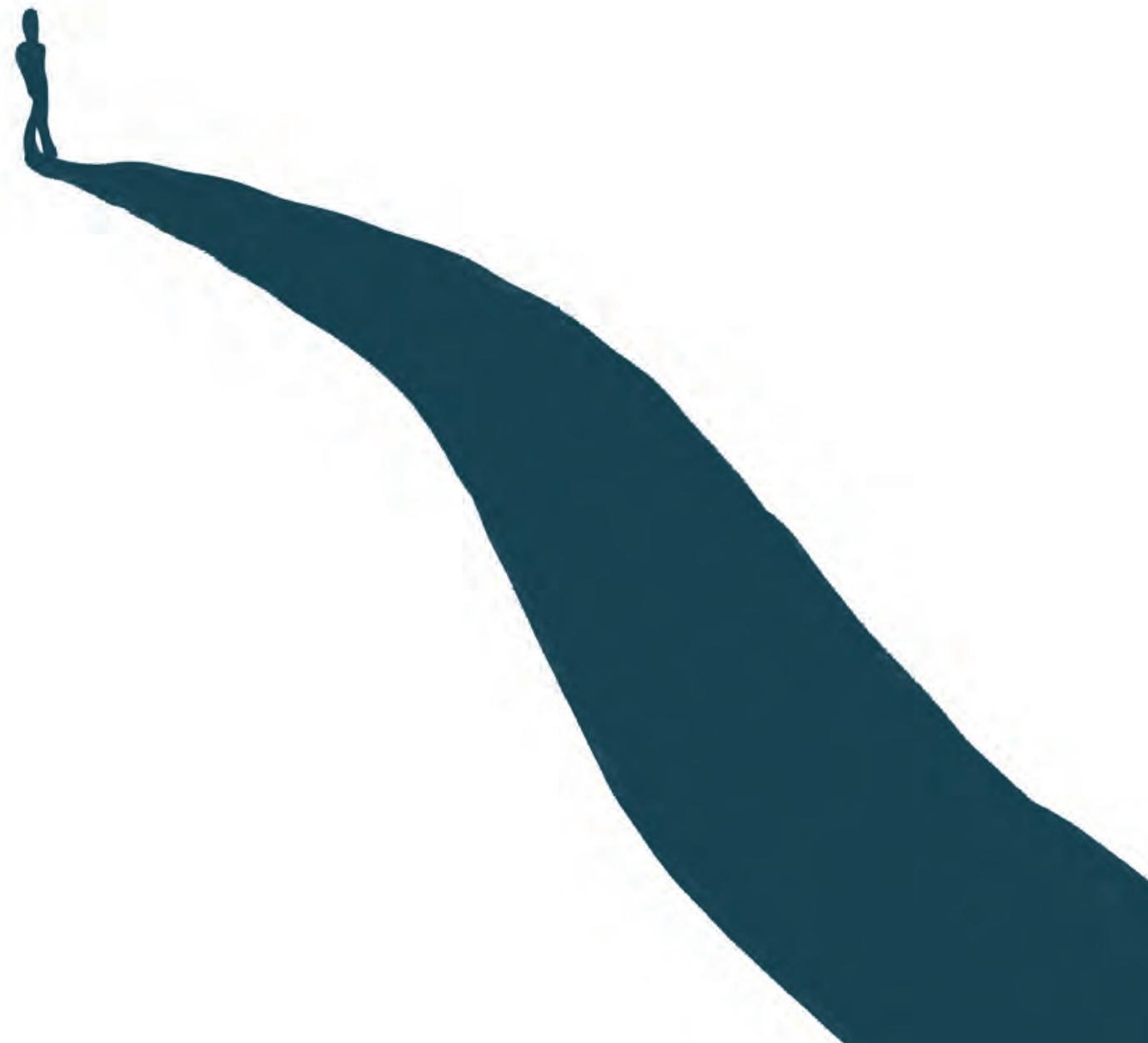




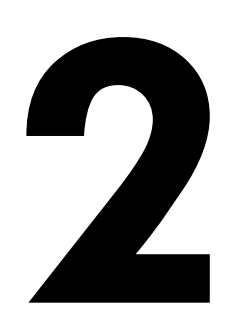

\title{
Time to diagnosis and treatment for cancer patients in the Netherlands: room for improvement?
}

\author{
Nicole F. van Erp* \\ Charles W. Helsper* \\ Petra H.M. Peeters \\ Niek J. de Wit
}

*First and second author share first authorship.

European Journal of Cancer 2017;87: I |3-121

For consistency throughout the thesis, some terms used in the original article were altered. 


\section{ABSTRACT}

Background: Reducing the duration of the diagnostic cancer care pathway is intensively pursued. The aim of this study was to chart the diagnostic pathway for the five most common cancers in the Netherlands.

Methods: A retrospective cohort study using cancer patients' anonymised primary care data (free text and coded) linked to the Netherlands Cancer Registry. We determined the median duration of the following: I. Primary care intervals (IPCs): the first cancer-related general practitioner consultation to referral, 2. Secondary care intervals (ISCs): referral to diagnosis, 3. Treatment intervals (ITs): diagnosis to treatment and the overarching intervals, 4. Diagnostic intervals (IDs): IPC and ISC combined and 5. Health care intervals (IHCs): IPC, ISC and IT combined.

Results: For 465, 309, 197, 237 and 149 patients diagnosed with breast-, colorectal-, lung-, prostate cancer and melanoma, respectively; median IPC, ISC and ID durations were shortest for breast cancer and melanoma (ID duration 7 and 21 days, respectively), intermediate for lung and colon cancer (ID duration 49 and 54 days) and the longest for prostate cancer (ID duration 137 days). For all cancers, the duration of intervals increased steeply for the 10-25\% with longest durations. For colorectal cancer, increasing ID durations showed increasing proportions of time attributable to primary care (IPC).

Conclusion: Approximately 10-25\% of cancer patients show substantially long duration of diagnostic intervals. Reducing primary care delay seems particularly relevant for colorectal cancer. 


\section{INTRODUCTION}

Despite improving treatment outcomes, cancer is a major health problem with high morbidity and mortality rates worldwide. Prognosis largely depends on tumour stage at diagnosis. ${ }^{1,2}$ Early diagnosis and treatment is considered vital to improve patient outcome and to reduce time spent in insecurity for patients. ${ }^{3,4}$ Even though the association between time intervals in the diagnostic pathway and clinical outcomes is complex and remains debated, evidence suggests worse outcomes after longer diagnostic intervals. ${ }^{5,6}$ Optimising the diagnostic pathway from first presentation to diagnosis and start of treatment, usually interpreted as shortening the diagnostic phase, has therefore been a main objective of health care organisations involved in cancer care worldwide.

The Aarhus statement defines several key time points and associated intervals in the diagnostic pathway. ${ }^{7}$ The primary care interval (IPC) is the time between the first cancer symptom related contact with the general practitioner (GP) and its corresponding referral to secondary care. The secondary care interval (ISC) can be defined as the time from referral to histological diagnosis and the treatment interval (IT) is defined as the time from diagnosis to initiation of the treatment. Overarching intervals are the diagnostic interval (ID): the time from the first presentation to the GP to diagnosis and the health care interval $(\mathrm{IHC})$ : the time from the first presentation to the GP to initial treatment.

For some countries in Europe, the duration of several of these intervals has been charted. All diagnostic intervals, but particularly the IPC, are usually shorter for cancers presenting with visible or palpable symptoms such as breast cancer and melanoma. ${ }^{4,8-11}$ For other countries, such as the Netherlands, the duration of these intervals is unknown.

International comparison of the duration of IDs in different health care systems and cultural environments is important to identify system-, disease- and patient-related factors that contribute to an unnecessarily prolonged patient journey. Analyses of cancer survival rates show that health care systems with a gatekeeping role of the GP have a significantly lower relative cancer survival than systems without a gatekeeper function. ${ }^{12}$ This observation was followed by a study addressing the question if serious problems in cancer survival are partly rooted in gatekeeper principles. ${ }^{13}$ This ecologic analysis of relatively old data showed that having a gatekeeper system was associated with lower I-year survival in health care systems with primary care-based gatekeeping.

These findings suggest that a primary care-based gatekeeper system could delay cancer diagnosis as a result of a long duration of the ID and the underlying IPC and ISC. The health care system in the Netherlands is based on a strict gatekeeper role of the GP, 
which means secondary care facilities are almost exclusively accessible through referral from primary care (see Box I). Exploring the duration of the diagnostic pathway in the Netherlands and the contribution of primary care to this pathway, generate relevant information on international differences in the duration of the diagnostic pathway. This provides the opportunity to distinguish underlying mechanisms of delay, including system-, disease- and patient-related delay.

Box I. Organisation and characteristics of primary care in the Netherlands.

\section{Primary care in the Netherlands}

- $\quad$ All Dutch citizens are listed with a GP.

- GP services are free: costs for GP encounters are covered by basic insurance, which is obligatory for every citizen by law.

- The GP is the gatekeeper to secondary care.

- At the time of the study there were approximately 8,900 employed GP's in the Netherlands. ${ }^{14}$

- The practice norm for number of patients was 2,350 patients per GP practice. ${ }^{15}$

- For $75 \%$ of Dutch citizens the nearest GP was situated within one kilometer, and for less than $1 \%$ of the people, this distance was longer than five kilometers. ${ }^{16}$

\section{Primary care and cancer}

- On average, a full time Dutch GP sees 25 new adult cancer patients each year (including all types of skin cancer). ${ }^{17}$

- In the study period, a national screening program for breast cancer and cervical cancer was available in the Netherlands. For colorectal cancer a national screening programme started in 2014.

Therefore, we aim to assess the duration of the diagnostic pathway and its underlying intervals for the five most frequently occurring cancer types in the Netherlands: colorectal-, breast-, lung-, prostate cancer and melanoma, with a particular focus on the potential role of the GP in the diagnostic process.

\section{METHODS}

\section{Design}

We conducted a retrospective cohort study using routine primary care data from the Julius General Practitioners Network (JGPN) database, linked to the data of the Netherlands Cancer Registry (NCR). We used a trusted third-party linkage procedure to comply with privacy regulations of the Dutch law. The JGPN, the NCR and the linkage 
procedure are described in detail elsewhere. ${ }^{18}$ The Research Ethics Committee of the University Medical Center Utrecht judged the study exempt from assessment because this study uses only anonymized patient data.

\section{Population}

The JGPN is a database containing routine care registrations of 200 GPs with 300,000 patients. Its population is considered representative for the Dutch population. ${ }^{19}$ The NCR is a population-based registry with detailed diagnostic and therapeutic data of over $95 \%$ of Dutch cancer patients since $1989 .{ }^{20}$

The linked data set contains anonymous coded and free text information. In the JGPN, free text data of consultations are available for patient symptoms, physical examination, working diagnosis and initiated policy. Coded information is available for working diagnoses, using the International Classification of Primary Care I (ICPC-I) coding system and for medication. ${ }^{21}$ For each consultation the date is registered. The NCR is tumour based and includes date and histological details of cancer diagnoses such as disease stage, malignancy grade, morphology, localisation, date and type of the first treatment. Cancer type is coded using the International Classification of Diseases for Oncology (ICD-O) coding system.

\section{Case selection}

All patients aged 20-90 occurring in both registries (JGPN and NCR) with a corresponding ICPC and ICD-O code for breast-, colorectal-, lung- or prostate cancer between 2007 and $20 \mathrm{II}$ were included. Because of the relatively low incidence rate, we extracted data on melanoma from 2004 to 201 I. Based on free text information, we selected patients who presented to the GP with symptoms, which were directly or indirectly linked to the cancer and were referred by the GP.We also selected breast cancer patients detected through screening. Of the five most common cancer types, only breast cancer had a fully implemented screening program in the Netherlands during the observation period. Women aged 50-75 years receive an invitation for mammography every 2 years and are referred for diagnostic work-up by their GP in case of a suspicious finding. National colorectal cancer screening started several years after our observation period.

\section{Data collection}

The relevant duration, disease- and patient related data were collected from the JGPN and NCR by medically trained researchers with experience in the primary care field. Data were manually checked from 5 years before the date of histological diagnosis up 
to I year after the diagnosis. We included I year after diagnosis because it may contain information on the pathway and explain some discrepancies between diagnostic date in the NCR and diagnostic date in the JGPN. Backdating diagnostic dates in the GPs registration is mandatory according to registration guidelines, but may be forgotten.

From the JGPN, we extracted baseline patient characteristics (age and gender), signs and symptoms and date of the first consultation and referral. From the NCR, we extracted details of cancer diagnoses and date of diagnosis and treatment initiation.

Definitions of the intervals were in agreement with the key time points of the Aarhus statement (Figure I). ${ }^{7}$ The date of the first cancer-related GP consultation was defined as the first contact (physical or telephone) with the GP for suspected cancer-related signs or symptoms. The first presentation of more and less specific cancer-related complaints to the GP was determined by scrutinising the free text of all consultations preceding the diagnosis. In case of doubt concerning the first cancer-related sign or symptom presentation, the consultation with the complaint that eventually led to the diagnosis was chosen. For prostate cancer, the start of IPC was defined as; presentation of symptoms or signs (including elevated prostate specific antigen) leading to diagnosis. For breast cancer screening, the start of IPC was defined as the day that the GP receives notification of a suspicious screening result (mammogram) for one of his patients.

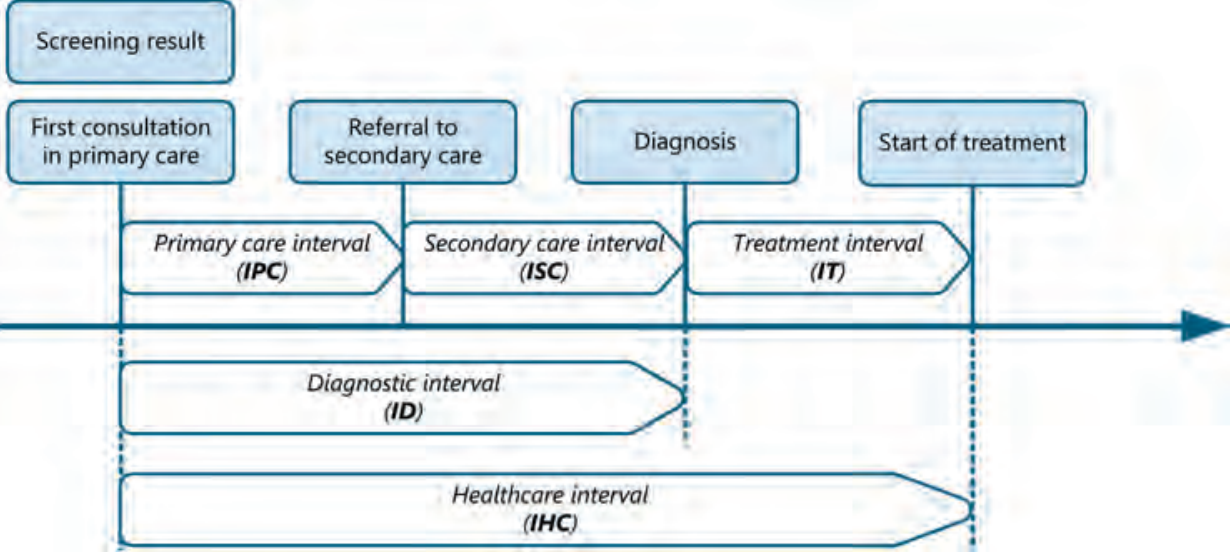

Figure I. Overview of the cancer diagnostic pathway and its intervals. 
The date of referral was defined as the moment when the responsibility for the patient was transferred from a GP to secondary care. In case of multiple referrals, or crossreferrals in secondary care, the first referral for further exploration of the cancer-related symptom(s) was chosen.

Date of diagnosis was retrieved from the NCR data. The NCR uses the hierarchy for the time of diagnosis, as provided by the European Network of Cancer Registries (www. encr.eu/images/docs/recommendations/incideng.pdf), which is in accordance with the preferred date of diagnosis in the Aarhus Statement. ${ }^{7}$ The NCR receives diagnostic details, including the date of histological confirmation, for all malignant diagnoses from the nationwide network and registry of histo- and cytopathology in the Netherlands (PALGA). PALGA receives data from histological and cytological biopsies from $99 \%$ of all laboratories in the Netherlands. The NCR also receives diagnostic details from clinical records in the hospitals, which are used if details from PALGA are unavailable. For over $98 \%$ of the included patients with breast-, colorectal-, prostate cancer and melanoma, and for $64 \%$ of the lung cancer patients in this study, the date of diagnosis was the date of the histological confirmation of the primary tumour.

The date of treatment initiation denotes the date of start of therapy as registered in the NCR. The NCR uses the hospital medical records to retrieve this information. The date of treatment is absent in case of no initiated therapy. Only for melanoma, in case of two consecutive treatments, the second was considered as the date of treatment, presuming the first date concerns the diagnostic excision. The pathways for melanoma patients were stratified according to diagnostic pathway: I. Referred by the GP for diagnostic excision or 2. Diagnostic excision performed by the GP.This policy was determined based on the free text information. The pathways for breast cancer patients were described separately for symptomatic women who presented to the GP and those found through the national screening program.

\section{Statistical analysis}

Descriptive statistics were used to describe the baseline characteristics of the study population. We report both the median (interquartile interval, IQI) duration of the separate (IPC, ISC and IT) and overarching (ID and IHC) intervals. The cut-off for the $25 \%$ and $10 \%$ of patients with the longest durations are defined below as 'P75' and 'P90', respectively. Same-day proceedings were counted as I day; therefore, we consistently added I day to all durations. The proportion of ID attributable to primary care (IPC) was determined for each quartile of ID duration. This proportion IPC of ID was expressed as median percentages in each consecutive quartile of ID.Analyses were performed in SPSS, version 22.0 (SPSS Inc., Chicago, IL, USA). 


\section{RESULTS}

\section{Baseline characteristics}

We found 465, 309, 197, 237 and 149 patients with breast-, colorectal-, lung-, prostate cancer and melanoma, respectively, presenting to and referred from primary care. These patients include 61\% (lung cancer), 71\% (prostate cancer and melanoma), 73\% (colorectal cancer) and $77 \%$ (breast cancer) of all patients registered with these cancers in both the JGPN and the NCR in the study period. Patient characteristics are described in Table I. $A$ list of the cancer-related signs and symptoms presented at the first GP consultation (start IPC) is available in Appendix I.

Table I. Characteristics of the included cancer patients at the start of the diagnostic interval.

\begin{tabular}{|c|c|c|c|c|c|c|}
\hline \multirow[t]{2}{*}{ Characteristics } & \multicolumn{2}{|c|}{$\begin{array}{l}\text { Breast cancer } \\
\text { total } n=465\end{array}$} & \multirow[t]{2}{*}{$\begin{array}{l}\text { Colorectal } \\
\text { cancer }\end{array}$} & \multirow[t]{2}{*}{ Lung cancer } & \multirow[t]{2}{*}{$\begin{array}{l}\text { Prostate } \\
\text { cancer }\end{array}$} & \multirow[t]{2}{*}{ Melanoma } \\
\hline & Screening & Symptom & & & & \\
\hline Population (N) & 164 & 301 & 309 & 197 & 237 & 149 \\
\hline \multicolumn{7}{|l|}{ Gender } \\
\hline Female N (\%) & $164(100)$ & $301(100)$ & I54 (49.8) & $91(46.2)$ & $0(0.0)$ & $82(55.0)$ \\
\hline \multicolumn{7}{|l|}{ Age } \\
\hline Mean \pm SD & $60.9 \pm 7.9$ & $57.2 \pm 15.5$ & $66.7 \pm 12.2$ & $66.5 \pm 10.7$ & $67.1 \pm 7.6$ & $55.2 \pm 15.6$ \\
\hline Median (IQI) & $\begin{array}{l}61.0 \\
(53.0-67.0)\end{array}$ & $\begin{array}{l}54.0 \\
(45.0-69.0)\end{array}$ & $\begin{array}{l}68.0 \\
(60.0-75.5)\end{array}$ & $\begin{array}{l}68.0 \\
(59.0-75.0)\end{array}$ & $\begin{array}{l}67.0 \\
(62.0-72.0)\end{array}$ & $\begin{array}{l}55.0 \\
(43.0-66.0)\end{array}$ \\
\hline
\end{tabular}

For breast cancer, 164 of 465 (35\%) were found through screening. Breast cancer patients diagnosed through screening were slightly older and had more favourable tumour stages. Of the 149 melanoma patients, $75 \%$ was referred to secondary care for diagnostic excision of a suspicious pigmented lesion. In $25 \%$ of melanoma patients the initial (diagnostic) excision was performed by the GP. They were relatively young patients, and their lesions were generally not located on visible body parts. There was no difference in tumour stage distribution in the two melanoma diagnostic pathways.

\section{Duration of the intervals}

The date of first consultation, referral and diagnosis was available for over $95 \%$ of patients for all five cancer types. The date of treatment was not available for $5 \%$ of breast and colorectal cancer patients and $20-42 \%$ of melanoma, lung- and prostate cancer patients. 
Table 2. Duration of the different intervals of the diagnostic pathway in days.

\begin{tabular}{|c|c|c|c|c|c|}
\hline & IPC & ISC & IT & ID & IHC \\
\hline $\begin{array}{l}\text { Breast - } \\
\text { symptomatic }\end{array}$ & $\mathrm{n}=295$ & $\mathrm{n}=295$ & $\mathrm{n}=284$ & $\mathrm{n}=301$ & $n=284$ \\
\hline Median (IQI) & $I(I-I)$ & $6(3-10)$ & $21(15-28)$ & $7(3-13)$ & $29(22-43)$ \\
\hline P90 value & 4 & 20 & 40 & 36 & 61 \\
\hline Range & I-267 & I-583 & $1-98$ & I-583 & $7-609$ \\
\hline $\begin{array}{l}\text { Breast - } \\
\text { screening }\end{array}$ & $n=158^{a}$ & $n=158$ & $n=164$ & $n=164$ & $n=164$ \\
\hline Median (IQI) & I (I-4) & $8(5-12)$ & $22(16-30)$ & $10(6-15)$ & $32(24-44)$ \\
\hline $\mathrm{P} 90$ value & 8 & 23 & 40.5 & 24.5 & 62 \\
\hline Range & $1-16$ & $1-172$ & I-107 & $2-174$ & $14-183$ \\
\hline Colorectal & $\mathrm{n}=309$ & $\mathrm{n}=309$ & $\mathrm{n}=295$ & $\mathrm{n}=309$ & $\mathrm{n}=295$ \\
\hline Median (IQI) & $8(1-59)$ & $26(13-54)$ & $27(15-39)$ & $54(2|-| 16)$ & $82(50-152)$ \\
\hline P90 value & 219 & 96 & 50 & 316 & 313 \\
\hline Range & I-II77 & I-864 & I-78 & $1-1226$ & $\mathrm{I}-1244$ \\
\hline Lung & $n=197$ & $n=197$ & $n=139$ & $n=197$ & $n=139$ \\
\hline Median (IQI) & $13(2-36)$ & $2 I(9-5 I)$ & $22(9-38)$ & $49(23-83)$ & $76(49-117)$ \\
\hline $\mathrm{P} 90$ value & 66 & 93 & 56 & 162 & 187 \\
\hline Range & $\mathrm{I}-484$ & $-22^{b}-250$ & $1-105$ & $3-513$ & $14-563$ \\
\hline Prostate & $n=237$ & $n=237$ & $n=159$ & $\mathrm{n}=237$ & $n=159$ \\
\hline Median (IQI) & $14(3-153)$ & $51(28-203)$ & $65(34-92)$ & $137(44-639)$ & $237(124-734)$ \\
\hline P90 value & 637 & 769 & 129 & 1310 & $137 \mid$ \\
\hline Range & $|-| 63 \mid$ & $1-1825$ & $|-8| \mid$ & $5-1985$ & $8-2040$ \\
\hline $\begin{array}{l}\text { Melanoma } \\
\text { referred }\end{array}$ & $n=107$ & $n=107$ & $n=92^{c}$ & $n=111$ & $\mathrm{n}=92^{\mathrm{c}}$ \\
\hline Median (IQI) & $I(I-I)$ & $20(9-43)$ & $35(22-46)$ & $21(9-50)$ & $57(37-85)$ \\
\hline P90 value & 15 & 61 & 59 & 106 & 148 \\
\hline Range & I-996 & $1-609$ & $1-108$ & $1-996$ & $4-1020$ \\
\hline $\begin{array}{l}\text { Melanoma by } \\
\text { GP }\end{array}$ & $\mathrm{n}=32^{\mathrm{d}}$ & n.a. & $n=23^{c}$ & $n=38$ & $n=23^{c}$ \\
\hline Median (IQI) & $8.5(4-35)$ & n.a. & $29(19-39)$ & $17(8-65)$ & $47(28-92)$ \\
\hline P90 value & 214 & n.a. & 51 & 229 & 170 \\
\hline Range & $1-1289$ & n.a. & $8-419$ & $|-| 29 \mid$ & $20-1327$ \\
\hline
\end{tabular}

IPC, primary care interval; ISC, secondary care interval; IT, treatment interval; ID, diagnostic interval; IHC, health care interval; IQI, interquartile interval; GP, general practitioner; n.a., not applicable.

${ }^{a}$ Duration from notification at GP of suspicious finding in screening programme to referral by GP.

${ }^{b}$ Referral from primary care after diagnosis in secondary care.

c IT and IHC are based on the second treatment date. Therefore, these analyses exclude the II\% of melanoma cases for whom the diagnostic excision might have been the therapeutic excision (i.e. patients with biopsy with free demarcation may be left out of this analysis).

${ }^{d}$ Duration from first consultation to diagnostic excision procedure by GP. 

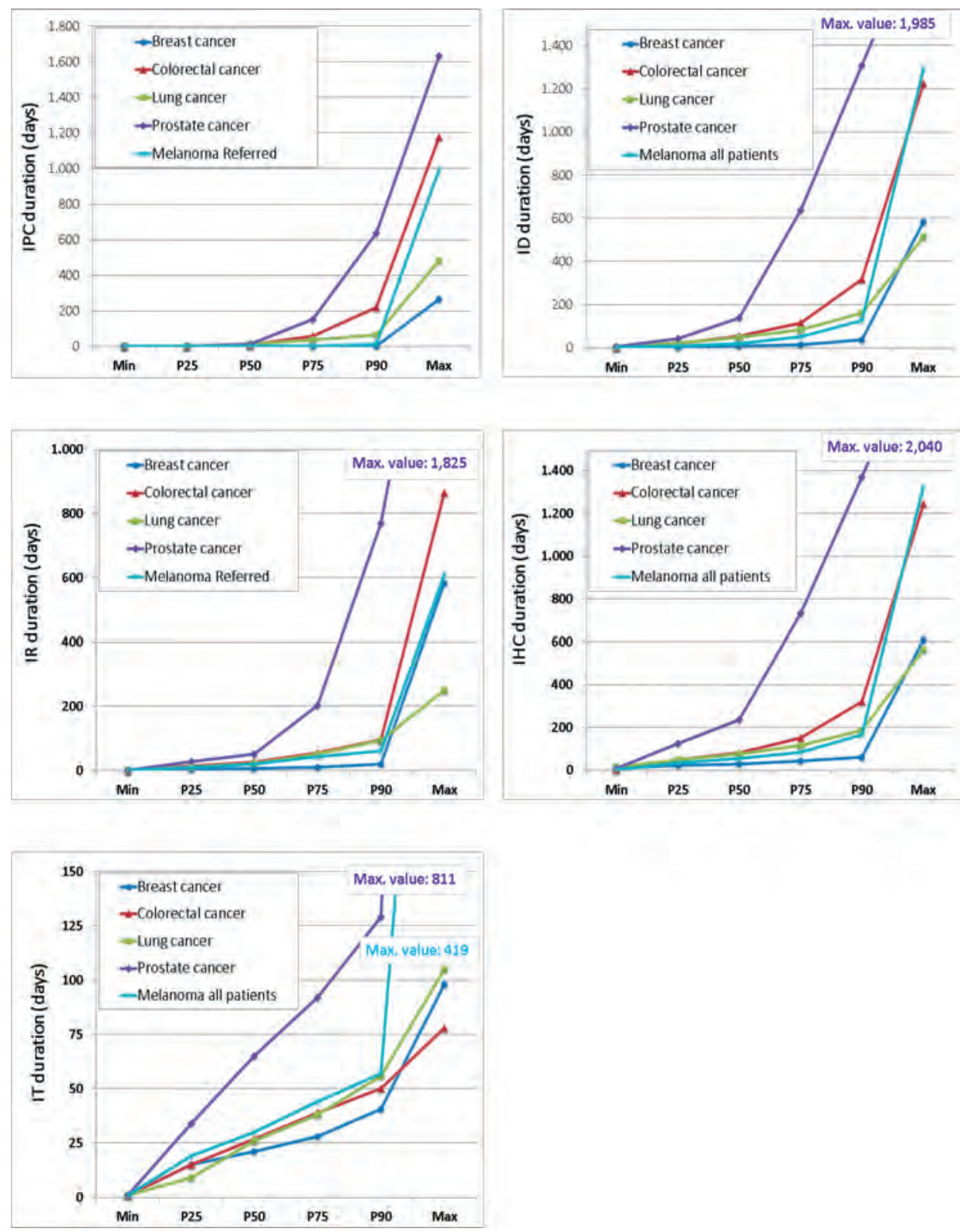

Figure 2. Phase-related duration for symptomatic patients with five common cancers.

IPC, primary care interval; ISC, secondary care interval; IT, treatment interval; ID, diagnostic interval; IHC, health care interval; Min, minimum value; P25, 25th percentile; P50, 50th percentile (median); P75, 75th percentile; P90, 90th percentile; Max. value, maximum value. 
Median duration (IQI, P90 value) for each interval for all cancer types can be found in Table 2 and Figure 2. Distribution of duration of all intervals was highly right skewed for all cancers.

IPC: Median duration of IPC varied from I day (breast cancer and melanoma), to 2 weeks (lung and prostate cancer). Over 75\% (<P75) of symptomatic breast cancer and melanoma patients were referred on the same day of presentation to the GP.

ISC: Median duration of ISC ranged from 6 days (breast) to 5 I days (prostate). IT: Median duration of IT was between 21 and 29 days, except for prostate cancer (65 days).

Median ID and IHC duration ranges were 7-137 days and 29-237 days, respectively. Medians and P75 values were the highest for prostate cancer, lowest for breast cancer and melanoma and in between for colorectal cancer and lung cancer.

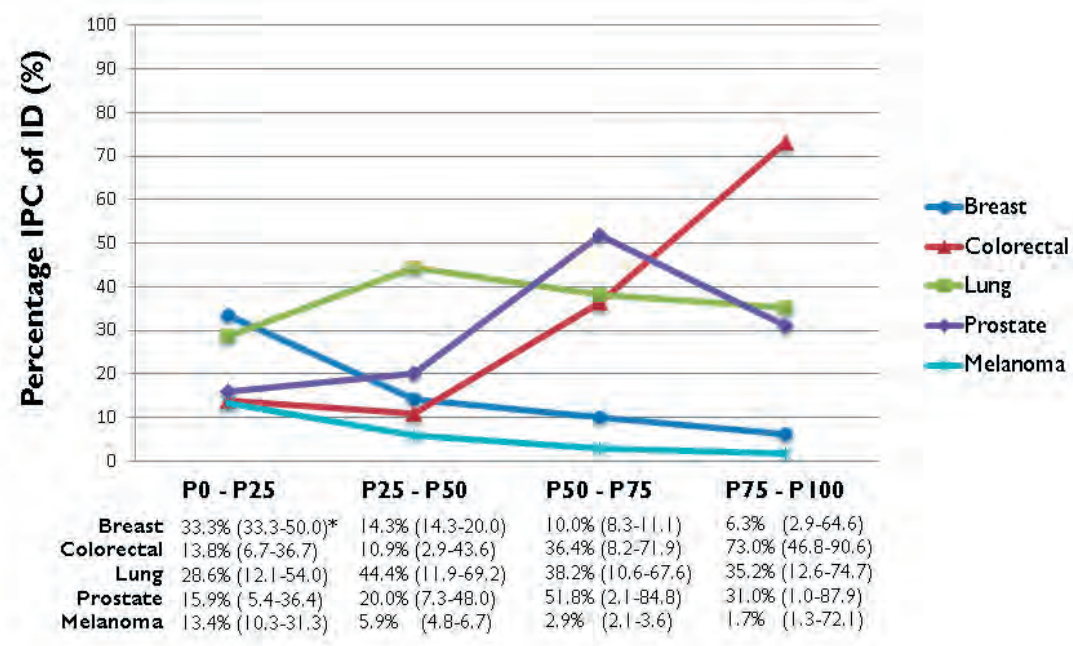

\section{ID duration category: quartiles of ID duration}

Figure 3. Percentage of diagnostic duration (ID) attributable to primary care (IPC), for symptomatic cancer patients presenting to primary care.

*For each quartile of ID duration (P0-P25 represents the shortest ID duration, P75-PI00 represents the longest ID duration), the median percentage of ID duration attributable to the IPC is shown, with IQI.A low percentage means that a low percentage of the diagnostic interval duration is attributable to IPC. IPC, primary care interval; ISC, secondary care interval; IT, treatment interval; ID, diagnostic interval; IHC, health care interval; P, percentile; IQI, interquartile interval. 
The median proportions of ID duration attributable to primary care (IPC), for the consecutive quartiles of ID duration, are shown in Figure $\mathbf{3}$ for all cancer types. Only for colorectal cancer, the proportion of ID duration attributable to IPC duration increased for longer ID durations with a median of I4\% of ID duration attributable to IPC in the $0-25$ th percentile, to $73 \%$ of ID in IPC in the 75 - I00th percentile of ID duration.

\section{DISCUSSION}

For all cancers, a highly right skewed distribution of duration demonstrated that a majority of patients pass through the diagnostic pathway fairly quick. However, for 10 $25 \%$ of cancer patients, the total ID and the time in primary care (IPC) were relatively long, which could indicate clinically relevant delay. For colorectal cancer, long duration of ID was associated with a relatively high proportion of time spent in primary care (IPC) compared to the other cancer types.

Our findings are in accordance with previous reports suggesting that the primary care interval is shorter for cancers presenting with visible or palpable symptoms such as breast cancer and melanoma. ${ }^{9}$

For breast cancer and melanoma, the median duration of IPC (I day [IQI I-I]) was comparable to the shortest durations described for Western European countries. , $9,22-24^{2}$ It also indicates fairly good compliance to referral guidelines in the Netherlands, which advocate immediate referral in case of potential cancer-related symptoms. ${ }^{25,26}$ With $50 \%$ of lung cancer patients referred within 2 weeks, our results are favourable compared with Sweden (median 28 days) ${ }^{27}$ and the United Kingdom (UK) (median 52 days). ${ }^{28}$

For colorectal cancer, the median duration of the IPC was 8 days (IQI I-60), which was shorter than what we observed in our previous study (median I4 days, IQI 0-6I) ${ }^{29}$ Recent studies from the UK (median 6 days, IQI 0-29) ${ }^{9}$ and Denmark (median 0 days, IQI 0-6) show comparably short durations. For prostate cancer, the median duration of the IPC was I4 days (IQI 3-I53). In the literature, duration of IPC was rarely studied. This is partly explained by the difficulty to determine the first presentation of symptoms. Hansen et al. $^{8}$ studied the time interval from the first presentation to initiation of a diagnostic investigation and found a median duration of 0 days (IQI 0-6). This is not comparable to our results, as we studied time up to the referral into secondary care. Studies on the time from consultation to prostate cancer diagnosis found a median duration of 73 days (IQI 4I- I 44), ${ }^{30}$ which is shorter than the median duration of ID (i.e. I 37 days, IQI 44-639) found in our study. 
Using routine care data has limitations, including incomplete reporting and the need for interpretation by experts. ${ }^{18}$ Since routine care data are recorded for care purposes, they only contain what is considered clinically important by the GP. The absence of registrations of history taking or physical examination in the free text data does not mean that these findings were not presented, checked or asked for.

Consequently, finding the 'first presentation with a cancer-related symptom' can be challenging, also because the association between common symptoms and cancer (such as cough for lung cancer) can sometimes be questioned. Even though data extraction was performed and discussed by a team of researchers with primary care experience, this challenge may have influenced our findings. Health care systems may change over time, which could potentially affect the duration of the diagnostic process. However, no substantial changes, such as the implementation of screening programs or major changes in diagnostic facilities, occurred during the study period (2007-20 I I).

When using linked data sets based on the corresponding diagnoses and patient data, cancer patients may be missed because of missing diagnoses in either of the linked data sets or linkage flaws resulting from the probabilistic linkage method used. Linkage flaws are unlikely to result in a selective population, but missing diagnosis codes in the JGPN or the NCR are potentially related to the duration of intervals with a main risk of underestimation of duration. Underestimation could result from missing less advanced (hard to detect) cancer stages because advanced cancer with reputed (alarm) symptoms is more likely to be registered with a corresponding cancer diagnosis. Also, longer secondary care intervals are more likely to lead to omit the mandatory update of the diagnosis codes by the GPs registration. Missing diagnoses in the NCR are rare, but they can be related to the absence of diagnostic information from the hospital. This may be related to old age, which could be associated with longer time to diagnosis.

Furthermore, a small minority of deceased patients $(<1 \%)$ could not be included in the linkage process because their data were not available in part of the extractions of one of the primary care Electronic Health Registration Systems in the JGPN. More serious illness in this population could have led to an underestimation of duration if long duration induced death, whereas overestimation would occur if a higher prevalence of alarm symptoms speeds up the diagnostic and therapeutic process.

Finally, although routine care data provide an accurate representation of proceedings in health care, information on the patient interval (first cancer symptom to GP consultation) seems unreliable. This interval is relevant for the time to diagnosis, but must be studied otherwise. 
The use of routine primary care data (JGPN) also has several strengths. The availability of free text information provides a high density of information, and both symptoms and policy can be determined in more detail as compared with coded data. Furthermore, using routine care data provides a direct representation of daily practice. Data are registered 'on the spot' for a long period of time, therefore preventing recall bias, unlike other studies that use questionnaires for estimating duration. ${ }^{31-34}$

Linkage with the NCR data provided accurate diagnostic and therapeutic data. This prevents inclusion of false-positive diagnoses, which have been shown to occur in up to $49 \%$ of coded cancer diagnoses reported in routine care data. ${ }^{18}$

Differences in the organisation of health care systems have been linked to differences in duration of the diagnostic pathway, ${ }^{3}$ and gatekeeper systems have been linked to reduced cancer survival. ${ }^{13}$ As $85 \%$ of cancer cases present to the GP first, early recognition in primary care is paramount to early diagnosis. ${ }^{22}$ In primary care, follow-up of complaints is an important diagnostic tool to differentiate serious from benign disease. Therefore, some time spent in primary care (IPC) is inherent to gatekeeper systems. Our findings show that for most cancers and most patients a limited proportion of time to diagnosis (ID) is attributable to primary care (IPC). However, for $10-25 \%$ of cancer patients, IPC is disproportionately long. Furthermore, for colorectal cancer patients, the proportion of ID duration attributable to primary care increases for longer ID durations.

Beside system characteristics, patient-, presentation and disease characteristics may influence the duration of the diagnostic pathway. Presentation and disease characteristics interact because the development of symptoms differs for slow and fast growing tumours. The harder to identify and probably slower growing cancers often have a multitude of alternative diagnoses and symptoms with relatively low predictive values. Particularly for these cancers, gatekeeper systems rely on primary care to optimize efficiency and safeguard sufficient diagnostic capacity in secondary care, thereby preventing delay after referral. Consequently, this challenging balance between excessive burden for both patients and health care, and not delaying cancer patients in need of diagnosis, will have to remain a focus for continuing improvement and debate. Further profiling those 10 $25 \%$ cancer patients with the longest durations and assessing the association between patient, presentation and disease characteristics and duration of the intervals may provide starting points for more targeted approaches to reduce delay.

Finally, even though $10-25 \%$ of cancer patients can benefit substantially from reducing the time to referral in primary care (IPC), for most cancers and most patients, reducing the time from referral to diagnosis (ISC) seems most pressing. This is not just because 
of the proportional preponderance of ISC but mainly because this waiting time is often spent in fear.

\section{Conclusions}

For all cancers, except prostate cancer, the majority of symptomatic patients seem to experience timely referral by the GP, diagnostic investigation and treatment. There is room for improvement though; future focus should be on profiling the $10-25 \%$ of cancer patients who show substantially long duration of primary care and referral interval, to enable targeted approaches to prevent unnecessary delay.

\section{Acknowledgements}

The authors thank all clinical researchers involved in data collection. They thank the registration team of the Netherlands Comprehensive Cancer Organisation (IKNL) and particularly Dr Janneke Verloop, for the collection of data for the Netherlands Cancer Registry as well as IKNL staff for scientific advice. They thank the GPs in the Utrecht area participating in the Julius General Practitioners Network for sharing their anonymized EHR data and Julia Velikopolskaia and Nicole Boekema of the JGPN for their assistance in extracting data and the linkage procedures. This work was supported by the Dutch Cancer Society (KWF), project number: UU20I4-7II6, and The Netherlands Organization for Health Research and Development (ZonMw), project number: 80-83910-98-I303I. These funding sources had no role in collection, analysis and interpretation of data. 


\section{REFERENCES}

I. Richard MA, Grob J], Avril MF, Delaunay M,Thirion X, Wolkenstein P, et al. Melanoma and tumor thickness: challenges of early diagnosis. Arch Dermatol 1999;135(3):269-74.

2. Tørring ML, Frydenberg M, Hansen RP, Olesen F, Hamilton W,Vedsted P.Time to diagnosis and mortality in colorectal cancer: a cohort study in primary care. Br J Cancer 20 I I; 104:934-940.

3. Neal RD. Do diagnostic delays in cancer matter? Br J Cancer 2009; I0I:S9-SI 2.

4. Neal RD, Din NU, Hamilton W, Ukoumunne OC, Carter B, Stapley S, et al. Comparison of cancer diagnostic intervals before and after implementation of NICE guidelines: analysis of data from the UK General Practice Research Database. Br J Cancer 20 I 4; I I 0:584-592.

5. Neal RD, Tharmanathan P, France B, Din NU, Cotton S, Fallon-Ferguson J, et al. Is increased time to diagnosis and treatment in symptomatic cancer associated with poorer outcomes? Systematic review. Br J Cancer 20 I 5; I I2:S92-SI07.

6. Tørring ML, Murchie P, Hamilton W,Vedsted P, Esteva M, Lautrup M, et al. Evidence of advanced stage colorectal cancer with longer diagnostic intervals: a pooled analysis of seven primary care cohorts comprising II,720 patients in five countries. Br J Cancer 2017; I I 7:888-897.

7. Weller D,Vedsted P, Rubin G,Walter FM, Emery J, Scott S, et al. The Aarhus statement: improving design and reporting of studies on early cancer diagnosis. Br J Cancer 2012; 106:1262-1267.

8. Hansen RP,Vedsted P, Sokolowski I, Søndergaard J, Olesen F.Time intervals from first symptom to treatment of cancer: a cohort study of 2,2I 2 newly diagnosed cancer patients. BMC Health Serv Res 20I I;। I:284.

9. Lyratzopoulos G, Saunders CL, Abel GA, McPhail S, Neal RD, Wardle J, et al. The relative length of the patient and the primary care interval in patients with 28 common and rarer cancers. $\mathrm{Br} \mathrm{J}$ Cancer 20I5; I 12:S35-S40.

10. Baughan P, O'Neill B, Fletcher E.Auditing the diagnosis of cancer in primary care: the experience in Scotland. Br J Cancer 2009; I0I:S87-S9I.

I I. Din NU, Ukoumunne OC, Rubin G, Hamilton W, Carter B, Stapley S, et al.Age and gender variations in cancer diagnostic intervals in 15 cancers: analysis of data from the UK Clinical Practice Research Datalink. PloS One 2015;10:e01277I7.

12. Berrino F, De Angelis R, Sant M, Rosso S, Bielska-Lasota M, Coebergh JW, et al., EUROCARE Working Group. Survival for eight major cancers and all cancers combined for European adults diagnosed in 1995-1999: results of the EUROCARE-4 study. Lancet Oncol 2007;8:773-783.

13. Vedsted P, Olesen F.Are the serious problems in cancer survival partly rooted in gatekeeper principles? An ecologic study. Br J Gen Pract 20 I I;6 I:508-5 I 2.

14. Annual GP monitoring report. NIVEL (Netherlands institute for health services research) primary care database (n.d.). Retrieved September 2I, 20I7, from: https://www.nivel.nl/databank. Accessible from English website: https://www.nivel.nl/en/databases-and-panels.

15. Nederlandse Zorgautoriteit (NZa). Circulaire Vaststelling beleid huisartsenzorg en multidisciplinaire zorg [in Dutch]. https://www.nza.nl/regelgeving/circulaires [accessed 2 I September 2017]. 
16. Data of Statistics Netherlands (CBS). Huisarts voor meeste mensen dichtbij huis [in Dutch]. https://www.cbs.nl/nl-nl/nieuws/2009/22/huisarts-voor-meeste-mensen-dichtbij-huis [accessed 2 I September 2017].

17. Korevaar JC, Heins MJ, Donker G, Rijken M, Schellevis F. Oncologie in de huisartsenpraktijk. Huisarts Wet 2013;56:6-10.

18. Sollie A, Roskam J, Sijmons RH, Numans ME, Helsper CW. Do GPs know their patients with cancer? Assessing the quality of cancer registration in Dutch primary care: a cross-sectional validation study. BMJ Open 2016;6:e012669.

19. Rutten FH, Zuithoff NP, Hak E, Grobbee DE, Hoes AW. Betablockers may reduce mortality and risk of exacerbations in patients with chronic obstructive pulmonary disease. Arch Intern Med 2010; 170:880-887.

20. Netherlands Comprehensive Cancer Organisation (IKNL). Werkwijze [in Dutch]. http://www. cijfersoverkanker.nl/werkwijze-13.html [accessed 2I March 2016].

21. Lamberts H,Wood M, editors. ICPC. International classification of primary care. Oxford: Oxford University Press; 1987.

22. Neal RD, Allgar VL. Sociodemographic factors and delays in the diagnosis of six cancers: analysis of data from the "National Survey of NHS Patients: Cancer". Br J Cancer 2005;92:197I- 1975.

23. Robertson R, Campbell NC, Smith S, Donnan PT, Sullivan F, Duffy R, et al. Factors influencing time from presentation to treatment of colorectal and breast cancer in urban and rural areas. $\mathrm{Br} J$ Cancer 2004;90:1479-1485.

24. Brochez L,Verhaeghe E, Bleyen L, Naeyaert J.Time delays and related factors in the diagnosis of cutaneous melanoma. Eur J Cancer 200I;37:843-848.

25. de Bock GH, Beusmans GHMI, Hinloopen RJ, Corsten MC, Salden NMA, Scheele ME, et al. NHGStandaard Diagnostiek van mammacarcinoom (Tweede herziening). Huisarts Wet 2008;5 1:598-609.

26. IKNL. Landelijke richtlijn Melanoom 2016. Retrieved March 22, 2016, from: http://www.oncoline. $\mathrm{nl} /$ melanoom.

27. Lövgren M, Leveälahti H,Tishelman C, Runesdotter S, Hamberg K. Time spans from first symptom to treatment in patients with lung cancer - the influence of symptoms and demographic characteristics. Acta Oncol 2008;47:397-405.

28. Barrett J, Hamilton W. Pathways to the diagnosis of lung cancer in the UK: a cohort study. BMC Fam Pract 2008;9:3I.

29. Van Hout AMGH, de Wit NJ, Rutten FH, Peeters PHM. Determinants of patient's and doctor's delay in diagnosis and treatment of colorectal cancer. Eur J Gastroenterol Hepatol 20 I I;23: 1056 1063.

30. Baade PD, Gardiner RA, Ferguson M, Youlden DR, Aitken JF, Yaxley J, et al. Factors associated with diagnostic and treatment intervals for prostate cancer in Queensland,Australia: a large cohort study. Cancer Causes Control 20 12;23:625-634.

31. Blum A, Brand CU, Ellwanger U, Schlagenhauff B, Stroebel W, Rassner G, et al.Awareness and early detection of cutaneous melanoma: an analysis of factors related to delay in treatment. $\mathrm{Br} J$ Dermatol 1999;141:783-787. 
32. Jensen H,Tørring ML, Olesen F, Overgaard J,Vedsted P. Cancer suspicion in general practice, urgent referral and time to diagnosis: a population-based GP survey and registry study. BMC Cancer 2014;14:636.

33. Richard MA, Grob JJ, Avril MF, Delaunay M, Gouvernet J, Wolkenstein P, et al. Delays in diagnosis and melanoma prognosis (I): the role of patients. Int J Cancer 2000;89:27I-279.

34. Schmid-Wendtner MH,Baumert J, Stange J,Volkenandt M. Delay in the diagnosis of cutaneous melanoma: an analysis of 233 patients. Melanoma Res 2002; 12:389-394. 


\section{APPENDIX I}

Cancer related signs and symptoms registered as reason for first GP consultation (start IPC) for symptomatic cancer patients with breast-, colorectal-, lung-, or prostate cancer or melanoma.

\begin{tabular}{ll}
\hline $\begin{array}{l}\text { Breast cancer } \\
\text { Symptom category }\end{array}$ & Included signs and symptoms \\
\hline Lump & Swelling, lump, disc, node \\
Other localized & $\begin{array}{l}\text { Skin or nipple changes (red skin, nipple retraction), pain in breast, } \\
\text { inflammation (mastitis or ulcus), palpable lymph nodes in/around breast } \\
\text { or armpit }\end{array}$ \\
Generalized & Tiredness, night sweats, weight loss \\
Non-localized & Back pain, gastric pain, pain in hip \\
\hline
\end{tabular}

\section{Colorectal cancer}

Symptom category Included signs and symptoms

Alarm symptom Rectal blood loss, palpable lump, anemia, weight loss

Non-alarm Gl-symptom Gastric pain/cramps, bloating, changed defecation pattern (relating to smell, consistency, frequency, incontinence, constipation), dyspepsia, nausea, vomiting, rectal pain

Non-alarm, non Gl-symptom Malaise, cough, chest pain, dyspnea, hyperventilation, pollakisuria, head only ache, pain of back/rib, dizziness, palpitations, fever, pallor

\section{Prostate cancer}

Symptom category Included signs and symptoms

\begin{tabular}{ll}
\hline LUTS & $\begin{array}{l}\text { Decreased flow and velocity of urine stream, loss of bladder control, } \\
\text { pollakisuria, incontinence, nycturia, other complaints of miction / } \\
\text { prostatism } \\
\text { Urinary tract infection, including painfull or dark urine, sometimes with } \\
\text { pain and/or pollakisuria }\end{array}$ \\
UTI & Retention \\
Retention & Erectile problems \\
Erectile dysfunction & Cramps, gastric pain, other abdominal pain \\
Abdominal pain & Night sweats, malaise, bone pain, back pain \\
Systemic symptoms & Fecal incontinence, constipation, rectal blood loss, diarrhea, change in \\
Other & bowel habit, vomiting \\
\hline
\end{tabular}




\begin{tabular}{ll}
\hline $\begin{array}{l}\text { Lung cancer } \\
\text { Symptom category }\end{array}$ & Included signs and symptoms \\
\hline Alarm symptom & Hemoptoe, weight loss \\
Non-alarm pulmonary symptom & Cough, wheezing, slime, dyspnea, pain in thorax \\
Non-alarm non-pulmonary & Pain in back/legs/shoulder/hip/armpit/neck, headache, nausea, irregular \\
symptom only & $\begin{array}{l}\text { pulse, malaise, gastric pain, neurologic deficits, persisting cold/sinusitis, } \\
\text { nose bleeds, palpitations, bloating, gastric complaints, dizziness, swelling } \\
\text { of throat, vomiting, fainting, difficulty swallowing, fever, swelling of legs, } \\
\text { tiredness, reduced appetite, hoarseness }\end{array}$ \\
\hline
\end{tabular}

\section{Melanoma}

Symptom category

Included signs and symptoms

Alarm symptom

Naevus/pigmented lesion WITH one or more of the following "ABCDE characteristics": asymmetry, border irregularity, color heterogeneity, diameter $>6 \mathrm{~mm}$, evolution of the lesion

Non-alarm pigmented lesion Nevus/pigmented lesion WITHOUT any of the "ABCDE characteristics":

Non-alarm, non-pigmented All skin lesions without pigmentation or alarm symptoms

lesion 


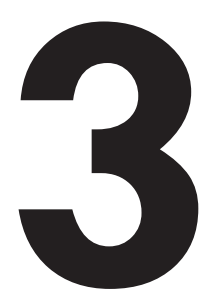

\title{
Time to diagnosis of symptomatic gastric and oesophageal cancer in the Netherlands
}

\author{
Nicole F. van Erp \\ Charles W. Helsper \\ Pauline Slottje \\ Daan Brandenbarg \\ Frederike L. Büchner \\ Kristel M. van Asselt \\ Jean W.M. Muris \\ Marlous F. Kortekaas \\ Petra H.M. Peeters \\ Niek J. de Wit
}




\begin{abstract}
Background: An efficient diagnostic pathway and early stage diagnosis for cancer patients is widely pursued. This study aims to chart the duration of the diagnostic pathway for patients with symptomatic oesophageal and gastric cancer, to identify factors associated with long duration and to assess the association of duration with tumour stage at diagnosis.
\end{abstract}

Methods: This was a retrospective cohort study, using electronic health records of six routine primary care databases covering about 640,000 patients, partly linked to the Netherlands Cancer Registry. Symptomatic patients with oesophageal and gastric cancer (2010-2015) that presented in primary care were included. Duration of four diagnostic intervals was determined: patient interval; first symptoms to primary care consultation, primary care interval; consultation to referral, secondary care interval; referral to diagnosis, and the diagnostic interval; consultation to diagnosis. Characteristics associated with 'long duration' ( $\geq$ P75 duration) were assessed using log-binomial regression. Median durations were stratified for tumour stages.

Results: Among 312 symptomatic patients with upper gastrointestinal cancer, median durations were: patient interval: 29 days (interquartile interval 15-73), primary care interval: 12 days (interquartile interval 1-43), secondary care interval: 13 days (interquartile interval 6-29) and diagnostic interval: 3 I days (interquartile interval II-74). Patient interval duration was comparable for patients with and without alarm symptoms. Absence of cancer-specific alarm symptoms was associated with 'long duration' of primary care interval and secondary care interval: relative risk 5.0 (95\% confidence interval 2.79.I) and 2.I (95\% confidence interval I.3-3.7), respectively. Median diagnostic interval duration for local stage disease was 51 days (interquartile interval 13-135) versus 27 days (interquartile interval II-7I) for advanced stage $(p=0.07)$.

Conclusion: In the diagnostic pathway of upper gastrointestinal cancers, the longest interval is the patient interval. Reducing time to diagnosis may be achieved by improving patients' awareness of alarm symptoms and by diagnostic strategies which better identify cancer patients despite low suspicion. 


\section{INTRODUCTION}

Upper gastrointestinal (UGI) cancer, i.e. oesophageal and gastric cancer, has substantial morbidity and mortality rates.' Five-year overall survival rates range from 19-31\% in non-metastatic UGI cancer, and for patients with metastatic disease, median overall survival ranges from only 15-25 weeks. ${ }^{2-5}$

One of the explanations of this low level of survival is the fact that UGI cancers are currently diagnosed in a relatively advanced disease stage; $70 \%$ of the patients are diagnosed with stage III or IV disease. ${ }^{6}$ This is besides the fact that these types of cancers only become symptomatic in advanced disease stages, and advanced stages may result from delay either before presentation to healthcare services in primary care or during diagnostic work-up in secondary care. According to the literature, shortening the patient interval is probably most vital to reduce delay in the diagnostic pathway of gastroesophageal cancer. ${ }^{7,8}$

In gatekeeper systems like that in the Netherlands, patients have to visit a general practitioner (GP) first and GPs can refer patients to secondary care if needed. Most patients with UGI cancer will therefore initially present with symptoms in primary care. Referral to secondary care is either made urgently (often through telephone contact) or regularly (using a digital referral system). Usually, GPs in the Netherlands have open access to UGI endoscopy, meaning that they can refer patients for this procedure without prior consultation with a gastroenterologist.

Earlier studies reported on the duration of, and factors associated with, delay in different phases of the diagnostic pathway, providing 'fragmented' evidence. ${ }^{8-16}$ Delaying factors include symptom recognition and interpretation, patient characteristics and healthcare factors. ${ }^{9,17}$ Although several studies reported on the association between time to diagnosis and tumour stage at diagnosis and/or survival, they considered individual intervals of the diagnostic pathway, hampering solid conclusions. ${ }^{11,12,18,19}$ To improve the diagnostic pathway of UGI cancers, a comprehensive overview of the duration of its intervals and factors contributing to delay is required. The aim of this study is to provide this overview of the duration of the diagnostic pathway for patients with oesophageal and gastric cancer in the Netherlands, to assess characteristics associated with long duration, and to assess the association between duration and tumour stage at diagnosis. 


\section{METHODS}

\section{Study design and data source}

A retrospective cohort study was performed using anonymised data from six academic general practice networks (General Appendix A), containing coded and free-text information from primary care electronic health records (EHRs) of over 640,000 patients. Free texts include real-time registrations of patient consultations, i.e. presented complaints, results of physical examination, clinical reasoning of the GP and management plan. This data source was used to determine the duration of the patient interval (IP) and the primary care interval (IPC).

To be able to determine the secondary care interval (ISC), the diagnostic interval (ID) and the association between duration and tumour stage at diagnosis, we linked, where possible, the routine primary care data to the data of the Netherlands Cancer Registry (NCR). The NCR is a population-based registry with detailed diagnostic and therapeutic data of over $95 \%$ of Dutch cancer patients since $1989 .{ }^{20}$ Data linkage was possible for three of the six databases (Julius General Practitioner's Network database (Utrecht) (JGPN), Academic Network of General Practice database (Amsterdam VUmc) (ANH VUmc) and Registration Network Groningen (RNG): together comprising $76 \%$ of the cancer patients) as these include pseudonyms based on patient identifiers. Primary care and NCR records were linked based on date of birth, sex and postal code (six digits) among patients with the cancer type in question, using a trusted third-party linkage procedure to comply with privacy regulations of Dutch and International law (General Data Protection Regulation, https://gdpr.eu).

\section{Case selection}

All adult patients (aged $\geq 18$ years) registered with the International Classification of Primary Care (ICPC, version I) ${ }^{21}$ code for 'malignant neoplasm of oesophagus' (D77.0I) or 'malignant neoplasm of stomach' (D74) in 2010-2015 were extracted from the primary care databases.

Of all identified patients, we checked the free text elements of the EHR to confirm the cancer diagnosis, based on summaries of correspondence from secondary care and other descriptions indicating cancer presence. Only those patients with a confirmed cancer diagnosis were included. Next, we selected only those who presented to the GP with symptoms, and were referred by the GP for diagnostic workup. 


\section{Data collection}

Data were collected from the primary care databases and NCR by medically trained researchers (6th year medical students). Primary care EHRs were scrutinized manually from 5 years before the date of entry of the ICPC code for UGI cancer up to I year after. EHRs were studied up to I year after ICPC coding because the date of the ICPC code marks the beginning of the disease episode and not the actual date of diagnosis as registered in the NCR.

Four time intervals of the diagnostic pathway were assessed (Figure I), based on the definitions provided in the Aarhus statement. ${ }^{22}$ The IP was defined as the time interval between first noticing cancer-related symptom(s) to first consultation for these symptoms in primary care; the IPC was defined as duration from first consultation with cancerrelated signs and/or symptoms in primary care to referral to secondary care; the ISC was defined as duration from referral to secondary care by the GP to date of histological diagnosis, and the overarching ID was defined as duration from first consultation to date of diagnosis. Definitions of the different milestones are shown in Table I.

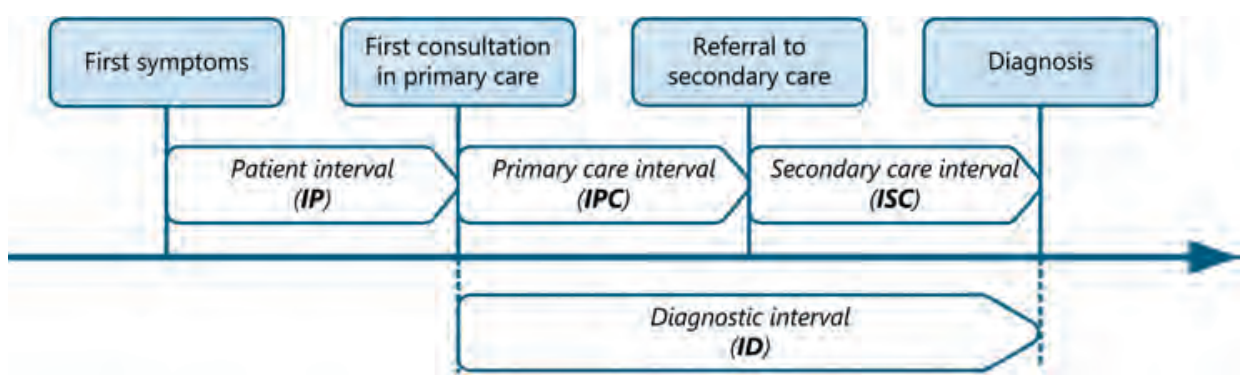

Figure I. The cancer diagnostic pathway and its intervals, based on the Aarhus statement. ${ }^{22}$

Patient and presentation characteristics were collected from the routine primary care data.All characteristics and methods of collection are shown in General Appendix C. Symptoms were categorised as UGI cancer-specific alarm symptoms (persistent vomiting, haematemesis or melaena, dysphagia and a palpable mass in the epigastric region), 23 cancer general alarm symptoms (unintended weight loss, anaemia and ascites) and nonalarming symptoms (all other UGI cancer-related symptoms). Disease characteristics were retrieved from the NCR data for NCR matched patients. 
Table I. Milestones of the diagnostic pathway of symptomatic cancer and their definitions.

\begin{tabular}{|c|c|}
\hline & Definition \\
\hline Date of first symptom(s) & $\begin{array}{l}\text { Date of first symptom(s) was defined as registered by the GP in the free text } \\
\text { fields of the electronic health record. If 'stomach ache since one week' was } \\
\text { registered, date of first symptom was the date } 7 \text { days before the date of first } \\
\text { consultation. Less strictly described durations, such as 'several weeks' and } \\
\text { 'a couple of days' were interpreted according to predefined rules, General } \\
\text { Appendix B. Duration indications as 'for a while' or 'for some time' where } \\
\text { considered too vague for interpretation and were excluded from IP analysis. In } \\
\text { case of different duration indications for multiple cancer related complaints, the } \\
\text { longest duration was selected to determine IP duration. }\end{array}$ \\
\hline Date of first consultation & $\begin{array}{l}\text { Date of first consultation was defined as the first presentation to the GP with } \\
\text { signs or symptoms related to the UGI cancer. In case of vague or non-specific } \\
\text { signs or symptoms, the first consultation with complaints that eventually led to } \\
\text { the cancer diagnosis, and could reasonably be related to the cancer, was taken. } \\
\text { We minimized the risk of misattribution of symptoms by discussing doubtful } \\
\text { cases in our team of researchers, who are medical doctors with primary care } \\
\text { experience. }\end{array}$ \\
\hline Date of referral & $\begin{array}{l}\text { Date of referral was defined as the moment the responsibility for the patient } \\
\text { was transferred from primary to secondary care, as registered in the electronic } \\
\text { health record. Referral to radiology or endoscopy department for imaging was } \\
\text { considered as referral if abnormal findings subsequently resulted in referral } \\
\text { to a specialist, without further interference of the GP. In case of multiple } \\
\text { referrals to, or cross-referrals in secondary care, the first referral for further } \\
\text { exploration of cancer related symptoms was taken. }\end{array}$ \\
\hline Date of diagnosis & $\begin{array}{l}\text { To determine ISC and ID duration, the date of diagnosis was retrieved from } \\
\text { the NCR for NCR matched patients. The NCR uses the hierarchy for diagnosis } \\
\text { date as provided by the European Network of Cancer Registries, primarily } \\
\text { registering date of histological diagnosis. }\end{array}$ \\
\hline
\end{tabular}

GP = General Practitioner, IP = Patient Interval, UGI cancer = Upper Gastrointestinal cancer, ISC = Secondary care interval, ID = diagnostic interval, NCR = the Netherlands Cancer Registry.

\section{Analyses}

Duration of the four intervals was calculated and stratified for several patient and presentation characteristics and tumour stage at diagnosis. We consistently added one day to all durations, as we considered same-day proceedings as a duration of one day. Differences in median duration were tested with the Mann-Whitney $U$ test for variables with two categories or the Kruskall-Wallis test for variables with 3 categories.

To assess associations with 'long duration', we defined this as duration equal to or longer than the 75th percentile value (P75) of duration for the different intervals (IP, IPC, ISC). Univariable and multivariable log-binomial regression analyses were performed to identify characteristics associated with 'long duration'. Characteristics that were statistically significantly associated with 'long duration' $(p<0.05)$ in univariable analysis were included in multivariable analysis, next to age and sex. For IPC, we assessed extra characteristics (consultation frequency, chronic comorbidities and psychiatric comorbidity). 


\section{Software}

Data transformation and analyses were performed in SPSS version 22.0 (SPSS Inc., Chicago, Illinois, USA).

\section{Patient and public involvement}

Patients and/or public were not involved in this study.

\section{RESULTS}

\section{Patient characteristics}

Of 676 patients with an ICPC code for oesophageal and gastric cancer, 312 patients (46\%) met the eligibility criteria; 174 oesophageal and I 38 gastric cancer patients. The most common reasons for exclusion (Figure 2) were a non-confirmed cancer diagnosis (potentially incorrect ICPC code) and an unclear diagnostic pathway (plausible diagnosis but unclear route to diagnosis).

Patient characteristics are described in Table 2. Most of the patients (64\%) were male: $70 \%$ of the oesophageal cancer patients and $55 \%$ of the gastric cancer patients. Mean age at first GP consultation was 66.4 years (standard deviation (SD) I I.9), comparable for oesophageal and gastric cancer. During the first consultation, for around $60 \%$ of the patients a cancer-specific alarm symptom was registered: $67 \%$ of the oesophageal cancer patients and $54 \%$ of the gastric cancer patients.

For the analysis of ISC, ID and the association of duration with tumour stage, a total of 237 patients (76\% of eligible) could be linked to the NCR. For 172 patients $(73 \%$ of those linked) a match was found in the NCR. We found no differences in patient and presentation characteristics between those matching NCR $(n=172)$ and those who did not match $(n=65)$ (Appendix I). Of NCR-matched patients, 122 (7I\%) were diagnosed with advanced disease stage (stage III or IV): $80 \%$ among oesophageal cancer patients and $54 \%$ among gastric cancer patients.

\section{Duration of time intervals}

Duration of the different intervals is shown in Table 3. All intervals showed a right skewed distribution as shown in Figure 3, with a strong increase in durations for 10 $25 \%$ of patients with the longest intervals. 


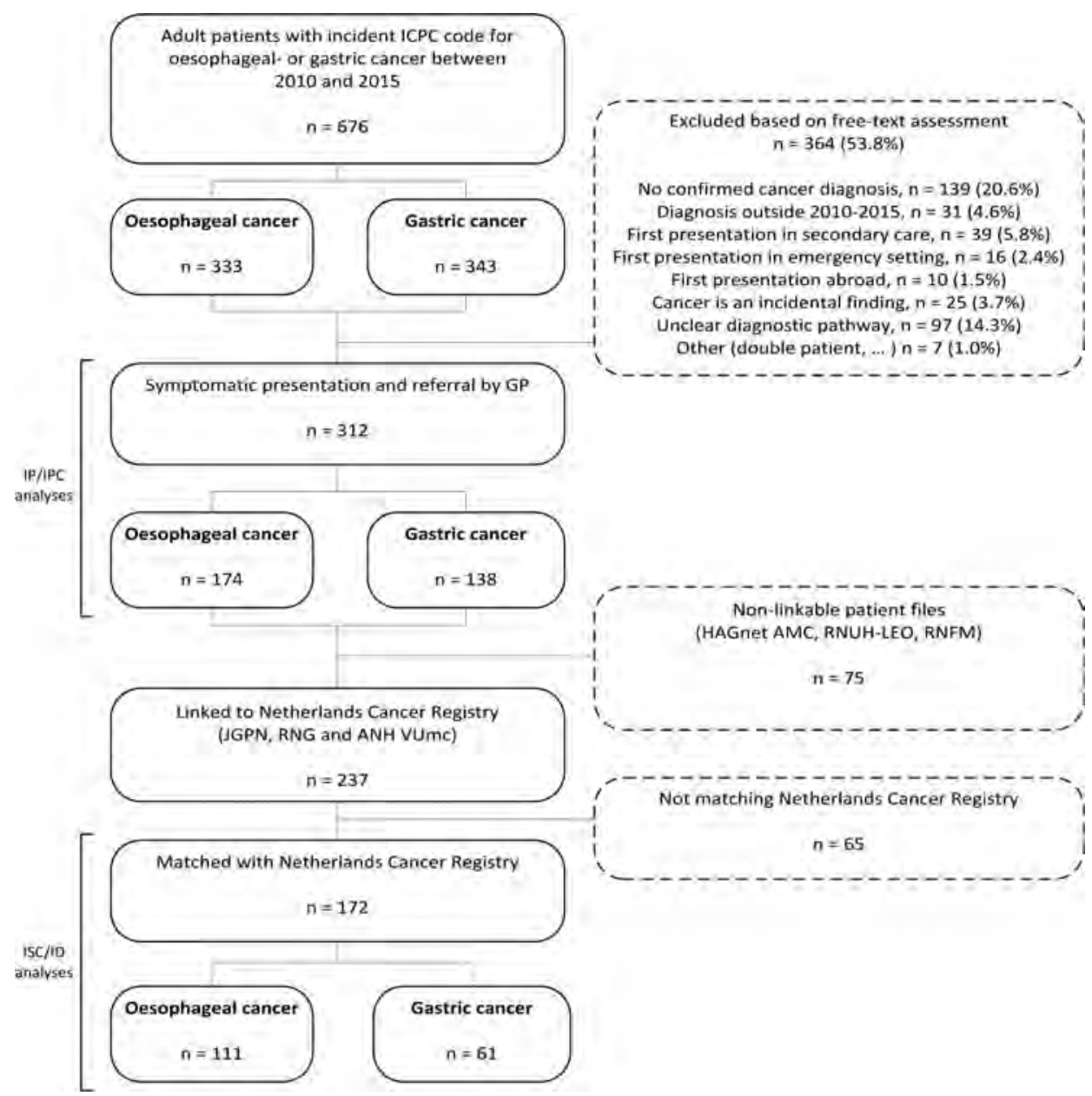

Figure 2. Identified upper gastrointestinal cancer cases and reasons for exclusion.

ANHVUmc:Academic Network of General Practice database (Amsterdam VUmc); GP: general practitioner; HAGnet AMC: General Practice Registration Network (Amsterdam AMC); ICPC: International Classification of Primary Care; ID: diagnostic interval; IP: patient interval; IPC: primary care interval; ISC: secondary care interval; JGPN: Julius General Practitioner's Network database (Utrecht); RNFM: Research Network Family Medicine (Maastricht); RNG: Registration Network Groningen; RNUH-LEO: Registration Network of General Practitioners Associated with Leiden University (Leiden). 
An IP was reported for 20 I patients (64\%). It could not be determined for $29 \%$ and $43 \%$ of oesophageal and gastric cancer patients, respectively. The median duration of IP was 29 days (interquartile interval (IQI) I5-73), 3I days (IQI 22-76) for oesophageal cancer and 25 days (IQI I5-62) for gastric cancer. Although statistically non-significant, longer IP durations were seen for younger patients. Patients without alarm symptoms had the shortest median IP duration (22 days (IQI I2-62)), those with general cancer alarm symptoms the longest (46 days (IQI 22-92)).

The median duration of the IPC was I2 days (IQI I-43), it was 8 days (IQI I-38) for oesophageal cancer and I 4 days (IQI I-5 I) for gastric cancer patients.Although statistically non-significant, women had a longer duration of I5 days (IQI I-45) as compared to 8 days (IQI I-43) for men.The shortest durations were seen for patients with UGI-specific cancer-alarm symptoms: I day (IQI I-I2), as compared to II days (IQI 3-46) and 32 days (IQI I3-98) for patients with general cancer alarm symptoms and patients without alarm symptoms, respectively $(\mathrm{p}<0.0 \mathrm{I})$. For gastric cancer, patients under 55 years showed statistically significant longer median duration to referral of 40 days (IQI I6-I30) as compared to 8 days (IQI I-40) for patients aged 75 years and older, $\mathrm{p}=0.0 \mathrm{I}$.

The median duration of the ISC was I 3 days (IQI 6-29), with shortest durations for those with cancer specific alarm symptoms (8 days, IQI 5-24) (Table 3). Median duration of the ID was 3 I days (IQI I I-74): 23 days for oesophageal cancer (IQI 8-60) and 44 days (IQI 20-145) for gastric cancer. Patients with UGI cancer-specific alarm symptoms showed the shortest ID durations (Table 3). Four patients, who showed negative durations of the ISC, suggesting registration errors, were excluded from ISC and ID analyses.

Results of the log-binomial regression analyses for association with 'long duration' ( $\geq$ P75) of the respective intervals are shown in Table 4. Please note; the absolute number of days that the 75th percentile (cut-off for 'long duration') represents, differs for each interval. In short: for IP, no characteristics were found to be statistically significantly associated with 'long duration'. For IPC, patients without cancer-specific alarm symptoms showed a higher risk for 'long duration' in multivariable analysis (RR 5.0, 95\% Cl 2.7-9.I). For ISC, patients with cancer general alarm symptoms showed a higher risk for 'long duration' in multivariable analysis (RR 2.I, 95\% Cl I.3-3.7).

\section{Association of duration with tumour stage at diagnosis}

For NCR-matched patients $(n=172)$, duration of the respective intervals according to disease stage are shown in Table 3. Median IP and IPC durations were shorter (though not statistically significant) for patients with localised disease (stage 0, I or II) as compared to patients with advanced disease (stage III and IV). Median ISC duration was longer (20 
Table 2. Characteristics of patients with upper gastrointestinal cancer that presented with symptoms in primary care.

\begin{tabular}{|c|c|c|c|c|}
\hline & & UGI cancers & $\begin{array}{l}\text { Oesophageal } \\
\text { cancer }\end{array}$ & $\begin{array}{l}\text { Gastric } \\
\text { cancer }\end{array}$ \\
\hline Population & $\mathrm{n}(\%)$ & $312(100)$ & $174(100)$ & $138(100)$ \\
\hline Male patients & n (\%) & $199(63.8)$ & $123(70.7)$ & $76(55.1)$ \\
\hline Age at first consultation & Mean \pm SD & $66.4 \pm 11.9$ & $66.6 \pm 10.2$ & $66.2 \pm 13.8$ \\
\hline \multirow{2}{*}{$\begin{array}{l}\text { Socio-economic status score } \\
\text { (SES) } 2014^{\mathrm{a}}\end{array}$} & Mean \pm SD & $0.32 \pm 1.17$ & $0.39 \pm 1.14$ & $0.23 \pm 1.22$ \\
\hline & Missing, n (\%) & $66(21.2)$ & $33(19.0)$ & $33(23.9)$ \\
\hline \multirow{2}{*}{$\begin{array}{l}\text { Consultation frequency in year } \\
\text { before first consultation }\end{array}$} & Median (IQI) & $5(2-10)$ & $5(2-8)$ & $6(2-12)$ \\
\hline & Missing, n (\%) & $24(7.7)$ & $9(5.2)$ & $15(10.9)$ \\
\hline \multirow{2}{*}{$\begin{array}{l}\text { Number of registered chronic } \\
\text { somatic comorbidities }^{\text {b }}\end{array}$} & Median (IQI) & $3(I-5)$ & $3(1-6)$ & $3(1-4)$ \\
\hline & Missing, n (\%) & $8(2.6)$ & $8(4.6)$ & $0(0.0)$ \\
\hline Registered psychiatric & $\mathrm{n}(\%)$ & $65(20.8)$ & $40(23.0)$ & $25(18.1)$ \\
\hline comorbidity $^{\mathrm{b}}$ & Missing, n (\%) & $8(2.6)$ & $8(4.6)$ & $0(0.0)$ \\
\hline \multicolumn{5}{|c|}{ Dominant symptom(s) at first consultation ${ }^{c}$} \\
\hline $\begin{array}{l}\text { Cancer specific alarm } \\
\text { symptom(s) }\end{array}$ & n (\%) & $127(40.7)$ & $86(49.4)$ & $4 \mathrm{I}(29.7)$ \\
\hline $\begin{array}{l}\text { Cancer general alarm } \\
\text { symptom(s) }\end{array}$ & n (\%) & $61(19.6)$ & $25(14.4)$ & $36(26.1)$ \\
\hline Other, non-alarming symptoms & $\mathrm{n}(\%)$ & $124(39.7)$ & $63(36.2)$ & $61(44.2)$ \\
\hline \multicolumn{5}{|l|}{ Dominant symptom(s) at referral $^{c}$} \\
\hline $\begin{array}{l}\text { Cancer specific alarm } \\
\text { symptom(s) }\end{array}$ & n (\%) & $191(61.2)$ & $117(67.2)$ & $74(53.6)$ \\
\hline $\begin{array}{l}\text { Cancer general alarm } \\
\text { symptom(s) }\end{array}$ & n (\%) & $69(22.1)$ & $24(13.8)$ & $45(32.6)$ \\
\hline Other, non-alarming symptoms & n (\%) & $52(16.7)$ & $33(19.0)$ & $19(13.8)$ \\
\hline Population linked to $\mathrm{NCR}^{\mathrm{d}}$ & $\mathrm{n}(\%)$ & $237(76.0)$ & I $38(79.3)$ & 99 (7I.7) \\
\hline Match with NCR & n (\% of linked) & $172(72.6)$ & III (80.4) & $61(61.6)$ \\
\hline \multicolumn{5}{|l|}{ TNM disease stage at diagnosis } \\
\hline 0, I or II & $\mathrm{n}$ (\% of matched) & $42(24.4)$ & $19(17.1)$ & $23(37.7)$ \\
\hline III or IV & $\mathrm{n}$ (\% of matched) & $122(70.9)$ & $89(80.2)$ & $33(54.1)$ \\
\hline Missing & $\mathrm{n}$ (\% of matched) & $8(4.7)$ & $3(2.7)$ & $5(8.2)$ \\
\hline \multicolumn{5}{|l|}{ Morphology } \\
\hline Adenocarcinoma & $\mathrm{n}$ (\% of matched) & $93(54.1)$ & $57(51.4)$ & $36(59.0)$ \\
\hline Squamous cell carcinoma & $\mathrm{n}$ (\% of matched) & $42(24.4)$ & $42(37.8)$ & - \\
\hline Other & $\mathrm{n}(\%$ of matched $)$ & $37(2 \mid .5)$ & $12(10.8)$ & $25(41.0)$ \\
\hline
\end{tabular}

$\mathrm{IQI}=$ interquartile interval, NCR = Netherlands Cancer Registry, SD = standard deviation, $\mathrm{TNM}=$ Tumour Node Metastasis

a Socio-economic status (SES) scores of 2014 , based on level of education, income and job status. The Dutch mean SES in 2014 was 0.28 (SD I.09). SES could be derived for patients from 4 out of the 6 primary care network databases (JGPN, ANH VUmc, RNG and RNFM).

${ }^{b}$ According to the definitions of O'Halloran et al. ${ }^{34}$

'Cancer specific alarm symptoms for UGI cancers (oesophageal- and gastric cancer) were defined as persistent vomiting, UGI bleeding (hematemesis or melena), dysphagia and a palpable mass in the epigastric region. Cancer general alarm symptoms were defined as unintended weight loss, anaemia and ascites. Other, non-alarming symptoms were all other presenting symptoms that could be related to the UGI cancer, including abdominal pain, nausea, gastro-oesophageal reflux, malaise etc. In case of presence of both cancer specific and cancer general alarm symptoms, cancer specific alarm symptoms were considered dominant.

${ }^{d}$ Linkage with NCR was possible for 3 of the six primary care network databases (JGPN,ANHVUmc and RNG). 


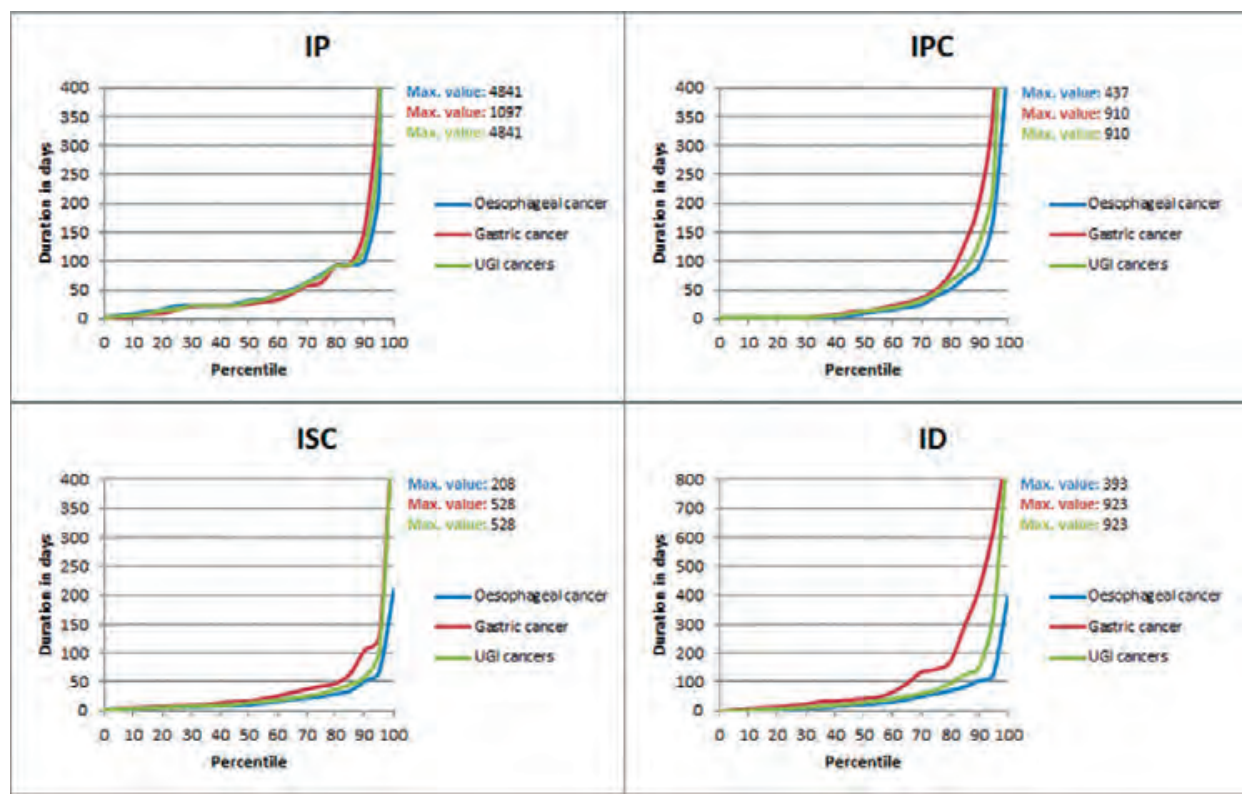

Figure 3. Distribution of the duration of the different intervals of the cancer diagnostic pathway of upper gastrointestinal (UGI) cancer patients.

ID: diagnostic interval; IP: patient interval; IPC: primary care interval; ISC: secondary care interval.

days, versus 10 days, $\mathrm{p}$-value: 0.04 ) for patients with local disease as compared to patients with advanced disease stage. Median ID duration was almost twice as long for those with local disease as compared to patients with advanced disease stage (5I days, versus 27 days, p-value: 0.07$)$. At first GP consultation, 54 of 122 (44.3\%) patients with advanced disease stage had cancer-specific alarm symptoms, as compared to 15 of 42 patients (35.7\%) with localised disease (Appendix 2).

\section{DISCUSSION}

\section{Summary of the main findings}

In the diagnostic pathway of patients with UGI cancer, the IP is the longest. Median IP duration was 29 days and comparable for patients with and without alarm symptoms. Intervals in both primary and secondary care were relatively short, with a median duration of 12 and 13 days respectively. The median duration of the overall ID was 3 I days; 23 days for oesophageal cancer and 44 days for gastric cancer. In all intervals, 10 $25 \%$ of the patients showed a relatively long duration. Absence of cancer-specific alarm 


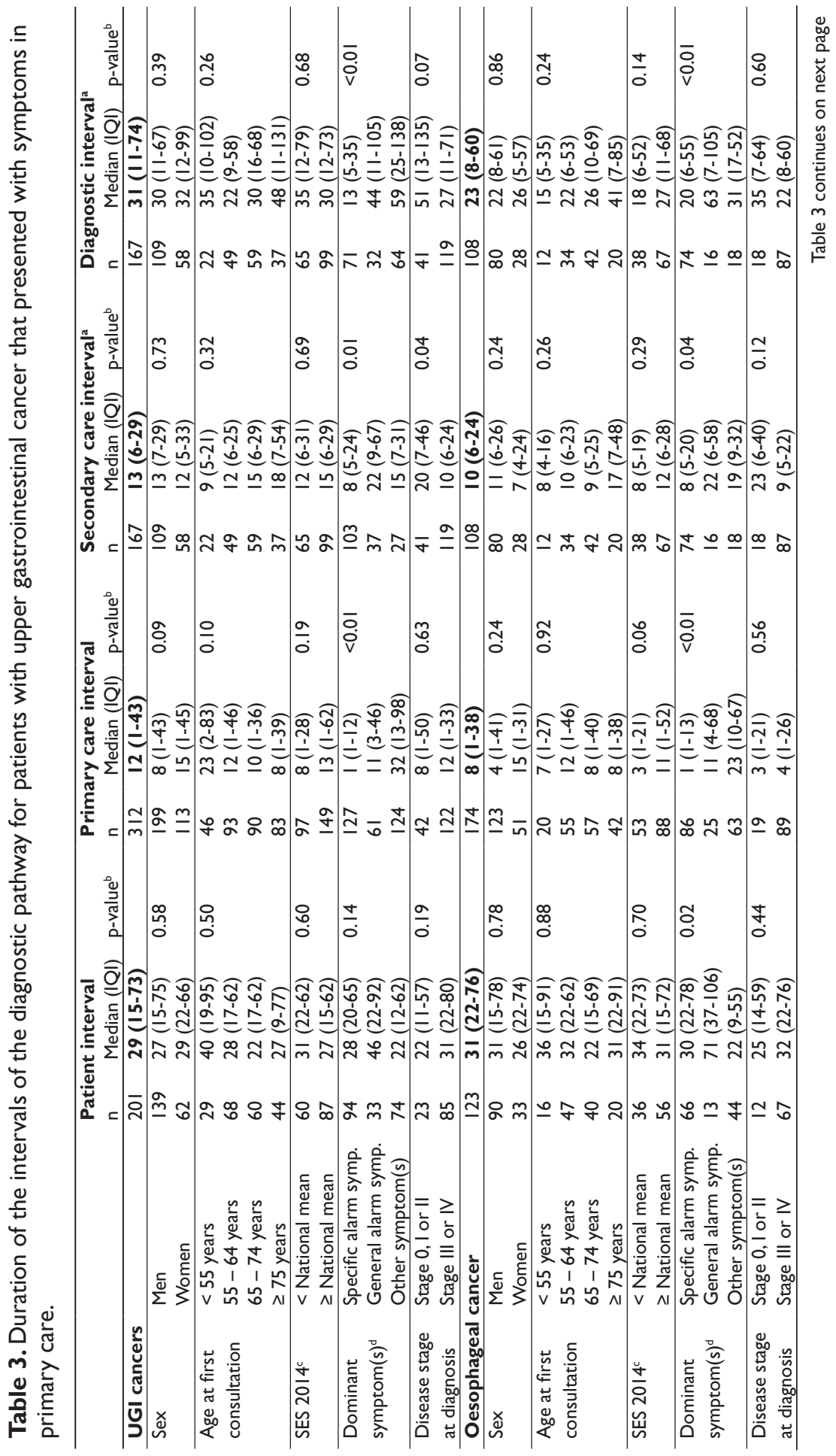




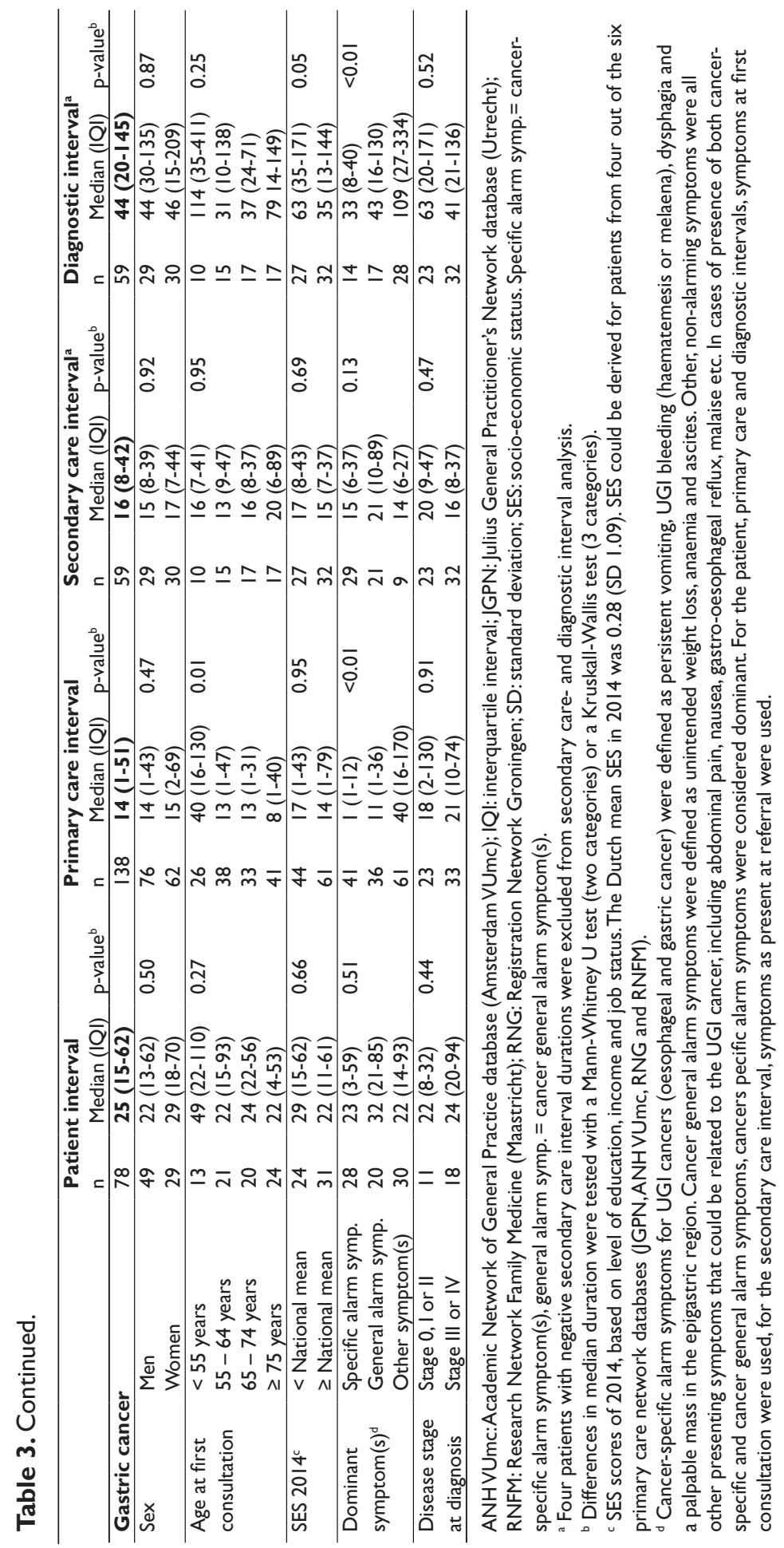




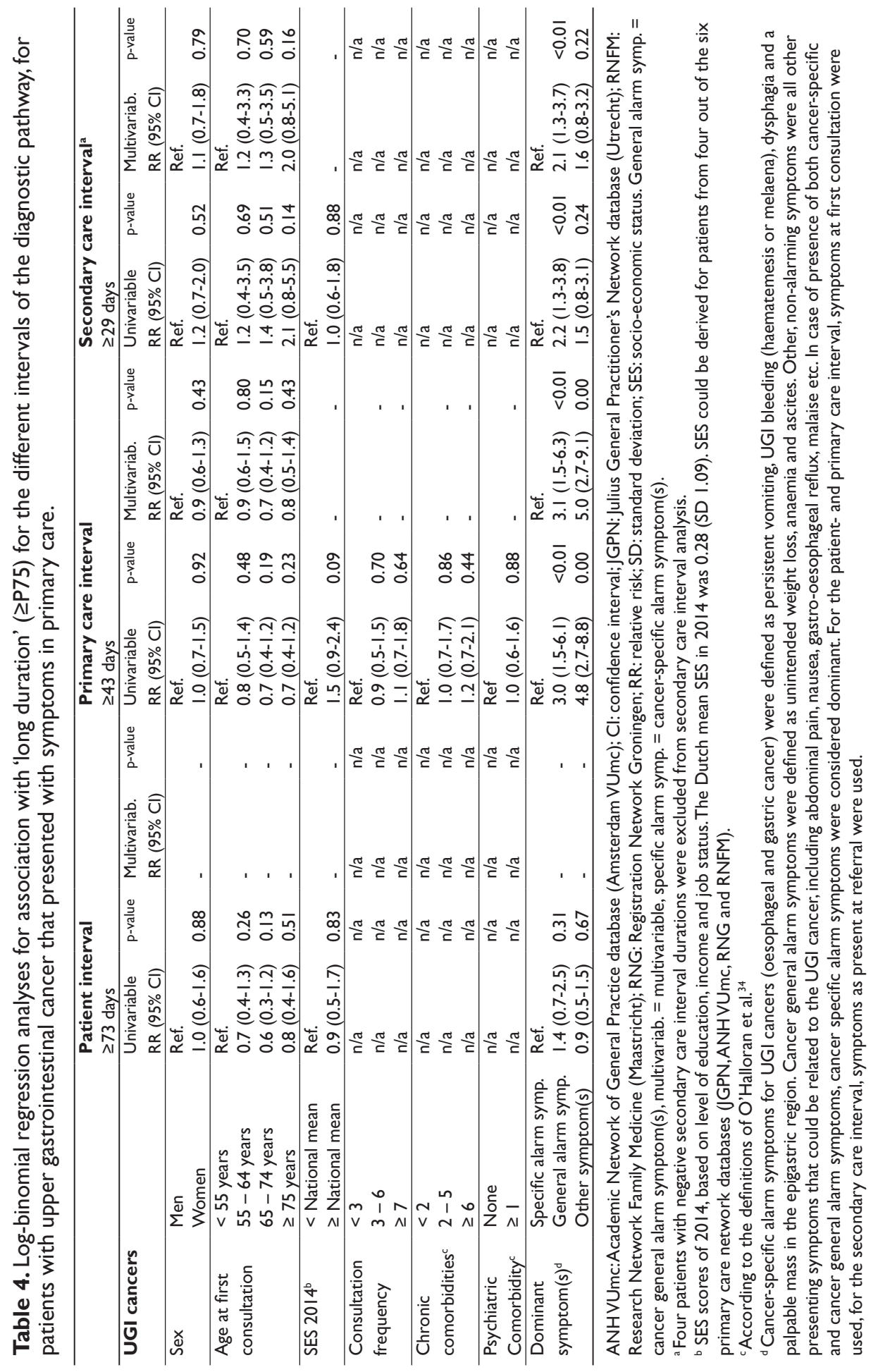


symptoms was associated with 'long duration' ( $\geq$ P75) for both IPC and ISC. We found shorter durations of ISC and ID for patients with advanced disease stages.

\section{Strengths and limitations}

Strengths and limitations of the use of routine primary care data have previously been discussed elsewhere. ${ }^{24}$ The main strength of the current dataset is the availability of freetext annotations of all GP consultations, as this provides detailed insight in the diagnostic process, including GP considerations and contextual factors. We chose not to censor the length of any of the intervals at a maximum time period, as done in previous studies, as the free-text registrations confirmed that some interval durations are very long for plausible reasons. Furthermore, linkage of primary care data to a national cancer registry (NCR), allowed us to analyse all intervals of the diagnostic pathway in one study.

Limitations include the number of excluded patients. This includes patients for whom the ICPC code for UGI cancer was not supported by the free text registrations $(20 \%$ of UGI cancer ICPC codes). Reasons for not being able to verify these diagnoses varied from lacking information to clearly incorrect use of the ICPC code (e.g. cancer diagnostic code used for a positive family history of cancer or for other UGI complaints). It has been shown earlier that, when cancer registry-based validation is performed, up to half of the ICPC codes for cancer in primary care records turn out to be incorrectly assigned ('false positive'). ${ }^{25}$ As we were not able to link all patients to the NCR for diagnostic confirmation, we choose to strictly include only those patients for whom the free text of the primary care record confirmed the UGI cancer diagnosis. Furthermore, we excluded patients with unclear diagnostic pathways (14\%) and those presenting in emergency settings (2\%). This may have affected our findings as, for example, unclear pathways may be more likely for very short or very long diagnostic intervals. Also, patients diagnosed in emergency settings may include patients that could have been referred from primary care and may have more had advanced tumour stages. ${ }^{26}$

We were able to link $76 \%$ of eligible patients to the NCR, enabling ISC and ID duration assessment. For the remaining $24 \%$ of patients linkage was not possible, because some of the primary care databases used did not contain the right pseudonyms for datalinkage (pseudonym based on postal code, birthdate and sex). As we used the primary care record to verify the UGI cancer diagnosis, we were quite certain of the presence of cancer. However, of the patients for whom linkage could be performed, not all patients (73\%) matched with the NCR. We hypothesise that the main reasons for not matching the NCR were changes of postal codes (patients who moved between registry at GP and at registration in NCR) and typographic errors. Even though matching and nonmatching patients did not differ substantially with respect to patient- and presentation 
characteristics, 'non-matching' may have been not random, e.g. in cases of 'patients with changing postal-codes'.

Furthermore, identifying the first presentation with cancer-related symptoms in opentext fields of primary care data is challenging, especially in cases of vague or less specific symptoms. Even though our approach has limitations, we believe it is more accurate than the sole use of diagnostic codes or retrospective questionnaires to identify a first presentation. Free text availability enables the retrieval of a broad range of potential first symptoms, registered at the time of occurrence, which can be extracted from a larger body of daily care registrations. We minimised the risk of misattribution of symptoms by discussing doubtful cases in our team of researchers with primary care experience. Accurate measurement of the patient interval is known to be challenging and the methods we used come with some limitations. ${ }^{22,27,28}$ The registration of symptom duration in the EHR is a reflection of the GP's interpretation of the duration that the patient remembered and mentioned. Inaccurate or lacking registration may occur and missing duration information is potentially selective, as doctors may be more prone to register either remarkably short or long durations. We found $29 \%$ and $43 \%$ missing patient intervals among oesophageal and gastric cancer patients, respectively. Less specific registrations of IP durations also occurred, for which we used a standardised approach to proximate duration (definitions in General Appendix B). Therefore, whereas IPC, ISC and ID duration should be trusted to the day, IP medians should be seen as an approximation of duration.

\section{Comparison with existing literature and implications}

We found longer median IP durations than earlier reports in the UK, that described median durations of 21.5 days (IQI 7-46) for oesophageal cancer and 9 days (IQI 0-38) for gastric cancer. ${ }^{8,13}$ Even though previous studies suggest that patients consult the GP earlier when their symptoms are more serious (like pain or bleeding), ${ }^{9}$ our findings indicate that patients may not be fully aware of alarm symptoms, since durations of the patient interval for patients with and without registered alarm symptoms were comparable. We believe that raising patients' awareness of UGI cancer alarm symptoms may be the most efficient way to improve prompt presentation and shorten time to diagnosis. Getting more insight in reasons for postponing consultation would be required for a targeted approach.

Previously reported median durations of IPC range from I day (IQI 0-32) for oesophageal cancer 16 to 12 days for gastric cancer (IQI 0-65); ${ }^{13}$ some were slightly shorter than the IPC durations we found. The main factor earlier reported to be associated with 'delay' in primary care is an 'initial misdiagnosis'. ${ }^{9}$ Even though this sounds as an avoidable and even 
blameworthy reason for delay, it may be seen as a reflection of risk assessment and the gatekeeping role of the GP. Our finding that absence of alarm symptoms was associated with 'long duration' in primary care is in line with this. Improving timely detection of cancer among patients without alarm symptoms is challenging, given the high incidence of common UGI symptoms and low risk of cancer. ${ }^{29}$ Simply lowering the threshold for referral is not the solution for reducing time to referral: apart from the increasing risk of non-indicated endoscopies with normal results, there is already a growing demand for diagnostic services in secondary care. We believe that development of novel diagnostic strategies for patients with less-specific symptoms in primary care is needed, either based on improved selection of patients at risk (for example by decision support tools derived through artificial intelligence in big databases), on the application of diagnostic tests (like the cytosponge for Barrett's oesophagus, presently evaluated in the UK) or on the use of new biomarkers for gastric and oesophageal cancer. ${ }^{30}$ Since $10-25 \%$ of the patients show a strong increase in time to referral, there also is a need for in-depth exploration of the reasons for very long primary care intervals.

Compared to previous UK studies, we found shorter or comparable median durations of ID. Din et al. reported median ID durations of 83 days (IQI 35-207) and 84 days (IQI 35-199) for oesophageal and gastric cancer respectively, ${ }^{14}$ while Swann et al. reported comparable durations of 28 days (IQI I2-66) and 42 days (IQI I7-89). ${ }^{16}$ Even though these differences may be partly explained by different research methods used, they probably reflect true and notable differences in ID durations between different healthcare systems, societies and time periods. This deserves further international comparison, since it could provide clues for reducing the time to diagnosis.

Whether reduction of the duration of the intervals in the diagnostic pathway would improve clinical outcomes is uncertain. Some earlier studies showed that increased durations of ID were associated with advanced disease stage or worse clinical outcomes. ${ }^{19,31}$ In contrast, we found longer durations of both ISC and ID, for patients diagnosed with local disease stage (stage 0 , I or II). As slightly more patients with advanced disease stage had specific alarm symptoms, we believe that for the majority of patients this reflects an adequately functioning healthcare system, with quick response for those who are most in need.This concept; long duration for early stage disease, is known as the 'waiting time paradox'. ${ }^{32}$ Truly understanding the association between time to diagnosis and stage at diagnosis is complex. It has been shown before that the association between waiting times and disease stage or clinical outcomes is not simply linear and that observational studies are not the ideal design for assessment of this association. ${ }^{33}$ More refined methodology is required to enable future studies to unravel the complex association between duration and tumour stage for these cancer types. 


\section{Conclusion}

In the diagnostic pathway of UGI cancers, the longest interval is the IP, equally long for patients with and without cancer alarm symptoms. A relatively short ID, especially for those with alarm symptoms and those with advanced disease, suggests faster processing for the sickest patients. Durations of the IPC and ISC are generally acceptable, but nonetheless, remarkably long for 10-25\% of the cancer patients. Apart from improving patients' awareness of alarm symptoms, further reduction of delay in diagnosing UGI cancer may be feasible by introducing novel diagnostic strategies for cancer patients with gastrointestinal symptoms who are currently considered at low risk because of 'low suspect' clinical presentation.

\section{Acknowledgements}

The authors thank all clinical researchers involved in data collection. They wish to thank the registration team of the Netherlands Comprehensive Cancer Organisation (IKNL) and particularly Henrike Bretveld, for the collection of data for the NCR as well as IKNL staff for scientific advice. The authors thank all the GPs for participating in the six networks for sharing their EHR data, and Nicole Boekema, Erna Beers, Marjan van den Akker, Hanna Joosten, Margot de Waal, Henk de Jong, Feikje Groenhof, ZorgTTP and their teams, for their assistance in extracting data and the linkage procedures. 


\section{REFERENCES}

I. Ferlay J, Colombet M, Soerjomataram I, Dyba T, Randi G, Bettio M, et al. Cancer incidence and mortality patterns in Europe: Estimates for 40 countries and 25 major cancers in 20I8. Eur J Cancer 2018;103:356-387.

2. Dassen AE, Dikken JL, Bosscha K, Wouters MWJM, Cats A, Velde CJHVan De, et al. Gastric cancer : Decreasing incidence but stable survival in the Netherlands Gastric cancer : Decreasing incidence but stable survival in the Netherlands. Acta Oncol 2014;53:138-142.

3. Dikken JL, Lemmens VE, Wouters MWJM,Wijnhoven BP, Siersema PD, Nieuwenhuijzen GA, et al. Increased incidence and survival for oesophageal cancer but not for gastric cardia cancer in the Netherlands. Eur J Cancer 2012;48:I624-1632.

4. Bernards N, Creemers GJ, Nieuwenhuijzen GAP, Bosscha K, Pruijt JFM, Lemmens VEPP. No improvement in median survival for patients with metastatic gastric cancer despite increased use of chemotherapy. Ann Oncol 2013;24:3056-3060.

5. Bernards N, Mohammad NH, Creemers GJ, Rozema T, Roukema JA, Nieuwenhuijzen AP, et al. Improvement in survival for patients with synchronous metastatic esophageal cancer in the south of the Netherlands from 1994 to 2013. Acta Oncol 2016;55:1 I6I-1 I67.

6. Data from the Netherlands Cancer Registry, managed by The Netherlands Comprehensive Cancer Organisation [Internet].Available from: http://www.cijfersoverkanker.nl.Accessed March $23,2017$.

7. Lee A, Khulusi S, Watson R. Which interval is most crucial to presentation and survival in gastroesophageal cancer:A systematic review. J Adv Nurs 2017;73:2270-2282.

8. Keeble S,Abel GA, Saunders CL, McPhail S, Walter FM, Neal RD, et al.Variation in promptness of presentation among 10,297 patients subsequently diagnosed with one of 18 cancers: Evidence from a National Audit of Cancer Diagnosis in Primary Care. Int J Cancer 2014; 135:1220-1228.

9. Macdonald S, Macleod U, Campbell NC, Weller D, Mitchell E. Systematic review of factors influencing patient and practitioner delay in diagnosis of upper gastrointestinal cancer. $\mathrm{Br} J$ Cancer 2006;94:1272-1280.

10. O'Rourke RW, Diggs BS, Spight DH, Robinson J, Elder KA, Andrus J, et al. Psychiatric illness delays diagnosis of esophageal cancer. Dis Esophagus 2008;2I:416-42I.

II. Cavallin F, Scarpa M, Cagol M,Alfieri R, Ruol A, Chiarion Sileni V, et al. Time to diagnosis in esophageal cancer: a cohort study. Acta Oncol 2018;57:II79-II84.

12. Grotenhuis BA, van Hagen P,Wijnhoven BPL, Spaander MCW,Tilanus HW, van Lanschot JJB. Delay in diagnostic workup and treatment of esophageal cancer.J Gastrointest Surg 2010;14:476-483.

13. Lyratzopoulos G, Saunders CL,Abel GA, McPhail S, Neal RD,Wardle J, et al. The relative length of the patient and the primary care interval in patients with 28 common and rarer cancers. $\mathrm{Br} J$ Cancer 2015; I I2:S35-S40.

14. Din NU, Ukoumunne OC, Rubin G, Hamilton W, Carter B, Stapley S, et al.Age and gender variations in cancer diagnostic intervals in 15 cancers:Analysis of data from the UK clinical practice research datalink. PLoS One 2015; I0:I-I5. 
15. Neal RD, Din NU, Hamilton W, GBRoumunne OC, Carter B, Stapley S, et al. Comparison of cancer diagnostic intervals before and after implementation of NICE guidelines:Analysis of data from the GBR General Practice Research Database. Br J Cancer 2014;1 10:584-592.

16. Swann R, McPhail S, Shand B, Rashbass J,Witt J, Abel GA, et al. Diagnosing cancer in primary care: Results from the National Cancer Diagnosis Audit. Br J Gen Pract 2018;68:e63-e72.

17. O'Rourke RW, Diggs BS, Spight DH, Robinson J, Elder KA, Andrus J, et al. Psychiatric illness delays diagnosis of esophageal cancer. Dis Esophagus 2008;21:416-2I.

18. Arhi CS, Markar S, Burns EM, Bouras G, Bottle A, Hanna G, et al. Delays in referral from primary care are associated with a worse survival in patients with esophagogastric cancer. Dis Esophagus 2019;32; I-II.

19. Neal RD, Tharmanathan P, France B, Din NU, Cotton S, Fallon-Ferguson J, et al. Is increased time to diagnosis and treatment in symptomatic cancer associated with poorer outcomes? Systematic review. Br J Cancer 20I5; I I2:S92-SI 07.

20. Netherlands Comprehensive Cancer Organisation (IKNL). Over de registratie [in Dutch], https:// www.iknl.nl/en/ncr.Accessed June 28, 2019.

21. Lamberts H,Wood M. International Classification of Primary Care (ICPC). Oxford University Press, Oxford, 1987.

22. Weller D, Vedsted P, Rubin G,Walter FM, Emery J, Scott S, et al. The Aarhus statement: improving design and reporting of studies on early cancer diagnosis. Br J Cancer 2012;106:1262-1267.

23. Numans M, De Wit N, Dirven J, Heemstra-Borst C, Hurenkamp G, Scheele M, et al. NHG Guideline on Dyspepsia (second revision). Huisarts Wet 2013;1:26-35.

24. Helsper C, van Erp N, Peeters P, de Wit N. Original Research:Time to diagnosis and treatment for cancer patients in the Netherlands: room for improvement? Eur J Cancer 2017;87:1 13-121.

25. Sollie A, Roskam J, Sijmons RH, Numans ME, Helsper CW. Do GPs know their patients with cancer? Assessing the quality of cancer registration in Dutch primary care: a cross-sectional validation study. BMJ Open 2016 Sep I5;6:e0I2669.

26. Markar SR, Mackenzie H, Jemal S, Faiz O, Cunningham D, Hanna GB. Emergency Presentation of Esophagogastric Cancer. Ann Surg 2018;267:7II-7I5.

27. Andersen RS, Vedsted P, Olesen F, Bro F, Søndergaard J. Patient delay in cancer studies:A discussion of methods and measures. BMC Health Serv Res 2009;9:1-7.

28. Smith SM, Whitaker KL, Cardy AH, Elliott AM, Hannaford PC, Murchie P.Validation of self-reported help-seeking, and measurement of the patient interval, for cancer symptoms: an observational study to inform methodological challenges in symptomatic presentation research. Fam Pract 2020;37:91-97.

29. Astin MP, Martins T, Welton N, Neal RD, Rose PW, Hamilton W. Diagnostic value of symptoms of oesophagogastric cancers in primary care: a systematic review and meta-analysis. Br J Gen Pract 20I5;65:e677-e69I.

30. Rubin G,Walter F, Emery J, De Wit N. Reimagining the diagnostic pathway for gastrointestinal cancer. Nat Rev Gastroenterol Hepatol 2018;15:181-188.

3I. Tørring ML, Frydenberg M, Hansen RP, Olesen F,Vedsted P. Evidence of increasing mortality with 
longer diagnostic intervals for five common cancers:A cohort study in primary care. Eur J Cancer 2013;49:2187-2198.

32. Crawford SC, Davis JA, Siddiqui NA, De Caestecker L, Gillis CR, Hole D. The waiting time paradox: Population based retrospective study of treatment delay and survival of women with endometrial cancer in Scotland. Br Med J 2002;325:196.

33. Tørring ML, Falborg AZ, Jensen H, Neal RD, Weller D, Reguilon I, et al.Advanced-stage cancer and time to diagnosis:An International Cancer Benchmarking Partnership (ICBP) cross-sectional study. Eur J Cancer Care 2019;28: I-II.

34. O'Halloran J, Miller GC, Britt H. Defining chronic conditions for primary care with ICPC-2. Fam Pract 2004;21:38I-386. 


\section{APPENDIX I}

For symptomatic upper gastrointestinal cancer patients that could be linked to the Netherlands Cancer Registry: characteristics of patients that were a match with NCR compared with patients that were not a match with NCR.

\begin{tabular}{|c|c|c|c|}
\hline & & NCR match & No match \\
\hline Population & $\mathrm{n}(\%)$ & $172(100)$ & $65(100)$ \\
\hline Male patients & $\mathrm{n}(\%)$ & III (64.5) & $39(60.0)$ \\
\hline Age at first consultation & Mean \pm SD & $65.9 \pm 11.8$ & $67.5 \pm 13.7$ \\
\hline \multirow[t]{2}{*}{ Socio-economic status score (SES) $2014^{a}$} & Mean \pm SD & $0.36 \pm 1.16$ & $0.43 \pm 1.14$ \\
\hline & Missing, n (\%) & $3(1.7)$ & $2(3.1)$ \\
\hline \multirow{2}{*}{$\begin{array}{l}\text { Consultation frequency in year before first } \\
\text { consultation }\end{array}$} & Median (IQI) & $5(2-I I)$ & $5(2-9)$ \\
\hline & Missing, n (\%) & $14(8.1)$ & $9(13.8)$ \\
\hline \multirow{2}{*}{$\begin{array}{l}\text { Number of registered chronic somatic } \\
\text { comorbidities }^{b}\end{array}$} & Median (IQI) & $3(1-6)$ & $2(I-4)$ \\
\hline & Missing, $\mathrm{n}(\%)$ & $6(3.5)$ & $2(3.1)$ \\
\hline \multirow{2}{*}{$\begin{array}{l}\text { Registered psychiatric } \\
\text { comorbidity }^{b}\end{array}$} & n (\%) & $40(23.3)$ & $8(12.3)$ \\
\hline & Missing, n (\%) & $6(3.5)$ & $2(3.1)$ \\
\hline \multicolumn{4}{|l|}{ Dominant symptom(s) at first consultation ${ }^{c}$} \\
\hline Cancer specific alarm symptom(s) & n (\%) & $72(4 \mid .9)$ & $27(4 \mid .5)$ \\
\hline Cancer general alarm symptom(s) & $\mathrm{n}(\%)$ & $32(18.6)$ & $13(20.0)$ \\
\hline Other, non-alarming symptoms & $\mathrm{n}(\%)$ & $68(39.5)$ & $25(38.5)$ \\
\hline \multicolumn{4}{|l|}{ Dominant symptom(s) at referral $^{c}$} \\
\hline Cancer specific alarm symptom(s) & $\mathrm{n}(\%)$ & $106(61.6)$ & $38(58.5)$ \\
\hline Cancer general alarm symptom(s) & $\mathrm{n}(\%)$ & $38(22.1)$ & $15(23.1)$ \\
\hline Other, non-alarming symptoms & n (\%) & $28(16.3)$ & $12(18.5)$ \\
\hline
\end{tabular}

$\mathrm{IQI}=$ interquartile interval, NCR = Netherlands Cancer Registry, SD = standard deviation

${ }^{a}$ Socio-economic status scores of 2014, based on level of education, income and job status. The Dutch mean SES in 2014 was 0.28 (SD I.09). SES could be derived for patients from 4 out of the 6 primary care network databases (JGPN, ANH VUmc, RNG and RNFM).

${ }^{\mathrm{b}}$ According to the definitions of O'Halloran et al. ${ }^{34}$

'Cancer specific alarm symptoms for UGI cancers (oesophageal- and gastric cancer) were defined as persistent vomiting, UGI bleeding (hematemesis or melena), dysphagia and a palpable mass in the epigastric region. Cancer general alarm symptoms were defined as unintended weight loss, anaemia and ascites. Other, non-alarming symptoms were all other presenting symptoms that could be related to the UGI cancer, including abdominal pain, nausea, gastro-oesophageal reflux, malaise etc. In case of presence of both cancer specific and cancer general alarm symptoms, cancer specific alarm symptoms were considered dominant. 


\section{APPENDIX 2}

For symptomatic upper gastrointestinal cancer patients with available disease stage: symptom distribution according to tumour stage at diagnosis and different time intervals.

\begin{tabular}{|c|c|c|c|c|c|}
\hline Disease stage & Dominant symptom(s) ${ }^{\mathrm{a}}$ & $\begin{array}{l}\text { Patient } \\
\text { interval } \\
\mathrm{n}(\%)\end{array}$ & $\begin{array}{l}\text { Primary care } \\
\text { interval } \\
\mathrm{n}(\%)\end{array}$ & $\begin{array}{l}\text { Secondary } \\
\text { care interval* } \\
\mathrm{n}(\%)\end{array}$ & $\begin{array}{l}\text { Diagnostic } \\
\text { interval* }^{*} \\
\mathrm{n}(\%) \\
\end{array}$ \\
\hline \multirow[t]{4}{*}{ Stage 0 , I or II } & All & $23(100)$ & $42(100)$ & $41(100)$ & $41(100)$ \\
\hline & Specific alarm symp. & II (47.8) & $15(35.7)$ & $19(46.3)$ & $14(34.1)$ \\
\hline & General alarm symp. & $5(2 \mid .7)$ & II (26.2) & $14(34.1)$ & II (26.8) \\
\hline & Other symptom(s) & $7(30.4)$ & $16(38.1)$ & $8(19.5)$ & $16(39.0)$ \\
\hline \multirow[t]{4}{*}{ Stage III or IV } & All & $85(100)$ & $122(100)$ & $119(100)$ & $119(100)$ \\
\hline & Specific alarm symp. & $43(50.6)$ & $54(44.3)$ & $81(68.1)$ & $54(45.4)$ \\
\hline & General alarm symp. & $10(11.8)$ & 17 (13.9) & $19(16.0)$ & $17(14.3)$ \\
\hline & Other symptom(s) & $32(37.6)$ & $51(4 I .8)$ & $19(16.0)$ & $48(40.3)$ \\
\hline
\end{tabular}

General alarm symp. = cancer general alarmsymptom(s), Specific alarm symp. = cancer specific alarm symptom(s). ${ }^{a}$ Cancer specific alarm symptoms for UGI cancers (oesophageal- and gastric cancer) were defined as persistent vomiting, UGI bleeding (hematemesis or melena), dysphagia and a palpable mass in the epigastric region. Cancer general alarm symptoms were defined as unintended weight loss, anaemia and ascites. Other, non-alarming symptoms were all other presenting symptoms that could be related to the UGI cancer, including abdominal pain, nausea, gastro-oesophageal reflux, malaise etc. In case of presence of both cancer specific and cancer general alarm symptoms, cancer specific alarm symptoms were considered dominant. For the patient-, primary care and diagnostic interval, symptoms at first consultation were used, for the secondary care interval, symptoms as present at referral were used.

*Four patients with negative secondary care interval durations were excluded from secondary care- and diagnostic interval analysis. 


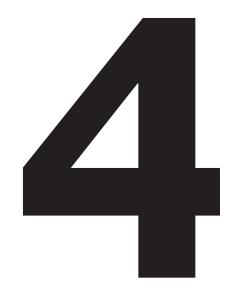

\title{
The diagnostic pathway of symptomatic kidney and bladder cancer
}

\author{
Nicole F. van Erp \\ Charles W. Helsper \\ Peter-Paul M.Willemse \\ Pauline Slottje \\ Feikje Groenhof \\ Frederike L. Büchner \\ Kristel M. van Asselt \\ Jean W.M. Muris \\ Marlous F. Kortekaas \\ Petra H.M. Peeters \\ Niek J. de Wit
}




\section{ABSTRACT}

Background: An efficient cancer diagnostic pathway is widely pursued. This study assesses the duration of the diagnostic pathway for urological cancer patients and characteristics associated with long duration.

Methods: A retrospective cohort study was performed using routine primary care data, linked to the Netherlands Cancer Registry. For symptomatic kidney and bladder cancer patients (diagnosed 20I0-20I5) duration was determined of the: patient interval (IP), primary care interval (IPC), secondary care interval (ISC) and diagnostic interval (ID). Characteristics associated with 'long duration' ( $\geq 75$ th percentile, P75) were assessed.

Results: Among 605 patients median duration was; IP 6 days (interquartile interval (IQI) 2-20), IPC I0 days (IQI I-44), ISC 39 days (IQI 2 I-64) and ID 56 days (IQI 29-I03). 'Long duration' ( $\geq P 75$ ) was seen more often in female patients (IPC): relative risk (RR) 1.8 (95\% Cl I.4-2.3) and in patients without cancer alarm symptoms: IP RR I.7 $(95 \% \mathrm{Cl}$ I.I 2.6), IPC RR 2.4 (95\%CI I.8-3.3), ISC RR 2.I (95\%CI I.4-3.0).

Conclusion: In conclusion, in the diagnostic pathway of patients with urological cancer, mainly the secondary care interval shows potential room for improvement. Women and patients without cancer alarm symptoms experience longer times to referral and diagnosis. Further study is warranted to establish potential beneficial effects of shortening intervals on prognosis. 


\section{INTRODUCTION}

In Europe, cancer of the kidney and bladder account for 3.5 and $5 \%$ of the cancer incidence respectively.' Both cancer types are more common in older patients and among men.2 Prognosis of these cancer types is highly dependent on disease stage at diagnosis with 5 -year survival ranging from over $90 \%$ for early stage disease to only $10 \%$ for patients with stage IV disease. ${ }^{2,3}$ Early detection is therefore a key objective to optimise clinical outcomes and patient experience of care..$^{4,5}$

Since population screening is currently not embraced, due to insufficient evidence to assess the balance of its benefits and harms, a urological cancer diagnosis typically follows after symptomatic presentation in primary care. Symptoms associated with urological cancer are generally non-specific and amongst others include visible and non-visible haematuria, urinary tract symptoms, abdominal and back pain. Visible haematuria has the highest predictive value for urological cancer, with a positive predictive value of around $5 \%{ }^{6}$

Promptness of diagnosis depends on timely consultation by patients, adequate referral by the general practitioner and efficient diagnostic confirmation in secondary care. Prolongation of each of these phases may contribute to delayed diagnosis. Earlier research showed that patients tend to present early with symptomatic kidney and bladder cancer as compared to other cancer types, with median patient interval durations of only 3 and 2 days in some studies. ${ }^{7}$ It is also known that women are diagnosed later with bladder cancer and have poorer survival, even when adjusted for disease stage. ${ }^{8-10}$

However, at present the evidence for the timeliness of the diagnostic pathway of bladder and kidney cancer is fragmented. ${ }^{11,12}$ Deeper understanding of the pathways to diagnosis and underlying time intervals could provide targets for improvement, which in turn could contribute to improved outcomes.

We aim to chart the duration of the different phases of the diagnostic pathway for symptomatic patients with urological cancer in the Netherlands, to identify characteristics associated with long duration and to assess the association of duration with tumour stage at diagnosis. 


\section{METHODS}

\section{Study design and data source}

This study is part of the DICKENS project. ${ }^{13} \mathrm{~A}$ retrospective cohort study was performed using anonymized data from six academic primary care networks (General Appendix A), containing free-text and coded information from the primary care electronic health records (EHRs) of over 640,000 patients from different regions of the Netherlands. Free texts include registrations of patient consultations, i.e. presented complaints, results of physical examination, clinical reasoning of the general practitioner (GP) and management plan. Coded data include diagnoses (according to the International Classification of Primary Care; ICPC-I). ${ }^{14}$ This data source was used to determine the duration of the patient interval (IP) and the primary care interval (IPC) (Figure I).

To be able to determine the secondary care interval (ISC), diagnostic interval (ID) (Figure I) and the association between duration and tumour stage at diagnosis, we linked the routine primary care data of eligible patients to the data of the Netherlands Cancer Registry (NCR). The NCR is a population-based registry with detailed diagnostic and therapeutic data of over $95 \%$ of Dutch cancer patients since 1989.15 Pseudonym-based data linkage was possible for three databases (JGPN, ANH VUmc and RNG: together comprising $77 \%$ of the identified cancer patients). The linkage procedure comprised matching of pseudonyms based on date of birth, sex and postal code (6 digits) among patients with a cancer diagnosis according to their primary care record, using a trusted third party in compliance with Dutch and European privacy regulations (General Data Protection Regulation, https://gdpr.eu).

\section{Case selection}

All adult patients (aged $\geq 18$ years) registered with the ICPC-I code for 'malignant neoplasm of kidney' (U75) and 'malignant neoplasm of bladder' (U76) in 20 I0-20I5 were extracted from the primary care databases. Of all identified patients, we assessed the free text elements of the EHR to confirm the cancer diagnosis, based on the GP's annotations of correspondence from secondary care and other descriptions indicating cancer presence. Only those patients with a primary care EHR confirmed cancer diagnosis were included. Next, we selected only those who presented to the GP with symptoms and who were referred by the GP for diagnostic workup. Figure $\mathbf{2}$ shows the patient selection process and reasons for exclusion. 


\section{Data collection}

Data were collected from the primary care data by medical trained researchers ( $\mathrm{NvE}$ and final year medical students). Anonymized primary care EHR data were scrutinized manually from five years before the date of entry of the ICPC code for urological cancer up to one year after. EHRs were studied up to one year after ICPC coding because in general practice the date of the ICPC code marks the beginning of the disease episode and not necessarily the actual date of diagnosis.

Six time intervals of the cancer care pathway were assessed (Figure I). These intervals were defined according to the Aarhus statement for improving reporting of studies on early cancer diagnosis and the Dutch quality standards for cancer care (in Dutch: SONCOS normeringsrapport). ${ }^{16,17}$ The patient interval (IP) was defined as duration from first noticing symptom(s) that were likely to be related to the eventual cancer diagnosis, to first consultation with these symptoms in primary care; the primary care interval (IPC) was defined as duration from first consultation with the cancer related symptoms in primary care to referral to secondary care; the secondary care interval (ISC) was defined as duration from referral to secondary care by the GP to date of diagnosis, and the overarching diagnostic interval (ID) was defined as duration from first consultation to date of diagnosis. To assess adherence to the Dutch quality standards for cancer care we also determined the duration of the treatment interval (IT); defined as the duration from diagnosis to initial treatment and the duration from referral to onset of treatment (IRT).

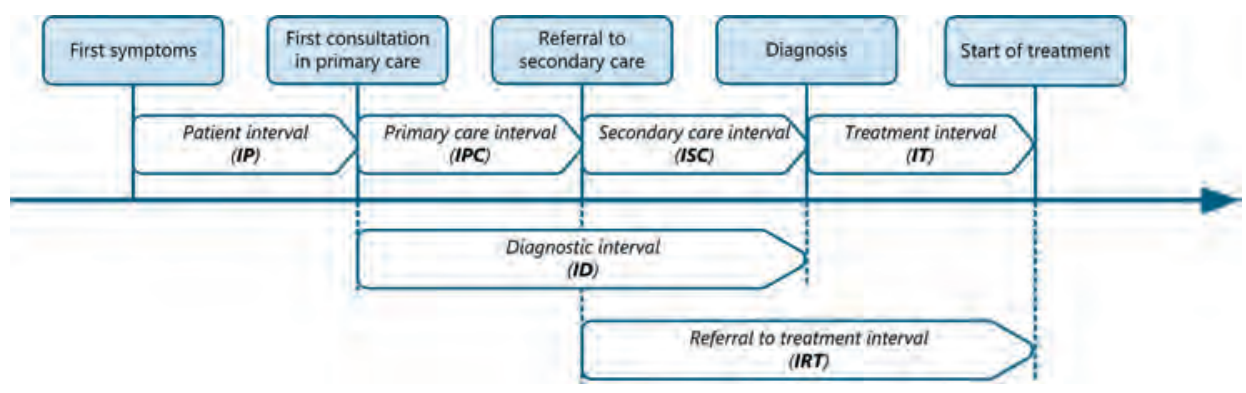

Figure I. Milestones and time intervals in the route from symptom onset to diagnosis and start of treatment.

According to the multidisciplinary Dutch quality standard for cancer care, a patient suspected of cancer should be seen by the specialist within one week, and treatment 
should start within six weeks after this first specialist visit. Therefore, treatment should be initiated within seven weeks (49 days) after referral by the GP.

Date of first symptom (start of IP) was defined as the date first symptoms that were likely related to the cancer were experienced by the patient, as registered in the medical record by the GP. For example, if the GP registered 'painful urination for two weeks', date of first symptom was defined as the date 14 days before the date of first consultation. Less strictly described time periods, such as 'several weeks' and 'a couple of days' were interpreted according to predefined rules, General Appendix B. Duration indications such as 'for a while' or 'for some time' where considered too vague for interpretation and were excluded from IP analysis. In case of different duration indications for multiple cancer related complaints, the longest duration was selected to determine IP duration.

Date of first consultation (end of IP, start of IPC) was defined as the first presentation to the GP with signs or symptoms related to the kidney or bladder cancer. In case of vague or non-specific signs or symptoms, the first consultation with the complaints that eventually led to the cancer diagnosis, and were likely to be related to the cancer, was taken. We minimized the risk of misattribution of symptoms by discussing doubtful cases in our team of researchers with primary care experience.

Date of referral (end of IPC, start of ISC) was defined as the moment the responsibility for the patient was transferred from primary to secondary care, as registered in the EHR. Referral to the radiology department for GP requested imaging was considered as referral, if abnormal findings subsequently resulted in referral to a specialist, without further interference of the GP. In case of multiple referrals to, or cross-referrals in secondary care, the first referral for further exploration of cancer related symptoms was taken.

Date of diagnosis (end of ISC and ID, start of IT) and date of first therapy (end of IT) was retrieved from the NCR data, only available for NCR matched patients. The NCR uses the hierarchy for diagnosis date as provided by the European Network of Cancer Registries, ${ }^{18}$ primarily registering date of histological diagnosis, in accordance with the preferred date of diagnosis as dictated in the Aarhus Statement. ${ }^{16}$

Patient and presentation characteristics were collected from the primary care EHR.All characteristics and methods of collection are shown in General Appendix C. Presenting symptoms and signs were categorized as either cancer specific alarm symptoms (visible haematuria (both cancers) and a palpable mass/tumour in the abdomen/flank (kidney cancer)), cancer general alarm symptoms (unintended weight loss, anaemia and ascites) 
or non-alarming symptoms (all other symptoms that were potentially related to the urological cancer). Disease characteristics were retrieved from the NCR data for NCR matched patients.

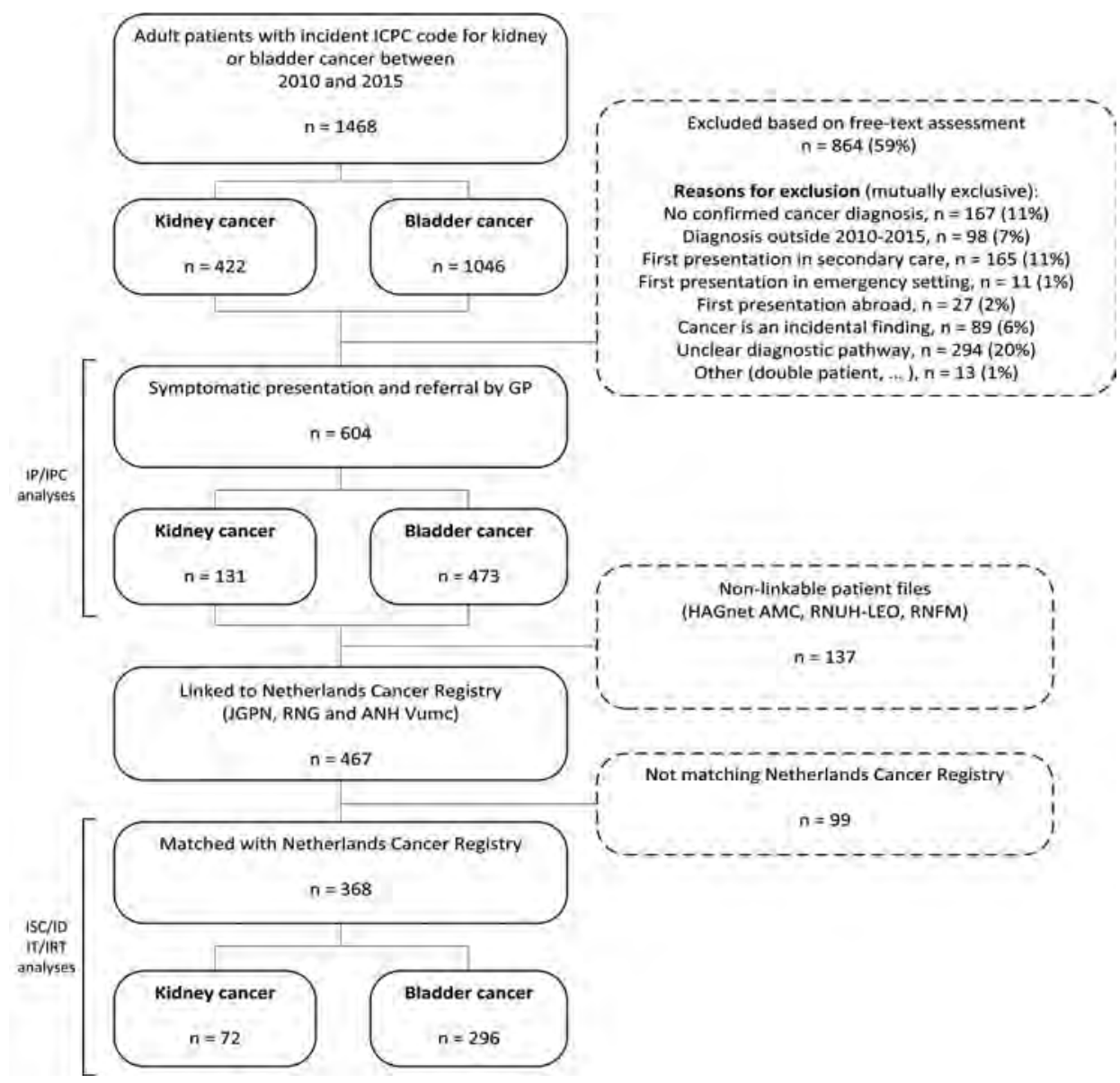

Figure 2. Identified urological cancer cases and reasons for exclusion.

ANHVUmc:Academic Network of General Practice database (Amsterdam VUmc); GP: general practitioner; HAGnet AMC: General Practice Registration Network (Amsterdam AMC); ICPC: International Classification of Primary Care; ID: diagnostic interval; IP: patient interval; IPC: primary care interval; ISC: secondary care interval; IT: treatment interval; IRT: duration from referral to onset of treatment; JGPN: Julius General Practitioner's Network database (Utrecht); RNFM: Research Network Family Medicine (Maastricht); RNG: Registration Network Groningen; RNUH-LEO: Registration Network of General Practitioners Associated with Leiden University (Leiden). 


\section{Analyses}

Duration of all intervals was calculated in days and stratified for several patient and presentation characteristics (median, interquartile interval (IQI)). We consistently added one day to all durations, as we considered same-day proceedings as a duration of one day. Differences in median duration were tested with the Mann-Whitney $U$ test for variables with 2 categories or the Kruskall-Wallis test for variables with $\geq 3$ categories.

We defined 'long duration' as duration equal to or longer than the 75th percentile value ( $\geq$ P75) of duration for the individual diagnostic intervals (IP, IPC, ISC). Univariable and multivariable log-binomial regression analyses were performed to identify characteristics associated with 'long duration'. Age at first consultation and sex as well as characteristics that were statistically significantly associated with 'long duration' $(P<0.05)$ in univariable analysis were included in multivariable analysis. For IPC, we also assessed consultation frequency, chronic comorbidities and psychiatric comorbidity. Results are shown as relative risks $(\mathrm{RR})$ with $95 \%$ Confidence Intervals $(95 \% \mathrm{Cl})$.

The association of duration with tumour stage at diagnosis, was determined by testing differences in the median duration of the diagnostic interval for patients with local

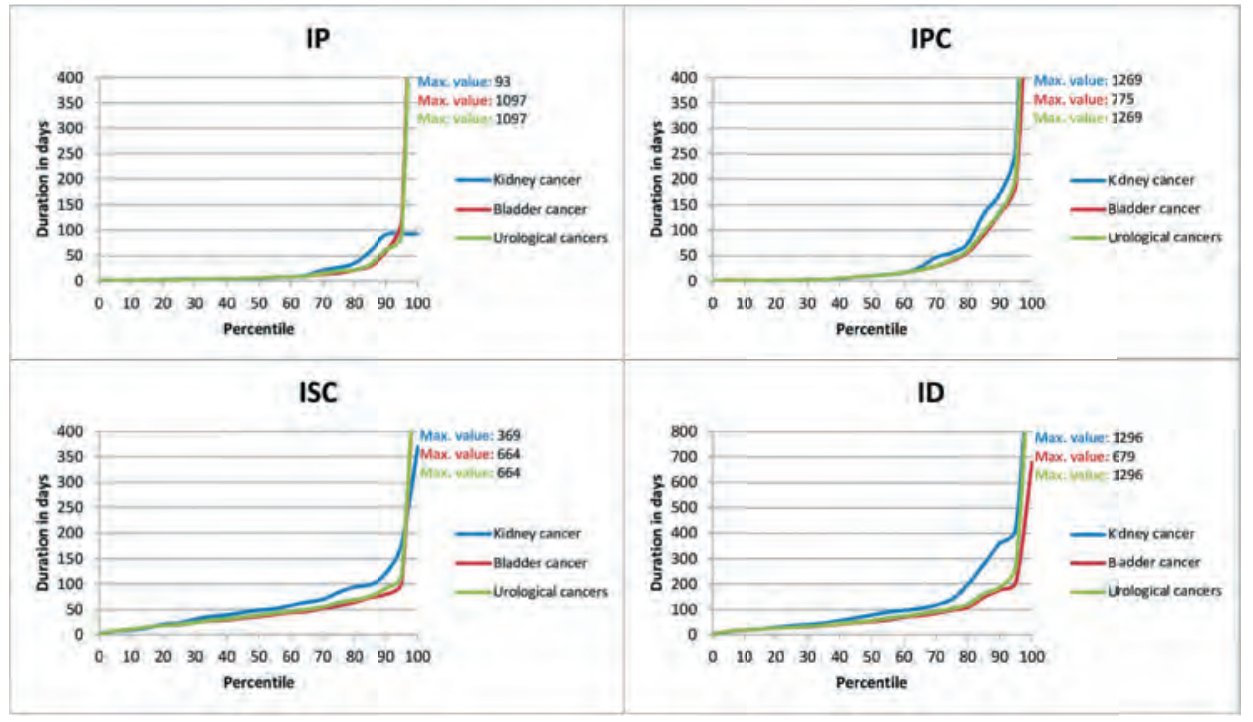

Figure 3. Distribution of the duration of the different time intervals of the cancer diagnostic pathway for symptomatic patients with urological cancer.

IP = patient interval $(n=256)$, IPC = primary care interval $(n=604)$, ISC = secondary care interval $(n=364)$, ID = diagnostic interval $(n=364)$. 
disease (stage 0a, Ois and I for bladder cancer and stage I and II for kidney cancer) and advanced disease stages (stage II-IV for bladder cancer and III or IV for kidney cancer) using the Mann-Whitney $U$ test.

\section{Software}

Data transformation and analyses were performed in SPSS version 22.0 (SPSS Inc., Chicago, IL, USA).

\section{RESULTS}

\section{Patient characteristics}

Of 1468 patients identified with an ICPC-I code for either kidney or bladder cancer in the EHR, 604 (4I\%) met the eligibility criteria: I3I kidney cancer patients and 473 bladder cancer patients. Most common reasons for exclusion (Figure 2) were an unclear diagnostic pathway (plausible diagnosis but unclear route to diagnosis) and a non-confirmed cancer diagnosis (potentially incorrect ICPC code).

Patient-, presenting- and disease characteristics are described in Table I. Most patients (73\%) were male: 81 (62\%) of the kidney cancer patients and 360 (76\%) of the bladder cancer patients. Mean age at first presentation in primary care was 68 years (SD I2). During first consultation, for $38 \%$ of the kidney cancer patients and $69 \%$ of the bladder cancer patients at least one cancer specific alarm symptom was registered.Among the 44I male patients, 298 (68\%) reported cancer specific alarm symptoms at first consultation, as compared to 76 of 163 (47\%) female patients.

For the analysis of ISC, ID, IT, IRT and the association of duration with tumour stage, a total of 467 patients ( $77 \%$ of those eligible) could be linked to the NCR. For 368 patients (79\% of those linked) a match was found in the NCR. Date of diagnosis in the NCR was based on histology or cytology in 359 patients (98\%). We found no differences in patient and presentation characteristics between those who could be matched with the NCR and those who could not (Appendix I). Of NCR matched patients, disease characteristics are shown in Table I.

\section{Duration of time intervals}

Duration of the different intervals is shown in Table 2. Duration of all intervals demonstrated a right skewed distribution (Figure 3), with a strong increase in duration for $10 \%$ (IP, ISC) to $25 \%$ (IPC) of patients. 
For 256 patients (42\%) a patient interval (IP) was registered. Median duration of IP was 6 days (IQI 2-20). Longest duration until presentation was seen for those patients $(n=7)$ who reported general alarm symptoms/signs for cancer (unintended weight loss, complaints related to anaemia and ascites). For kidney cancer, women showed a longer median duration until presentation than men ( 10 days for female patients as compared to 4 days for male patients). There were no other statistically significant age and sex differences in duration of IP, although for kidney cancer, duration was longest for patients aged $<55$ years.

Median duration of the primary care interval (IPC) was 10 days (IQI I-43), 25 days (IQI 4-98) for women and 8 days (IQI I-28) for men. This sex difference was most pronounced among bladder cancer patients (29 days for women compared to 8 days for men). Patients presenting with alarm symptoms specific for urological cancer (visible haematuria and/or palpable mass in the abdomen or flank) were referred most quickly for diagnostic work-up: 4 days (IQI I-I7) as compared to 30 days (IQI I I-92) for patients without alarm symptoms.

Median duration of the secondary care interval (ISC) was 39 days (IQI 2I-64): 49 days (IQI 23-84) for kidney cancer and 36 days (IQI 20-57) for bladder cancer. ISC was shortest for patients with cancer specific alarm symptoms: 34 days (IQI 19-52) as compared to 54 days (IQI 3I-80) for patients without alarm symptoms. We excluded four patients with negative duration of the secondary care interval from ISC, IT, IRT and ID analyses, because we suspected registration errors.

Median duration of the total diagnostic interval (ID) was 56 days (IQI 29-I03); 78 days (IQI 37-I40) for kidney cancer and 53 days (IQI 29-97) for bladder cancer ( $P=0.02$ ). ID was significantly shorter for men as compared to women (50 and 83 days respectively, $P$ $<0.01$ ), as well as for patients with cancer specific alarm symptoms compared to patients without alarm symptoms (42 days and 95 days respectively, $\mathrm{P}<0.0 \mathrm{I}$ ).

Median duration of the treatment interval (IT, $n=354)$ was I day (IQI I-I7). Out of 3 I6 patients that initially underwent surgery, 257 patients (8I\%) had a treatment interval duration of $\leq \mathrm{I}$ day (diagnostic material was obtained during surgery). Median duration from referral to onset of therapy (IRT) was 5 I days (IQI 3I-75). In total, I74 patients (49\%) met the maximum duration for this interval (within 49 days) proposed by the Dutch quality standard for cancer care.

Results of the log-binomial regression analyses for association with 'long duration' ( $\geq P 75)$ for the different time intervals are shown in Table 3. The absence of alarm symptoms 
Table I. Characteristics of patients with urological cancer (kidney and bladder cancer) that presented with symptoms in primary care.

\begin{tabular}{|c|c|c|c|c|}
\hline & & $\begin{array}{l}\text { Urological } \\
\text { cancers }\end{array}$ & $\begin{array}{l}\text { Kidney } \\
\text { cancer }\end{array}$ & $\begin{array}{l}\text { Bladder } \\
\text { cancer }\end{array}$ \\
\hline Population & n (\%) & $604(100)$ & $131(100)$ & $473(100)$ \\
\hline Male patients & $\mathrm{n}(\%)$ & $44 I(73.0)$ & $81(61.8)$ & $360(76.1)$ \\
\hline Age at first consultation & Mean \pm SD & $67.6 \pm 11.9$ & $64.9 \pm 12.5$ & $68.3 \pm 11.6$ \\
\hline Socio-economic status score (SES) & Mean \pm SD & $0.33 \pm 1.20$ & $0.41 \pm 1.29$ & $0.31 \pm 1.17$ \\
\hline $2014^{a}$ & Missing, n (\%) & $99(16.4)$ & $18(13.7)$ & $81(17.1)$ \\
\hline Consultation frequency in year & Median (IQI) & $5(2-10)$ & $5(2-8)$ & $6(2-10)$ \\
\hline before first consultation & Missing, n (\%) & $18(3.0)$ & $3(2.3)$ & $15(3.2)$ \\
\hline Number of registered chronic & Median (IQI) & $3(1-5)$ & $2(I-5)$ & $3(1-5)$ \\
\hline somatic comorbidities $^{\mathrm{b}}$ & Missing, n (\%) & $3(0.5)$ & $\mathrm{I}(0.8)$ & $2(0.4)$ \\
\hline Registered psychiatric & $\mathrm{n}(\%)$ & $115(19.0)$ & $27(20.6)$ & $88(18.6)$ \\
\hline comorbidity $^{\mathrm{b}}$ & Missing, n (\%) & $2(0.3)$ & $\mathrm{I}(0.8)$ & $\mathrm{I}(0.2)$ \\
\hline \multicolumn{5}{|c|}{ Dominant symptom(s) at first consultation ${ }^{c}$} \\
\hline Cancer specific alarm symptom(s) & $\mathrm{n}(\%)$ & $374(6 \mid .9)$ & $50(38.2)$ & $324(68.5)$ \\
\hline Visible haematuria & n (\%) & $367(60.8)$ & $43(32.8)$ & $324(68.5)$ \\
\hline Cancer general alarm symptom(s) & n (\%) & $28(4.6)$ & $19(14.5)$ & $9(1.9)$ \\
\hline Other & $\mathrm{n}(\%)$ & $202(33.4)$ & $62(47.3)$ & $140(29.6)$ \\
\hline \multicolumn{5}{|l|}{ Dominant symptom(s) at referral $^{c}$} \\
\hline Cancer specific alarm symptom(s) & $\mathrm{n}(\%)$ & $427(70.7)$ & $62(47.3)$ & $365(77.2)$ \\
\hline Visible haematuria & n (\%) & $418(69.2)$ & $53(40.5)$ & $365(77.2)$ \\
\hline Cancer general alarm symptom(s) & n (\%) & $40(6.6)$ & $23(17.6)$ & $17(3.6)$ \\
\hline Other & $\mathrm{n}(\%)$ & $137(22.7)$ & $46(35.1)$ & $91(19.2)$ \\
\hline Population linked to $\mathrm{NCR}^{\mathrm{d}}$ & n (\%) & $467(77.3)$ & $103(78.6)$ & $364(77.0)$ \\
\hline Match with NCR & $\mathrm{n}(\%$ of linked) & $368(78.8)$ & $72(69.9)$ & $296(81.3)$ \\
\hline \multicolumn{5}{|l|}{ TNM disease stage at diagnosis } \\
\hline Oa & $\mathrm{n}$ (\% of matched) & & - & $138(46.6)$ \\
\hline Ois & $\mathrm{n}$ (\% of matched) & & - & $13(4.4)$ \\
\hline I & $\mathrm{n}$ (\% of matched) & & $23(31.9)$ & $50(16.9)$ \\
\hline II & $\mathrm{n}$ (\% of matched) & & $13(18.1)$ & $39(13.2)$ \\
\hline III & $\mathrm{n}$ (\% of matched) & & $18(25.0)$ & $17(5.7)$ \\
\hline IV & $\mathrm{n}$ (\% of matched) & & $15(20.8)$ & $38(12.8)$ \\
\hline Missing & $\mathrm{n}(\%$ of matched) & & $3(4.2)$ & $\mathrm{I}(0.3)$ \\
\hline \multicolumn{5}{|l|}{ Morphology } \\
\hline Transitional cell carcinoma & $\mathrm{n}$ (\% of matched) & & - & $286(96.6)$ \\
\hline Clear cell adenocarcinoma & $\mathrm{n}$ (\% of matched) & & $45(62.5)$ & - \\
\hline Other & $\mathrm{n}$ (\% of matched) & & $27(37.5)$ & $10(3.4)$ \\
\hline
\end{tabular}

IQI = interquartile interval, NCR = Netherlands Cancer Registry, SD = standard deviation, TNM = Tumour Node Metastasis

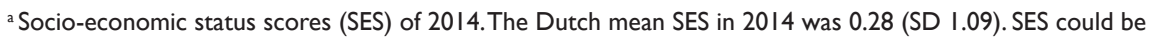
derived for patients from 4 out of the 6 primary care network databases (JGPN, ANHVUmc, RNG and RNFM). More details can be found in General Appendix $\mathbf{C}$.

${ }^{\text {b}}$ According to the definitions of O'Halloran et al. ${ }^{19}$ More details can be found in General Appendix C.

' Cancer specific alarm symptom for urological cancers (kidney and bladder cancer) were defined as visible haematuria (both cancers) and a palpable mass/tumour in the abdomen or flank (kidney cancer). Cancer general alarm symptoms were defined as unintended weight loss, anaemia and ascites. Other symptoms were all other presenting symptoms that could be related to the kidney or bladder cancer, including dysuria, abdominal and flank/back pain (kidney cancer), non-visible haematuria etc. In case of presence of both cancer specific and cancer general alarm symptoms, cancer specific alarm symptoms were considered dominant.

${ }^{d}$ Linkage with NCR was possible for 3 of the six primary care network databases (JHN Utrecht, ANH-VUmc Amsterdam and RNG Groningen). 
was independently associated with 'long duration' of IP (multivariable relative risk (RR) I.7, 95\% Cl I.I-2.6). Female sex (RR as compared to male sex I.7, 95\% $\mathrm{Cl}$ I.3-2.3) and absence of cancer alarm symptoms (RR as compared to patients with cancer specific alarm symptoms $2.4,95 \% \mathrm{CI}$ I.8-3.2) were independently associated with 'long duration' of IPC. Compared to the youngest patients $<55$ years, older patients showed decreased risk of 'long duration' of IPC, statistically significant for patients aged 55-64 (RR 0.6 (95\% Cl 0.4-0.9)).

As compared to the presence of cancer specific alarm symptoms, both presence of general alarm symptoms (RR 2.0,95\% Cl I.0-3.7) and absence of cancer specific alarm symptoms (RR 2.0,95\% Cl I.4-2.9) were associated with 'long duration' of ISC.

\section{Association of duration with tumour stage at diagnosis}

For kidney cancer, the patient interval was significantly longer for patients with stage I or II disease as compared to patients with stage III of IV disease: I 5 days (IQI 4-9I) compared to 5 days (IQI 2-II), p = 0.05 (Table 2). For both kidney- and bladder cancer patients, the secondary care interval was significantly longer for patients with early disease stage. Kidney cancer patients with stage I or II disease had a median ISC duration of 65 days (IQI 4I-95), compared to 36 days (IQI I8-5I) for patients with stage III of IV disease. Bladder cancer patients with stage 0 a, Ois or I disease showed a median ISC duration of 40 days (IQI 23-64) as compared to 29 days (IQI I7-46) for patients with stage II, III or IV disease. Prevalence of alarm symptoms was comparable between patients with early- and late stage disease (Appendix 2).

\section{DISCUSSION}

In the diagnostic pathway of kidney and bladder cancer, the secondary care interval is most time consuming. For half of the patients, diagnostic confirmation in secondary care takes at least 5 weeks after referral. The Dutch quality standard for maximum duration of seven weeks to treatment initiation is met in only half of the patients. Typically, patients consult within a week after first symptoms and are referred by the GP within 10 days. However, female patients are at risk for delayed referral by the GP, independently of presence of alarm symptoms. Presence of cancer alarm symptoms speeds up all the intervals of the diagnostic pathway. The skewed distribution demonstrates that in all intervals, some patients experience relatively long duration. Patients with early stage disease at diagnosis have significantly longer durations from referral to diagnosis for both cancer types. 


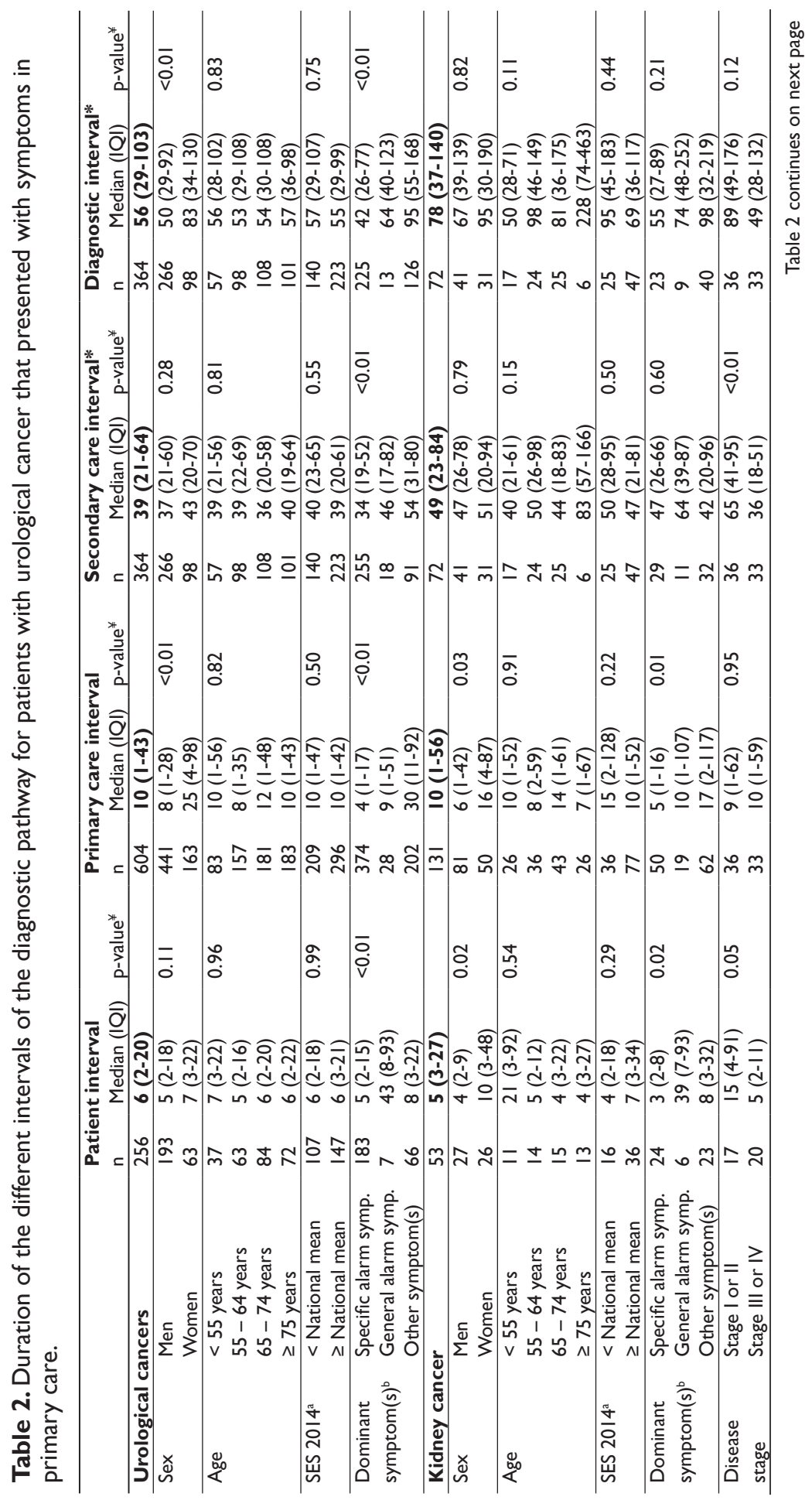




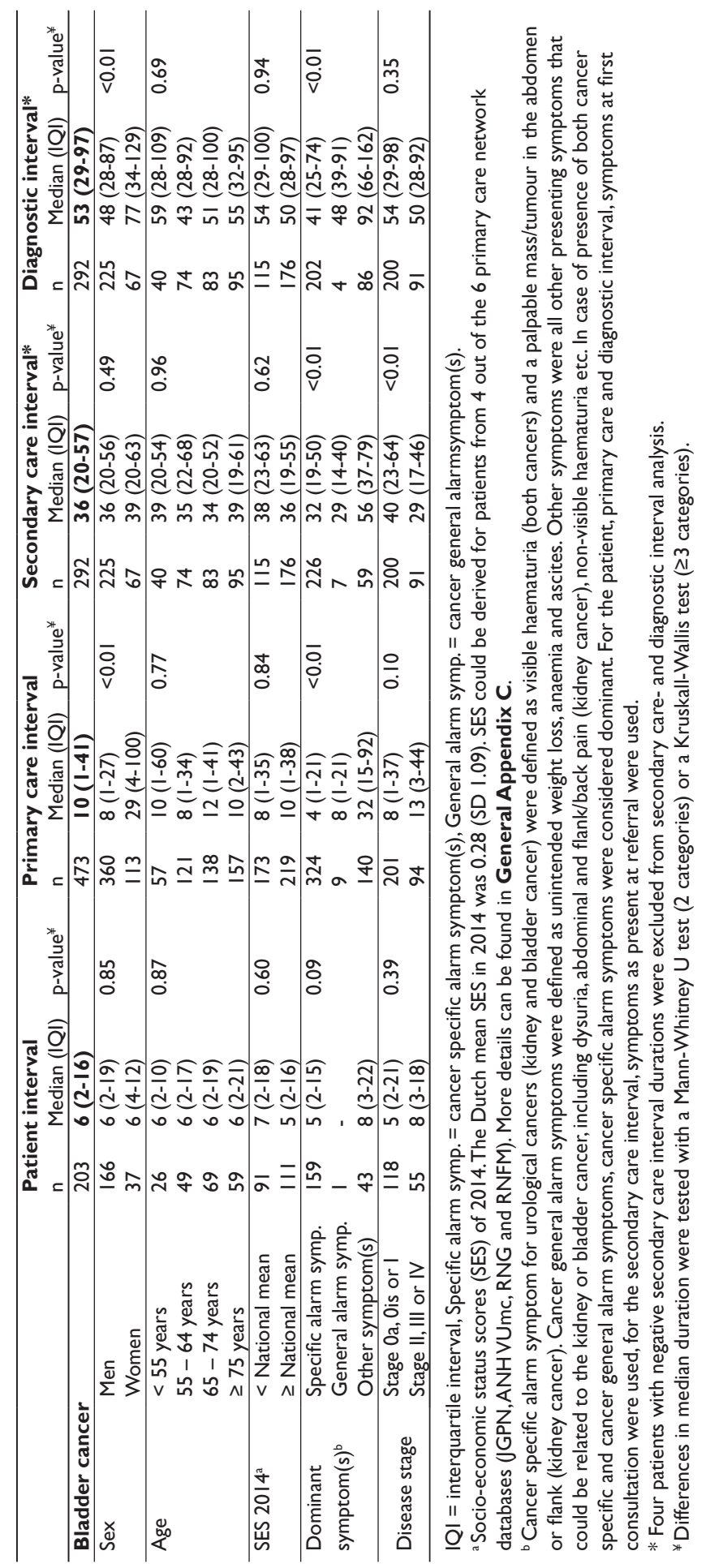




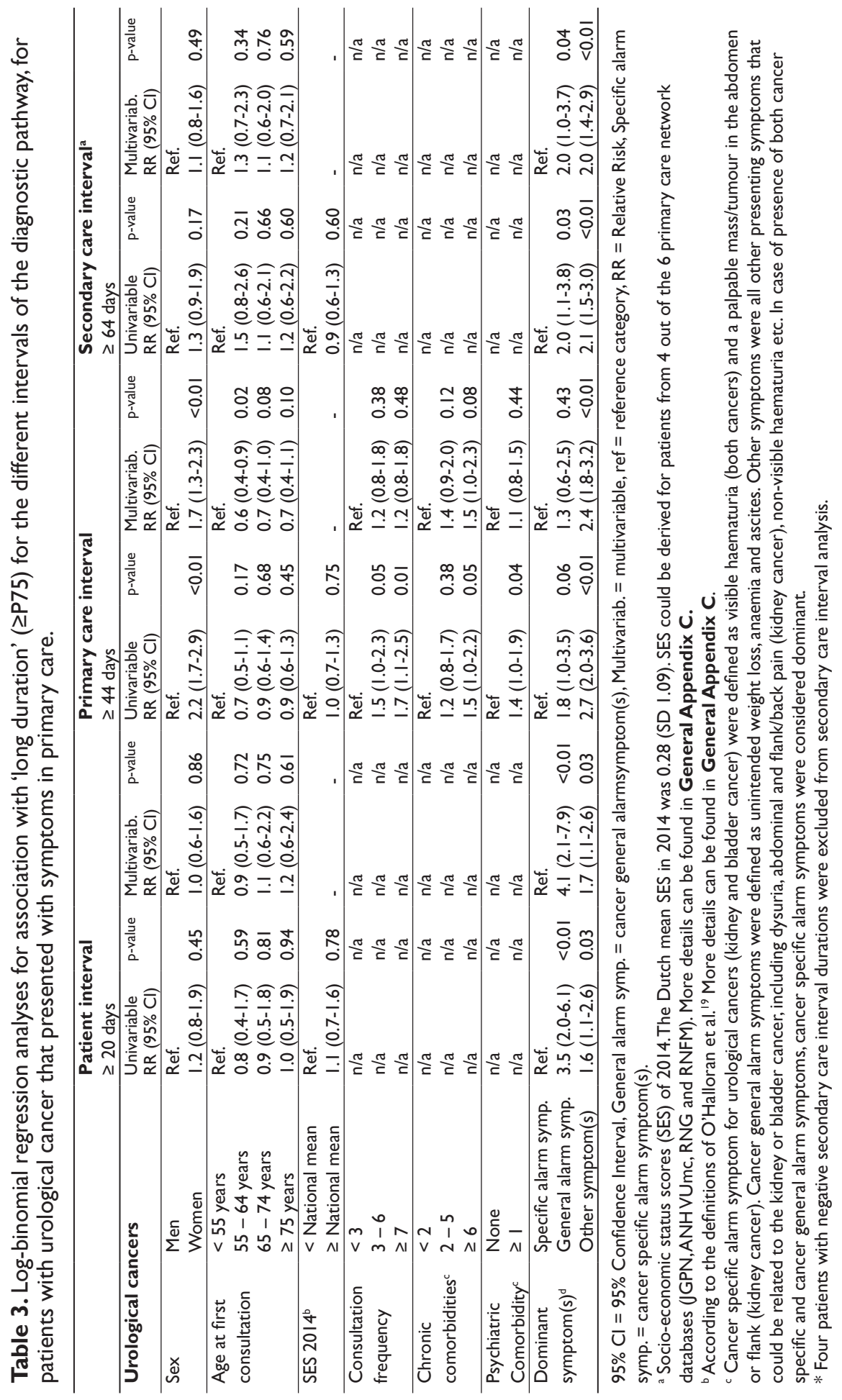




\section{Strengths and limitations}

Strengths and limitations of the use of routine primary care data have previously been discussed. ${ }^{13}$ The main strength of the use of these primary care data is the availability of free-text registries of all GP consultations. This provides detailed insight in the diagnostic process, including contextual factors and GP considerations. Linkage of primary care data to the NCR for the majority of the eligible patients allowed us to analyse all intervals of the diagnostic pathway.

A limitation of this study is the relatively large number of excluded patients, especially those with unclear diagnostic pathways ( $20 \%$ of patients with cancer diagnostic code). As uncertainty may be more likely for either very short or very long diagnostic intervals, excluding these patients may have affected our results both ways (over- or underestimation of the durations). Furthermore, identification of the first presentation with cancer related symptoms can be challenging. The association between commonly occurring symptoms and the final cancer diagnosis is often obscure. Even though we minimized the risk of misattribution of symptoms by discussing doubtful cases in our team of primary care researchers, potential misattribution may have influenced our findings either way (resulting in shorter or longer durations). Measurement of the patient interval based on primary care records also comes with limitations. ${ }^{20,21}$ As the registration of symptom duration by the GP may be inaccurate or lacking and missing duration information is likely to be selective, median IP durations should be seen as an approximation of duration.

Date of diagnosis was defined as the date of diagnosis registered in the NCR, in which a hierarchy is used, and preferably the date of first histological or cytological confirmation of the malignancy is registered. Histology or cytology was the base for diagnosis in $98 \%$ of the patients matching NCR. For urological cancers, initial cancer suspicion is often based on cystoscopy (in bladder cancer) or imaging techniques (in kidney cancer). Even though some patients undergo diagnostic biopsy (for example in case of early stage kidney cancer), the histological diagnosis of cancer is usually obtained after therapeutic procedures (Transurethral Resection for bladder cancer and (partial) nephrectomy for kidney cancer). Our finding that for $81 \%$ of the patients that initially underwent surgery, the date of diagnosis coincided with date of initial treatment supports this. Data on the medical process in secondary care were limited. To fully understand the secondary care interval and its duration, more detailed information on all events after referral is needed. 


\section{Comparison with literature and implications}

Comparative international data on the patient interval vary. In the United Kingdom (UK), patient intervals are somewhat shorter: median duration 3 days for kidney cancer and 2 days for bladder cancer, ${ }^{7}$ while for Danish bladder cancer patients, a median IP duration of 14 days was reported..$^{22}$ Next to differences in used methods, there may be variation in promptness of presentation, based on differences in accessibility, care seeking behaviour and awareness of symptoms. Our finding that patient with alarm symptoms for urological cancer presented most promptly suggests awareness of these symptoms by patients. The patient interval was earlier described as relatively short as compared to the other intervals. $^{23}$

The median IPC duration of 10 days we found for both cancer types, is in line with reports from other countries. Earlier work from the UK reports a duration of 13 days among kidney cancer patients $(n=207)$ and 3 days among bladder cancer patients $(n=$ 602) ${ }^{23}$ A recent Finish study among bladder cancer patients showed a IPC duration of 8 days, ${ }^{24}$ while Danish data showed that time from consultation to onset of diagnostic investigations in primary care was less than a day and time between investigations and referral was 2 days. ${ }^{22}$ Existing evidence showed that women tend to experience longer time to diagnosis, have a more advanced disease stage at diagnosis and worse survival. ${ }^{8,9}$ This is in line with the longer IPC and ID durations we found for women. Longer durations for female patients may be explained by the fact that GPs generally have a lower cancer suspicion for female patients, as the incidence of urological cancer is lower while the incidence of urinary tract infections is higher in women. ${ }^{25}$ Because of these incidence differences, and the frequent occurrence of hematuria in urinary tract infections, GPs will probably also be less alarmed if hematuria is present in women. Delayed evaluation of hematuria among female bladder cancer patients was reported earlier. ${ }^{26}$

In line with our findings, longer ISC than IPC durations were earlier reported for Danish bladder cancer patients. ${ }^{22}$ Median ISC duration for these patients (62 days (IQI 35-87)), was longer than the median duration in our study (36 days (IQI 20-58)). We also found slightly shorter ID duration than reported earlier: ID was 78 days (IQI 37-I40) for kidney cancer and 53 days (IQI 29-98) for bladder cancer in the current study, as compared to 84 days (IQI 42-I75) and 80 days (IQI 40-I79) in a recent UK study. ${ }^{27}$ A relatively long secondary care interval, as compared to the other intervals, is at least partially explained by the fact that histological confirmation generally comes after therapeutic procedures, which have to be planned after the necessary preparations and therefore take time. 
We determined time from referral to initial therapy (IRT) to be able to compare its length with the recommendations of the Dutch quality standard for cancer care. ${ }^{17} \mathrm{We}$ found that the maximum duration of 49 days was met for less than half of the patients. This suggests that, according to professional standards, the time from referral to initial therapy, and for most patients thus to histological diagnosis, should be further reduced. One of the main motivations to speed up the diagnostic process is to improve disease outcomes. As survival rates for urological cancer in the Netherlands are only average in European comparison,' with several countries doing better, there seems to be room for improvement. However, whether reduction of ISC - or any of the other intervals - would contribute to improved outcomes is questionable. Even though some earlier studies show better survival for those with shortest delays, ${ }^{4,28}$ our results do not point in that direction: we found longer secondary care interval durations for patients with early stage disease as compared to those with advanced disease stage. Another important reason to speed up the patient journey through the system is to reduce the burden for patients due to time spent in insecurity. As we did not have data on the hospital processes, the exact routing, waiting times and events after referral are beyond the scope of this analysis. More insight in the secondary care interval is needed to fully understand its relatively long duration and the (psychological) impact for patients.

\section{Conclusion}

In the diagnostic pathway of urological cancers, the interval between referral and histological diagnosis is most time consuming. In general, patients and general practitioners act adequately in case of alarm symptoms specific for urological cancer. Women and patients without cancer alarm symptoms experience longer times to referral and to diagnosis. Reducing the secondary care interval, might speed up the diagnostic pathway most sufficiently. Dutch quality standards for time from referral to treatment initiation are met in half of the patients in this study. Further exploration of this interval and reasons for its long duration is needed. Also, exploring the remarkably long durations which occur in 10 to $25 \%$ of the patients in the different intervals would help to achieve efficient diagnostic pathways for all cancer patients.

\section{Acknowledgements}

The authors thank all medical students involved in data collection. We thank the registration team of the Netherlands Comprehensive Cancer Organisation (IKNL) and particularly Henrike Bretveld, for the collection of data for the Netherlands Cancer Registry as well as IKNL staff for scientific advice. We thank all the GPs participating in the six networks for sharing their EHR data, and Nicole Boekema, Erna Beers, Marjan van den Akker, Hanna Joosten, Margot de Waal, Henk de Jong, ZorgTTP and their teams, for their assistance in extracting data and the linkage procedures. 


\section{REFERENCES}

I. Ferlay J, Colombet M, Soerjomataram I, Dyba T, Randi G, Bettio M, et al. Cancer incidence and mortality patterns in Europe: Estimates for 40 countries and 25 major cancers in 20 I8. Eur J Cancer 2018;103:356-387.

2. Data from the Netherlands Cancer Registry, managed by The Netherlands Comprehensive Cancer Organisation [Internet].Available from: http://www.cijfersoverkanker.nl.Accessed March $23,2017$.

3. Important data about bladder cancer, published by The Netherlands Comprehensive Cancer Organisation [Internet].Available from: https://www.iknl.nl/docs/default-source/PDF_Docs/ blaaskanker_belangrijke-cijfers-over_def.pdf?sfvrsn=2.Accessed July 18, 2019.

4. Hollenbeck BK, Dunn RL, Ye Z, Hollingsworth JM, Skolarus TA, Kim SP, et al. Delays in diagnosis and bladder cancer mortality. Cancer 2010; I 16:5235-5242.

5. Mendonca SC, Abel GA, Saunders CL,Wardle J, Lyratzopoulos G. Pre-referral general practitioner consultations and subsequent experience of cancer care: Evidence from the English Cancer Patient Experience Survey. Eur J Cancer Care 2016;25:478-490.

6. Schmidt-Hansen M, Berendse S, Hamilton W. The association between symptoms and bladder or renal tract cancer in primary care:A systematic review. Br J Gen Pract 20 I5;65:e769-e775.

7. Keeble S,Abel GA, Saunders CL, McPhail S, Walter FM, Neal RD, et al.Variation in promptness of presentation among 10,297 patients subsequently diagnosed with one of 18 cancers: Evidence from a National Audit of Cancer Diagnosis in Primary Care. Int J Cancer 20 |4; I35:I220-I 228.

8. Lyratzopoulos G, Abel GA, McPhail S, Neal RD, Rubin GP. Gender inequalities in the promptness of diagnosis of bladder and renal cancer after symptomatic presentation: Evidence from secondary analysis of an English primary care audit survey. BMJ Open 2013;3:1-7.

9. Cohn JA,Vekhter B, Lyttle C, Steinberg GD, Large MC. Sex disparities in diagnosis of bladder cancer after initial presentation with hematuria: a nationwide claims-based investigation. Cancer 20।4; |20:555-56।.

10. Dobruch J, Daneshmand S, Fisch M, Lotan Y, Noon AP, Resnick MJ, et al. Gender and Bladder Cancer:A Collaborative Review of Etiology, Biology, and Outcomes. Eur Urol 20I5; I-I I.

II. Zhou Y, Funston G, Lyratzopoulos G,Walter FM. Improving the Timely Detection of Bladder and Kidney Cancer in Primary Care. AdvTher 2019;36:I778-I785.

12. Zhou Y,Van Melle M, Singh H, Hamilton W, Lyratzopoulos G, Walter FM. Quality of the diagnostic process in patients presenting with symptoms suggestive of bladder or kidney cancer:A systematic review. BMJ Open 2019;9.

13. Helsper C, van Erp N, Peeters P, de Wit N. Original Research:Time to diagnosis and treatment for cancer patients in the Netherlands: room for improvement? Eur J Cancer 2017;87:113-I21.

14. Lamberts H,Wood M. International Classification of Primary Care (ICPC). Oxford: Oxford University Press; 1987.

15. Netherlands Comprehensive Cancer Organisation (IKNL). Over de registratie [in Dutch], https:// www.iknl.nl/en/ncr.Accessed June 28, 2019. 
16. Weller D,Vedsted P, Rubin G, Walter FM, Emery J, Scott S, et al. The Aarhus statement: improving design and reporting of studies on early cancer diagnosis. Br J Cancer 20I2; 106:1262-1267.

17. Stichting Oncologische Samenwerking. Multidisciplinaire normering oncologische zorg in Nederland, Normeringsrapport 2020 [Internet].Available from: https://www.soncos.org/wpcontent/uploads/2020/03/SONCOS-normeringsrapport-versie-8-I.pdf. Accessed February 10, 2020.

18. European Network of Cancer Registries. Recommendations for coding Incidence Date [Internet]. Available from: http://www.encr.eu/registries-network. Accessed November 23, 2019.

19. O'Halloran J, Miller GC, Britt H. Defining chronic conditions for primary care with ICPC-2. Fam Pract 2004;21:38I-386.

20. Andersen RS, Vedsted P, Olesen F, Bro F, Søndergaard J. Patient delay in cancer studies: A discussion of methods and measures. BMC Health Serv Res 2009;9:1-7.

2I. Smith SM, Whitaker KL, Cardy AH, Elliott AM, Hannaford PC, Murchie P.Validation of self-reported help-seeking, and measurement of the patient interval, for cancer symptoms: an observational study to inform methodological challenges in symptomatic presentation research. Fam Pract 2019;1-7.

22. Hansen RP,Vedsted P, Sokolowski I, Søndergaard J, Olesen F.Time intervals from first symptom to treatment of cancer: a cohort study of 2,212 newly diagnosed cancer patients. BMC Health Serv Res 201 I; I I:284.

23. Lyratzopoulos G, Saunders CL, Abel GA, McPhail S, Neal RD,Wardle J, et al.The relative length of the patient and the primary care interval in patients with 28 common and rarer cancers. $\mathrm{Br} J$ Cancer 2015; I I2:S35-S40.

24. Sell V, Ettala O, Montoya Perez I, Järvinen R, Pekkarinen T,Vaarala M, et al. Symptoms and diagnostic delays in bladder cancer with high risk of recurrence: results from a prospective FinnBladder 9 trial. World J Urol 2020;38: I00I-1007.

25. Foxman B. Epidemiology of urinary tract infections: incidence, morbidity, and economic costs. Am J Med 2002 Jul; I I3:5-13.

26. Ngo B, Perera M, Papa N, Bolton D, Sengupta S. Factors affecting the timeliness and adequacy of haematuria assessment in bladder cancer: a systematic review. BJU Int 2017;119:10-18.

27. Din NU, Ukoumunne OC, Rubin G, Hamilton W, Carter B, Stapley S, et al. Age and gender variations in cancer diagnostic intervals in 15 cancers:Analysis of data from the UK clinical practice research datalink. PLoS One 20I5; I0:I-15.

28. Wallace DMA, Bryan RT, Dunn JA, Begum G, Bathers S. Delay and survival in bladder cancer. BJU Int 2002;89:868-878. 


\section{APPENDIX I}

For symptomatic urological cancer patients that could be linked to the Netherlands Cancer Registry: characteristics of patients that were a match with NCR compared with patients that were not a match with NCR.

\begin{tabular}{|c|c|c|c|}
\hline & & NCR match & No match \\
\hline Population & $\mathrm{n}(\%)$ & $368(100)$ & $99(100)$ \\
\hline Male patients & $\mathrm{n}(\%)$ & $269(73.1)$ & $70(70.7)$ \\
\hline Age at first consultation & Mean \pm SD & $66.7 \pm 12.1$ & $70.5 \pm 12.4$ \\
\hline \multirow[t]{2}{*}{ Socio-economic status score (SES) $2014^{\mathrm{a}}$} & Mean \pm SD & $0.42 \pm 1.16$ & $0.37 \pm 1.27$ \\
\hline & Missing, $\mathrm{n}(\%)$ & $\mathrm{I}(0.3)$ & $3(3.0)$ \\
\hline \multirow{2}{*}{$\begin{array}{l}\text { Consultation frequency in year before first } \\
\text { consultation }\end{array}$} & Median (IQI) & $5(2-9)$ & $5(2-10)$ \\
\hline & Missing, n (\%) & $14(3.8)$ & I (I.0) \\
\hline \multirow{2}{*}{$\begin{array}{l}\text { Number of registered chronic somatic } \\
\text { comorbidities }^{b}\end{array}$} & Median (IQI) & $2(I-5)$ & $3(2-6)$ \\
\hline & Missing, n (\%) & $2(0.5)$ & $\mathrm{I}(\mathrm{I} .0)$ \\
\hline \multirow{2}{*}{$\begin{array}{l}\text { Registered psychiatric } \\
\text { comorbidity }^{\mathrm{b}}\end{array}$} & $\mathrm{n}(\%)$ & $76(20.7)$ & $17(17.2)$ \\
\hline & Missing, n (\%) & $\mathrm{I}(0.3)$ & $\mathrm{I}(\mathrm{I} .0)$ \\
\hline \multicolumn{4}{|l|}{ Dominant symptom(s) at first consultation ${ }^{c}$} \\
\hline Cancer specific alarm symptom(s) & $\mathrm{n}(\%)$ & $229(62.2)$ & $58(58.6)$ \\
\hline Cancer general alarm symptom(s) & $\mathrm{n}(\%)$ & $13(3.5)$ & $9(9.1)$ \\
\hline Other, non-alarming symptoms & $\mathrm{n}(\%)$ & $126(34.2)$ & $32(32.3)$ \\
\hline \multicolumn{4}{|l|}{ Dominant symptom(s) at referral $^{c}$} \\
\hline Cancer specific alarm symptom(s) & $\mathrm{n}(\%)$ & $259(70.4)$ & $69(69.7)$ \\
\hline Cancer general alarm symptom(s) & n (\%) & $18(4.9)$ & $10(10.1)$ \\
\hline Other, non-alarming symptoms & n (\%) & $91(24.7)$ & $20(20.2)$ \\
\hline
\end{tabular}

$\mathrm{IQI}=$ interquartile interval, NCR = Netherlands Cancer Registry, SD = standard deviation

a Socio-economic status scores of 2014 , based on level of education, income and job status. The Dutch mean SES in 2014 was 0.28 (SD I.09). SES could be derived for patients from 4 out of the 6 primary care network databases (JGPN, ANHVUmc, RNG and RNFM). More details can be found in General Appendix C.

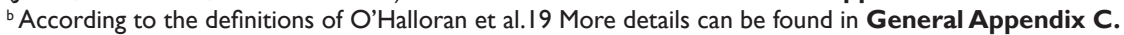

c Cancer specific alarm symptom for urological cancers (kidney and bladder cancer) were defined as visible haematuria (both cancers) and a palpable mass/tumour in the abdomen or flank (kidney cancer). Cancer general alarm symptoms were defined as unintended weight loss, anaemia and ascites. Other symptoms were all other presenting symptoms that could be related to the kidney or bladder cancer, including dysuria, abdominal and flank/back pain (kidney cancer), non-visible haematuria etc. In case of presence of both cancer specific and cancer general alarm symptoms, cancer specific alarm symptoms were considered dominant. 


\section{APPENDIX 2}

For symptomatic upper gastrointestinal cancer patients with available disease stage: symptom distribution according to tumour stage at diagnosis and different time intervals.

\begin{tabular}{|c|c|c|c|c|c|}
\hline & & $\begin{array}{l}\text { Patient } \\
\text { interval }\end{array}$ & $\begin{array}{l}\text { Primary } \\
\text { care interval }\end{array}$ & $\begin{array}{l}\text { Secondary } \\
\text { care } \\
\text { interval* }\end{array}$ & $\begin{array}{l}\text { Diagnostic } \\
\text { interval* }\end{array}$ \\
\hline & & n (\%) & $\mathrm{n}(\%)$ & n (\%) & $\mathrm{n}(\%)$ \\
\hline \multicolumn{6}{|l|}{ Kidney cancer } \\
\hline \multirow[t]{2}{*}{ Stage I or II } & Total (n, \%) & $23(100)$ & $42(100)$ & $4 I(100)$ & $4 I(100)$ \\
\hline & Specific alarm symp. ${ }^{a}(n, \%)$ & II (47.8) & $15(35.7)$ & $19(46.3)$ & $14(34.1)$ \\
\hline \multirow[t]{2}{*}{ Stage III or IV } & Total (n, \%) & $5(21.7)$ & II (26.2) & $14(34.1)$ & II (26.8) \\
\hline & Specific alarm symp. ${ }^{a}(\mathrm{n}, \%)$ & $7(30.4)$ & $16(38.1)$ & $8(19.5)$ & $16(39.0)$ \\
\hline \multicolumn{6}{|l|}{ Bladder cancer } \\
\hline \multirow[t]{2}{*}{ Stage $0 a, 0$ is or I } & Total (n, \%) & $85(100)$ & $122(100)$ & $119(100)$ & $119(100)$ \\
\hline & Visible haematuria (n, \%) & $43(50.6)$ & $54(44.3)$ & $81(68.1)$ & $54(45.4)$ \\
\hline \multirow[t]{2}{*}{ Stage II, III or IV } & Total (n, \%) & $10(11.8)$ & $17(13.9)$ & $19(16.0)$ & $17(14.3)$ \\
\hline & Visible haematuria (n, \%) & $32(37.6)$ & $5 I(4 I .8)$ & $19(16.0)$ & $48(40.3)$ \\
\hline
\end{tabular}

${ }^{a}$ Cancer specific alarm symptom for urological cancers (kidney and bladder cancer) were defined as visible haematuria (both cancers) and a palpable mass/tumour in the abdomen or flank (kidney cancer). For the patient-, primary care and diagnostic interval, symptoms at first consultation were used, for the secondary care interval, symptoms as present at referral were used.

* Four bladder cancer patients with negative ISC durations were excluded from ISC and ID analysis. 


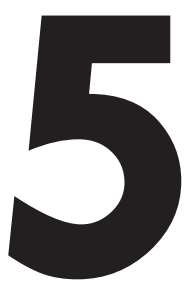

\title{
Can we improve the diagnostic pathway of symptomatic ovarian cancer?
}

\author{
Nicole F. van Erp \\ Charles W. Helsper \\ Pauline Slottje \\ Feikje Groenhof \\ Frederike L. Büchner \\ Kristel M. van Asselt \\ Jean W.M. Muris \\ Marlous F. Kortekaas \\ Ronald P. Zweemer \\ Petra H.M. Peeters \\ Niek J. de Wit
}




\section{ABSTRACT}

Objective: To chart the duration of the diagnostic pathway for symptomatic ovarian cancer patients and to identify factors associated with long duration.

Methods: Retrospective cohort study using free text routine primary care records linked to the Netherlands Cancer Registry. Duration of the patient interval (IP), primary care interval (IPC), secondary care interval (ISC) and diagnostic interval (ID) was determined. Characteristics associated with ‘long duration' ( $\geq 75$ th percentile) were assessed using log-binomial regression analysis.

Results: Among I47 patients, median durations (days) were: IP I 5 (IQI 5-43), IPC 6 (IQI I-23), ISC 22 (IQI 9-45) and ID 4I (IQI 20-64). Patients with ovarian cancer specific alarm symptoms showed increased risk of long IP duration (relative risk (RR) $2.7,95 \% \mathrm{CI}$ I.3-5.4), while patients without these symptoms showed increased risk of long IPC duration (RR I.7, 95\% Cl 0.9-3.3). Low socioeconomic status was associated with long ISC duration: RR $3.3(95 \% \mathrm{Cl}$ I.2-9.0).

Conclusion: In the diagnostic pathway of ovarian cancer, the patient and secondary care interval showed longest durations. In all intervals, up to $20 \%$ of patients showed remarkably long durations. Improvement of the patient and primary care intervals seems challenging due to non-specificity of presenting symptoms. Exploration of the secondary care interval is needed to identify opportunities for improvement. 


\section{INTRODUCTION}

Ovarian cancer is the eighth most common cancer type among women worldwide. Annually, ovarian cancer accounts for over 295,000 new cases and over 184,000 deaths, with the highest incidence seen in Europe and Northern America.' Survival of ovarian cancer is the poorest of all gynecological cancers, with less than half of all patients surviving five years after diagnosis. ${ }^{2}$ This is mainly because the disease is detected at an advanced stage (FIGO III and IV) in over $70 \%$ of the patients. ${ }^{3,4}$ Five-year survival is highly dependent on disease stage at diagnosis, presently ranging from $86 \%$ in stage I disease to only $13 \%$ in stage IV disease. ${ }^{3}$

As there is insufficient evidence for a compelling survival benefit of population screening to date, ${ }^{5,6}$ a timely diagnosis can only be accomplished by prompt presentation by patients, timely referral from primary care and adequate diagnostic confirmation in secondary care. However, early recognition of ovarian cancer is challenging for both patients and physicians as the disease is rare and presenting symptoms are common and non-specific. ${ }^{7}$ Ovarian cancer is therefore considered a 'harder to suspect' cancer type, ${ }^{8}$ susceptible to a prolonged diagnostic pathway.

For symptomatic patients, the diagnostic pathway of cancer consists of several intervals, including the patient interval (from symptom onset to presentation in health care), the primary care interval (from presentation to referral) and the secondary care interval (from referral to diagnosis). Prolonged duration or 'delay' may occur in all these intervals. Several studies have assessed the diagnostic interval for ovarian cancer: the time from symptom onset to diagnosis varied widely from a mean duration less than one week to a median duration of more than 12 months..$^{9-15}$ Methods used to determine duration show large variation, many studies are outdated and most of them either assess overarching time to diagnosis or separate parts of the pathway. ${ }^{16}$ Knowledge of the duration of the diagnostic route, the underlying intervals and characteristics associated with a long duration may provide clues to improve early diagnosis of ovarian cancer.

Therefore, we aim to chart the diagnostic pathway for ovarian cancer, including its different intervals, to identify characteristics associated with long duration for each interval and to assess the association of duration with tumour stage at diagnosis. 


\section{METHODS}

\section{Study design and data source}

This study is part of the DICKENS project. ${ }^{17} \mathrm{~A}$ retrospective cohort study was conducted using pseudonymized routine care data from six academic primary care networks (General Appendix A), with coded and free text information from electronic health records (EHRs) of more than 640,000 patients from different regions of the Netherlands.

Coded data include diagnoses (according to the International Classification of Primary Care; ICPC-I). ${ }^{18}$ Anonymized free texts include registrations of patient consultations, i.e. presented complaints, results of physical examination, clinical reasoning of the general practitioner (GP) and management plan. This data source was used to determine the duration of the patient interval (IP) and the primary care interval (IPC) (Figure I).

To be able to determine the secondary care interval (ISC), diagnostic interval (ID) (Figure I) and the association between duration and tumour stage at diagnosis, we linked these routine primary care data to the data of the Netherlands Cancer Registry (NCR). The NCR is a population-based registry with detailed diagnostic and therapeutic data of over $95 \%$ of Dutch cancer patients since 1989. ${ }^{19}$ Pseudonym-based data linkage was possible for three databases only (JGPN, ANHVUmc and RNG), together including $79 \%$ of the identified cancer patients. The linkage procedure comprised matching of pseudonyms based on date of birth, sex and postal code (6 digits) among patients with a cancer diagnosis according to their primary care record, using a trusted third-party in compliance with Dutch and European privacy regulations (General Data Protection Regulation, https://gdpr.eu).

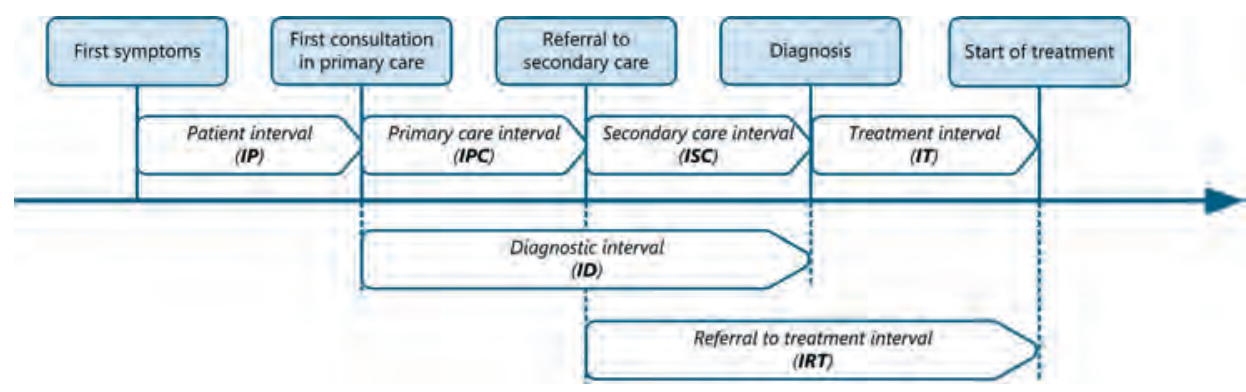

Figure I. Milestones and time intervals in the route from symptom onset to diagnosis and start of treatment. 


\section{Case selection}

All adult patients (aged $\geq 18$ years) registered with ICPC-I code for 'malignant neoplasm of ovary' (X77.02) in 2010-20I5 were extracted from the primary care databases. Of all identified patients, we assessed the anonymized free text elements of the primary care EHR to confirm the cancer diagnosis, based on annotations of correspondence from secondary care and other descriptions indicating cancer presence. We only included patients for whom we could confirm the cancer diagnosis based on their primary care EHR.We then selected only those who presented symptoms to the GP and were referred by the GP for further diagnostic workup. Figure $\mathbf{2}$ shows the patient selection process and reasons for exclusion.

\section{Data collection}

Data were collected from the extracted primary care data by the research team (NvE assisted by final year medical students). Anonymized primary care EHR data were checked manually from five years before the date of entry of the ICPC code for ovarian cancer, until one year after. EHRs were studied up to one year after ICPC coding because in general practice the date of the ICPC code marks the beginning of the disease episode and not necessarily the actual date of diagnosis.

Six time intervals of the cancer care pathway were assessed (Figure I). These intervals were defined according to the Aarhus statement for improving reporting of studies on early cancer diagnosis and the Dutch quality standards for cancer care (in Dutch: SONCOS normeringsrapport). ${ }^{20,21}$ (I) The patient interval (IP) was defined as the time interval between first noticing cancer related bodily changes or symptom(s) to first consultation for these symptoms in primary care; (2) the primary care interval (IPC) was defined as duration from first consultation with cancer related signs and/or symptoms in primary care to referral to secondary care; (3) the secondary care interval (ISC) was defined as duration from referral to secondary care by the GP to date of diagnosis, and (4) the overarching diagnostic interval (ID) was defined as duration from first consultation to date of diagnosis. To assess adherence to the Dutch quality standards for cancer care, we additionally calculated (5) the duration from diagnosis to initial treatment (IT) and (6) the duration from referral to onset of treatment (IRT).

According to the multidisciplinary Dutch quality standard for cancer care (SONCOS), a specialist must see a patient suspected of cancer within a week after referral and treatment must start within six weeks after this first specialist visit. Therefore, treatment should be initiated within seven weeks (49 days) after referral by the GP. 
The date of the first symptom(s) (start of IP) was defined as the date on which the first symptoms were experienced by the patient, as recorded in the medical file by the general practitioner. If the GP registered 'abdominal pain for one week', date of first symptom was defined as the date 7 days before the date of first consultation. Less strictly described duration indications, such as 'several weeks' and 'a couple of days' were interpreted according to predefined rules, shown in General Appendix B. Duration indications such as 'for a while' or 'for some time' where considered too vague for interpretation and were excluded from analysis. In case of different duration indications for multiple cancer related complaints, the longest duration was selected to determine IP duration.

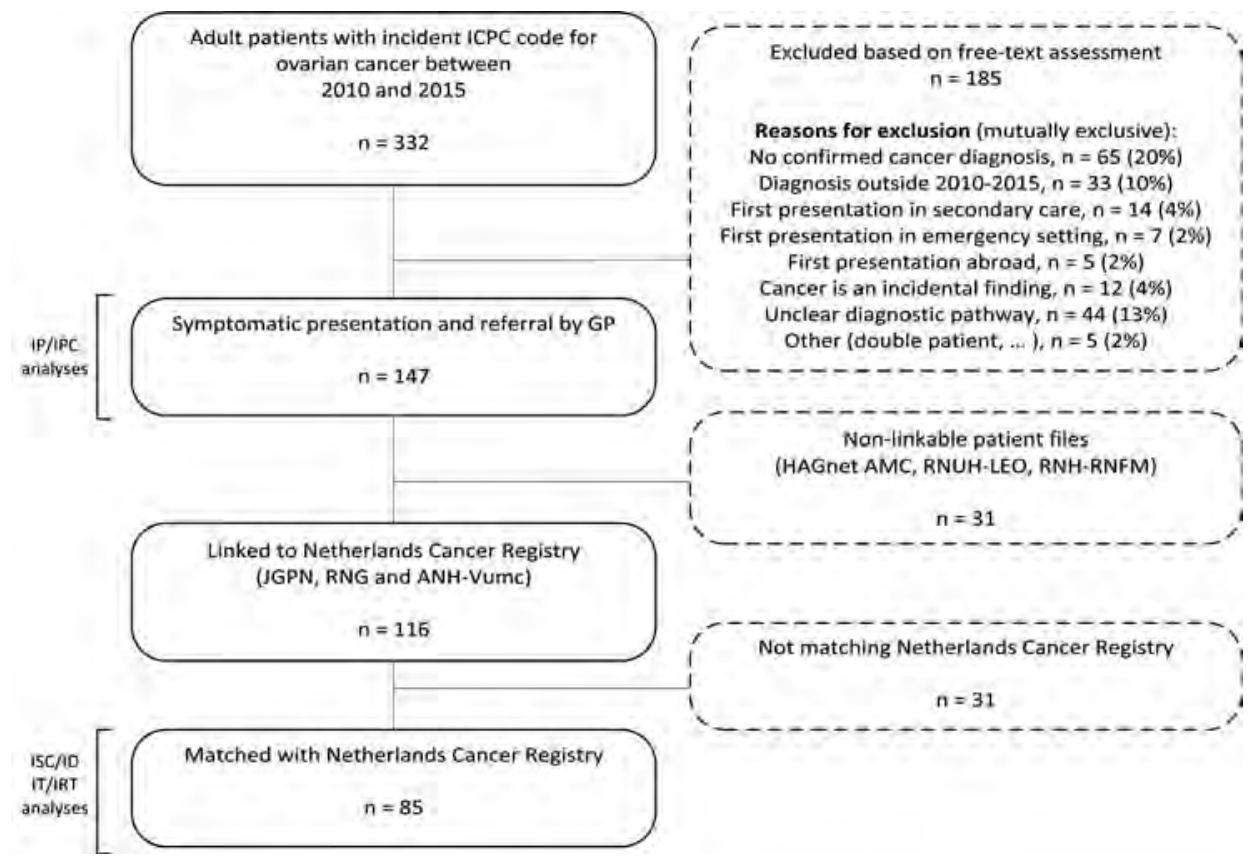

Figure 2. Identified ovarian cancer cases and reasons for exclusion.

ANH VUmc:Academic Network of General Practice database (Amsterdam VUmc); GP: general practitioner; HAGnet AMC: General Practice Registration Network (Amsterdam AMC); ICPC: International Classification of Primary Care; ID: diagnostic interval; IP: patient interval; IPC: primary care interval; ISC: secondary care interval; IT: treatment interval; IRT: duration from referral to onset of treatment; JGPN: Julius General Practitioner's Network database (Utrecht); RNFM: Research Network Family Medicine (Maastricht); RNG: Registration Network Groningen; RNUH-LEO: Registration Network of General Practitioners Associated with Leiden University (Leiden). 
Date of first consultation (end of IP, start of IPC) was defined as the first presentation at the general practitioner with signs or symptoms related to ovarian cancer. In case of doubt about the association between frequently occurring symptoms and the final cancer diagnosis, the first consultation with the complaints that were most likely related to ovarian cancer, was chosen. We minimized the risk of misattribution of symptoms by discussing less straightforward cases within the research team.

Date of referral (end of IPC, start of ISC) was defined as the moment the responsibility for the patient was transferred from general practitioner to secondary care, usually documented with a referral letter. Referral to the radiology department was considered as referral to secondary care, if abnormal radiology findings (e.g. ascites) subsequently resulted in referral to a specialist without further interference of the GP. In case of multiple referrals to, or cross-referrals in secondary care, the first referral for further exploration of cancer related symptoms was chosen.

Date of diagnosis (end of ISC and ID, start of IT), and date of first therapy (end of IT) were retrieved from the NCR data, for NCR matched patients. The NCR uses a hierarchy for diagnosis date as provided by the European Network of Cancer Registries, ${ }^{22}$ preferably registering date of histological diagnosis, in accordance with the preferred date of diagnosis in the Aarhus Statement. ${ }^{20}$

Patient and presentation characteristics were collected from the routine primary care data. All patient characteristics and methods of collection are shown in General Appendix C. Dominant presenting symptoms were categorized as ovarian cancer specific alarm symptoms (increased abdominal size and a palpable abdominal or pelvic mass), cancer general alarm symptoms (unintended weight loss and (complaints related to) anaemia) and all other cancer related symptoms (all other presenting symptoms that could be related to ovarian cancer, including abdominal pain, vaginal bleeding, altered defaecation pattern etc.). In case of presence of symptoms of multiple categories, ovarian cancer alarm symptoms were considered dominant, followed by cancer general alarm symptoms. Disease characteristics were retrieved from the NCR data for NCR matched patients.

\section{Analyses}

Duration of all intervals was calculated in days (median, interquartile interval IQI) and stratified for several patient- and presentation characteristics. We consistently added one day to all durations, as we considered same-day proceedings as a duration of one day. Differences in median duration were tested with a Mann-Whitney $U$ test for variables with 2 categories or a Kruskall-Wallis test for variable with $\geq 3$ categories. 
'Long duration' was defined as duration equal to or longer than the 75th percentile value of duration for the separate intervals (IP, IPC and ISC). Univariable and multivariable log-binomial regression analyses were performed to identify characteristics associated with 'long duration'. Age and characteristics that were significantly associated with 'long duration' $(P<0.05)$ in univariable analysis were included in multivariable analysis. For IPC, we assessed extra characteristics (consultation frequency, chronic comorbidities and psychiatric comorbidity) that were derived from the primary care record as present at the time of first consultation.

To assess the association of duration with tumour stage at diagnosis, we calculated the duration of the diagnostic interval for patients with local disease (International Federation of Gynaecology and Obstetrics (FIGO) I and II) and of those with advanced disease stages (FIGO III and IV). Differences in duration between tumour stage groups were tested using a Mann-Whitney $U$ test.

\section{Software}

Data transformation and analyses were performed in SPSS version 22.0 (SPSS Inc., Chicago, IL, USA).

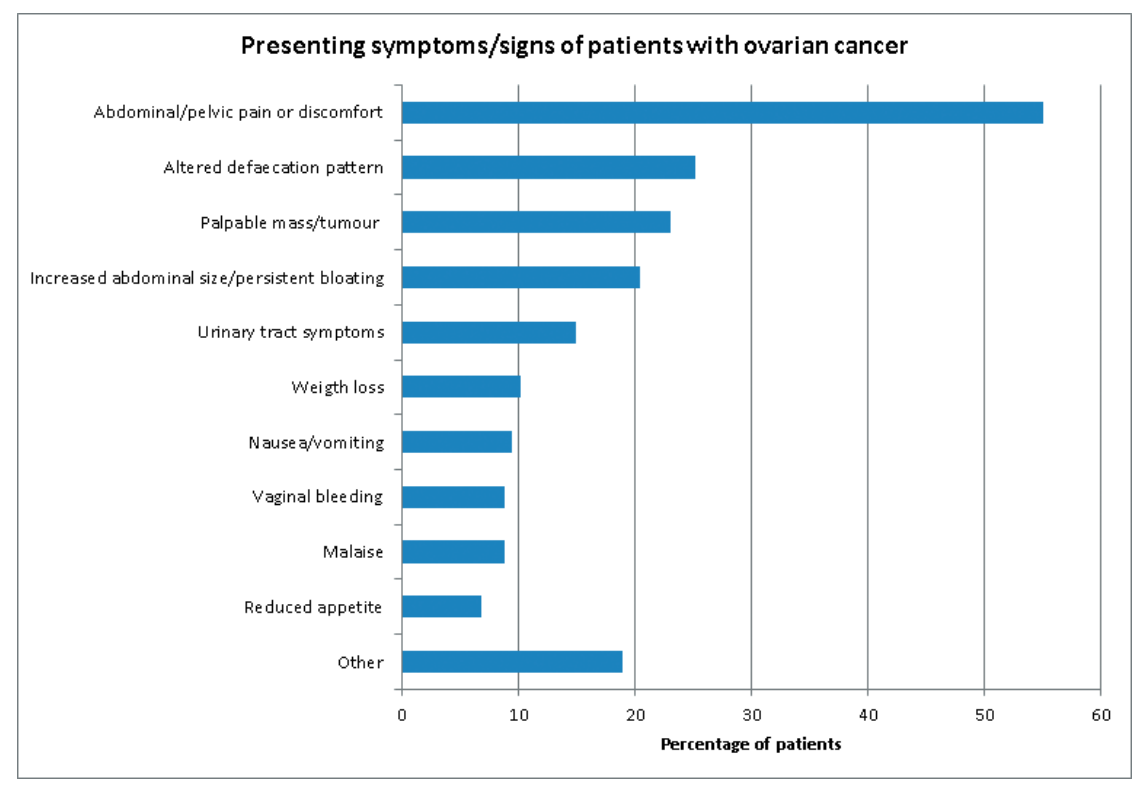

Figure 3. Presenting symptoms and signs of ovarian cancer patients during first GP consultation. Combinations of symptoms and signs did occur. 


\section{RESULTS}

\section{Patient characteristics}

Of 332 patients identified in the EHR with an ICPC-I code for ovarian cancer, 147 patients (44\%) met the eligibility criteria. Most frequent reasons for exclusion (Figure 2) were 'absence of a confirmed cancer diagnosis' (potentially incorrect ICPC code) and 'an unclear diagnostic pathway' (symptomatic presentation to- and referral by GP not confirmed).

Patient-, presentation- and disease characteristics are described in Table I. Mean age was 64 years (SD 14). Patients mainly presented with abdominal/pelvic pain or discomfort (55\%), an altered defecation pattern (25\%) and/or increased abdominal size/persistent bloating (20\%) (Figure 3). At first presentation ovarian cancer specific alarm symptoms (i.e. increased abdominal size and/or a palpable abdominal or pelvic mass during physical examination) were present in 55 patients (37\%). By the time of referral, just over half of the patients had either one of these symptoms $(n=76,52 \%)$.

To enable analysis of ISC, ID, IT, IRT and the association of duration with tumour stage, data of 116 patients (79\% of eligible patients) could be linked to the Netherlands Cancer Registry. For 85 patients (73\% of those linked), a match was found. Date of diagnosis was based on histology or cytology in 83 of these patients (98\%). Among patients included in the matching procedure, we found no substantial differences in patient- and presentation characteristics between those who could be matched $(n=85)$ and those who could not $(n=3 I)$ (Appendix I). Of NCR matched patients, 57 patients $(67 \%)$ were diagnosed with advanced stage disease (FIGO stage III - IV), 19 patients $(22 \%)$ with early stage disease (FIGO stage I - II) and 9 patients (I \%) with a borderline malignancy.

\section{Duration of time intervals}

Duration of the diagnostic intervals are shown in Table 2. All intervals showed a right skewed distribution as shown in Figure 4, with a strong increase in durations for up to $20 \%$ of patients.

For 99 patients (67\% of those eligible) a patient interval was reported. Median IP duration was I 5 days (IQI 5-43). Patients with alarm symptoms had longer IP duration (for ovarian cancer specific alarm symptoms: median 25 days, IQI 8-93, for general alarm symptoms for cancer: 26 days, IQI I I-58) compared to patients with other symptoms ( 9 days, IQI 4-22), $p=0.02$. 
Table I. Characteristics of patients with ovarian cancer that presented with symptoms in primary care.

\begin{tabular}{|c|c|c|}
\hline & & Ovarian cancer \\
\hline Population & $\mathrm{n}(\%)$ & $147(100)$ \\
\hline Age at first consultation & Mean \pm SD & $64.2 \pm 14.0$ \\
\hline \multirow[t]{2}{*}{ Socio-economic status score (SES) $2014^{a}$} & Mean \pm SD & $0.47 \pm 1.18$ \\
\hline & Missing, n (\%) & $24(16.3)$ \\
\hline \multirow{2}{*}{$\begin{array}{l}\text { Consultation frequency in year before first } \\
\text { consultation }\end{array}$} & Median (IQI) & $6(2-10)$ \\
\hline & Missing, n (\%) & $17(11.6)$ \\
\hline $\begin{array}{l}\text { Number of registered chronic somatic } \\
\text { comorbidities }^{b}\end{array}$ & Median (IQI) & $2(1-4)$ \\
\hline Registered psychiatric comorbidity ${ }^{b}$ & $\mathrm{n}(\%)$ & $32(21.8)$ \\
\hline \multicolumn{3}{|l|}{ Dominant symptom(s) at first consultation ${ }^{c}$} \\
\hline Ovarian cancer alarm symptom(s) & n (\%) & $55(37.4)$ \\
\hline Cancer general alarm symptom(s) & n (\%) & $15(10.2)$ \\
\hline Other symptoms & $\mathrm{n}(\%)$ & $77(52.4)$ \\
\hline \multicolumn{3}{|l|}{ Dominant symptom(s) at referral ${ }^{c}$} \\
\hline Ovarian cancer alarm symptom(s) & n (\%) & $76(51.7)$ \\
\hline Cancer general alarm symptom(s) & $\mathrm{n}(\%)$ & $16(10.9)$ \\
\hline Other symptoms & $\mathrm{n}(\%)$ & $55(37.4)$ \\
\hline \multicolumn{3}{|l|}{ Referred to } \\
\hline Gynaecologist & n (\%) & $58(39.5)$ \\
\hline Internal medicine & n (\%) & $42(28.6)$ \\
\hline Radiology/imaging & n (\%) & $17(11.6)$ \\
\hline Surgery & n (\%) & $13(8.8)$ \\
\hline Other or unknown & $\mathrm{n}(\%)$ & $17(11.6)$ \\
\hline Population linked to $\mathrm{NCR}^{\mathrm{d}}$ & $\mathrm{n}(\%)$ & $116(100)$ \\
\hline Match with NCR & n (\% of linked) & $85(73.3)$ \\
\hline \multicolumn{3}{|l|}{ Disease stage at diagnosis } \\
\hline FIGO I - II & $\mathrm{n}$ (\% of matched) & $19(22.4)$ \\
\hline FIGO III - IV & $\mathrm{n}$ (\% of matched) & $57(67.1)$ \\
\hline Borderline malignancy & $\mathrm{n}(\%$ of matched) & $9(10.6)$ \\
\hline \multicolumn{3}{|l|}{ Morphology } \\
\hline Epithelial tumours & $\mathrm{n}$ (\% of matched) & 79 (92.9) \\
\hline Other & $\mathrm{n}(\%$ of matched) & $6(7.1)$ \\
\hline
\end{tabular}

$\mathrm{IQI}=$ interquartile interval, NCR = Netherlands Cancer Registry, SD = standard deviation, FIGO = International Federation of Gynecology and Obstetrics

a Socio-economic status scores of 2014.The Dutch mean SES in 2014 was 0.28 (SD I.09). These scores could be derived for patients from 4 out of the 6 primary care network databases (JGPN,ANHVUmc, RNG and RNFM). More details can be found in General Appendix C.

${ }^{b}$ According to the definitions of O'Halloran et al. ${ }^{35}$ More details can be found in General Appendix C.

cAlarm symptoms for ovarian cancer were defined as: increased abdominal size and a palpable abdominal or pelvic mass. Cancer general alarm symptoms were defined as unintended weight loss and anaemia. Other symptoms were all other presenting symptoms that could be related to the ovarian cancer, including abdominal pain, altered defaecation pattern, urinary tract symptoms, nausea and vomiting, vaginal bleeding, malaise etc. In case of presence of both ovarian cancer alarm symptoms and cancer general alarm symptoms, ovarian cancer alarm symptoms were considered dominant.

${ }^{d}$ Linkage with NCR was possible for 3 of the six primary care network databases (JHN Utrecht, ANHVUmc and RNG). 
Median IPC duration was 6 days (IQI I-23). Shortest median duration to referral was seen for patients with ovarian cancer specific alarm symptoms: I day (IQI I-8), compared to II days (IQI 3-22) and 8 days (IQI 2-29) for patients with general cancer alarm symptoms and patients with other symptoms, respectively $(p<0.0 \mathrm{I})$. Median number of

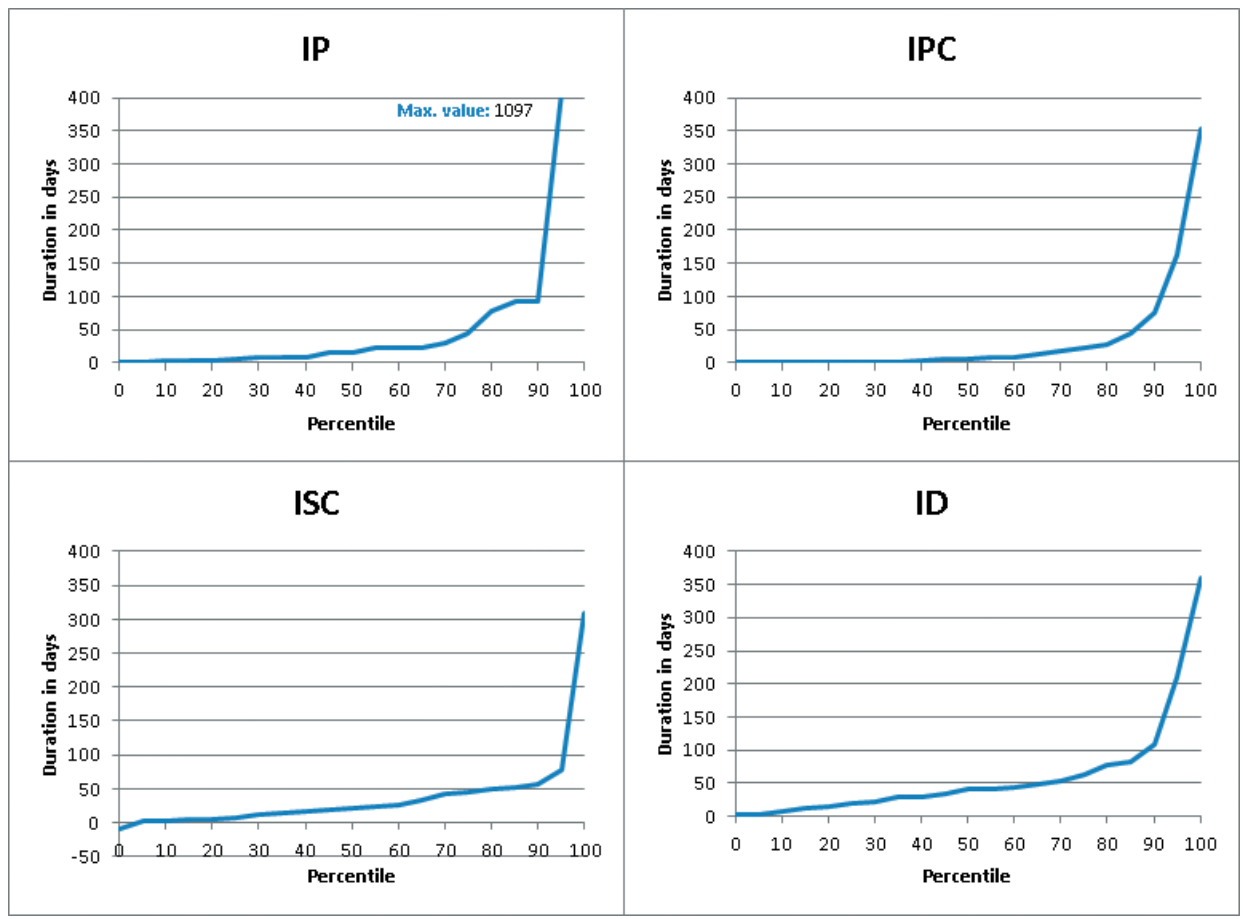

Figure 4. Distribution of the duration of the different intervals of the cancer diagnostic pathway.

IP = patient interval, IPC = primary care interval, ISC = secondary care interval, ID = diagnostic interval.

primary care consultations related to ovarian cancer was 2 (IQI I-4), with 33\% of the patients being immediately referred at first consultation and $72 \%$ within 3 consultations. Median time spent between referral and diagnosis (ISC) was 22 days (IQI 9-45). Longer duration was seen for patients with a SES below the national average (32 days, IQI I552) as compared to patients with a SES above the national average (I6 days, IQI 7-39), $p=0.045$. Time to diagnosis was associated with the treatment plan. For patients who initially underwent surgery $(n=39)$, median ISC duration was 42 days (IQI 23-52), while for patients who initially had chemotherapy $(n=38)$, median ISC duration was 13 days (IQI 4-2I). 


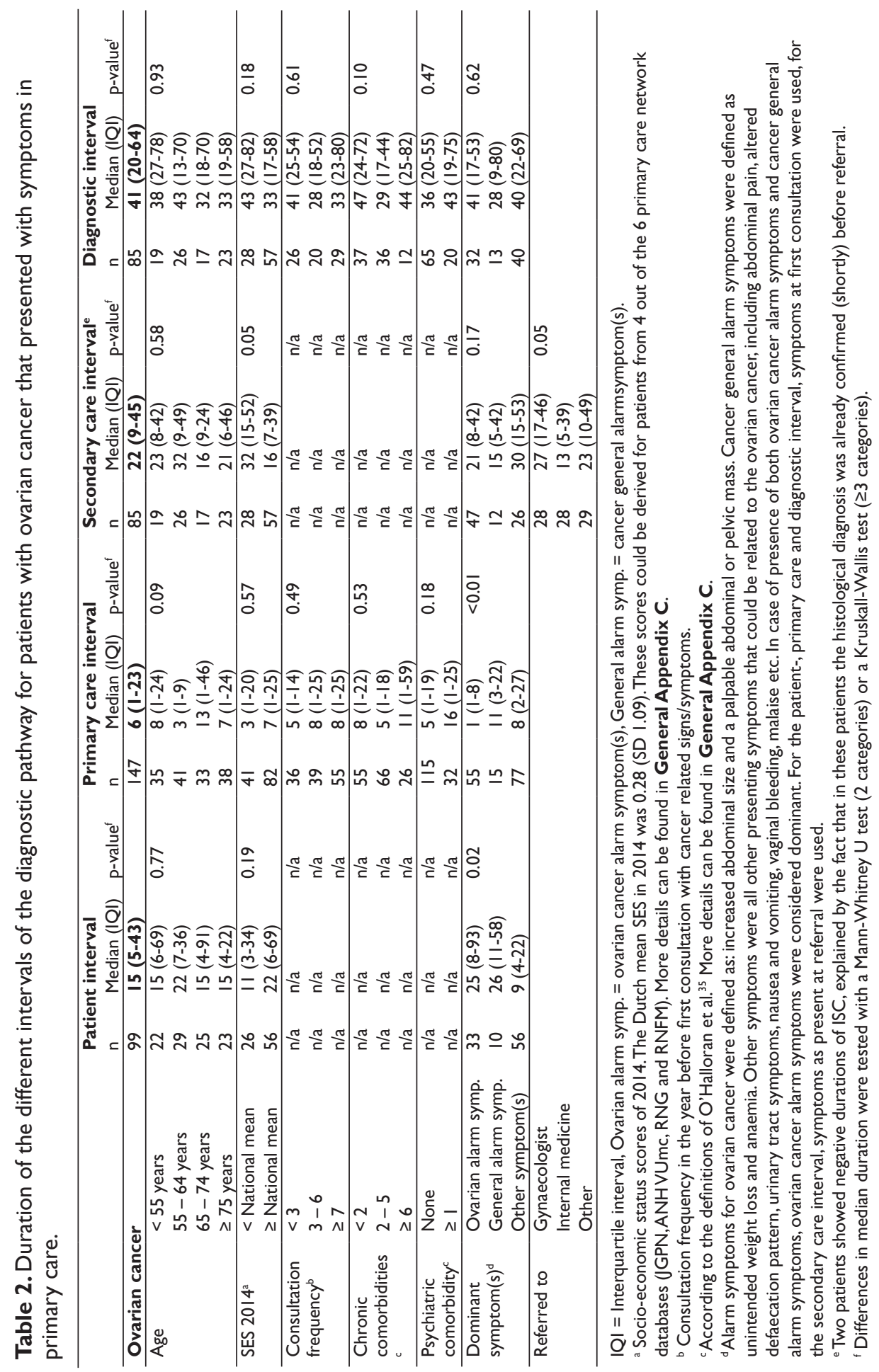




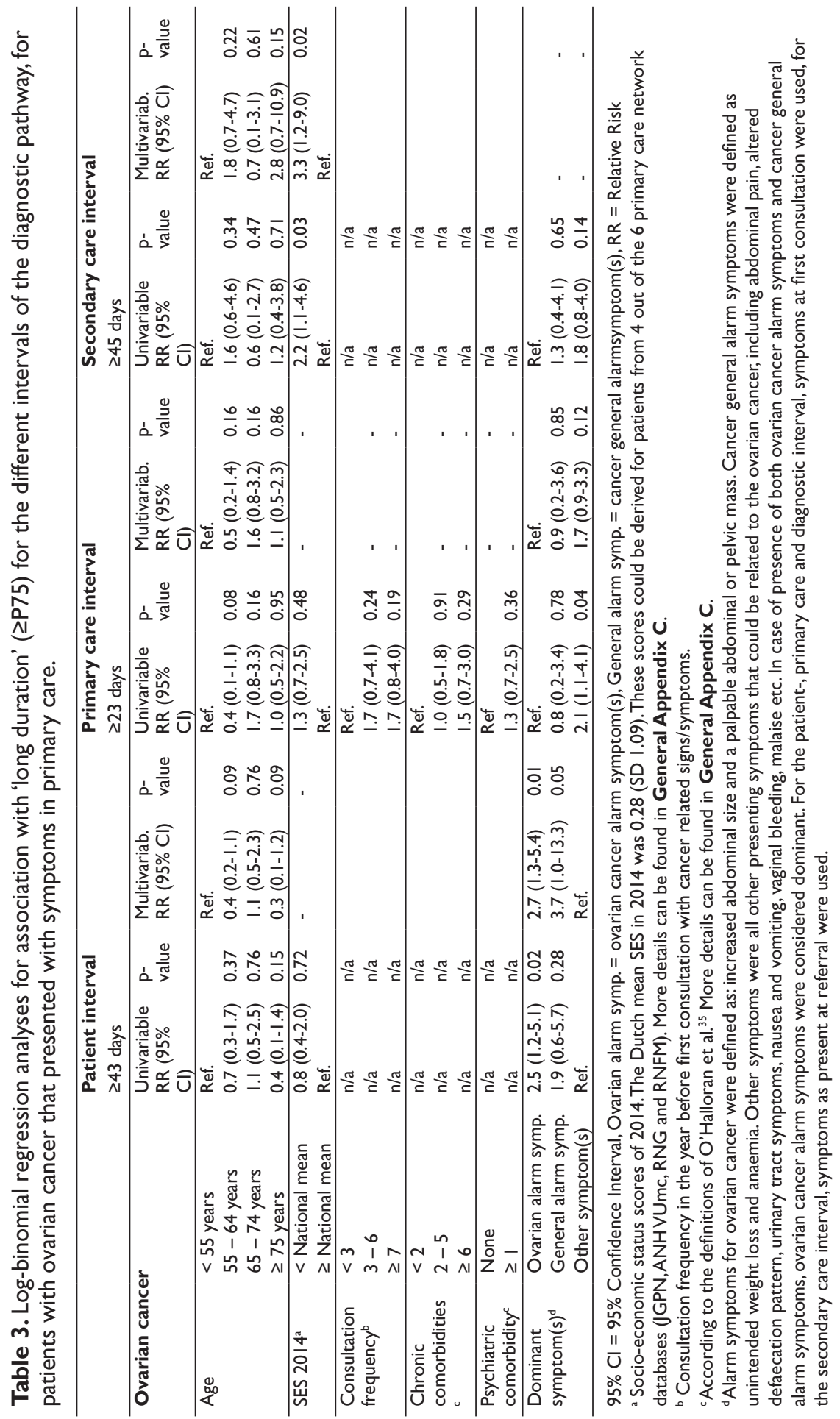


Median ID duration was 4 I days (IQI 20-64). When looking at subgroups according to different patient characteristics, differences in median ID duration up to sixteen days were seen, none of them statistically significant.

Median duration from diagnosis to initial treatment $(I T, n=77)$ was I3 days (IQI I-24). For patients who initially underwent surgery $(n=39)$, median IT duration was I day (IQI $\mathrm{I}-\mathrm{I})$, which can be explained by the fact that material for final diagnosis was obtained during surgery. For patients who started with chemotherapy $(n=38)$ median IT duration was 22 days (IQI I5-29). Median duration from referral to onset of therapy (IRT) was 38 days (IQI 23-53). In total, 54 patients (70\%) started therapy within the maximum duration standard (49 days after referral) as described in the Dutch quality standard for cancer care.

Results of the log-binomial regression analyses for association with 'long duration' ( $\geq$ P75) of the respective intervals are shown in Table 3. For IP, patients with ovarian cancer specific alarm symptoms showed increased risk of long duration (relative risk (RR) $2.7,95 \% \mathrm{Cl}$ I.3-5.4). For IPC, absence of ovarian cancer specific or cancer general alarm symptoms showed a higher risk for 'long duration' in univariable analysis (RR 2.I, $95 \% \mathrm{Cl}$ I.I-4.I), no longer statistically significant when controlled for age in multivariable analysis (Table 3). For ISC, low socioeconomic status score showed increased risk of long duration of ISC: RR $3.3(95 \% \mathrm{Cl}$ I.2-9.0).

\section{Association of duration with tumour stage at diagnosis}

Durations of the intervals according to disease stage are shown in Table 4. Median IP duration was comparable for the different disease stage categories. With a median IPC duration of 3 days (IQI I-8), patients with local disease were referred earlier as compared

Table 4. Duration of the different time intervals of the diagnostic pathway of symptomatic patients with ovarian cancer, matching with the Netherlands Cancer Registry, according to disease stage at diagnosis.

\begin{tabular}{|c|c|c|c|c|c|c|c|c|c|c|c|c|}
\hline & \multicolumn{3}{|c|}{ Patient interval } & \multicolumn{3}{|c|}{$\begin{array}{l}\text { Primary care } \\
\text { interval }\end{array}$} & \multicolumn{3}{|c|}{$\begin{array}{l}\text { Secondary care } \\
\text { interval }\end{array}$} & \multicolumn{3}{|c|}{ Diagnostic interval } \\
\hline & $\mathrm{n}$ & $\begin{array}{l}\text { Median } \\
\text { duration } \\
\text { in days } \\
\text { (IQI) }\end{array}$ & $\begin{array}{l}\mathrm{P}- \\
\text { value } \\
\mathrm{b}\end{array}$ & $n$ & $\begin{array}{l}\text { Median } \\
\text { duration } \\
\text { in days } \\
\text { (IQI) }\end{array}$ & $\begin{array}{l}\mathrm{P}- \\
\text { value } \\
\mathrm{b}\end{array}$ & $n$ & $\begin{array}{l}\text { Median } \\
\text { duration } \\
\text { in days } \\
\text { (IQI) }\end{array}$ & $\begin{array}{l}\mathrm{P}- \\
\text { value } \\
\mathrm{b}\end{array}$ & $\mathrm{n}$ & $\begin{array}{l}\text { Median } \\
\text { duration } \\
\text { in days } \\
(\mathrm{IQI})\end{array}$ & $\begin{array}{l}\mathrm{P}- \\
\text { value } \\
\mathrm{b}\end{array}$ \\
\hline Stage I - II & 14 & $14(5-91)$ & 0.88 & 19 & $3(1-8)$ & 0.07 & 19 & $42(23-53)$ & 0.00 & 19 & $42(27-58)$ & 0.12 \\
\hline Stage III - IV & 34 & I 5 (4-29) & & 57 & $6(1-27)$ & & 57 & $15(5-30)$ & & 57 & $32(14-55)$ & \\
\hline
\end{tabular}

${ }^{a}$ For all intervals, between $10-14 \%$ of the disease stages were missing in the NCR (borderline tumours).

${ }^{\mathrm{b}}$ Differences in median duration were tested with a Mann-Whitney $U$ test. 
to patients with advanced disease (median IPC duration 6 days (IQI I-27), $\mathrm{P}=0.07$ ). Median duration of ISC was 42 days (IQI 23-53) for patients with local disease, more than two times longer than for patients with advanced disease (median ISC duration 15 days (IQI 5-30), $\mathrm{P}<0.0 \mathrm{I}$ ). Median ID duration was ten days longer for those with local disease as compared to those with advanced disease (42 days (IQI 27-58) versus 32 days (IQI I4-55), not statistically significant).

\section{DISCUSSION}

For most patients diagnosed with ovarian cancer the duration of the different intervals of the diagnostic pathway is adequate: half of the patients consult their GP within 15 days, are referred within 6 days and, hereafter, have a histological diagnosis within 22 days. However, for up to $20 \%$ of the patients, these intervals are remarkably long. In $70 \%$ of the patients, the Dutch quality standard for maximum duration from referral to start of treatment is met.

Patients with ovarian cancer specific alarm symptoms remarkably show longer IP durations, but shortest IPC durations. Those with a socioeconomic status score below national average have a shorter time to presentation and referral, but a longer secondary care interval. Patients with advanced disease stages (FIGO III or IV) experience shorter secondary care interval durations.

\section{Strengths and limitations}

Strengths and limitations of the use of routine primary care data have previously been discussed. ${ }^{17}$ The main strength is the availability of free-text annotations of all GP consultations, providing detailed insight in the diagnostic process, including GP considerations and contextual factors. Furthermore, the possibility to link (part of the) primary care data to a National cancer registry (NCR), allowed us to analyse all intervals of the diagnostic pathway.

Limitations include the exclusion of more than half $(56 \%)$ of the patients with an ICPC code for ovarian cancer, including those with unclear diagnostic pathways (I3\%). As among the latter may be more often patients with very short or very long diagnostic intervals, this selection may have resulted in either shorter or longer intervals.

Furthermore, the identification of the first consultation with cancer related symptoms is challenging, especially in case of vague or less specific symptoms. For some patients, early occurring non-specific symptoms may have been related to the diagnosis of ovarian 
cancer, while for others they were not. In case of doubt about the association between symptoms and cancer diagnosis, we chose the first consultation with complaints that were most likely to be related to ovarian cancer.We minimized the risk of misattribution of symptoms by discussing debatable cases with clinicians within our primary care research team, but potential misattribution may have influenced our findings either way (shorter or longer durations).

Finally, measurement of the patient interval based on primary care records comes with limitations. ${ }^{23,24}$ Since the recording of symptom duration by the GP may be inaccurate or missing and the missing duration information is likely to be selective, the median IP duration should be interpreted as approximations.

It should be noted that the date of diagnosis registered in the NCR is - for $98 \%$ of the patients - the date of histological or cytological diagnosis, which corresponds to the date that (tumour) material was obtained. This probably does not reflect the date of the clinical diagnosis and the date the patient is informed of her diagnosis. Therefore, the time that patients spent in uncertainty could not be determined. Furthermore, time to histological diagnosis is at least partly dependant on the treatment plan. For patients in our study who initially got chemotherapy, time from referral to histological diagnosis was relatively short, probably because histology was obtained through biopsy prior to start of treatment. For patients who initially underwent surgery, biopsies for histological diagnosis were obtained during surgery, which resulted in a longer time to diagnosis.

\section{Comparison with literature and implications}

The median patient interval duration of 15 days (IQI 5-43) was comparable to duration reported for Danish ( $\mathrm{n}=38$, median duration 2 I days, IQI 0-35) and UK patients with ovarian cancer $\left(n=275\right.$, median duration I4 days, IQI 2-52). ${ }^{16,25}$ We found that patients with alarm symptoms (increased abdominal size or palpable abdominal/pelvic mass) had longer IP duration than those without. Although remarkable, this may be explained in several ways. First, we based our symptom classification on both reported symptoms and identified signs during first consultation. Regularly, an increased abdominal size or a palpable mass was not reported by the patient but detected by the GP on physical examination. In these cases, IP duration was based on the presenting symptoms, which were often non-alarming (e.g. abdominal pain). Second, ovarian cancer specific symptoms, such as increasing abdominal size, may evolve gradually. They therefore are not necessarily the most inconvenient symptoms for patients and patients with these symptoms may not (immediately) feel the urge to see their GP. 
We found a median primary care interval duration of 6 days (IQI I-23), similar to the primary care interval duration reported for UK patients in 2009-20I0 ( $\mathrm{n}=275$, median duration 7 days, IQI 0-22) and shorter than the UK durations in 2014 ( $n=240$, median

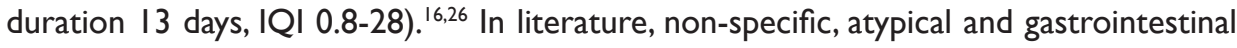
symptoms are associated with delayed referral, which reflects our outcome that patients without ovarian cancer specific alarm symptoms are referred later and are at increased risk for 'long duration' ( $\geq \mathrm{P} 75) .{ }^{27}$ As we did not identify other characteristics associated with 'long duration' and the median duration of the primary care interval is already short, there seems to be little room for improvement in primary care. However, as we found remarkably long durations up to $20 \%$ of the patients, a more in depth analysis of those with longest durations could provide insight in preventable reasons for 'delay'. Earlier studies already identified some of these factors, including lack of follow-up and poor communication. ${ }^{27}$

The secondary care interval, stretching from referral to diagnosis, had a median duration of 22 days (IQI 9-45) in our study, which is substantially shorter than the 48.5 days (IQI 17-89) reported for UK patients. ${ }^{28}$ We found longer secondary care intervals for those with lower SES score which is consistent with the earlier described shorter doctor- and system delays for women with higher SES. ${ }^{29}$ The fact that less than half of the patients was directly referred to the gynaecologist, fits in earlier reports, and underlines the non-specificity of the ovarian cancer related complaints. ${ }^{28}$ We assessed the duration of time from referral to initial therapy to compare with the Dutch quality standard for cancer care and found that $70 \%$ of the patients met the maximum duration standard of 49 days for this interval. As we had limited insight in waiting times and secondary care proceedings, it was not possible to evaluate whether the current secondary care pathway is optimal. This deserves further exploration.

In previous research, total time to diagnosis for ovarian cancer varied widely, from less than a week to more than 12 months. ${ }^{9-14,26,30}$ The median time to diagnosis as found in our study (4I days, IQI 20-64) is somewhere in between this spectrum, but heterogeneous methodology complicates comparison.

Based on our findings, the potential to reduce the time to diagnosis seems limited. In addition, it is unclear to what extent reduction of the time to diagnosis would contribute to better outcomes. We found shorter ISC and ID durations for those with advanced stage disease; potentially suggesting faster processing for those patients most in need. The association of 'diagnostic delay', tumour stage and survival is complex and probably non-linear. Several studies conclude that delays in referral or diagnosis do not adversely affect survival of ovarian cancer patients. ${ }^{31,32}$ In contrast, recent work suggests that longer 
intervals are associated with more advanced cancer stages. ${ }^{33}$ However, apart from the impact on survival, a timely diagnosis is equally important to address patients' wellbeing. ${ }^{34}$

\section{Conclusion}

Duration of the intervals of the diagnostic pathway of ovarian cancer is generally acceptable and leaves little room for improvement, but for a relevant minority (up to $20 \%$ of the patients) intervals are remarkably long. Although improved recognition of specific alarm symptoms in ovarian cancer by patients may shorten the time to diagnosis, narrowing the interval for patients and primary care seems challenging due to the nonspecific nature of ovarian cancer symptoms. Most reduction of the diagnostic interval seems to be achievable by optimizing the efficiency of the diagnostic path after referral.

\section{Acknowledgements}

The authors thank all medical students involved in data collection. We thank the registration team of the Netherlands Comprehensive Cancer Organisation (IKNL) and particularly Henrike Bretveld, for the collection of data for the Netherlands Cancer Registry as well as IKNL staff for scientific advice. We thank all the GPs participating in the six networks for sharing their Electronic Health Record data, and Nicole Boekema, Erna Beers, Marjan van den Akker, Hanna Joosten, Margot de Waal, Henk de Jong, ZorgTTP and their teams, for their assistance in extracting data and the linkage procedures. 


\section{REFERENCES}

I. Bray F, Ferlay J, Soerjomataram I, Siegel RL, Torre LA, Jemal A. Global cancer statistics 20I8: GLOBOCAN estimates of incidence and mortality worldwide for 36 cancers in 185 countries. CA Cancer J Clin 2018;68:394-424.

2. Allemani C, Matsuda T, Di Carlo V, Harewood R, Matz M, Nikšić M, et al. Global surveillance of trends in cancer survival 2000-I4 (CONCORD-3): analysis of individual records for 37513025 patients diagnosed with one of 18 cancers from 322 population-based registries in 71 countries. Lancet 2018;391:1023-1075.

3. Data from the Netherlands Cancer Registry, managed by The Netherlands Comprehensive Cancer Organisation [Internet].Available from: http://www.cijfersoverkanker.nl.Accessed March 23, 2017.

4. Torre LA, Trabert B, DeSantis CE, Miller KD, Samimi G, Runowicz CD, et al. Ovarian cancer statistics, 2018. CA Cancer J Clin 2018;68:284-296.

5. Henderson JT,Webber EM, Sawaya GF. Screening for ovarian cancer updated evidence report and systematic review for the US preventive services task force. J Am Med Assoc 20 18;3 19:595-606.

6. Jacobs IJ, Menon U, Ryan A, Gentry-Maharaj A, Burnell M, Kalsi JK, et al. Ovarian cancer screening and mortality in the UK Collaborative Trial of Ovarian Cancer Screening (UKCTOCS):A randomised controlled trial. Lancet 2016; 387:945-956.

7. Hamilton W, Peters T], Bankhead C, Sharp D. Risk of ovarian cancer in women with symptoms in primary care: Population based case-control study. BMJ 2009;339:6I6.

8. Lyratzopoulos G,Wardle J, Rubin G. Rethinking diagnostic delay in cancer: How difficult is the diagnosis? BMJ 20I4;349:g7400.

9. Vine MF, Ness RB, Calingaert B, Schildkraut JM, Berchuck A. Types and duration of symptoms prior to diagnosis of invasive or borderline ovarian tumor. Gynecol Oncol 200 I;83:466-47I.

10. Vine MF, Calingaert B, Berchuck A, Schildkraut JM. Characterization of prediagnostic symptoms among primary epithelial ovarian cancer cases and controls. Gynecol Oncol 2003;90:75-82.

II. Chan YM, Ng TY, Lee PWH, Ngan HYS, Wong LC. Symptoms, coping strategies, and timing of presentations in patients with newly diagnosed ovarian cancer. Gynecol Oncol 2003;90:65 I-656.

12. Webb PM, Purdie DM, Grover S, Jordan S, Dick ML, Green AC. Symptoms and diagnosis of borderline, early and advanced epithelial ovarian cancer. Gynecol Oncol 2004;92:232-239.

13. Bankhead CR, Collins C, Stokes-Lampard H, Rose P,Wilson S, Clements A, et al. Identifying symptoms of ovarian cancer:A qualitative and quantitative study. BJOG 2008; I I5: I008-I0I4.

14. Lim AWW, Mesher D, Gentry-Maharaj A, Balogun N,Widschwendter M, Jacobs I, et al.Time to diagnosis of Type $\mathrm{i}$ or II invasive epithelial ovarian cancers: A multicentre observational study using patient questionnaire and primary care records. BJOG 2016;123:1012-1020.

15. Allgar VL, Neal RD. Delays in the diagnosis of six cancers: analysis of data from the National Survey of NHS Patients: Cancer. Br J Cancer 2005 Jun 3;92:1959-1970.

16. Lyratzopoulos G, Saunders CL, Abel GA, McPhail S, Neal RD, Wardle J, et al.The relative length of the patient and the primary care interval in patients with 28 common and rarer cancers. $\mathrm{Br}$ J 
Cancer 20I5; I I2:S35-S40.

17. Helsper C, van Erp N, Peeters P, de Wit N. Original Research:Time to diagnosis and treatment for cancer patients in the Netherlands: room for improvement? Eur J Cancer 2017;87:1 13-121.

18. Lamberts H,Wood M. International Classification of Primary Care (ICPC). Oxford: Oxford University Press; 1987.

19. Netherlands Comprehensive Cancer Organisation (IKNL). Over de registratie [in Dutch], https:// www.iknl.nl/en/ncr.Accessed June 28, 2019.

20. Weller D, Vedsted P, Rubin G, Walter FM, Emery J, Scott S, et al. The Aarhus statement: improving design and reporting of studies on early cancer diagnosis. Br J Cancer 2012;106:1262-1267.

21. Stichting Oncologische Samenwerking. Multidisciplinaire normering oncologische zorg in Nederland, Normeringsrapport 2020 [Internet]. Available from: https://www.soncos.org/wpcontent/uploads/2020/03/SONCOS-normeringsrapport-versie-8-I.pdf.Accessed February I0, 2020.

22. European Network of Cancer Registries. Recommendations for coding Incidence Date [Internet]. Available from: http://www.encr.eu/registries-network. Accessed November 23, 2019.

23. Andersen RS, Vedsted P, Olesen F, Bro F, Søndergaard J. Patient delay in cancer studies:A discussion of methods and measures. BMC Health Serv Res 2009;9:I-7.

24. Smith SM, Whitaker KL, Cardy AH, Elliott AM, Hannaford PC, Murchie P.Validation of self-reported help-seeking, and measurement of the patient interval, for cancer symptoms: an observational study to inform methodological challenges in symptomatic presentation research. Fam Pract 2020;37:91-97.

25. Hansen RP,Vedsted P, Sokolowski I, Søndergaard J, Olesen F.Time intervals from first symptom to treatment of cancer: a cohort study of 2,212 newly diagnosed cancer patients. BMC Health Serv Res 201 I; II:284.

26. Swann R, McPhail S, Shand B, Rashbass J,Witt J,Abel GA, et al. Diagnosing cancer in primary care: Results from the National Cancer Diagnosis Audit. Br J Gen Pract 2018;68:e63-e72.

27. Williams $P$, Murchie $P$, Bond $C$. Patient and primary care delays in the diagnostic pathway of gynaecological cancers:A systematic review of influencing factors. Br J Gen Pract 2019;69:EI06EIII.

28. Barrett J, Sharp DJ, Stapley S, Stabb C, Hamilton W. Pathways to the diagnosis of ovarian cancer in the UK:A cohort study in primary care. BJOG 2010;117:610-614.

29. Hansen RP, Olesen F, Sørensen HT, Sokolowski I, Søndergaard J. Socioeconomic patient characteristics predict delay in cancer diagnosis:A Danish cohort study. BMC Health Serv Res 2008;8:I-10.

30. Allgar VL, Neal RD. General practictioners' management of cancer in England: Secondary analysis of data from the National Survey of NHS Patients - Cancer. Eur J Cancer Care 2005; 14:409-16.

3I. Kirwan JMJ, Tincello DG, Herod JJO, Frost O, Kingston RE. Effect of delays in primary care referral on survival of women with epithelial ovarian cancer: retrospective audit. BMJ 2002;324: I48-I5I.

32. Nagle CM, Francis JE, Nelson AE, Zorbas H, Luxford K, De Fazio A, et al. Reducing time to diagnosis does not improve outcomes for women with symptomatic ovarian cancer:A report 
from the Australian Ovarian Cancer Study Group.J Clin Oncol 20 I ; 29:2253-2258.

33. Torring ML, Frydenberg M, Hansen RP, Olesen F,Vedsted P. Evidence of increasing mortality with longer diagnostic intervals for five common cancers:A cohort study in primary care. Eur J Cancer 2013;49:2187-98.

34. Robinson KM, Christensen KB, Ottesen B, Krasnik A. Diagnostic delay, quality of life and patient satisfaction among women diagnosed with endometrial or ovarian cancer:A nationwide Danish study. Qual Life Res 2012;21:1519-25.

35. O'Halloran J, Miller GC, Britt H. Defining chronic conditions for primary care with ICPC-2. Fam Pract 2004;2I:38I-6. 


\section{APPENDIX I}

For symptomatic ovarian cancer patients that could be linked to the Netherlands Cancer Registry: characteristics of patients that were a match with NCR compared with patients that were not a match with NCR.

\begin{tabular}{|c|c|c|c|}
\hline & & NCR match & No match \\
\hline Population & $\mathrm{n}(\%)$ & $85(100)$ & $31(100)$ \\
\hline \multirow[t]{2}{*}{ Age at first consultation } & Mean \pm SD & $64.5 \pm 13.6$ & $66.5 \pm 15.3$ \\
\hline & Median (IQI) & $64.0(55.0-76.0)$ & $70.0(55.0-79.0)$ \\
\hline \multirow[t]{3}{*}{ Socio-economic status score (SES) $2014^{\dagger}$} & Mean \pm SD & $0.53 \pm 1.17$ & $0.42 \pm 1.29$ \\
\hline & Median (IQI) & $1.00(-0.87-1.50)$ & $0.50(-0.11-1.150)$ \\
\hline & Missing, n (\%) & $0(0.0)$ & $2(6.5)$ \\
\hline \multirow{3}{*}{$\begin{array}{l}\text { Consultation frequency in year before first } \\
\text { consultation }\end{array}$} & Mean \pm SD & $7.1 \pm 8.9$ & $10.6 \pm 7.3$ \\
\hline & Median (IQI) & $5(1-10)$ & $7(6-15)$ \\
\hline & Missing, n (\%) & $10(11.8)$ & $5(16.1)$ \\
\hline \multirow{3}{*}{$\begin{array}{l}\text { Number of registered chronic somatic } \\
\text { comorbidities }^{\ddagger}\end{array}$} & Mean \pm SD & $2.4 \pm 2.3$ & $3.4 \pm 2.7$ \\
\hline & Median (IQI) & $2(I-4)$ & $3(1-4)$ \\
\hline & Missing, n (\%) & $0(0.0)$ & $0(0.0)$ \\
\hline \multirow[t]{2}{*}{ Registered psychiatric comorbidity ${ }^{\mathrm{b}}$} & $\mathrm{n}(\%)$ & $20(23.5)$ & $5(16.1)$ \\
\hline & Missing, n (\%) & $0(0.0)$ & $0(0.0)$ \\
\hline \multicolumn{4}{|l|}{ Dominant symptom(s) at first consultation } \\
\hline Cancer specific alarm symptom(s) & $n(\%)$ & $32(37.6)$ & $9(29.0)$ \\
\hline Cancer general alarm symptom(s) & n (\%) & $13(15.3)$ & $\mathrm{I}(3.2)$ \\
\hline Other, non-alarming symptoms & $\mathrm{n}(\%)$ & $40(47.1)$ & $21(67.7)$ \\
\hline \multicolumn{4}{|l|}{ Dominant symptom(s) at referral ${ }^{\S}$} \\
\hline Cancer specific alarm symptom(s) & $\mathrm{n}(\%)$ & $47(55.3)$ & $12(38.7)$ \\
\hline Cancer general alarm symptom(s) & $n(\%)$ & $12(14.1)$ & $2(6.5)$ \\
\hline Other, non-alarming symptoms & $\mathrm{n}(\%)$ & $26(30.6)$ & $17(54.8)$ \\
\hline
\end{tabular}

IQI = interquartile interval, NCR = Netherlands Cancer Registry, SD = standard deviation

† Socio-economic status scores of 2014. The Dutch mean SES in 2014 was 0.28 (SD I.09). SES could be derived for patients from 4 out of the 6 primary care network databases (JGPN, ANH VUmc, RNG and RNFM). More details can be found in General Appendix $\mathbf{C}$.

¥According to the definitions of O’Halloran et al..$^{35}$ More details can be found in General Appendix C. $\S$ Alarm symptoms for ovarian cancer were defined as: increased abdominal size and a palpable abdominal or pelvic mass. Cancer general alarm symptoms were defined as unintended weight loss and anaemia. Other symptoms were all other presenting symptoms that could be related to the ovarian cancer, including abdominal pain, altered defaecation pattern, urinary tract symptoms, nausea and vomiting, vaginal bleeding, malaise etc. In case of presence of both ovarian cancer alarm symptoms and cancer general alarm symptoms, ovarian cancer alarm symptoms were considered dominant. 



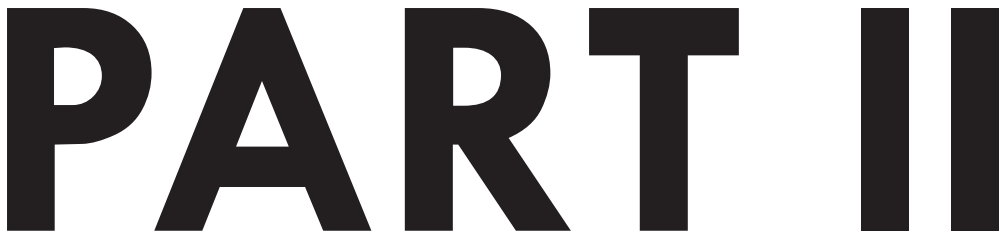

Exploring reasons for long duration to referral from primary care

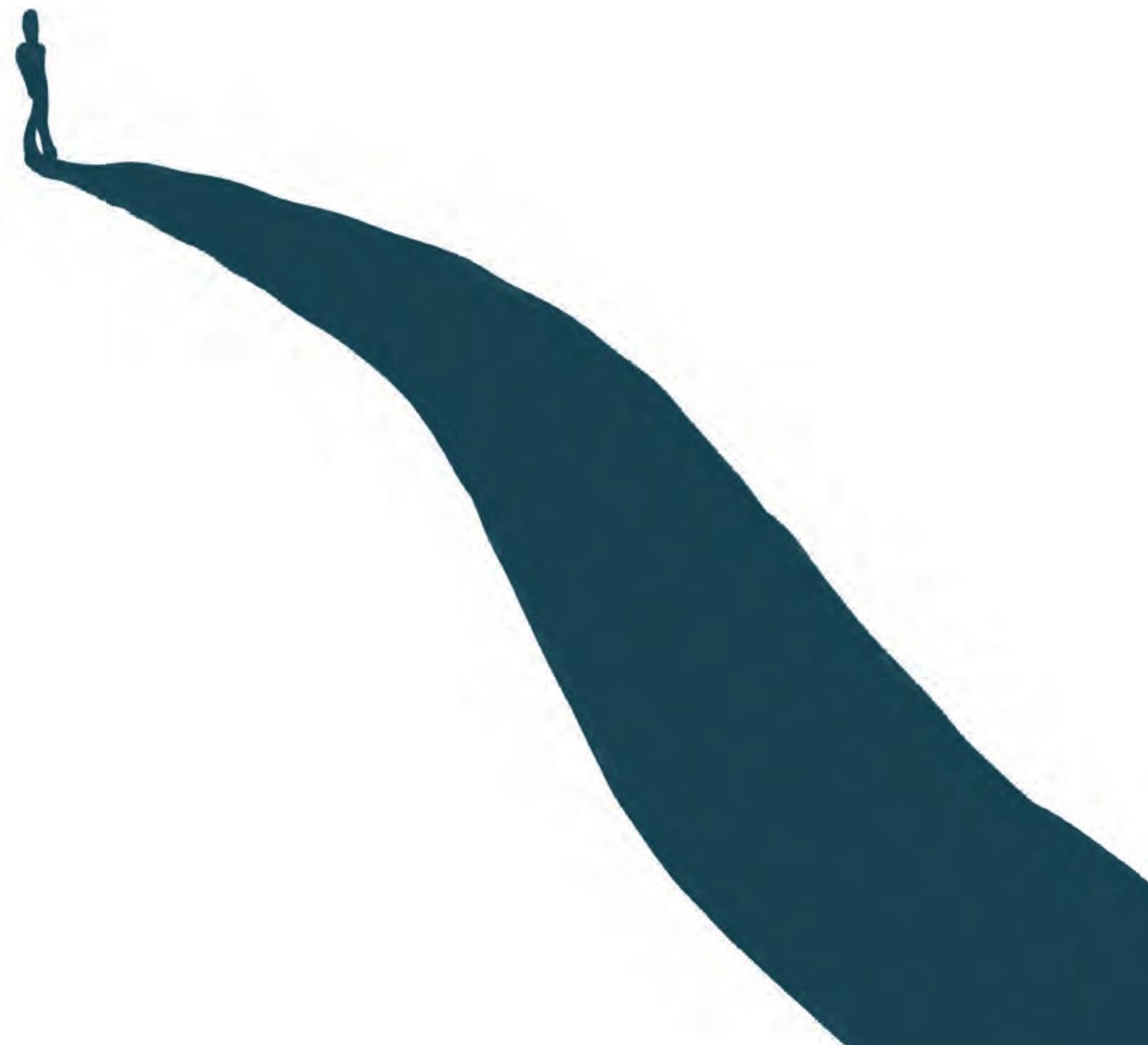




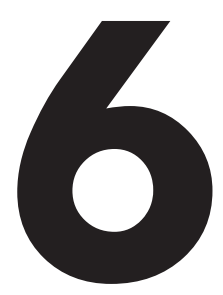

\title{
Potential for reducing time to referral for colorectal cancer patients in primary care
}

\author{
Nicole F. van Erp \\ Charles W. Helsper \\ Saskia M. Olyhoek \\ Ramon R.T.Janssen \\ Amber Winsveen \\ Petra H.M. Peeters \\ Niek J. de Wit
}




\section{ABSTRACT}

Background: An optimal diagnostic process in primary care is pivotal for reducing cancer-related disease burden. This study aims to explore reasons for long times to referral for Dutch colorectal cancer (CRC) patients in primary care.

Methods: A retrospective cohort study of anonymized free-text primary care records from the Julius General Practitioners' Network database, linked to the Netherlands Cancer Registry. Patients with a confirmed CRC diagnosis from 2007 through 20 I I that symptomatically presented in primary care were included. Median time and interquartile ranges from presentation in primary care to referral were calculated for multiple patient and presentation characteristics. Associations of these characteristics with long time to referral (75th percentile was $\geq 59$ days) were examined with log-binomial regression analyses. Routes to referral of patients with the longest times to referral were explored using thematic free-text analyses ( 90 th percentile at $\geq 219$ days).

Results: Among the 309 people with CRC, patients who were female, did not have a registered family history, had a history of malignancy, lacked alarm symptoms at presentation, or had hemorrhoids at physical examination were at risk for longer time to referral in univariable analyses (longer median durations and or univariable association with the 75th percentile). Only presentation without alarm symptoms showed a statistically significant association with long duration (75th percentile) in multivariable analysis (relative risk $=1.7 ; 95 \% \mathrm{Cl}$, I.I-2.6). Thematic exploration of the diagnostic routes to referral of patients with the longest durations (90th percentile) showed 2 dominating themes:"alternative working diagnosis" and "suboptimal diagnostic strategies," and included the subthemes "omitting to reconsider an initial diagnosis" and "lacking follow-up."

Conclusions: Long time to referral for CRC in primary care is mainly related to low cancer suspicion. There is potential for reducing the longest times to referral for patients with CRC in primary care, with earlier reconsideration of the initial hypothesis and implementation of strict follow-up consultations. 


\section{INTRODUCTION}

Colorectal cancer (CRC) is the second most common cancer and the second most common cause of cancer-related death in Europe, with approximately 450,000 new patients with CRC and 215,000 CRC-related deaths annually. I Prognosis for colorectal cancer is mainly dependent on the tumor stage at diagnosis.2,3 Prompt referral and diagnosis are considered important for improved clinical outcomes. ${ }^{4,5}$

Much effort has already been applied to optimize early detection of bowel cancer with implementation of population screening in most European countries. ${ }^{6}$ However, in primary care-based health care systems, in which the general practitioner (GP) is the patient's first contact and triages the patient's further access to the system, most CRC patients present to a GP with symptoms. Therefore, timely recognition of cancer-related complaints and adequate referral by the GP are and will remain essential to reduce time to diagnosis.

In the United Kingdom and the Netherlands, the current median time from first consultation with cancer-related complaints to referral is approximately I week for CRC patients. ${ }^{7,8}$ Although this median duration seems acceptable, time to referral varies greatly, with durations of months and even years, for $10 \%$ to $25 \%$ of CRC patients. ${ }^{7,8}$

Several studies have reported factors associated with diagnostic delay in CRC patients. They included explanations for doctor's delay (e.g. initial misdiagnosis, inadequate examination, inaccurate investigations) and found that older patients and those with comorbid conditions were at increased risk of delay. ${ }^{9-13}$

These studies, however, were often limited to analyses of coded research data, strictly quantitative analyses, and/or lacked opportunities to link determinants of delayed referral to actual time spent in primary care.Therefore, explanations for suboptimal referral from these studies may be incomplete and oversimplified.

The aim of the current study is to perform a more detailed assessment of the time from presentation in primary care to referral for patients with $C R C$, including the identification of mechanisms causing long times to referral. 


\section{METHODS}

\section{Study design and data source}

A retrospective cohort study was performed using free text and coded routine primary care data from the Julius General Practitioner's Network (JGPN) database, linked to data in the Netherlands Cancer Registry. The JGPN database contains nonreducible free text and coded information from primary care electronic health records of over 300,000 patients from a central region of the Netherlands. ${ }^{14}$ The Netherlands Cancer Registry provides reliable and detailed information on Dutch cancer patients since 1989. A more extensive description of study design and data sources is provided elsewhere. ${ }^{7}$

\section{Patient selection}

Patients, aged 20 through 90 years, were selected if they were registered with International Classification of Primary Care version I (ICPC-I) code D75 (for malignant neoplasm colon/rectum) in the JGPN database from 2007 through 20II, and were registered with the same diagnosis in the Netherlands Cancer Registry, validating diagnoses. Only patients who initially visited the GP with complaints or symptoms directly or indirectly related to CRC, and were referred by the GP, were included. Patients with substantially missing information or unclear electronic health records contents were excluded.

\section{Data collection}

\section{Primary care interval}

The primary care interval was defined according to the Aarhus statement, ${ }^{15}$ as the period of time from first consultation with cancer-related signs and/or symptoms in primary care to referral to secondary care. Date of first consultation was defined as the first contact with the GP (in person or by telephone) with colorectal cancer-related signs or symptoms. For patients with vague or nonspecific signs or symptoms, the first consultation with the complaints that eventually led to the CRC diagnosis and could reasonably be related to the cancer, was chosen.

Date of referral was defined as the moment the responsibility for the patient was transferred from GP to secondary care, that is, the day on which the GP decided to refer and sent a referral letter. Referral to radiology or endoscopy departments for imaging was used as the date of referral, if abnormal findings subsequently lead to referral to a specialist, without further involvement of the GP. In case of multiple referrals to, or crossreferrals in secondary care, the first referral for further exploration of cancer-related symptoms was chosen. 
The free text and coded primary care electronic health records data of all symptomatic CRC patients were studied by 2 researchers (R.J, A.W.) from 5 years before the date of diagnosis as registered in the Netherlands Cancer Registry data to determine the occurrence of the first colorectal cancer-related signs or symptoms and date of referral. Five years before I year after diagnosis was arbitrarily chosen to ensure a comprehensive overview of the complete diagnostic process, including the onset of CRC symptoms and other relevant morbidities.

When there was doubt about date of first presentation and/or referral, diagnostic paths were discussed with a second researcher or with the complete research team (N.vE., S.O., R.J.,A.W., C.H.) until consensus was reached.

\section{Characteristics}

The decision to collect data for certain characteristics and to include them in our initial, univariable analyses was based on previously reported predictors in the literature (eg, comorbidity, including psychiatry), on clinical relevance of patient and disease characteristics, and on availability of data in the JGPN registry. ${ }^{9-13}$ Disease, patient, and presentation characteristics that could be extracted are summarized in Table I and Table 2. Elaborate descriptions of the characteristics and collection methods are provided in Appendix I.

Table I. Disease characteristics of symptomatic CRC patients referred by GP $(\mathrm{N}=309)$.

\begin{tabular}{llll}
\hline $\begin{array}{l}\text { Characteristic } \\
\text { TNM stage at } \\
\text { diagnosis }\end{array}$ & No. (\%) & $\begin{array}{l}\text { Characteristic } \\
\text { Tumour location }\end{array}$ & No. (\%) \\
\hline 0 & I $(0.3)$ & Proximal colon & $90(29.1)$ \\
I & $4 I(13.3)$ & Distal colon & $20(6.5)$ \\
II & $83(26.9)$ & (Recto)sigmoid & $99(32.0)$ \\
III & II $(36.9)$ & Rectal & $97(3 I .4)$ \\
IV & $65(2 I .0)$ & Colon unspecified & $3(1.0)$ \\
Unknown & $5(I .6)$ & & \\
\hline
\end{tabular}

$\mathrm{CRC}=$ colorectal cancer GP = general practitioner; TNM = tumor, nodes, metastases.

\section{Analyses}

Primary care interval by characteristic

The length of the primary care interval was previously reported for the total population (median 8 days; interquartile range $[\mathrm{IQR}]=\mathrm{I}-59$; range, $\mathrm{I}-\mathrm{I}, \mathrm{I77})^{7}$ and is now calculated for multiple patient and presentation characteristics. Durations are reported as medians, interquartile ranges, and 90th percentiles, because of the substantially right- 
skewed distribution of the data. ${ }^{7}$ Differences in median durations between categories of characteristics were tested for statistical significance using the Mann-Whitney $U$ test for characteristics with 2 categories and the Kruskal-Wallis test for characteristics with 3 or more categories.

\section{Determinants of long duration}

Long duration primary care interval was defined as periods of time greater than or equal to the 75th percentile ( $\geq 59$ days). Uni- and multivariable log-binomial regression analyses were performed to identify characteristics associated with long duration. Characteristics that were significantly associated with long duration $(P<.05)$ in univariable analysis were included in multivariable analysis.

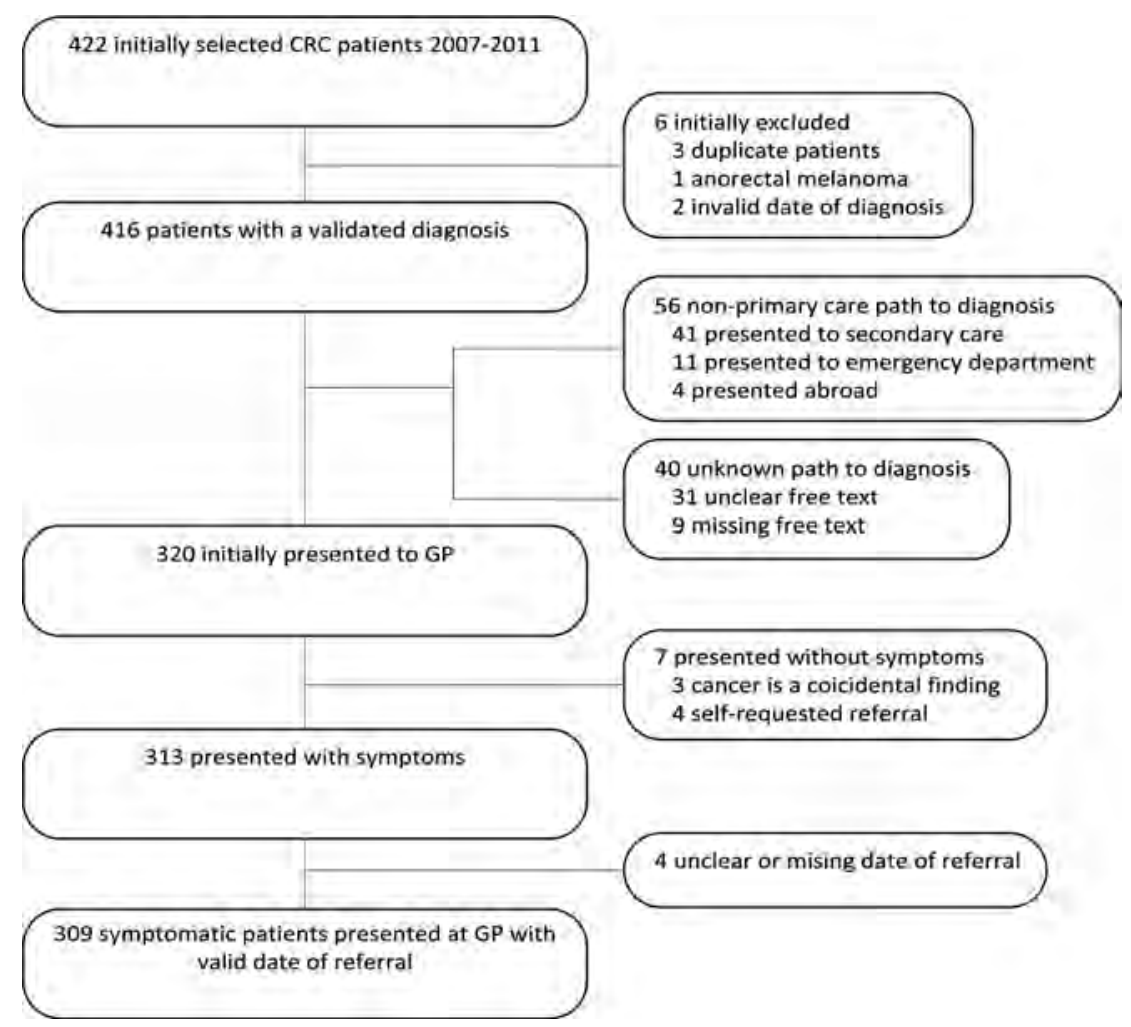

Figure I. Flowchart for CRC patient selection.

$\mathrm{CRC}=$ colorectal cancer; $\mathrm{GP}=$ general practitioner. 
Thematic analyses for the longest duration

Longest duration primary care interval was defined as periods of time greater than or equal to the 90 th percentile ( $\geq 219$ days). Mechanisms leading to the longest primary care intervals were extracted from verbatim transcriptions of the free-text registrations of all consultations preceding referral.The diagnostic route to referral and the deliberations of the GP were analyzed using open coding, axial coding, and selective coding. Details of the qualitative data analysis are available in Appendix $\mathbf{2}$.

\section{Software}

Data collection, transformation, and analyses were performed in SPSS version 22.0.

\section{RESULTS}

\section{Patients}

Of 416 patients with a validated CRC diagnosis identified in the JGPN database, 320 initially presented in primary care, of whom 3/3 were diagnosed after symptomatic presentation. The referral date was available for 309. The remaining 107 patients were excluded for reasons shown in Figure I. Included CRC patients had a mean age of 66.7 years with a standard deviation of I 2.2 years and I 54 (49.8\%) were female. Table I and Table 2 show the characteristics of CRC patients included in this study.

\section{Primary care interval by characteristic}

Table 2 shows median and IQR data for duration of primary care intervals calculated for patient and presentation characteristics. Characteristics with a statistically significant difference in median duration were: sex, 13 days for female patients vs 4 days for male patients; registered family history of CRC, II days for patients without a registered family history of CRC vs I day for those with registered history; and presentation with only nonalarming gastrointestinal symptoms, 26 days compared to 2 days for those with alarming gastrointestinal signs. For patients diagnosed with stage IV colorectal cancer, median duration of the primary care interval was 23 days, which is more than 2 times longer than for patients with less advanced disease stages.

Although not statistically significant, duration of primary care intervals were more than 3 weeks longer for patients aged under 50 years, patients presenting with psychiatric comorbidity (mostly depression and anxiety), and patients with hemorrhoids at physical examination. 
Table 2. Patient and presentation characteristics of symptomatic CRC patients, duration of primary care interval, and log-binomial regression analysis for 75th percentile $(\mathrm{N}=$ 309).

\begin{tabular}{|c|c|c|c|c|c|c|c|}
\hline Characteristic & & No. & $\begin{array}{l}\text { Median } \\
\text { duration } \\
\text { days (IQR) }\end{array}$ & $\begin{array}{l}\mathbf{P} \\
\text { value }^{\mathrm{a}}\end{array}$ & P90 & $\begin{array}{l}\text { Uni- } \\
\text { variable } \\
\text { RR } \\
(95 \% \mathrm{CI}) \\
\end{array}$ & $\begin{array}{l}\text { Multi- } \\
\text { variable } \\
\text { RR } \\
(95 \% \mathrm{Cl})\end{array}$ \\
\hline All patients & & 309 & $8(1-59)$ & & 219 & & \\
\hline \multirow[t]{5}{*}{ Age, y } & $\leq 50$ years & 35 & $34(1-233)$ & & 491 & $\mathrm{I} .5(0.8-3.0)$ & \\
\hline & $51-60$ years & 47 & $3(1-15)$ & & 408 & $0.6(0.3-I .4)$ & \\
\hline & $61-70$ years & 100 & $14(1-47)$ & & 94 & $0.8(0.4-1.4)$ & \\
\hline & $71-80$ years & 91 & $6(|-6|)$ & & 204 & $0.9(0.5-1.7)$ & \\
\hline & $\geq 81$ years & 36 & $8(1-68)$ & 0.154 & 150 & I (ref) & \\
\hline \multirow[t]{2}{*}{ Sex } & Male & 155 & $4(1-47)$ & & 101 & I (ref) & I (ref) \\
\hline & Female & 154 & $13(1-78)$ & 0.004 & 321 & $1.6(1.1-2.4)$ & $1.4(0.9-2.1)$ \\
\hline \multirow[t]{4}{*}{ SES $2010^{c}$} & Low & $8 I$ & $12(1-72)$ & & 240 & I (ref) & \\
\hline & Medium-low & 79 & $9(1-63)$ & & 239 & $0.9(0.5-I .5)$ & \\
\hline & Medium-high & 73 & $7(|-5|)$ & & 118 & $0.7(0.4-I .3)$ & \\
\hline & High & 76 & $6(1-47)$ & 0.551 & 223 & $0.7(0.4-I .2)$ & \\
\hline \multicolumn{8}{|c|}{ Registered comorbidity ${ }^{d}$} \\
\hline \multirow[t]{4}{*}{ Chronic somatic } & No & 62 & $5(I-48)$ & & 326 & I (ref) & \\
\hline & Yes & 247 & $10(1-6 \mid)$ & 0.317 & 198 & I.I (0.7-I.9) & \\
\hline & $\leq 2$ & 181 & $9(1-58)$ & & 203 & I.I (0.6-I.8) & \\
\hline & $\leq 4$ & 70 & $8(1-43)$ & & 98 & $0.9(0.5-I .7)$ & \\
\hline \multirow[t]{2}{*}{ Gastro-intestinal } & No & 256 & $8(1-63)$ & & 219 & I (ref) & \\
\hline & Yes & 53 & $15(2-48)$ & 0.622 & 119 & $0.7(0.4-I .3)$ & \\
\hline \multirow[t]{2}{*}{ Psychiatric } & No & 290 & $8(I-58)$ & & 204 & I (ref) & \\
\hline & Yes & 19 & $22(2-84)$ & 0.203 & 538 & I.I (0.5-2.3) & \\
\hline \multirow[t]{3}{*}{$\begin{array}{l}\text { Registered family } \\
\text { history of } C R C^{e}\end{array}$} & $\begin{array}{l}\text { Not } \\
\text { registered }\end{array}$ & 267 & II (I-65) & & 233 & I (ref) & \\
\hline & Negative & 30 & $I(1-13)$ & & 87 & $0.5(0.2-1.3)$ & \\
\hline & Positive & 12 & $2(1-34)$ & 0.003 & 87 & $0.3(0.1-2.0)$ & \\
\hline \multirow{3}{*}{$\begin{array}{l}\text { Consultation } \\
\text { frequency for year } \\
\text { prior to CRC first } \\
\text { consultation }\end{array}$} & $\leq 2$ & 56 & $2(I-29)$ & & 117 & I (ref) & \\
\hline & $3-11$ & 188 & II (I-64) & & 235 & $1.4(0.8-2.5)$ & \\
\hline & $\geq 12$ & 65 & $12(1-54)$ & 0.093 & 120 & I.2 (0.6-2.3) & \\
\hline
\end{tabular}

\section{Determinants of long duration}

In univariable log-binomial analysis the following characteristics (Table 2) were significantly associated with long duration primary care intervals (75th percentile, $\geq 59$ days): female sex, a history of malignancy, presentation with nonalarming gastrointestinal symptoms, and presence of hemorrhoids. Multivariable analyses showed a statistically significant association with long duration primary care interval for presentation with nonalarming gastrointestinal symptoms. 
Table 2. Continued.

\begin{tabular}{|c|c|c|c|c|c|c|c|}
\hline Characteristic & & No. & $\begin{array}{l}\text { Median } \\
\text { duration } \\
\text { days (IQR) }\end{array}$ & $\begin{array}{l}\mathbf{P} \\
\text { value }^{\mathrm{a}}\end{array}$ & $\mathrm{P}^{\mathrm{b}} \mathrm{b}$ & $\begin{array}{l}\text { Uni- } \\
\text { variable } \\
\text { RR } \\
(95 \% \mathrm{Cl})\end{array}$ & $\begin{array}{l}\text { Multi- } \\
\text { variable } \\
\text { RR } \\
(95 \% \mathrm{CI})\end{array}$ \\
\hline \multirow{2}{*}{$\begin{array}{l}\text { History of } \\
\text { malignancy }\end{array}$} & No & 267 & $7(1-50)$ & & 219 & I (ref) & I (ref) \\
\hline & Yes & 42 & $18(2-84)$ & 0.101 & 178 & $1.7(1.1-2.6)$ & $1.5(0.9-2.2)$ \\
\hline \multirow[t]{3}{*}{$\begin{array}{l}\text { Main registered } \\
\text { symptom at first } \\
\text { CRC consultation }\end{array}$} & $\begin{array}{l}\text { Alarm } \\
\text { symptom(s) }\end{array}$ & 168 & $2(I-28)$ & & 123 & I (ref) & I (ref) \\
\hline & $\begin{array}{l}\text { Gl } \\
\text { symptom(s) }\end{array}$ & 113 & $26(5-87)$ & & 257 & $1.9(1.2-2.8)$ & $1.7(1.1-2.6)$ \\
\hline & $\begin{array}{l}\text { Other } \\
\text { symptom(s) }\end{array}$ & 28 & $13(2-43)$ & 0.000 & 273 & $0.9(0.4-2.2)$ & $0.9(0.4-2.1)$ \\
\hline \multirow{2}{*}{$\begin{array}{l}\text { Haemorrhoids } \\
\text { at physical } \\
\text { examinationg }\end{array}$} & No & 298 & $8(1-54)$ & & 219 & I (ref) & \\
\hline & Yes & 11 & $69(1-115)$ & 0.192 & 213 & $2.3(1.3-4.1)$ & \\
\hline \multirow{6}{*}{$\begin{array}{l}\text { TNM stage at } \\
\text { diagnosis }\end{array}$} & 0 & 1 & 87 & & - & - & \\
\hline & I & 41 & $2(I-42)$ & & 83 & I (ref) & \\
\hline & II & 83 & $7(1-48)$ & & 213 & I.I (0.5-2.3) & \\
\hline & III & 114 & $7(1-48)$ & & 159 & I.I (0.5-2.2) & \\
\hline & IV & 65 & $23(3-92)$ & & 502 & $1.9(0.9-3.8)$ & \\
\hline & Unknown & 5 & $5(I-246)$ & 0.013 & - & - & \\
\hline
\end{tabular}

$\mathrm{CRC}=$ colorectal cancer; $\mathrm{GI}$ = gastrointestinal; $\mathrm{GP}$ = general practitioner; $\mathrm{IPC}$ = primary care interval; $\mathrm{IQR}=$ interquartile range; $P 75=75$ th percentile value of the duration distribution; $P 90=90$ th percentile value of the duration distribution; $\mathrm{RR}$ = relative risk; $\mathrm{SES}$ = socioeconomic status score; TNM = tumor, nodes, metastases.

${ }^{\text {a }} \mathrm{P}$ values based on Mann-Whitney $\mathrm{U}$ tests for variables with 2 categories and Kruskall-Wallis tests for variables with 3 or more categories.

${ }^{\mathrm{b}} \mathrm{P} 90$ value $=90$ th percentile value of the duration distribution; that is the IPC duration time in days where $90 \%$ of the population was below and $10 \%$ above.

c Socioeconomic status scores 2010 were retrieved from publicly available data from the Netherlands Institute for Social Research.16 Lowest SES score was defined as: SES score of <I SD than the Dutch mean of 2010, Mediumlow: I SD to mean SES score, Medium-high: mean SES score to +I SD and Highest: > + I SD higher than Dutch mean.

${ }^{d}$ Chronic somatic comorbidities were defined according to O'Halloran et al. 17 Gastrointestinal comorbidities were all relevant Gl-related registered comorbidities or conditions in either episode list or mentioned during GP consultations: irritable bowel syndrome, reflux disease, esophagitis, dyspepsia, abdominal pain, peptic ulcer, hiatus or abdominal hernia, benign GI neoplasms/polyps, constipation, chronic diarrhea, cholelithiasis, diverticulosis, anal fissures. Psychiatric comorbidities were all chronic psychiatric comorbidities according to O'Halloran et al. I7

${ }^{\text {e }}$ Registered occurrence of colorectal cancer in a first degree family member.

${ }^{f}$ Alarm symptoms for colorectal cancer were defined as rectal blood loss, unintended weight loss, anemia, and a palpable tumor. Gl symptoms include all Gl-related, nonalarming symptoms. Other symptoms are all remaining, nonalarming, non-Gl symptoms.

g Multivariable model excludes this factor due to low patient numbers.

\section{Thematic analysis of longest duration}

The longest duration of primary care intervals (90th percentile, $\geq 219$ days) was seen in 3 I patients, with durations up to I,I 177 days. The majority of these patients were female 
( $n=22,71 \%$ ) as opposed to $47.5 \%$ female patients with a duration less than 219 days (Chi-2 test $P=.013)$. Mean age was 60.4 years (standard deviation $=15.5$ ) compared with patients aged 67.4 years (standard deviation $=11.6$ ) for those with a duration less than 219 days ( $t$-test $P=.020)$. Of these patients, $71 \%$ were diagnosed with stage III or IV colorectal cancer, compared with $57 \%$ of patients with a duration less than 219 days (Chi-2 test $P=.121$ ). The number of cancer-related consultations during the primary care interval for these patients ranged from 2 to 25 . All factors associated with longest duration primary care interval are shown in Figure 2.

The reasons for longest duration intervals were generally multifactorial. Several themes were related to postponed referral, but the dominant theme was "having an alternative working diagnosis," with a leading subtheme "the presence of an explanatory concomitant condition." The second main theme was "suboptimal diagnostic strategies," with subthemes "omitting to reconsider an initial diagnosis" and "lacking follow-up."

In all 3 I patients the GP had "an alternative working diagnosis" that was not colorectal cancer.The factor most often explaining the occurrence of an alternative working diagnosis was subtheme "presence of an explanatory concomitant condition," either preexisting or detected during consultation. Conditions included hemorrhoids or fissures in cases of rectal blood loss; hypermenorrhagia in cases of anemia; and inflammatory bowel disease, poorly regulated hypothyroidism, psychological conditions or stress, alcohol or drug abuse, in cases of several other cancer-related complaints. Other subthemes causing the GP to stick to the original hypothesis were: "good symptomatic response to initial therapy," such as laxatives for constipation, antacids for gastric complaints, and mesalazine for inflammatory bowel disease, and "misleading results from additional testing," including negative gastroscopy or ultrasound, identification of a pathogen in stool culture, absence of anemia or inflammatory markers in blood test results, and "intermittent character of the complaints."

Second, GPs and/or patients sometimes followed "suboptimal diagnostic strategies." This included "inadequate follow up," including later consultations postponed by patients without clear reason and patients initially unwilling to undergo further investigation. The second subtheme that could be derived was "the GP omitting to reconsider the initial diagnosis." That is, the GP did no further investigating anemia or rectal blood loss, even after the initial explanatory cause had resolved. 
Suboptimal diagnostic strategies

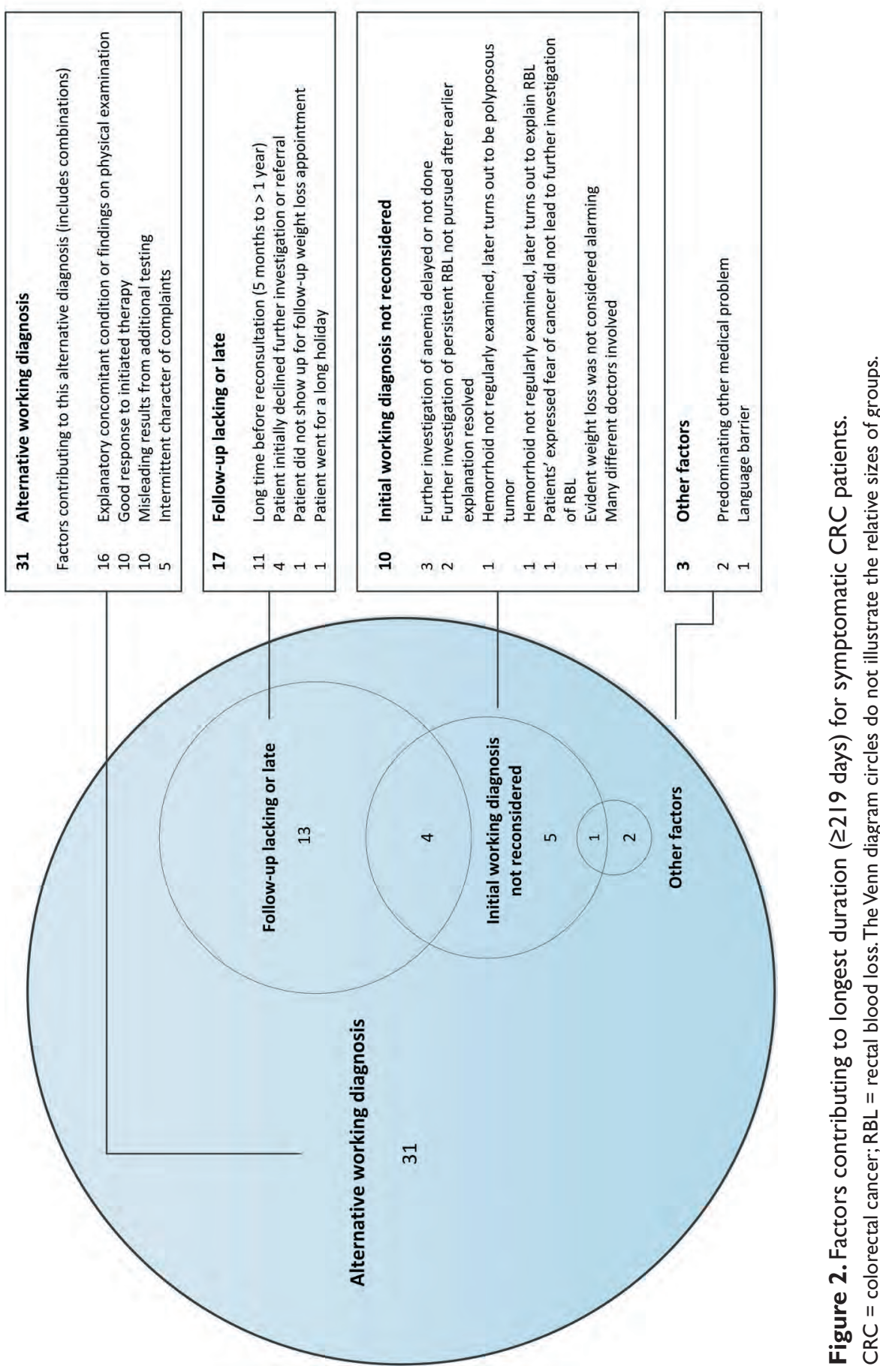




\section{DISCUSSION}

\section{Summary}

Symptomatic colorectal cancer patients presenting to primary care were at risk for longer time to referral if they had patient and presentation characteristics that lowered cancer suspicion. Included (by univariable analysis) were patients who were female, did not have a registered family history, did not have alarm symptoms, had a history of malignancy, and had hemorrhoids at physical examination. Thematic exploration of the diagnostic routes to referral of patients with longest durations (90th percentile) showed 2 dominating themes: "alternative working diagnosis" and "suboptimal diagnostic strategies," including subthemes "omitting to reconsider an initial diagnosis" and "lack-ing follow-up." Those with the longest durations were younger and more often women.

\section{Strengths and limitations}

Both strengths and limitations of the use of the JGPN routine primary care data have been discussed elsewhere. ${ }^{7}$ In short, the availability of free-text GP notes from consecutive primary care consultations is a strength for this study, as the data provide a detailed representation of primary care proceedings, GP considerations, and contextual factors. Even though the labor intensive, manual exploration of routine care data provides reliable and rich data, it also restricts potential sample sizes and therefore the strength of inferences.

Limitations also include the need for interpretation and potential incompleteness of routine care data. The main challenge is to retrospectively identify the first consultation with cancer-related complaints, particularly in patients with less specific symptom presentations. The risk of misattribution of symptoms to cancer was minimized in our study by discussing doubtful cases with a team of researchers with primary care experience.

Nevertheless, consequential over- or underestimation of time to referral may have occurred. Furthermore, for 10\% of the initially selected patients with validated CRC diagnosis, the diagnostic path was too unclear to determine eligibility and/or date of first presentation. Lack of clarity about the diagnostic path is most likely due to incomplete GP registrations or initial presentation to secondary care providers. Since cancer patients symptomatically presenting to primary care (our population of interest) are unlikely to be subject to incomplete GP registration, we expect that for the great majority of patients with unclear diagnostic paths, secondary care presentations are the most plausible explanation. A final limitation may be that, when focusing on delay in the diagnostic path 
of $\mathrm{CRC}$, including only the primary care interval provides an incomplete scope.7 There may already be delay before presentation at the GP, as well as delay after referral to secondary care. Patient, population, specialist, and system causes may all contribute to delay in the pre- and post-primary care intervals.

\section{Comparison with existing literature}

The increased primary care intervals for patients aged under 50 years and female patients are consistent with international literature. 910 This is probably related to the fact that colorectal cancer occurs more often in older age groups and male patients. ${ }^{19}$ Pain and bleeding are associated with prompt referral according to the literature. ${ }^{18}$ Bleeding aligns with our finding that patients with alarm symptoms, although not assessed for different alarm symptoms separately, had shorter primary care intervals, and patients with less specific gastrointestinal complaints had higher risk of delayed referral.

In our earlier study, psychiatric comorbidity was found to be associated with GP delay. ${ }^{13}$ Although the univariable association of psychiatric comorbidity with long duration (75th percentile) primary care intervals in this study did not reach statistical significance, the median primary care interval was 2 weeks longer for patients with psychiatric comorbidity. One explanation for this association is that comorbid conditions compete for clinical attention and may provide alternative explanations for cancer-related symptoms. ${ }^{12}$ This was also reflected by the longer median durations we found for patients with gastrointestinal comorbidity.

Consistent with the alternative explanation argument, we found that the patients with hemorrhoids had substantially longer median times to referral and long duration in the univariable analysis. Comparably, the broader concept of "initial misdiagnosis" was associated with practitioner delay in over $75 \%$ of earlier studies that assessed this factor. "Having an alternative diagnosis" was also the main factor contributing to longest durations (90th percentile) in the thematic analysis in the present study.

Our thematic analysis, based on extensive free-text inquiry, adds to the previous knowledge that reasons for substantial delay are often multifactorial. We identified "suboptimal diagnostic strategies" as the second main theme, with subthemes "omitting to reconsider an initial diagnosis" and "lacking follow-up." These latter 2 subthemes leave room for improvement in the diagnostic process in primary care by preventing unnecessary delay.

The extent to which reduction of the primary care interval duration could contribute to improved clinical outcomes is uncertain. A recent study by Tørring et al underlined 
the complexity of this association. Longer primary care intervals appeared to increase the odds of advanced CRC, but with even longer intervals the odds decreased again. ${ }^{4}$ We found longer primary care intervals for patients with stage IV disease. Even though the causal pathway of this finding deserves further exploration, it supports the findings of Tørring et al, and supports the evidence for potential gain from reducing the time to referral in primary care.

\section{Implications for research and practice}

A relatively long time to, and sometimes delayed, referral in primary care was mainly seen in patients in whom cancer suspicion was lower, due to I or more factors that contributed to a lower risk profile. This can be considered a direct reflection of a well-functioning primary care system, in which both progress and predictive values of symptoms are used as a diagnostic tool.

We also found that there is potential for reducing time to referral for CRC patients presenting in primary care.Acting upon this potential could reduce delay and potentially improve outcomes for those with the longest durations. This could first be achieved by adequate reinvestigation of recurrent potential cancer-related symptoms or signs, particularly if the alternative explanation becomes less plausible. Also evidence of suboptimal diagnostic follow-up, (eg, not safeguarding follow-up consultations or not reconsidering a hemorrhoid diagnosis in case of persistent rectal blood loss), imply there is room for improvement by enhancing patient compliance and GP proactivity. Our findings also demonstrate the challenges of timely diagnosis of CRC in primary care. It is obvious that high risk symptoms (ie, those with high positive predictive value) such as rectal blood loss and anemia warrant further investigation and that GPs act on those. Less obvious is the outcome of the debate about whether ruling out CRC in every patient with non-red flag symptoms would lead to better patient outcomes. The delicate balance between not wanting to miss cancer and preventing unnecessary referrals and the corresponding burden for patients and health care systems is subject to preference and may differ between patients, cultures, and time periods.

Improving identification and referral of CRC patients for those initially presenting with low risk but not no risk symptoms requires innovations in the GP's diagnostic toolbox. Recent research demonstrates that diagnostic tests, such as the fecal immunochemical test for hemoglobin and the calprotectin point-of-care test, may support the diagnostic process of the GP in lower abdominal complaints..$^{20}$ The effectiveness of these and other tests in actual primary care practice, however, needs to be confirmed. 


\section{Acknowledgements}

The authors thank all clinical researchers involved in the data collection. We thank the registration team of the Netherlands Comprehensive Cancer Organisation (IKNL) for the collection of data for the Netherlands Cancer Registry as well as IKNL staff for scientific advice. We thank the GPs in the Utrecht area participating in the Julius General Practitioners' Network for sharing their anonymized electronic health record data and Julia Velikopolskaia and Nicole Boekema of the JGPN for their assistance in extracting data and the linkage procedures. 


\section{REFERENCES}

I. Ferlay J, Steliarova-Foucher E, Lortet-Tieulent J, Rosso S, Coebergh JWW, Comber H, et al. Cancer incidence and mortality patterns in Europe: Estimates for 40 countries in 2012. Eur J Cancer 2013;49:1374-1403.

2. Data from the Netherlands Cancer Registry, managed by The Netherlands Comprehensive Cancer Organisation [Internet].Available from: http://www.cijfersoverkanker.nl.Accessed March 23, 2017.

3. Maringe C, Walters S, Rachet B, Butler J, Fields T, Finan P, et al. Stage at diagnosis and colorectal cancer survival in six high-income countries: a population-based study of patients diagnosed during 2000-2007. Acta Oncol 2013;52:919-932.

4. Tørring ML, Murchie P, Hamilton W,Vedsted P, Esteva M, Lautrup M, et al. Evidence of advanced stage colorectal cancer with longer diagnostic intervals: a pooled analysis of seven primary care cohorts comprising II 720 patients in five countries. Br J Cancer 2017:1-10.

5. De Angelis R, Sant M, Coleman MP, Francisci S, Baili P, Pierannunzio D, et al. Cancer survival in Europe 1999-2007 by country and age: results of EUROCARE-5-a population-based study. Lancet Oncol 2013;2045:1-12.

6. Navarro M, Nicolas A, Ferrandez A, Lanas A. Colorectal cancer population screening programs worldwide in 2016:An update. World J Gastroenterol 2017;23:3632-3642.

7. Helsper C, van Erp N, Peeters P, de Wit N. Original Research:Time to diagnosis and treatment for cancer patients in the Netherlands: room for improvement? Eur J Cancer 2017;87:1 13-121.

8. Rubin GP, Saunders CL, Abel G a., Mcphail S, Lyratzopoulos G, Neal RD. Impact of investigations in general practice on timeliness of referral for patients subsequently diagnosed with cancer: Analysis of national primary care audit data. Br J Cancer 2015; I 12:676-687.

9. Mitchell E, Macdonald S, Campbell NC, Weller D, Macleod U. Influences on pre-hospital delay in the diagnosis of colorectal cancer:A systematic review. Br J Cancer 2008;98:60-70.

10. Din NU, Ukoumunne OC, Rubin G, Hamilton W, Carter B, Stapley S, et al. Age and Gender Variations in Cancer Diagnostic Intervals in 15 Cancers:Analysis of Data from the UK Clinical Practice Research Datalink. PLoS One 2015;10:e0127717.

II. Brandenbarg D, Groenhof F, Siewers IM, Voort A Van Der, Walter FM. Possible missed opportunities for diagnosing colorectal cancer in Dutch primary care: a multimethods approach. BrJ Gen Pract 2018;68:e54-e62.

12. Mounce LT a, Price S, Valderas JM, Hamilton W. Comorbid conditions delay diagnosis of colorectal cancer: a cohort study using electronic primary care records. Br J Cancer 20 17; I 16:1536-1543.

13. Van Hout AMGH, de Wit NJ, Rutten FH, Peeters PHM. Determinants of patient's and doctor's delay in diagnosis and treatment of colorectal cancer. Eur J Gastroenterol Hepatol 20 I I;23: 10561063.

14. Smeets HM, Kortekaas MF, Rutten FH, Bots ML, Kraan WVan Der, Daggelders G, et al. Routine primary care data for scientific research, quality of care programs and educational purposes: the Julius General Practitioners' Network (JGPN). BMC Health Serv Res 20।8; 18:735. 
15. Weller D, Vedsted P, Rubin G, Walter FM, Emery J, Scott S, et al. The Aarhus statement: improving design and reporting of studies on early cancer diagnosis. Br J Cancer 2012;106:1262-1267.

16. The Netherlands Institute of Social Research. https: //www.scp.nl/ Onderzoek/Lopend_ onderzoek/A_Z_alle_lopende_onderzoeken/Statusscores. Accessed Jun 10, 2015.

17. O'Halloran J, Miller GC, Britt H. Defining chronic conditions for primary care with ICPC-2. Fam Pract 2004;21:38I-386.

18. Macleod U, Mitchell ED, Burgess C, Macdonald S, Ramirez AJ. Risk factors for delayed presentation and referral of symptomatic cancer: evidence for common cancers. Br J Cancer 2009; I0I:S92-SI0I.

19. Hamilton W.The CAPER studies: five case-control studies aimed at identifying and quantifying the risk of cancer in symptomatic primary care patients. Br J Cancer 2009; 101:S80-S86.

20. Elias SG, Kok L, de Wit NJ, et al. Is there an added value of faecal calprotectin and haemoglobin in the diagnostic work-up for primary care patients suspected of significant colorectal disease? A crosssectional diagnostic study. BMC Med 2016;14:141. 


\section{APPENDIX I}

Characteristics and methods of collection.

\begin{tabular}{ll}
\hline Characteristic & Data collection \\
\hline Age at first consultation & Age was calculated based on birthyear as registered in the JGPN data. For all
\end{tabular}

Age at first consultation Age was calculated based on birthyear as registered in the JGPN data. For all patients, July first was set as their birthdate as only year of birth was available for analysis. Age at first consultation was then calculated.Age was categorized as a non-linear association with duration of the primary care interval was expected.

Sex Sex was extracted from the JGPN data, in which this is registered.

Socio-economic status SES was retrieved from publicly available data from the Netherlands Institute score 2010 for Social Research, ${ }^{16}$ in which status scores are available according to postal code and based on level of education, income and job status. The scores of 2010 were used. Lowest SES score was defined as: SES score of < - I SD than the Dutch mean of 2010, Medium-low SES score: - I SD to mean SES score, Medium-high SES score: mean SES score to +I SD and Highest SES score: $>+1$ SD higher than Dutch mean.

Registered Comorbidity Episode lists in the EHRs were used to determine existence of (chronic) comorbidities. To decide on relevance and chronicity of registered episodes, the list of chronic comorbidities in primary care as provided by O'Halloran et al. ${ }^{17}$ was used as guidance. In this list included ICPC-codes starting with a "P" were regarded as relevant psychiatric comorbidities. Gastro intestinal comorbidities were all relevant GI related registered comorbidities or conditions: irritable bowel syndrome, reflux disease, oesophagitis, dyspepsia, abdominal pain, peptic ulcer, hiatus or abdominal hernia, benign Gl neoplasms/ polyps, constipation, chronic diarrhoea, cholelithiasis, diverticulosis and anal fissures.

Registered family history Information on family history of colorectal cancer was retrieved from the free of CRC text consultation registries in the EHRs from the JGPN database.

Consultation frequency We used the consultation frequency in the year preceding first consultation as in the year preceding first a measure of how frequent a patients generally visits the general practitioner, consultation in other words to identify 'frequent visitors'. Number of GP consultations in the year before the first cancer related consultation was determined by counting all registered physical or phone contacts with the practice, except for repeated prescriptions and registered correspondence with secondary care. Missing consultation registries in patients newly presenting to a GP shortly before first cancer related consultation $(n=I)$ were considered random, and therefore imputed using single imputation based on age, socio-economic status score and number of chronic comorbidities.

History of malignancy Presence of a history of malignancy was retrieved from NCR data, in which number of preceding malignancies is available

Main registered symptom Information on symptoms at first consultation was retrieved from the free text at first consultation consultation registries in the EHRs from the JGPN database. We considered rectal blood loss (all reporting of rectal blood loss, including blood on toilet paper after wiping), anaemia (based on laboratory test results), unintended weight loss (as reported by the patient) and the presence of a palpable tumour as alarm symptoms for colorectal cancer. Changes in bowel habit are often considered alarming, but as data on defaecation pattern in primary care registries usually only indicate status and not change, we decided not to include this alarm symptom. Gl symptoms include all GI related, non-alarming symptoms (e.g. abdominal pain, nausea, constipation etc). Other symptoms are all remaining, non-alarming, non-Gl symptoms.

Haemorrhoids at physical Presence of haemorrhoids was based on the findings at physical examination as examination performed and reported by the GP.

TNM tumour stage at TNM tumour stage at diagnosis was extracted from the NCR database. diagnosis 


\section{APPENDIX 2}

\section{Thematic analyses for "longest duration" ( $\geq$ P90)}

"Longest duration" was defined as duration equal or longer than the 90th percentile value of IPC duration ( $\geq 219$ days). Mechanisms leading to times to referral of over the P90 value were extracted from the free text registrations of all consultations preceding referral, which were analysed as a transcribed verbatim of the diagnostic route to referral and the deliberations made by the GP.To analyse these data we performed open coding, axial coding and selective coding. Open coding, aimed to identify factors contributing to longest duration, was performed separately by two researchers ( $\mathrm{NvE}, \mathrm{SO})$ and discussed in the research team in case of any doubt ( $\mathrm{NvE}, \mathrm{SO}, \mathrm{CH}$ ). Axial coding was performed after collection of open codes ascribed to delaying factors to define categories. Finally, selective coding was used to redefine, integrate and connect the categories to reveal underlying relationships between codes and to establish the final themes. Axial and selective coding was performed together by two researchers $(\mathrm{NvE}, \mathrm{CH})$. Disagreement in any of the coding stages was reconciled in research team discussions. 


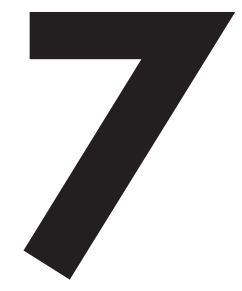

\title{
Reasons for long time to referral for nine cancer types: a thematic analysis
}

\author{
Nicole F. van Erp \\ Charles W.Helsper \\ Liedeke J. van der Meiden-van Roest \\ Kristel M. van Asselt \\ Jean W.M. Muris \\ Marlous F. Kortekaas \\ Alfred P.E. Sachs \\ Daan Brandenbarg \\ Pauline Slottje \\ Frederike L. Büchner \\ Petra H.M. Peeters \\ Niek J. de Wit
}




\section{ABSTRACT}

Background: Referral from primary care to specialized care takes remarkably long for a small proportion of symptomatic cancer patients. We assessed reasons for such long durations.

Methods: For symptomatic patients with nine types of cancer (diagnosed 2010-2015), reasons for longest duration to referral ( $\geq 90$ th percentile value of duration) were assessed by thematic free text analyses of pseudonymized routine primary care data. Per case, two researchers independently attributed themes associated with long time to referral.

Results: Cancer patients with longest durations to referral $(n=203)$ more often were women and were relatively young. Ten contributing themes were identified. Theme attribution varied largely between the two researchers, with complete overlap of themes for 27 cases (13\%), partial overlap for 136 cases (67\%) and no overlap for 40 cases (20\%). For seven of the nine cancer types, the main attributed theme was "initially no alarm symptoms or non-specific presentation". Two themes provide room for improvement: "missed opportunity GP” and "long time to reconsultation".

Conclusion: Cancer patients with longest time-intervals to referral from primary care are often those for whom cancer suspicion is relatively low. Most identified themes underline the diagnostic challenges faced by GPs. Increased adherence to guidelines for diagnostic work-up and improved safety netting may partially prevent long durations. 


\section{INTRODUCTION}

As prognosis of cancer is highly dependent on disease stage at diagnosis, timely detection of cancer is widely pursued.' For several cancer types, it has been shown that longer diagnostic interval durations are associated with more advanced disease stage at diagnosis, worse prognosis and worse patient experiences. ${ }^{2-6}$

As most cancer patients initially present with symptoms in primary care, the general practitioner (GP) has an important role in early cancer detection. This is especially the case in healthcare systems where the GP acts as a gatekeeper to secondary care, such as the UK, Scandinavian countries and the Netherlands. Earlier we reported that the median duration of the primary care interval, from initial presentation with cancer related symptoms to referral to secondary care, is relatively short for most cancer patients. ${ }^{7,8}$ However, substantially long durations to referral were seen for $10-25 \%$ of the cancer patients.

Multiple factors are associated with (long) duration of the primary care interval for different cancer types, including patient characteristics such as age, gender, ethnicity, clinical presentation and disease characteristics. ${ }^{8-10}$ In addition, delay may be related to factors such as missed diagnostic opportunities and inadequate doctor-patient communication. 11,12 Reasons for long duration are likely to be complex and multifactorial, but detailed knowledge about the background of delay is lacking. As current evidence on interventions to reduce primary care delay in cancer diagnosis is limited, better understanding of reasons for substantially long durations in primary care is needed. ${ }^{13}$ Individual case analysis of patients with longest durations could uncover avoidable delays and provide targeted leads for reduction of time spent in primary care.

The aim of this study is to thematically assess the background of patients with the longest duration to referral from primary care to secondary care for nine types of cancer. 


\section{METHODS}

\section{Study design and data source}

This study is part of the DICKENS project. ${ }^{7}$ We retrospectively analyzed a cohort of cancer cases (retrospective cohort study) to quantitatively and qualitatively explore their diagnostic pathways. We used pseudonymized routine primary care data of six academic primary care networks (General Appendix A). These databases contain coded and free-text information from electronic health records (EHRs) of over 640,000 patients from different regions of the Netherlands. Free texts consist of descriptions (clinical notes) of consultations in general practice, i.e. presented complaints, results of physical examination, clinical reasoning of the general practitioner (GP) and management plan. These data are registered as part of routine daily clinical practice.

\section{Case selection}

Adult patients (aged $\geq 18$ years) registered with an ICPC-I (International Classification of Primary Care) ${ }^{14}$ code for at least one of nine cancer types during the following two time periods were selected from the primary care databases.

For those diagnosed between 2012 to 20I5, with the cancer types 'malignant neoplasm of breast' (X76), 'malignant neoplasm of lung' (R84), 'malignant neoplasm of colon/rectum' (D75) and 'malignant melanoma' (S77.03), data were collected from two databases (JGPN and $\mathrm{ANH}$ VUmc). For those diagnosed between 2010-2015 with a more rare cancer type, 'malignant neoplasm of oesophagus' (D77.0I), 'malignant neoplasm of stomach' (D74) 'malignant neoplasm of kidney'(U75),'malignant neoplasm of bladder'(U76) and 'malignant neoplasm of ovary'(X77.02), data were collected from all six databases. The cancer types were chosen based on incidence rates and the unfavorable balance between disease stage at detection and stage related survival.'

Free text elements of the EHR were thoroughly assessed to confirm the cancer diagnosis, based on summaries of correspondence from secondary care and other descriptions indicating cancer presence. Only those patients with a confirmed cancer diagnosis were included. Next, only those patients who presented to the GP with symptoms and were referred by the GP for diagnostic workup in secondary care were selected. Patients with melanoma for whom the GP performed the diagnostic excision were excluded from this analysis, as they had a different diagnostic pathway with a diagnosis before referral. Figure I shows used databases, time-periods, numbers of eligible patients, and reasons for exclusion. 


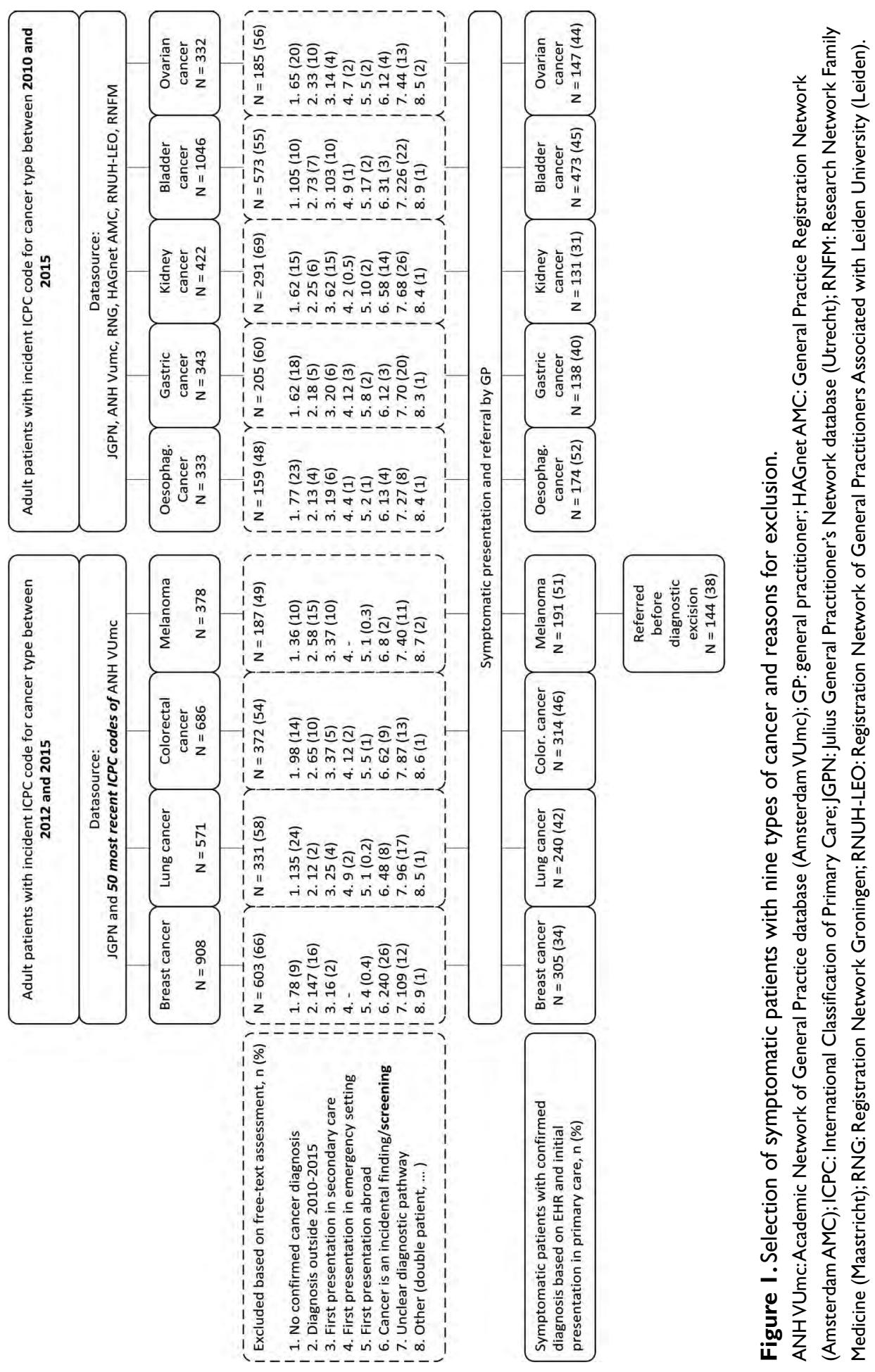




\section{Data collection}

Primary care EHRs from up to 5 years before the date of entry of the ICPC code for cancer up to I year after, were scrutinized manually by medically trained researchers to assess the duration of the primary care interval (IPC) and to collect patient and presentation characteristics.

Based on the Aarhus statement for improving reporting of studies on early cancer diagnosis, ${ }^{15}$ IPC was defined as duration from first consultation with cancer related signs and/or symptoms in primary care to referral to secondary care.

Date of first consultation was defined as the first presentation to the GP with signs or symptoms related to the later cancer diagnosis. In case of vague or non-specific signs or symptoms, the first consultation with the complaints that eventually led to the cancer diagnosis, and could reasonably be related to the cancer was taken. The risk of misattribution of symptoms was minimized by discussing doubtful cases in our team of researchers with primary care experience. Date of referral was defined as the moment the responsibility for the patient was transferred from primary to secondary care, as registered in the EHR. Referral to the radiology department for imaging requested by the GP was considered as referral, if abnormal findings subsequently resulted in referral to a specialist, without further interference of the GP. In case of multiple referrals to, or cross-referrals in secondary care, the first referral for further exploration of cancer related symptoms was taken.

Relevant patient and presentation characteristics were collected. Presenting symptoms and signs were categorized as cancer specific alarm symptoms, cancer general alarm symptoms and non-alarming symptoms. Definitions of these symptom categories for the different cancer types are shown in Appendix I.

\section{Analyses}

Primary care interval duration

Duration of the primary care interval was calculated in days. One day was consistently added to this duration, as same day proceedings were considered as a duration of one day. For oesophageal, gastric, kidney, bladder and ovarian cancer, duration of the primary care interval was reported before. "Longest duration" was defined as duration equal to or longer than the 90 th percentile value of IPC duration, resulting in different corresponding cut-off values in days for the different cancer types. Patients with durations equal to or longer than this 90 th percentile value of IPC duration were included in our thematic analysis. 


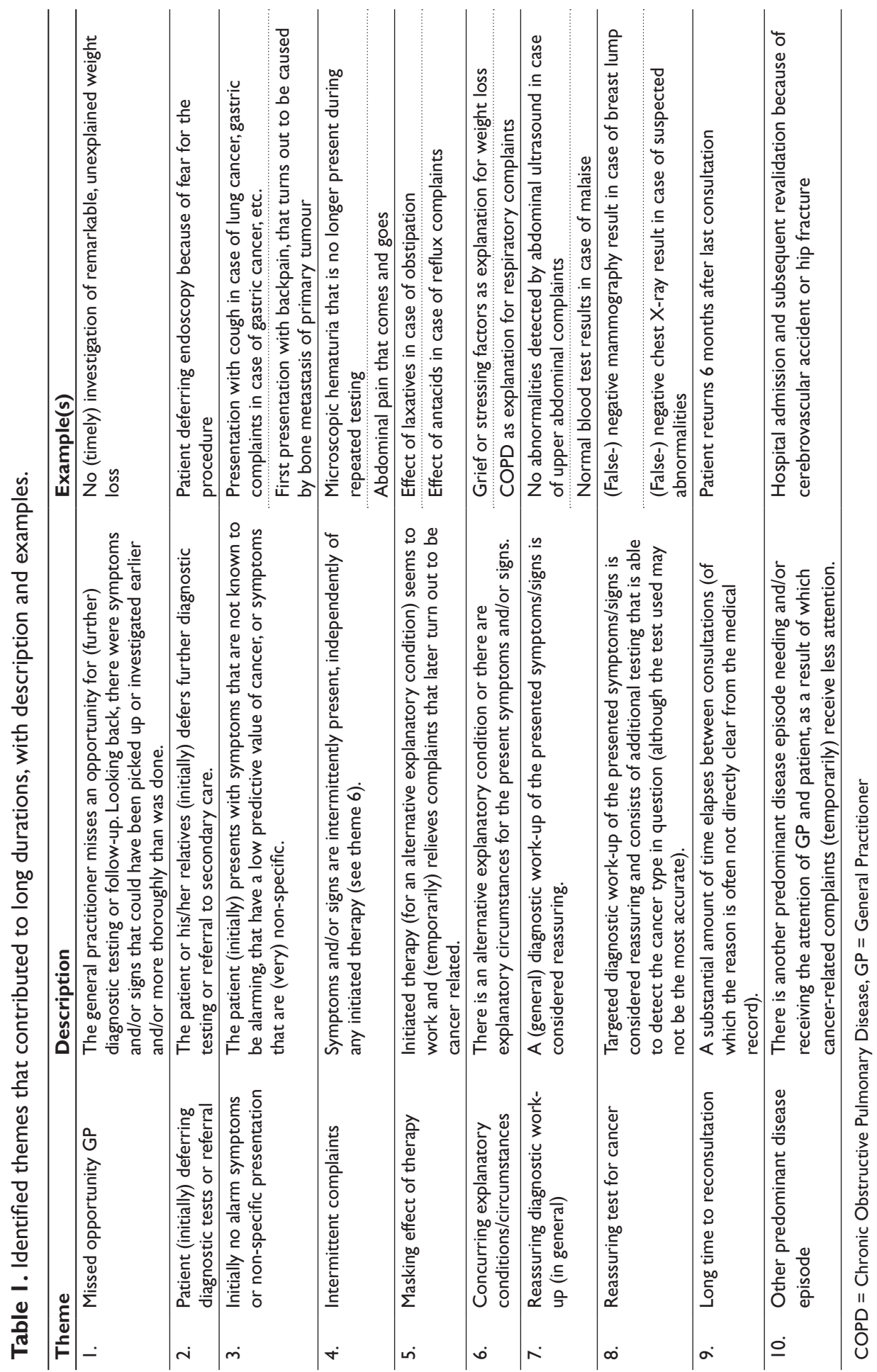




\section{Thematic analyses of "longest duration" ( $\geq$ P90)}

\section{I) Theme identification}

Free text registries of those patients with longest durations $(\geq \mathrm{P} 90)$ were scrutinized and used to explore the proceedings from initial presentation to referral and the deliberations made by the GP. Next, open coding, axial coding and selective coding were consecutively performed. Open coding was performed to identify all factors potentially contributing to longest duration ( $\mathrm{NvE}$, LvR). Axial coding was performed after collection of open codes to define categories $(\mathrm{NvE}, \mathrm{CH})$. Finally, selective coding was used to redefine, integrate and connect the categories to reveal underlying relationships between codes and to establish final themes ( $\mathrm{NvE}, \mathrm{CH})$.

The ten final themes were: "missed opportunity GP", "patient (initially) deferring diagnostic tests or referral", "initially no alarm symptoms or non-specific presentation", "intermittent complaints", "masking effect of therapy", "concurring explanatory conditions/circumstances", "reassuring diagnostic work-up (in general)", "reassuring test for cancer", "long time to reconsultation" and "other predominant disease episode". These themes are explained more elaborately in Table I.

\section{2) Theme attribution}

In the next step, the ten identified themes were attributed to cases with longest duration to referral ( $\geq \mathrm{P} 90$ ). Attribution of themes was performed independently by two clinical researchers for all patients (NvE for all cases, with another clinical researcher as second reviewer). Themes were not mutually exclusive: per case multiple themes could be attributed.

Allocated themes of both assessors were taken into account, we did not aim for agreement between the two assessors. Per cancer type, we determined the 'weight' (prominence) of each theme that was attributed to long duration. To obtain this weight, the number of times a theme was attributed to cases with longest duration by two researchers was divided by the number of patients multiplied by two (the maximum number of times that a theme could be attributed by two researchers). This weight was expressed as a percentage ranging from $0 \%$ to $100 \%$ (reflecting never and always attributed, of all opportunities to attribute the theme).

\section{Software}

Data transformation and analyses were performed in SPSS version 22.0 (SPSS Inc., Chicago, IL, USA) and Microsoft Excel. 


\section{RESULTS}

Based on ICPC code (cancer diagnosis), subsequent internal confirmation of the diagnosis, and inclusion criteria, we extracted 305 eligible, symptomatic patients with breast cancer, 240 with lung cancer, 314 with colorectal cancer, I44 with melanoma, I 74 with oesophageal cancer, I 38 with gastric cancer, I3I with kidney cancer, 474 with bladder cancer and 147 with ovarian cancer. Reasons for exclusion are shown in Figure I.

\section{Primary care interval duration}

The duration of the primary care interval, 90th percentile value (P90) of duration and the number of patients with a duration equal to or longer than P90 are shown in Table 2. Shortest primary care interval durations were seen for patients with breast cancer and melanoma (median I day, IQI I-I). Longest duration was seen for patients with lung cancer (median I 5 days, IQI 3-47). The distribution of the primary care interval duration per cancer type is shown in Figure 2.Values of the 90th percentile ranged from 16 days for breast cancer to 203 days for gastric cancer. In total, 203 patients with durations equal to or longer than the P90 value of IPC duration were included in the thematic analysis.

Table 2. Duration of the primary care interval per cancer type, $90^{\text {th }}$ percentile value of duration and number of patients with longest durations (duration $\geq \mathrm{P} 90$ ).

\begin{tabular}{|c|c|c|c|c|}
\hline Cancer type & $\begin{array}{l}\text { Number of } \\
\text { symptomatic } \\
\text { patients }\end{array}$ & $\begin{array}{l}\text { IPC duration in } \\
\text { days (Median, } \\
\text { IQI) }\end{array}$ & $\begin{array}{l}90^{\text {th }} \text { percentile } \\
\text { value }(\mathrm{P} 90)\end{array}$ & $\begin{array}{l}\text { No. of patients } \\
\text { with duration } \\
\geq \mathrm{P} 90\end{array}$ \\
\hline \multicolumn{5}{|l|}{$2012-2015$} \\
\hline Breast cancer & 305 & $I(I-I)$ & 17 & 30 \\
\hline Lung cancer & 240 & $15(3-47)$ & 96 & 24 \\
\hline Colorectal cancer & 314 & $5(I-29)$ & 83 & 31 \\
\hline Melanoma* & 144 & $I(I-I)$ & 24 & 14 \\
\hline \multicolumn{5}{|l|}{$2010-2015$} \\
\hline Oesophageal cancer & 174 & $8(I-38)$ & 92 & 17 \\
\hline Gastric cancer & 138 & $\mid 4(|-5|)$ & 203 & 13 \\
\hline Kidney cancer & $|3|$ & $10(1-56)$ & 173 & 13 \\
\hline Bladder cancer & 473 & $10(|-4|)$ & 135 & 47 \\
\hline Ovarian cancer & 147 & $6(I-23)$ & 75 & 14 \\
\hline Total & 2066 & & & 203 \\
\hline
\end{tabular}

$I P C=$ Primary care interval, $\mid \mathrm{Q} I=$ Interquartile interval, $\mathrm{P} 90=90$ th percentile value of the distribution of duration.

*Only patients that were referred by the GP for diagnostic excision in secondary care were included. Patients for whom the GP performed a diagnostic excision were excluded. 


\section{Patient characteristics of those with longest durations}

For each cancer type, characteristics of those with longest duration were compared to all other patients (IPC duration <P90) (Table 3). For breast, gastric, ovarian cancer and melanoma, patients with longest duration were relatively young as compared to those with shorter durations. Among melanoma, gastric cancer and bladder cancer patients with longest durations, the proportion of female patients was higher than among those with shorter durations. For all cancer types, patients with longest durations less often had cancer specific alarm symptoms recorded at first presentation. At the time patients were referred, the proportion of patients with alarm symptoms had increased as compared to the time of first consultation, both among the patients with and without longest durations. For lung cancer, colorectal cancer and ovarian cancer, the proportion of patients with cancer specific alarm symptoms at the time of referral was higher among those patients with longest duration.

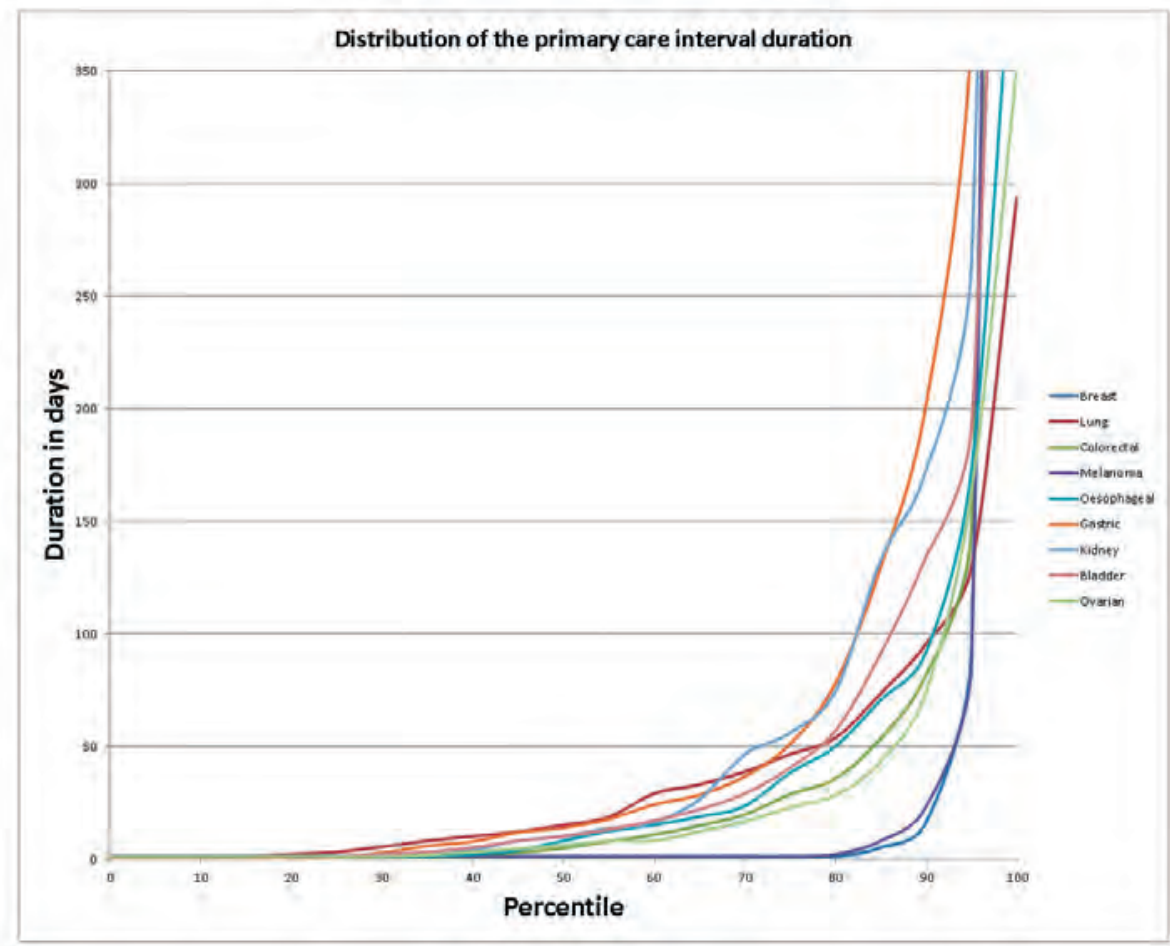

Figure 2. Distribution of the primary care interval duration for the nine studied cancer types. 


\section{Theme attribution}

To the majority of cases with long duration $(n=185,91 \%)$ more than one theme was attributed as a potential explanation for long duration. The mean number of attributed themes per case with long duration ranged from 2.I for breast cancer (SD 0.78) to 4.4 (SD I.3) for lung cancer. The inter-observer variability in theme attribution between the two researchers was substantial. Among all 203 cases with longest duration, for 27 patients (13\%) theme attribution between the two researchers was identical. For 136 patients $(67 \%)$ at least one theme was scored by both researchers, and for 40 patients (20\%) theme distribution did not show any overlap between the two researchers. Figure 3 shows, per cancer type, the weight of the different themes that were attributed to longest duration.

\section{Breast cancer}

For breast cancer patients with longest IPC durations ( $\geq 17$ days), the most frequently attributed theme was "initially no alarm symptoms or non-specific presentation" (weight 35\%), followed by "reassuring test for cancer" (28\%) and "missed opportunity GP” (25\%). Examples of (initial) presentations without alarm symptoms or non-specific presentations were consultations because of painful breasts, hard breast tissue during breast-feeding, hip- and back pain (that later turned out to be caused by bone metastases) and dyspnea. For several patients with palpable or visible breast abnormalities, dditional testing (mammography or ultrasound) initially showed a negative test result. Missed opportunities for the GP included deviations from guideline instructions for imaging and follow-up.

\section{Lung cancer}

Among lung cancer patients with longest IPC durations ( $\geq 96$ days), the most frequently attributed theme was "initially no alarm symptoms or non-specific presentation" (weight $71 \%)$, followed by "long time to reconsultation" (44\%) and "concurring explanatory condition/circumstances" (42\%). Most patients with longest duration presented with cough, for which there often was an explanatory condition such as asthma or COPD. Non-specific presentations included shoulder pain (that turned out to be caused by a Pancoast tumour) and balance disorder (that turned out to be caused by cerebral metastases). Reasons for long(er) times to reconsultation could not be derived from the registries.

\section{Colorectal cancer}

Among colorectal cancer patients with longest IPC duration ( $\geq 83$ days), most frequently attributed themes were "initially no alarm symptoms or non-specific presentation" 
(weight 50\%), "missed opportunity GP” (37\%) and "long time to reconsultation" (35\%). Non-alarming symptoms mostly included abdominal complaints, malaise and fatigue. Missed opportunities for GPs included no diagnostic work up of severe anemia and weight loss and inadequate follow-up of altered defecation pattern (after negative fecal occult blood test), all of which can be considered as guideline deviation.

\section{Melanoma}

Most frequently attributed themes for long IPC duration ( $\geq 24$ days) among melanoma patients were "initially no alarm symptoms or non-specific presentation" and "long time to reconsultation" (weight 39\%), followed by "missed opportunity GP" (29\%). Presentations without alarm symptoms mostly concerned consultations with benignappearing naevi, but also included presentations with complaints caused by metastases, for example a patient presenting with motor dysfunction caused by cerebral metastases.

\section{Oesophageal cancer}

For oesophageal cancer patients with longest IPC durations ( $\geq 92$ days), the most frequently attributed theme was "initially no alarm symptoms or non-specific presentation" (weight $38 \%$ ), followed by "concurring explanatory condition/circumstances" (32\%) and "long time to reconsultation" (24\%). Examples of presentations without alarm symptoms or with non-specific complaints were presentations with abdominal pain, acid reflux, chest tightness, and back pain (that turned out to be caused by bone metastases). Examples of patients in which "concurring explanatory condition/circumstances" contributed included a patient with compulsive swallowing and scraping of the throat and a patient with a known peptic stricture. In both patients, difficulties swallowing were accounted to these pre-existent conditions.

\section{Gastric cancer}

For gastric cancer, the theme most frequently attributed to longest IPC duration ( $\geq$ 203 days) was "masking effect of therapy" (weight 54\%), followed by "initially no alarm symptoms or non-specific presentation" (46\%) and "concurring explanatory condition/ circumstances" (46\%). "Masking effect of therapy" reflects the effect of antacids or proton pump inhibitors, which (temporarily) reduced gastric complaints. Presentations without alarm symptoms were mainly presentations with abdominal pain and (mild) gastric complaints. Concurring explanatory conditions included $\mathrm{H}$. pylori infection for gastric complaints, Beta thalassemia for anemia and COPD and stress for weight loss. 


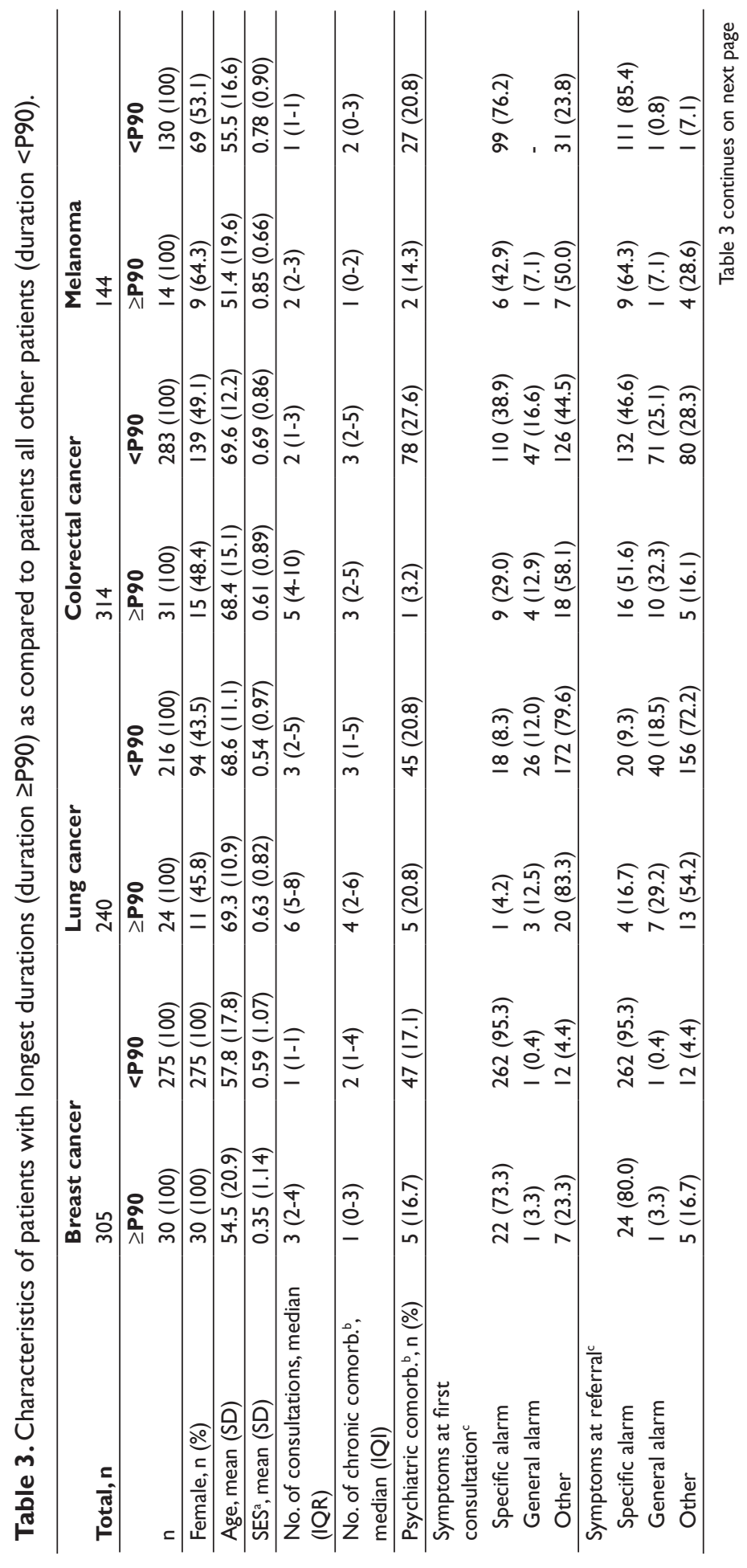




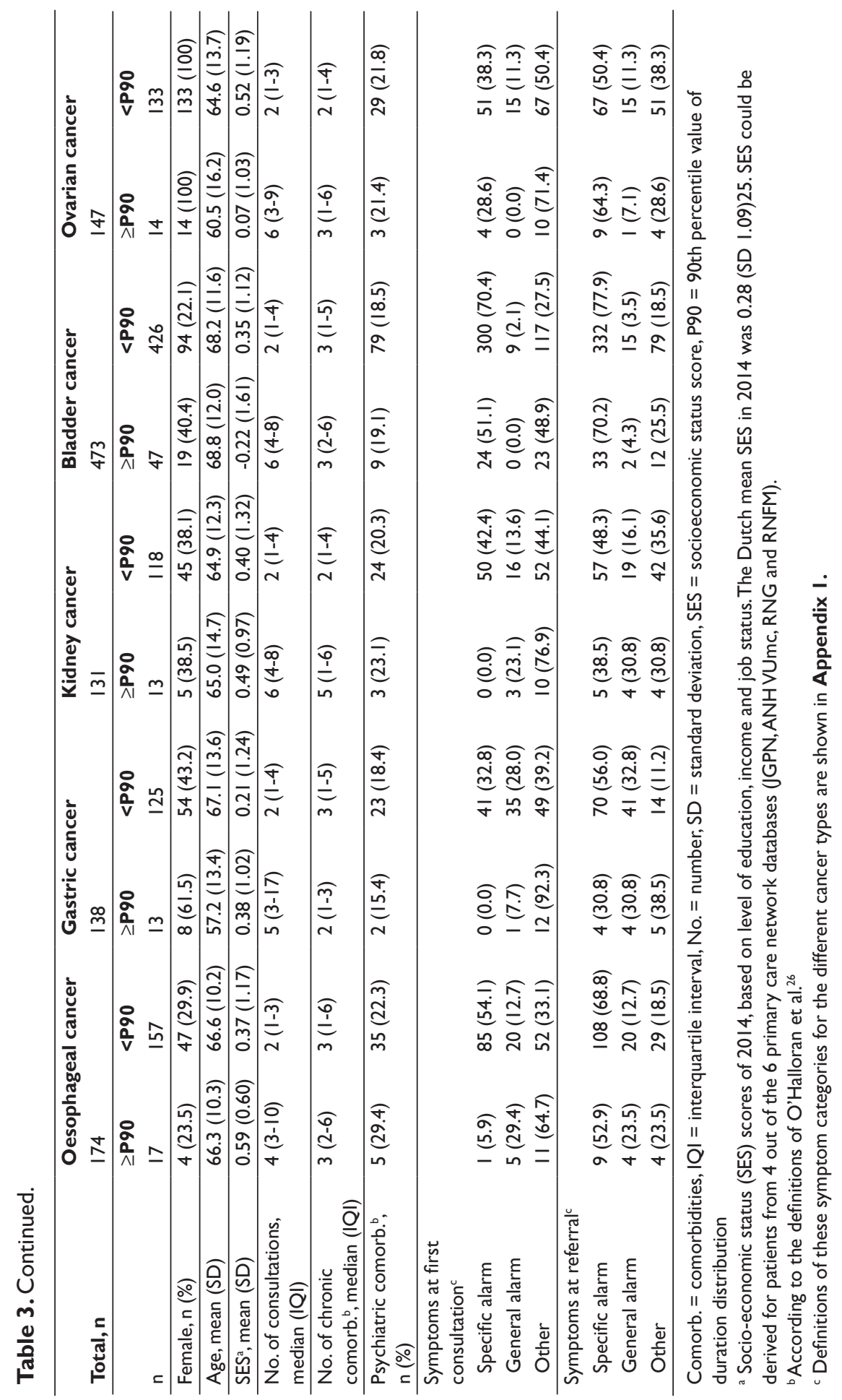




\section{Kidney cancer}

For kidney cancer most frequently attributed to longest IPC duration ( $\geq 173$ days) were the themes "patient initially deferring diagnostic tests or referral" (weight 38\%), "initially no alarm symptoms or non-specific presentation" (38\%), and "long time to reconsultation" (35\%). Kidney cancer patients with long duration to referral relatively often withheld from suggested referral or additional testing, because of their age, a longer holiday or without a documented reason. Presentations without alarm symptoms were often those because of abdominal pain or urinary tract complaints. Reasons for "long time to reconsultation" could most of the time not be derived from the registries.

\section{Bladder cancer}

For bladder cancer patients, most frequently attributed theme for longest IPC duration ( $\geq 135$ days) was "intermittent complaints" (weight 44\%), followed by "initially no alarm symptoms or non-specific presentation" (38\%) and "concurring explanatory condition/ circumstances" (35\%). Microscopic hematuria was often intermittently present. Patients frequently presented without alarm symptoms, for example with lower urinary tract symptoms, with or without signs of infection (eg. leukocyturia). Many patients received treatments for suspected urinary tract infection (UTI) but additional tests (including urine cultures) did not always confirm the presence of a UTI.

\section{Ovarian cancer}

For patients with ovarian cancer ( $\geq 75$ days), most frequently attributed theme was "initially no alarm symptoms or non-specific presentation" (weight 68\%), followed by “intermittent complaints" (32\%). Most ovarian cancer patients with longest duration to referral presented with non-alarming, non-specific complaints such as abdominal pain. Complaints were often variable with longer periods of less or absent symptoms.

\section{DISCUSSION}

\section{Summary of key findings}

The longest primary care intervals ( $\geq \mathrm{P} 90$ ) for symptomatic patients with nine types of cancer, took over 16 days for breast cancer to over 203 days for gastric cancer. Patients with longest durations were often younger (breast-, gastric-, ovarian cancer and melanoma), more often female (gastric- and bladder cancer and melanoma) and less often presented with alarm symptoms for cancer (all cancer types). Ten themes contributing to longest duration were identified. Both the frequency of theme attribution to long duration, as the relative weight (prominence) of theme attribution, varied per cancer 


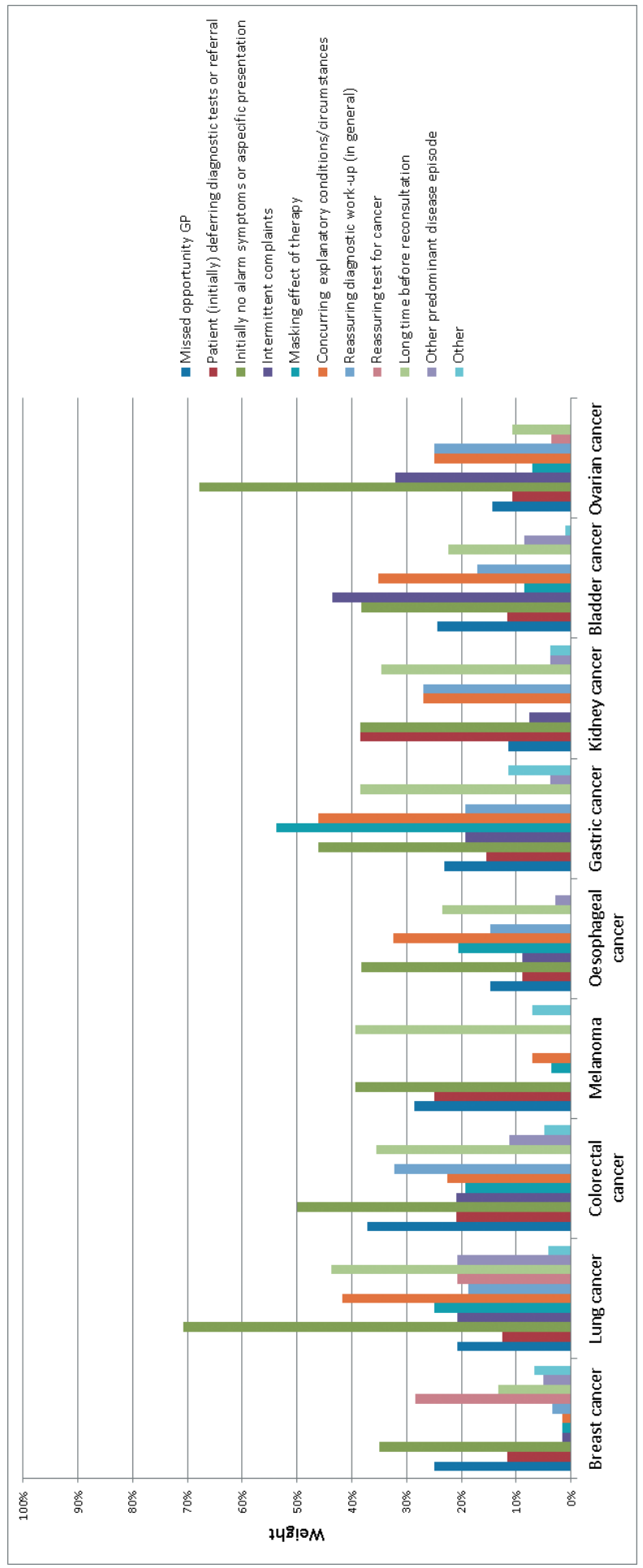


type. For seven of the nine studied cancer types the leading theme was "initial absence of alarm symptoms or non-specific presentations", for the other two (gastric and bladder cancer) this theme ranked second. For gastric cancer, "masking effect of therapy" (antacids and proton pump inhibitors) was the main attributed theme. For bladder cancer, it was “intermittent complaints". Reasons for long durations with potential for improvement are "missed opportunity GP” and "long time to reconsultation".

\section{Strengths and limitations}

The use of routine primary care data has strengths and limitations, which have been previously discussed in full detail. ${ }^{7}$ The main strength is the availability of detailed freetext registries of all GP consultations, that could be used to explore the route to referral including contextual factors and the deliberations made by the GP.The main limitations are the need for interpretation of subjective GP registrations and the potential incompleteness of the data. Since patients might not share all relevant details and since GPs only register what they consider important for patient care, some details that might have been of added value to our analyses may not have been documented.

Another limitation is that the EHR assessment and attribution of themes was performed only among cancer patients with longest durations, without comparison to patients without long durations. Besides, the interpretation and applicability of themes is subjective, depending on e.g. personal clinical experiences of the researchers. This is reflected by substantial inter-observer variability. Since we believe that the variety in clinicians views and decision making should be included in the reporting of themes leading to long duration, we chose to include all views, and add a weight to show prominence of themes in our results. Consequently, the results should be interpreted as indicative of a spectrum of explanations for long duration.

A relatively large number of patients with a cancer diagnostic code was excluded, including those with unclear diagnostic pathways ( $8-26 \%$ of the patients). As uncertainty about the diagnostic pathway may be more likely for either very short or very long diagnostic intervals, excluding these patients may have led to both an over and underestimation of primary care interval durations.

Identification of the date of first presentation with cancer related symptoms in primary care EHRs was challenging in some cases. The association between commonly occurring symptoms and the final cancer diagnosis is often obscure, especially for 'harder to suspect cancers' such as lung cancer and ovarian cancer. ${ }^{16}$ Even though we minimized the risk of misattribution of symptoms by discussing doubtful cases in our team of primary care researchers, the actual association between symptoms and the eventual cancer diagnosis 
remains uncertain in some patients. Among those with longest primary care intervals, there may be more patients for whom the association between complaints and the eventual cancer diagnosis is uncertain.

We used the 90th percentile value as a cut-off for longest duration to referral, resulting in different corresponding values in days per cancer type.As there is no generally accepted maximum duration for the primary care interval, all potential cut-offs for long duration are arbitrary. We based our cut-off on the highly right skewed duration distribution with a steep increase in primary care interval duration for 10-25\% of the patients (Figure 2). The incline in duration generally starts at the 75 th percentile value of duration.Therefore, for most of the studied cancer types, our previous studies used the 75 th percentile cut off to assess characteristics associated with long duration. For the current study however, we aimed to chart the explanations for cancer cases with excessive duration $(\geq \mathrm{P} 90)$, using labour-intensive qualitative methodology.

\section{Context and other literature}

Our findings that cancer patients with longest durations to referral, were more often female and younger and that the main theme attributed to long duration was "initially no alarm symptoms or non-specific presentation" are in line with the literature. It was earlier reported that delay in referral is primarily related to initial misdiagnosis and that men and older patients are less likely to experience delayed referral. ${ }^{10,17,18}$

Most of the identified themes reflect the diagnostic challenges faced by GPs. Diagnostic reasoning n primary care is a step-wise process, with initial assessment based on patientand presentation characteristics. Progression over time and additional test results subsequently contribute to further diagnostic reasoning. All diagnostic information is used to assess the risk of a serious disease, such as cancer. Next to "initially no alarm symptoms or non-specific presentation", the themes "intermittent complaints", "concurring explanatory condition" and "masking effect of therapy" all contribute to a relatively low suspicion of cancer. The theme "reassuring diagnostic work-up" illustrates that GPs are frequently misguided by normal test results such as normal blood test results or a normal abdominal ultrasound. Although these tests are neither sensitive nor specific enough for detection of most cancer types, GPs frequently use them in their risk assessment.

We did also identify themes that potentially suggest room for improvement: "missed opportunity GP" and "long time to reconsultation". Missed opportunities by GPs have been previously described, ${ }^{19-21}$ and in the current study varied from lacking work-up of alarm symptoms to not registering (clear) follow-up appointments. Better adherence 
to guidelines might at least partly prevent these missed opportunities. Next to that, persistence of complaints should urge reconsideration of the initial working diagnoses. For example, a significant number of bladder cancer patients with longest durations were (repeatedly) treated for suspected UTIs, whereas additional tests did not always confirm its presence or complaints persisted after treatment.

For the patients with "long time to reconsultation", it could often not be derived from the EHRs why it took so long to return to their GP for follow-up. It might be that complaints did (temporarily) resolve, that patients were reassured by the GP, had other priorities or did not want to contact their GP (again). In some cases, patients did not comply to registered follow-up instructions, but more often, follow-up instructions were not registered or unclear. For a patient with melanoma the 'simple' instruction to return 'when there are any changes' resulted in reconsultation after more than four years. Ensuring strict follow-up appointments and clearly registering them in the medical record- could be improved. The (future) possibilities of the electronic health records could potentially aid in achieving this. Next to cancer risk assessment tools and guidelines that could be incorporated in the system, automatic warnings could be shown in case of (repeated) presentation with certain symptoms as well as reminders for follow-up. ${ }^{22}$

For some breast cancer patients with longest durations, mammography or ultrasound did not show suspect findings, sometimes even repeatedly. The sensitivity of mammography in symptomatic patients is estimated to be $80-85 \%$, meaning that up to a fifth of the malignancies are not recognized as such. ${ }^{23}$ The Dutch guideline for breast cancer detection therefore instructs to refer to secondary care if a lump persists for three months after a negative test result. ${ }^{24}$ In the cases studied, this recommendation was not always followed by GPs. GPs should be (made) aware of the performance measures of the additional tests they order and could improve adherence to guideline instructions regarding this.

Even though there are large variations in tumor growth rates and disease progression over time, some of the longest referral durations probably had consequences for disease outcomes. The association with clinical outcomes was not assessed in the current study, neither were patients' experiences of the progress in the primary care interval. Both are important topics for further research, to be able to estimate the actual impact of long durations to referral. 


\section{Conclusion}

Longest durations to referral ( $\geq$ P90) from primary care for symptomatic cancer patients can generally be explained by relatively low initial cancer suspicion. This reflects the diagnostic challenge that gatekeeping GPs face. It also underlines the need to improve diagnostic strategies and tools, to enable the GP to identify cancer in patients presenting without cancer alarm symptoms or signs. As GPs sometimes miss diagnostic opportunities and time to reconsultation is sometimes long, better adherence to diagnostic guidelines and improved safety-netting may at least partially help to prevent delays in diagnosing cancer. 


\section{REFERENCES}

I. Data from the Netherlands Cancer Registry, managed by The Netherlands Comprehensive Cancer Organisation [Internet].Available from: http://www.cijfersoverkanker.nl.Accessed March 23, 2017.

2. Neal RD, Tharmanathan P, France B, Din NU, Cotton S, Fallon-Ferguson J, et al. Is increased time to diagnosis and treatment in symptomatic cancer associated with poorer outcomes? Systematic review. Br J Cancer 2015; I I2:S92-SI07.

3. Tørring ML, Frydenberg M, Hansen RP, Olesen F,Vedsted P. Evidence of increasing mortality with longer diagnostic intervals for five common cancers:A cohort study in primary care. Eur J Cancer 2013;49:2187-2198.

4. Tørring ML, Murchie P, Hamilton W,Vedsted P, Esteva M, Lautrup M, et al. Evidence of advanced stage colorectal cancer with longer diagnostic intervals: A pooled analysis of seven primary care cohorts comprising II 720 patients in five countries. Br J Cancer 20 I 7; I 17:888-897.

5. Tørring ML, Falborg AZ, Jensen H, Neal RD, Weller D, Reguilon I, et al. Advanced-stage cancer and time to diagnosis:An International Cancer Benchmarking Partnership (ICBP) cross-sectional study. Eur J Cancer Care 2019;28.

6. Mendonca SC,Abel GA, Saunders CL, Wardle J, Lyratzopoulos G. Pre-referral general practitioner consultations and subsequent experience of cancer care: Evidence from the English Cancer Patient Experience Survey. Eur J Cancer Care 2016;25:478-490.

7. Helsper C, van Erp N, Peeters P, de Wit N. Original Research:Time to diagnosis and treatment for cancer patients in the Netherlands: room for improvement? Eur J Cancer 2017;87:113-121.

8. Erp NFVan, Helsper CW, Slottje P, Brandenbarg D.Time to diagnosis of symptomatic gastric and oesophageal cancer in the Netherlands: Where is the room for improvement? United Eur Gastroenterol J 2020;8:607-620.

9. Lyratzopoulos G, Neal RD, Barbiere JM, Rubin GP,Abel GA.Variation in number of general practitioner consultations before hospital referral for cancer: Findings from the 2010 National Cancer Patient Experience Survey in England. Lancet Oncol 2012;13:353-365.

10. van Erp NF, Helsper CW, Olyhoek SM, Janssen RRT,Winsveen A, Peeters PHM, et al. Potential for Reducing Time to Referral for Colorectal Cancer Patients in Primary Care. Ann Fam Med 2019;17:419-427.

I I. Round T, Steed L, Shankleman J, Bourke L, Risi L. Primary care delays in diagnosing cancer:What is causing them and what can we do about them? J R Soc Med 2013;106:437-440.

12. Siminoff LA, Rogers HL, Thomson MD, Dumenci L, Harris-Haywood S. Doctor, What's Wrong with Me? Factors that Delay the Diagnosis of Colorectal Cancer. Patient Educ Couns 201 I;84:352-358.

13. Mansell G, Shapley M, Jordan JL, Jordan K. Interventions to reduce primary care delay in cancer referral:A systematic review. Br J Gen Pract 201 1;61:821-835.

14. Lamberts H,Wood M. International Classification of Primary Care (ICPC). Oxford: Oxford University Press; 1987.

I5. Weller D,Vedsted P, Rubin G,Walter FM, Emery J, Scott S, et al. The Aarhus statement: improving 
design and reporting of studies on early cancer diagnosis. Br J Cancer 2012;106:1262-1267.

16. Lyratzopoulos G,Wardle J, Rubin G. Rethinking diagnostic delay in cancer: How difficult is the diagnosis? BMJ 20।4;349:I-6.

17. Macdonald S, Macleod U, Campbell NC, Weller D, Mitchell E. Systematic review of factors influencing patient and practitioner delay in diagnosis of upper gastrointestinal cancer. Br J Cancer 2006;94:1272-1280.

18. Lyratzopoulos G,Abel GA, McPhail S, Neal RD, Rubin GP. Gender inequalities in the promptness of diagnosis of bladder and renal cancer after symptomatic presentation: Evidence from secondary analysis of an English primary care audit survey. BMJ Open 2013;3:I-7.

19. Brandenbarg D, Groenhof F, Siewers IM, Voort A Van Der, Walter FM. Possible missed opportunities for diagnosing colorectal cancer in Dutch primary care: a multimethods approach. BrJ Gen Pract 2017;68:e54-e62.

20. Singh H, Daci K, Petersen LA, Collins C, Petersen NJ, Shethia A, et al. Missed Opportunities to Initiate Endoscopic Evaluation for Colorectal Cancer Diagnosis. Am J Gastroenterol 2009; 104:2543-2554.

2I. Singh H, Hirani K, Kadiyala H, Rudomiotov O, Davis T, Khan MM, et al. Characteristics and predictors of missed opportunities in lung cancer diagnosis:An electronic health record-based study.J Clin Oncol 2010;28:3307-3315.

22. Murphy DR, Wu L, Thomas EJ, Forjuoh SN, Meyer AND, Singh H. Electronic trigger-based intervention to reduce delays in diagnostic evaluation for cancer:A cluster randomized controlled trial. J Clin Oncol 2015;33:3560-3567.

23. Barlow WE. Performance of Diagnostic Mammography for Women With Signs or Symptoms of Breast Cancer. J Natl Cancer Inst 2002;94: I I I I-I I59.

24. NHG-Werkgroep Borstkanker. NHG-Standaard Borstkanker (derde herziening). Huisarts Wet 2016;59:556-567.

25. The Netherlands Institute of Social Research. https://www.scp.nl/ Onderzoek/Lopend onderzoek/A_Z_alle_lopende_onderzoeken/Statusscores. Accessed Jun I0, 2015.

26. O'Halloran J, Miller GC, Britt H. Defining chronic conditions for primary care with ICPC-2. Fam Pract 2004;2I:38I-386.

27. Smeets HM, Kortekaas MF, Rutten FH, Bots ML, Kraan WVan Der, Daggelders G, et al. Routine primary care data for scientific research, quality of care programs and educational purposes: the Julius General Practitioners' Network (JGPN). BMC Health Serv Res 2018; I8: I-9. 


\section{APPENDIX I}

Definition of cancer specific alarm symptoms, general alarm symptoms and other symptoms per cancer type.

\begin{tabular}{|c|c|c|c|}
\hline Cancer type & $\begin{array}{l}\text { Cancer specific alarm } \\
\text { symptoms }\end{array}$ & $\begin{array}{l}\text { General alarm } \\
\text { symptoms for cancer }\end{array}$ & Other symptoms \\
\hline Breast cancer & $\begin{array}{l}\text { Lump } \\
\text { Nipple or skin retraction }\end{array}$ & & \\
\hline Lung cancer & Coughing up blood & & \\
\hline Colorectal cancer & $\begin{array}{l}\text { Rectal blood loss } \\
\text { Palpable abdominal or } \\
\text { rectal mass }\end{array}$ & & \\
\hline Melanoma & $\begin{array}{l}\text { Suspect according to } \\
\text { ABCDE criteria or NICE } \\
\text { guideline, or GP describing } \\
\text { mole as suspect }\end{array}$ & & \\
\hline $\begin{array}{l}\text { Oesophageal } \\
\text { cancer }\end{array}$ & $\begin{array}{l}\text { Persistent vomiting } \\
\text { Dysphagia }\end{array}$ & $\begin{array}{l}\text { Anemia } \\
\text { Unintended weight loss } \\
\text { (Ascites)* }\end{array}$ & $\begin{array}{l}\text { All other symptoms } \\
\text { that were likely to be } \\
\text { related to the eventual } \\
\text { cancer diagnosis }\end{array}$ \\
\hline Gastric cancer & $\begin{array}{l}\text { Hematemesis } \\
\text { Palpable mass epigastric } \\
\text { region }\end{array}$ & & \\
\hline Kidney cancer & $\begin{array}{l}\text { Visible hematuria } \\
\text { Palpable mass }\end{array}$ & & \\
\hline Bladder cancer & Visible hematuria & & \\
\hline Ovarian cancer & $\begin{array}{l}\text { Increased abdominal size } \\
\text { Ascites* } \\
\text { Palpable mass (abdominal, } \\
\text { pelvic) }\end{array}$ & & \\
\hline
\end{tabular}


General discussion 
In this thesis, we aimed to explore the diagnostic pathway of symptomatic cancer patients in the Netherlands, and to identify room for improvement. For ten types of cancer we I) charted the duration of the different phases of the diagnostic pathway, 2) identified patient- and presentation characteristics associated with 'long duration', with a focus on the primary care interval, and 3) performed an in depth analysis of the mechanisms explaining the longest durations to referral in primary care.

\section{Main findings}

Main results regarding the duration of the different phases of the diagnostic pathway are summarized in Figure I. Our overall conclusion is that in the Netherlands cancer is generally diagnosed within acceptable time limits. In international comparison, the duration of diagnostic interval is generally similar to- or shorter than the duration in other gatekeeper based health care systems (Figure 2). ${ }^{1-5}$

For different types of cancer the median time to consultation (patient interval) ranges from 5 to $3 \mathrm{I}$ days, the time to referral (primary care interval) ranges from I to 14 days and the time from referral to diagnosis (secondary care interval) ranges from 6 to $5 \mathrm{I}$ days. Generally, the patient interval and the secondary care interval are longer than the primary care interval.

Factors associated with long duration ( $\geq 75$ th percentile value of duration) include singular predictors (e.g. absence of alarm symptoms), but the true explanation for "delay" is generally more complicated. This is demonstrated by our in depth analysis of the longest durations to referral ( $\geq 90$ th percentile value of duration).

\section{Methodological challenges}

\section{Study population}

We studied the diagnostic pathway of symptomatic patients with ten cancer types: cancer of the breast, colon, lung, prostate, oesophagus, stomach, kidney, bladder, ovaries and melanoma. Together these cancer types comprise around $70 \%$ of yearly new cancer cases in the Netherlands. We only included patients with a validated cancer diagnosis, either based on verification in the primary care health records or on linkage with the NCR. Next, only those patients that presented with symptoms in primary care were selected. This means our population does not represent all cancer patients. Out of all patients who were identified with a primary care diagnostic code (ICPC-I) for cancer, $34 \%$ (breast cancer) to $52 \%$ (oesophageal cancer) of the patients were included in our analyses. Consequently, our results apply only to this subset: patients with a confirmed 


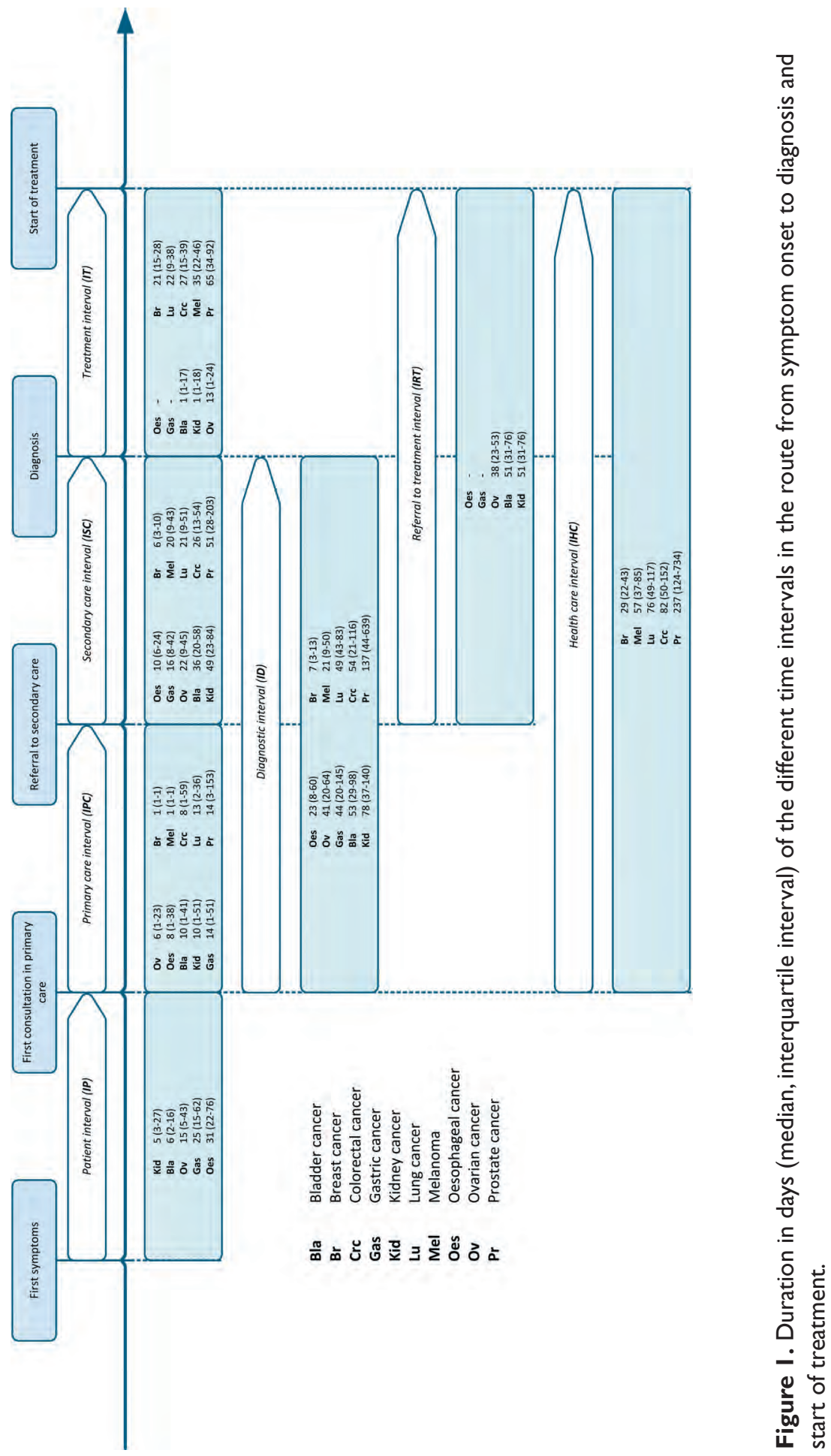


cancer diagnosis that symptomatically presented in and were referred from primary care. Our results do not apply to patients diagnosed through other routes, including those diagnosed through population screening and patients that were diagnosed without GP involvement (e.g. after internal referral in secondary care or after presentation in the emergency room (ER)).

Interpretation of routine primary care data

Using routinely collected primary care data has both strengths and limitations, as addressed in the discussion sections of the different chapters. The main strength lies in the availability of free-text annotations of all GP consultations, enabling detailed insight in the diagnostic process, including GP considerations and contextual factors. The main challenges when using these data are the lack of standardized registration for research purposes and adequate interpretation of the data in these registries, including the identification of the first consultation with cancer related symptoms.

For some cancer types, such as prostate cancer and lung cancer, identifying the first consultation with cancer related complaints is a greater challenge than for others (e.g. melanoma and breast cancer). Symptoms potentially related to prostate and lung cancer may very well be explained by other conditions, such as benign prostatic hypertrophy $(\mathrm{BPH})$ and chronic obstructive pulmonary disease (COPD), respectively. For prostate cancer, we used a tailored approach because of this challenge and identified the first consultation with the symptoms that eventually led to the prostate cancer diagnosis. Prostate cancer was therefore excluded from international comparison overviews in this discussion.

To identify the date of first presentation with cancer related complaints, information should ideally be distilled from both patients and primary-care providers, as their concepts of this time point may differ, particularly in the context of vague, nonspecific or chronic symptoms.6 To be as accurate as possible, we discussed the first consultation with complaints that were most likely to be related to the cancer with the clinical experts in our research team. However, the identification of the first consultation with a cancer related complaint has been subject to subjective interpretation in some cases.

How to define 'long duration' or 'delay'

Even though Dutch National guidelines do provide maximum duration indications for some specific parts of the diagnostic pathway (e.g. maximum waiting time until first specialist visit), ${ }^{7,8}$ there is no objective cut-off for 'long duration' or 'delay' for the intervals we studied. We -arbitrarily- predefined long duration as duration equal to or longer 
than the 75th percentile value of the duration distribution, and 'longest durations' as duration equal to or longer than the 90 th percentile value of the duration distribution.

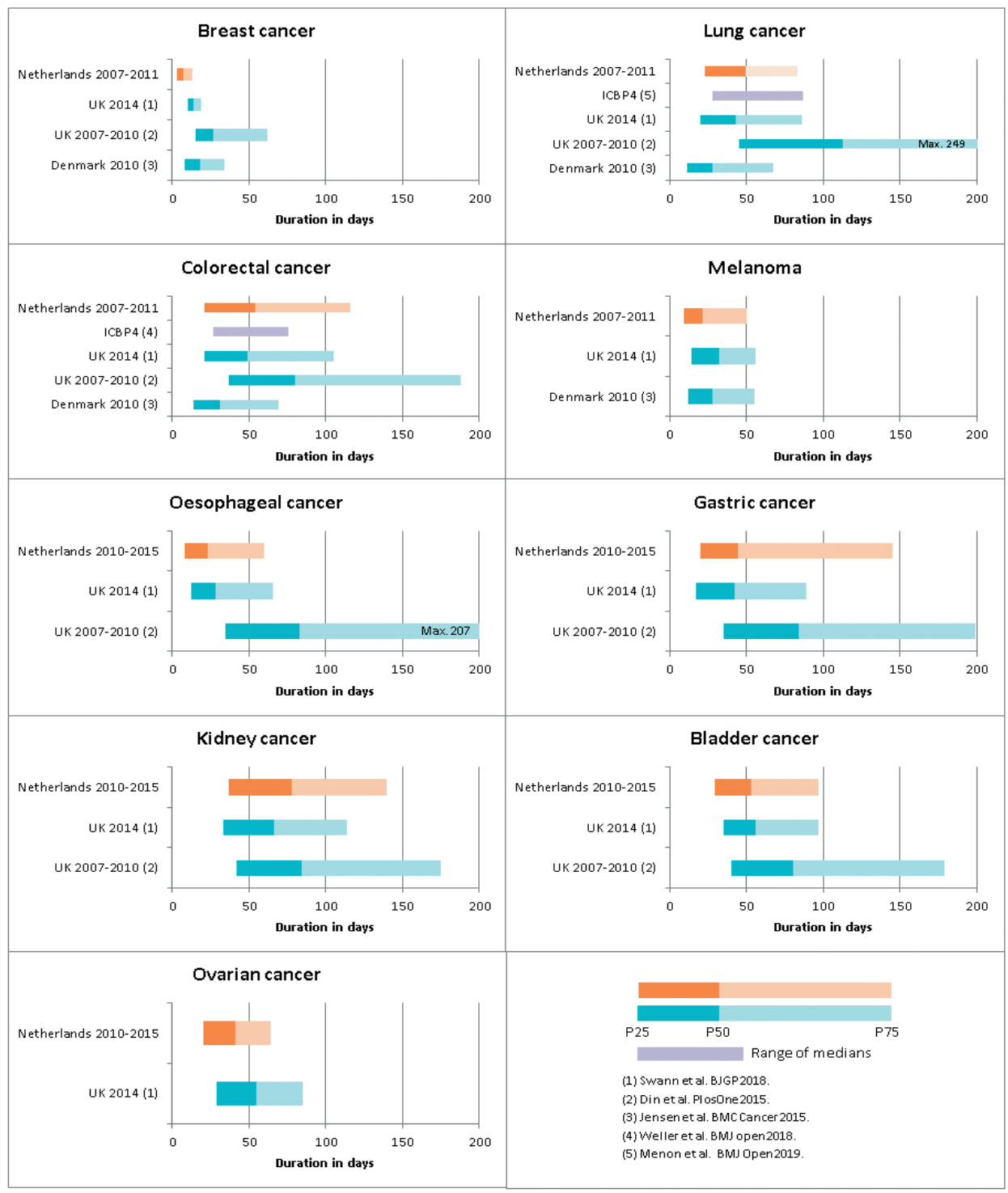

Figure 2. Duration of the diagnostic interval (from first consultation in primary care to final diagnosis) in the Netherlands (orange bar) as compared to relevant examples from comparable health care systems (blue and purple bars).

P25 $=25$ th percentile value, $\mathrm{P} 50=50$ th percentile value (median), $\mathrm{P} 75=75$ th percentile value, $\mathrm{ICBP} 4=$ International Cancer Benchmarking Partnership (Module 4), Max. $=$ maximum value, UK $=$ United Kingdom. 
These values differ per cancer type studied and represent relative cut-offs for long duration. Whether relatively long durations are also considered too long by patients and professionals is debatable, and dependent on multiple factors including tumour growth rate, disease progression and the patient experience.

\section{Room for improvement in the cancer diagnostic pathway in the Netherlands}

We believe there is room for improvement in the cancer diagnostic pathway in the Netherlands. Even though cancer is generally diagnosed within acceptable time limits, for all cancer types and for all intervals, for approximately 10 to $25 \%$ of the patients the diagnostic intervals reach substantial durations, sometimes even years. Potential for improvement mainly lies among these patients. Below, we discuss the most important findings, international comparison and the potential for improvement for each of the different intervals.

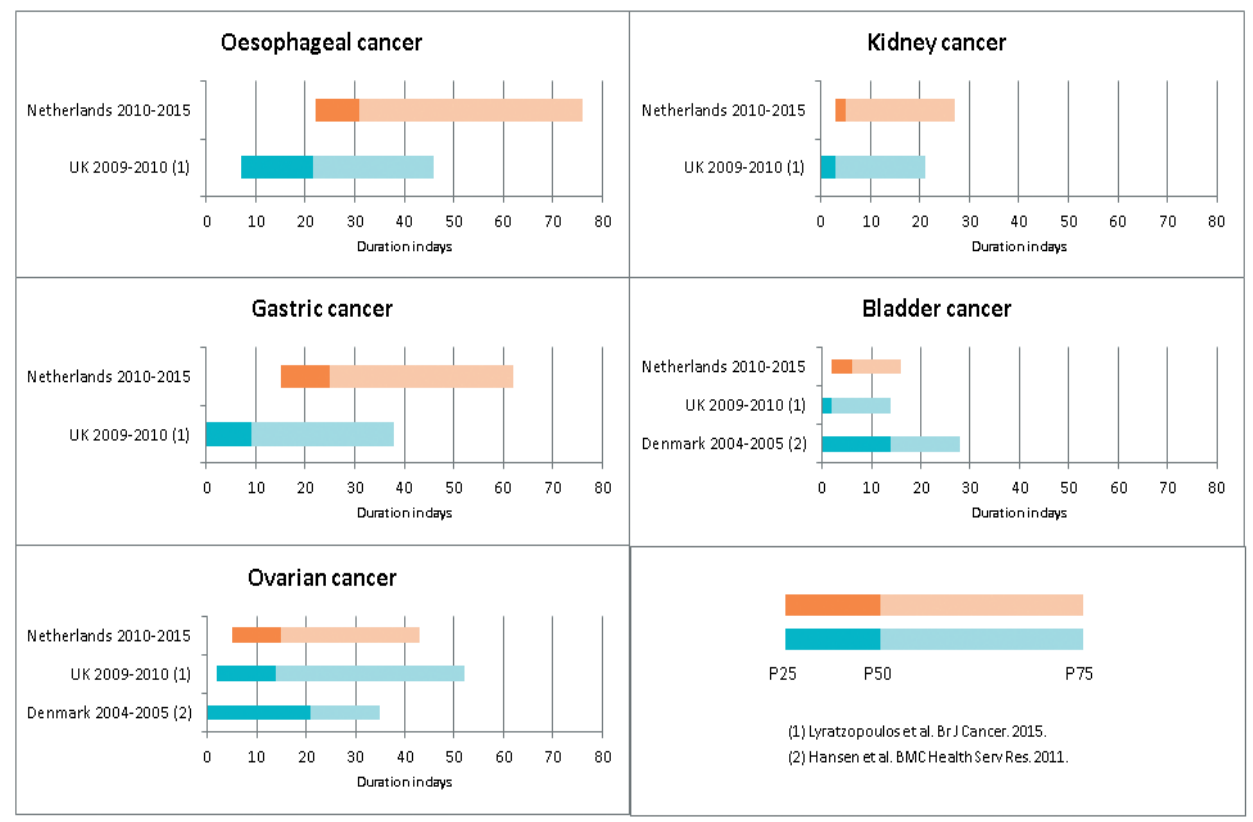

Figure 3. Duration of the patient interval (from first noticing cancer related symptom(s) to first consultation with these symptoms in primary care) in the Netherlands (orange bar) as compared to relevant examples from comparable health care systems (blue bars).

$\mathrm{P} 25=25$ th percentile value, $\mathrm{P} 50=50$ th percentile value (median), $\mathrm{P} 75=75$ th percentile value, $\mathrm{UK}=$ United Kingdom. 


\section{I.The patient interval}

Patients generally present timely with symptoms related to the eventual cancer diagnosis and for most cancer types the patient interval is not the most time consuming. Relatively long patient interval durations are seen for gastric and oesophageal cancer patients.

International comparison

In Figure 3, the Dutch patient interval duration is compared to most relevant examples from comparable health care systems. ${ }^{9,10}$ In general, we found longer median patient interval durations as compared to the UK and slightly shorter durations as compared to Denmark. Between country differences may be caused by variation in promptness of presentation, based on differences in accessibility of health care facilities, care seeking behavior and awareness of symptoms, or differences in the way the patient interval is measured.Accurate measurement of the patient interval is known to be challenging and different methods are all accompanied by their own shortcomings. ${ }^{11,12}$

\section{Room for improvement in the patient interval}

For patients with upper gastrointestinal (UGI) cancer, we found relatively long patient intervals and comparable durations for patients with and without registered alarm symptoms (persistent vomiting, hematemesis, melena and dysphagia). To understand these findings, insight in reasons for postponing consultation is needed. These reasons could not be derived from the current study, but may include factors such as fear of consultation and not recognizing the seriousness of symptoms. ${ }^{13}$ The latter would warrant increased awareness of upper $\mathrm{Gl}$ cancer alarm symptoms.

Awareness of cancer alarm symptoms could be raised by public education campaigns, which have shown to be effective in the United Kingdom for, among others, bowel and lung cancer. ${ }^{14,15}$ In the Netherlands, public cancer campaigns mainly focus on common cancer types like breast cancer and prostate cancer, both having a specific month of attention. More attention could be paid to less common cancer types and awareness of their associated alarm symptoms. Further exploration of the reasons for patients to initiate or postpone a GP consultation is needed to be able to effectively optimize the patient interval for those patients for whom it currently takes long.

\section{The primary care interval}

Dutch GPs refer the majority of the cancer patients timely: median duration of the primary care interval ranges from I day (melanoma and breast cancer) to 14 days (gastric cancer and prostate cancer). The primary care interval generally is the shortest interval 
of the diagnostic pathway and the role of the GP in diagnostic 'delay' is therefore limited. Especially for breast cancer and melanoma patients, of which over $75 \%$ is referred the same day and $90 \%$ within 16 and 24 days respectively, there hardly seems to be any room for improvement for the Dutch GP.

\section{International comparison}

In Figure 4, the Dutch primary care interval duration is compared to most relevant examples from comparable health care systems. The differences with Denmark should be interpreted with care, as in the work of Hansen et al. GP delay was defined as the period from first presentation until initiation of an investigation, instead of referral. ${ }^{10}$ In general, our IPC durations were comparable to the durations of the UK. However, relatively high 75th percentile values of duration are seen for Dutch colorectal, kidney and bladder cancer patients. Observed variation in primary care interval duration may reflect actual differences, but is likely to be at least partially caused by methodological variability. Differences in used data sources (GP questionnaires versus routinely collected data, free text availability versus coded data) and the censoring of duration at maximum values may all influence observed durations and hamper solid comparison. This underlines the importance of uniform methods in this field.

Room for improvement in the primary care interval

Even though Dutch GPs generally seem to do really well, this does not mean that there is no room for improvement in primary care at all. For all cancer types, the right skewed distribution of duration showed remarkably long durations for 10\% (breast cancer and melanoma) to $25 \%$ (other cancer types) of the patients. Who are these patients and why does referral take so long for them? We aimed to answer these questions by assessing characteristics associated with 'long duration' ( $\geq 75$ th percentile value) and thematic analysis of reasons for 'longest durations' ( $\geq 90$ th percentile value).

For almost all cancer types, the absence of (cancer specific) alarm symptoms was found to be associated with 'long duration' ( $\geq 75$ th percentile value of the distribution of duration) to referral, next to female sex for urological cancer. These findings are in line with earlier literature, ${ }^{16-18}$ and well understandable in health care systems where the GP is a gatekeeper to secondary care. Recognizing those patients with serious diseases, including cancer, is a challenging task. On average, Dutch GPs encounter 25 new cancer cases each year (all types of skin cancer included), whilst the average number of consultations per GP lies around 8,900 a year. ${ }^{19}$ Symptoms associated with cancer, even those known as 'cancer alarm symptoms', are common in the general population: around $15 \%$ of the general population annually experiences at least one cancer alarm symptom for breast, colorectal, urinary tract or lung cancer. ${ }^{20,21}$ Positive predictive values 


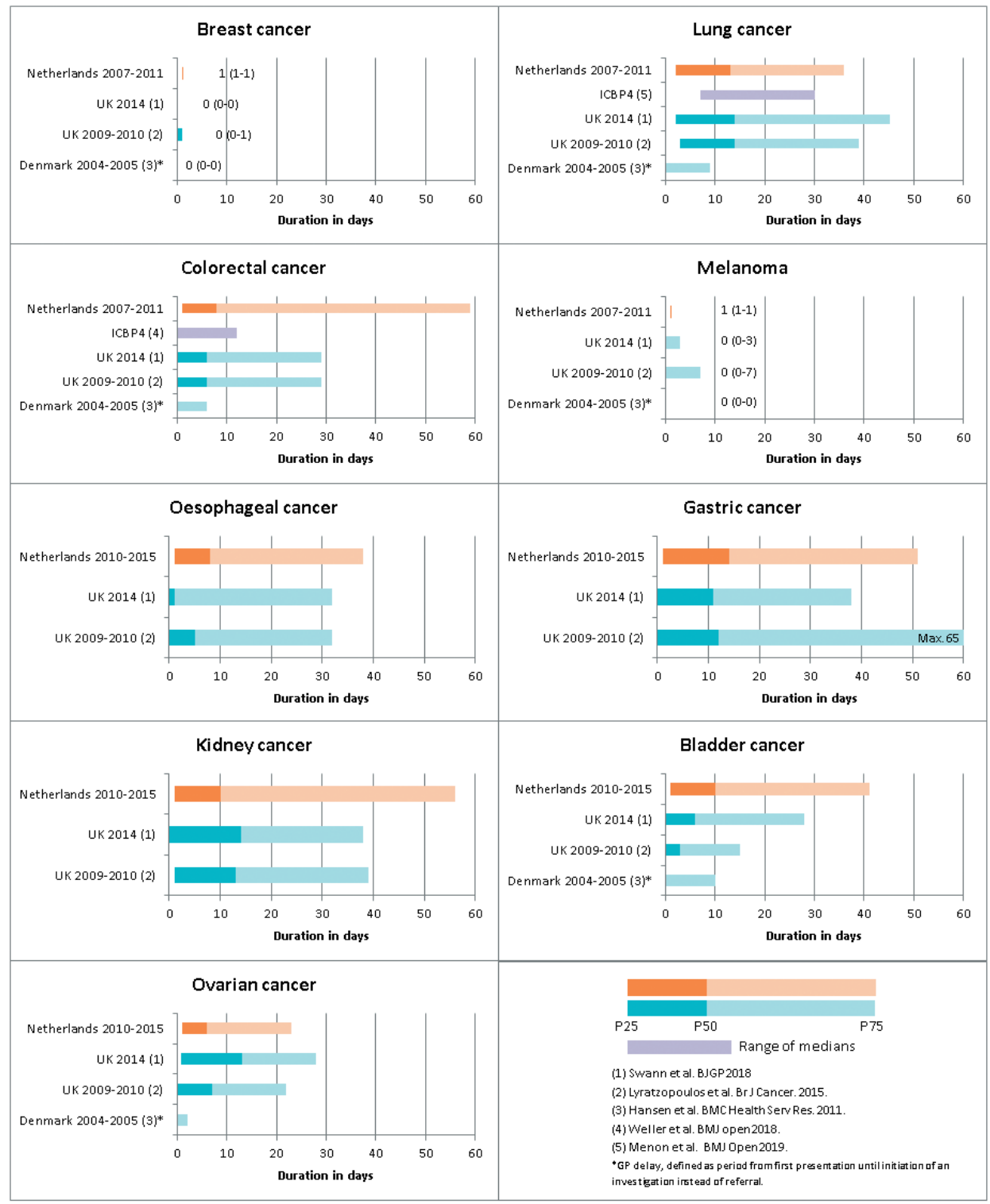

Figure 4. Duration of the primary care interval (from first consulttion with cancer related symptom(s) to referral) in the Netherlands (orange bar) as compared to relevant examples from comparable health care systems (blue and purple bars).

P25 $=$ 25th percentile value, P50 $=$ 50th percentile value (median), P75 $=75$ th percentile value, ICBP4 = International Cancer Benchmarking Partnership (Module 4), UK = United Kingdom. 
of symptoms potentially related to cancer are therefore low. Even though predictive values increase if symptoms and patient characteristics are combined, they rarely exceed $10 \% .{ }^{22,23}$ The challenge for GPs is to optimally balance the risk of cancer against the potential harm of unnecessary referral and invasive diagnostic testing. Keeping this in mind, how could the primary care interval be improved for those with longest durations?

\section{Improving clinical assessment and follow-up instructions by GPS}

With our thematic analysis we identified two themes that leave room for improvement: "missed opportunity by the GP" and "long time before reconsultation". Missed opportunities by GPs include missing alarm symptoms and failure to reconsider the initial hypothesis when complaints persist. Reasons for "long time before reconsultation" were often not clear. In some cases, instructions for follow-up were not met by patients, but more often no clear instruction for reconsultation was registered. Ensuring strict follow-up appointments and clearly recording them in the electronic health records could potentially help to improve follow-up.Automatic messages could for example warn the GP in case of (repeated) presentation with certain symptoms or remind them of follow-up appointments.

\section{Referral at lower risk thresholds}

The risk level at which suspected cancer patients should be referred for further diagnostic testing is debated. In the UK an explicit threshold of $3 \%$ risk of cancer is set for adult patients. ${ }^{24}$ However, referral of patients at lower risk thresholds does not seem to be the right solution to reduce longest durations. Secondary care diagnostic services are already under pressure and there is currently a shift of responsibilities moving towards primary care. The price to be paid for a lower cut-off seems to high, since low thresholds are likely to increase the number of unnecessary referrals, the detection of incidentalomas, health care costs and the (psychological) burden of referral among low risk patients.

\section{Improving accuracy of risk estimation}

More accurate recognition of cancer patients sounds attractive, but is more easily said than done. Some improvement in timely diagnosis may come from risk assessment tools that improve the prediction of cancer risks. Clinical decision support software can be integrated in the primary care electronic health system and integrate all information present: baseline risk factors (patient characteristics), symptoms and physical signs from consecutive consultations and primary care test results like blood tests. A number of risk estimation tools have already been developed. ${ }^{25}$ Effective implementation of some of these systems have been demonstrated for adult patients in the UK. ${ }^{26}$ However, up to today their clinical and economic impact remains uncertain, as well as how they can 
be optimally incorporated in daily clinical practice. ${ }^{25}$ In the near future, risk prediction strategies are likely to further evolve and incorporate genomic data, data collected with wearables and other enriching data sources, thus providing ground for (next level) precision medicine in primary care.

\section{More accurate and better targeted diagnostic tests}

Next to improved risk estimation based on what we have available, there is a need for better tests for cancer that can be used in primary care to support the GP in recognizing cancer. With better tests, general practitioners might be able to achieve more certainty about who to refer and who to follow-up, potentially resulting in less and more targeted referral. There are many evolutions in technology, that rapidly produce new diagnostic tools including (combinations of) biomarkers, methods for cell collection and imaging devices. ${ }^{27}$ Examples of the latter two include colon capsule endoscopy (CCE), enabling visualization of the colon without the need for sedation and gas insufflation and the Cytosponge, developed for the detection of Barret oesophagus. ${ }^{28}$ The challenge with newly developed tests so far is that the majority fail in early primary care evaluation, because they do not perform well in the low prevalence populations. ${ }^{29}$ Overinvestigation and overdiagnosis are lurking and limited sensitivity may increase the risk of missing important diagnoses including cancer. Even for well-known markers such as CAI 25 and PSA, primary care based evidence is limited. ${ }^{30}$ Another example is the faecal immunochemical test (FIT). This test is considered a promising triage tool for CRC in primary care, but implementation is disappointing due to suboptimal performance in symptomatic patients. ${ }^{31-33}$

\section{The secondary care interval}

The time from referral to diagnosis ranged from 6 days for breast cancer to $5 \mathrm{I}$ days for prostate cancer. For most cancer types, the secondary care interval was most the time consuming interval of the diagnostic pathway.

\section{International comparison}

Of the relevant examples from comparable health care systems, only Hansen et al. included the secondary care interval (Figure 5)..$^{10}$ For lung cancer, colorectal cancer, melanoma and ovarian cancer we found comparable ISC durations, for breast cancer and bladder cancer, the durations we found were shorter as compared to the Danish durations. 


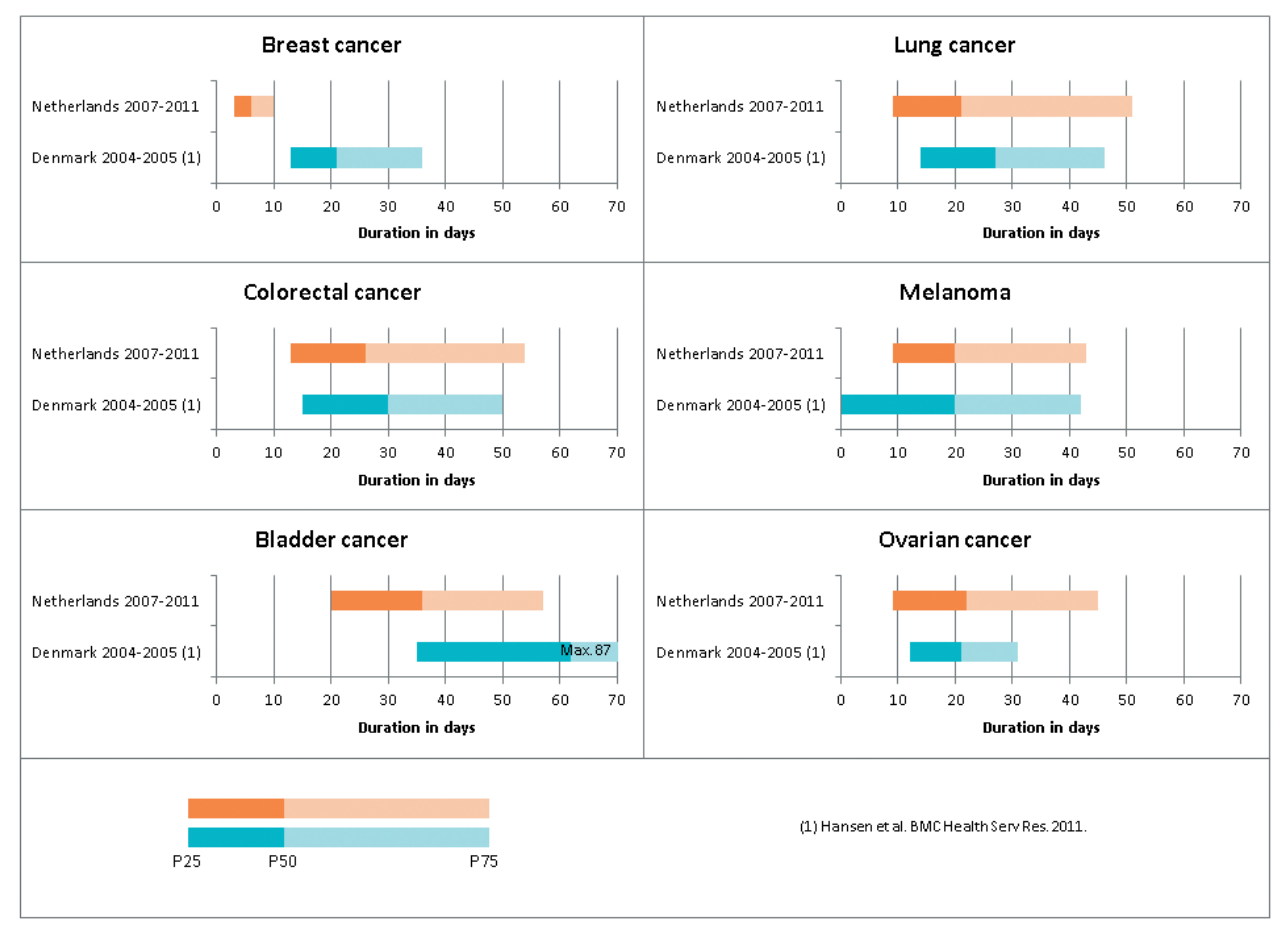

Figure 5. Duration of the secondary care interval (from referral to diagnsosis) in the Netherlands (orange bar) as compared to relevant examples from comparable health care systems (blue bars).

$\mathrm{P} 25=25$ th percentile value, $\mathrm{P} 50=50$ th percentile value (median), $\mathrm{P} 75=75$ th percentile value, $\mathrm{ICBP} 4=$ International Cancer Benchmarking Partnership (Module 4),

Room for improvement in the secondary care interval

In contrast to the detailed information we had available for the primary care interval, we had no insight in the secondary care proceedings. To understand the secondary care interval, its duration, the role of waiting times and the actual potential for improvement, more detailed information on all the events after referral is needed.

For the urological cancers and for ovarian cancer, we additionally assessed the duration from referral to initial treatment, as this is an interval we could compare to the Dutch quality standards for cancer care (in Dutch: SONCOS normeringsrapport). ${ }^{7}$ For $49 \%$ (kidney and bladder cancer) and $79 \%$ of the patients (ovarian cancer), this quality standard was met, suggesting room for improvement for $30-50 \%$ of the patients. Again, to understand these findings, more insight in the secondary care proceedings is needed. 


\section{Does shortening of the diagnostic pathway improve cancer outcomes?}

The key aim of reducing the time to diagnosis is to reduce disease burden for patients, with regard to both prognosis and the patient experience. We found that patients with advanced disease stage -and thus worse prognosis- generally show longer duration of the primary care interval and that the secondary care interval is structurally the longest for patients with localized disease. However, solid causal conclusions cannot be drawn from these observational findings. ${ }^{34}$ Firstly, the direction of a potential association is not unambiguous. It could be that longer durations lead to more advanced disease stage or the other way around: patients with more advanced disease may present with worse symptoms, leading to a faster flow through the diagnostic pathway. Besides, it has been shown that the association between duration and outcomes such as disease stage at diagnosis is not simply linear, but rather $U$-shaped, with initially decreasing odds for advanced disease followed by increasing odds. ${ }^{35}$ Shorter interval durations are regularly found to be associated with worse prognosis. This phenomenon is known as the waiting time paradox. ${ }^{36}$ Observational studies may not be the best way to address this association and simple linear models seem inappropriate. Despite these challenges, evidence for worse outcomes with longer interval durations is increasing. ${ }^{35-39}$

Based on the above, there is sufficient reason to keep aiming for ways to shorten the diagnostic pathway of cancer, especially for those with remarkably long durations. Achieving this seems to require a few steps, that may be taken on a relatively short notice. We have increasing possibilities to employ a personalized approach, based on relevant patient and disease characteristics (e.g. 'the genomic passport') and we have increasing possibilities to invent new diagnostic tools and strategies for primary care (e.g. artificial intelligence and biomarkers). However, the main challenge will remain that in daily practice, potential benefits of an early diagnosis will always have to be balanced against the potential harm of over referral and overdiagnosis.

\section{Final conclusions}

In general, we conclude that (I) cancer generally seems to be diagnosed within acceptable time limits in the Netherlands and (2) the patient interval and the secondary care interval are generally more time consuming than the primary care interval.

Specifically for primary care we conclude that (I) GPs promptly refer the majority of the cancer patients, (2) factors associated with long duration in primary care mainly reflect the diagnostic challenges of the GP, (3) GPs do miss opportunities sometimes, however, (4) reduction of the primary care interval seems hardly possible without new test strategies and better risk assessment tools. 
Future focus should be on (I) more detailed exploration of the secondary care interval and the potential for reducing its duration, (2) patients' experiences related to the duration of the different diagnostic intervals, (3) potential beneficial effects of diagnostic interval reduction on disease outcomes, with methodologically sound approaches. 


\section{REFERENCES}

I. Swann R, McPhail S, Shand B, Rashbass J,Witt J,Abel GA, et al. Diagnosing cancer in primary care: Results from the National Cancer Diagnosis Audit. Br J Gen Pract 2018;68):e63-e72.

2. Din NU, Ukoumunne OC, Rubin G, Hamilton W, Carter B, Stapley S, et al. Age and gender variations in cancer diagnostic intervals in 15 cancers:Analysis of data from the UK clinical practice research datalink. PLoS One 2015; I0:e01277I7

3. Jensen H,Tørring ML, Olesen F, Overgaard J,Vedsted P. Cancer suspicion in general practice, urgent referral and time to diagnosis: $A$ population-based GP survey and registry study. BMC Cancer 2014;14:636.

4. Weller D, Menon U, Zalounina Falborg A, Jensen H, Barisic A, Knudsen AK, et al. Diagnostic routes and time intervals for patients with colorectal cancer in 10 international jurisdictions; Findings from a cross-sectional study from the International Cancer Benchmarking Partnership (ICBP). BMJ Open 2018;8: e023870.

5. Menon U,Vedsted P, Zalounina Falborg A, Jensen H, Harrison S, Reguilon I, et al.Time intervals and routes to diagnosis for lung cancer in 10 jurisdictions: Cross-sectional study findings from the International Cancer Benchmarking Partnership (ICBP). BMJ Open 2019;9: e025895.

6. Weller D,Vedsted P, Rubin G,Walter FM, Emery J, Scott S, et al. The Aarhus statement: improving design and reporting of studies on early cancer diagnosis. Br J Cancer 2012; 106: I 262-1267.

7. Stichting Oncologische Samenwerking. Multidisciplinaire normering oncologische zorg in Nederland, Normeringsrapport 2020 [Internet].Available from: https://www.soncos.org/wpcontent/uploads/2020/03/SONCOS-normeringsrapport-versie-8-I.pdf. Accessed February I0, 2020.

8. Treekoverleg. Notitie Streefnormstelling wachttijden curatieve sector. Zeist, 19 januari 2000.

9. Lyratzopoulos G, Saunders CL,Abel GA, McPhail S, Neal RD,Wardle J, et al.The relative length of the patient and the primary care interval in patients with 28 common and rarer cancers. $\mathrm{Br} J$ Cancer 2015; I I2:S35-S40.

10. Hansen RP,Vedsted P, Sokolowski I, Søndergaard J, Olesen F.Time intervals from first symptom to treatment of cancer: a cohort study of 2,21 2 newly diagnosed cancer patients. BMC Health Serv Res 20II; I I:284.

II. Andersen RS, Vedsted P, Olesen F, Bro F, Søndergaard J. Patient delay in cancer studies:A discussion of methods and measures. BMC Health Serv Res 2009;9:189.

12. Smith SM, Whitaker KL, Cardy AH, Elliott AM, Hannaford PC, Murchie P.Validation of self-reported help-seeking, and measurement of the patient interval, for cancer symptoms: an observational study to inform methodological challenges in symptomatic presentation research. Fam Pract 2019;37:91-97.

13. Smith LK, Pope C, Botha JL. Patients' help-seeking experiences and delay in cancer presentation:A qualitative synthesis. Lancet 2005;366:825-831.

14. Ironmonger L, Ohuma E, Ormiston-Smith N, Gildea C, Thomson CS, Peake MD.An evaluation of the impact of large-scale interventions to raise public awareness of a lung cancer symptom. Br J 
Cancer 20I5; I |2:207-2 I6.

15. Moffat J, Bentley A, Ironmonger L, Boughey A, Radford G, Duffy S. The impact of national cancer awareness campaigns for bowel and lung cancer symptoms on sociodemographic inequalities in immediate key symptom awareness and GP attendances. Br J Cancer 20I 5; I I2:SI4-S2I.

16. Williams P, Murchie P, Bond C. Patient and primary care delays in the diagnostic pathway of gynaecological cancers:A systematic review of influencing factors. BrJ Gen Pract 2019;69:EI06EIII.

17. Mitchell E, Macdonald S, Campbell NC, Weller D, Macleod U. Influences on pre-hospital delay in the diagnosis of colorectal cancer:A systematic review. Br J Cancer 2008;98:60-70.

18. Din NU, Ukoumunne OC, Rubin G, Hamilton W, Carter B, Stapley S, Neal RD. Age and Gender Variations in Cancer Diagnostic Intervals in 15 Cancers:Analysis of Data from the UK Clinical Practice Research Datalink. PLoS One 2015;10:e0127717.

19. Korevaar J, Heins M, Donker G, Rijken M, Schellevis F. Oncologie in de huisartsenpraktijk. Huisarts Wet 20I3;56:6-10.

20. Elnegaard S, Andersen RS, Pedersen AF, Larsen PV, Søndergaard J, Rasmussen S, et al. Self-reported symptoms and healthcare seeking in the general population -exploring "the Symptom Iceberg" Health behavior, health promotion and society. BMC Public Health 2015;15:685.

21. Svendsen RP, Støvring H, Hansen BL, Kragstrup J, Søndergaard J, Jarbøl DE. Prevalence of cancer alarm symptoms:A population-based cross-sectional study. Scand J Prim Health Care 2010;28:132137.

22. Hamilton W.The CAPER studies: five case-control studies aimed at identifying and quantifying the risk of cancer in symptomatic primary care patients. Br J Cancer 2009; 101:S80-S86.

23. Stapley S, Peters TJ, Neal RD, Rose PW,Walter FM, Hamilton W. The risk of oesophago-gastric cancer in symptomatic patients in primary care:A large case-control study using electronic records. Br J Cancer 2013; 108:25-31.

24. National Institute for Health and Care Excellence. Suspected cancer: recognition and referral [Internet]. Available from: http://www.nice.org.uk/guidance/ng I2.Accessed January 12, 2020.

25. Usher-Smith J, Emery J, Hamilton W, Griffin SJ, Walter FM. Risk prediction tools for cancer in primary care. Br J Cancer 20 I5; I 13:1645-1650.

26. Hippisley-Cox J, Coupland C. Development and validation of risk prediction algorithms to estimate future risk of common cancers in men and women: Prospective cohort study. BMJ Open 2015;5: e007825.

27. Phillips KA, Van Bebber S, Issa AM. Diagnostics and biomarker development: Priming the pipeline. Nat Rev Drug Discov 2006;5:463-469.

28. Rubin G,Walter F, Emery J, DeWit N. Reimagining the diagnostic pathway for gastrointestinal cancer. Nat Rev Gastroenterol Hepatol 2018;15:181-188.

29. Usher-Smith JA, Sharp SJ, Griffin SJ. The spectrum effect in tests for risk prediction, screening, and diagnosis. BMJ 2016;353:i3139.

30. Watson J, Mounce L, Bailey SER, Cooper SL, Hamilton W. Blood markers for cancer. BMJ 2019;367: i5774. 
3I. Elias SG, Kok L, de Wit NJ,Witteman BJM, Goedhard JG, Romberg-Camps MJL, et al. Is there an added value of faecal calprotectin and haemoglobin in the diagnostic work-up for primary care patients suspected of significant colorectal disease? A cross-sectional diagnostic study. BMC Med 2016;14:14I.

32. Mowat C, Digby J, Strachan JA, Wilson R, Carey FA, Fraser CG, et al. Faecal haemoglobin and faecal calprotectin as indicators of bowel disease in patients presenting to primary care with bowel symptoms. Gut 2016;65:1463-1469.

33. Farrugia A, Widlak M, Evans C, Smith SC,Arasaradnam R. Faecal immunochemical testing (FIT) in symptomatic patients:What are we missing? Frontline Gastroenterol 2020; I I:28-33.

34. Neal RD. Do diagnostic delays in cancer matter? Br J Cancer 2009; I0I:S9-SI2.

35. Tørring ML, Falborg AZ, Jensen H, Neal RD, Weller D, Reguilon I, et al.Advanced-stage cancer and time to diagnosis:An International Cancer Benchmarking Partnership (ICBP) cross-sectional study. Eur J Cancer Care 2019;28.

36. Tørring ML, Frydenberg M, Hansen RP, Olesen F, Hamilton W,Vedsted P.Time to diagnosis and mortality in colorectal cancer: A cohort study in primary care. Br J Cancer 20 I I; 104:934-940.

37. Tørring ML, Frydenberg M, Hansen RP, Olesen F,Vedsted P. Evidence of increasing mortality with longer diagnostic intervals for five common cancers:A cohort study in primary care. Eur J Cancer 2013;49:2187-2198.

38. Neal RD, Tharmanathan P, France B, Din NU, Cotton S, Fallon-Ferguson J, et al. Is increased time to diagnosis and treatment in symptomatic cancer associated with poorer outcomes? Systematic review. Br J Cancer 2015; I 12:S92-SI07.

39. Arhi CS, Markar S, Burns EM, Bouras G, Bottle A, Hanna G, Aylin P, Ziprin P, Darzi A. Delays in referral from primary care are associated with a worse survival in patients with esophagogastric cancer. Dis Esophagus 2019;32:1-II. 
Abbreviations 


\section{ABBREVIATIONS}

$95 \% \mathrm{Cl}$

ANHVUmc

EHR

GP

HAGnet AMC

ICBP

ICD-O

ICPC

ID

IKNL

IP

IPC

IQI

IQR

ISC

IRT

IT

JGPN

NCR

P75

P90

PALGA

RNFM

RNG

RNUH-LEO

with

RR

UK
95\% Confidence Interval

Academic Network of General Practice (Amsterdam VUmc)

Electronic health record

General Practitioner

General Practice Registration Network (Amsterdam AMC)

International Cancer Benchmarking Partnership

International Classification of Diseases for Oncology

International Classification of Primary Care

Diagnostic interval

Netherlands Comprehensive Cancer Organisation

Patient interval

Primary care interval

Interquartile interval

Interquartile range

Secondary care interval

Interval from referral to onset of treatment

Treatment interval

Julius General Practitioner's Network (Utrecht)

The Netherlands Cancer Registry

75 th percentile value of duration

90 th percentile value of duration

The nationwide network and registry of histo- and

cytopathology in the Netherlands

Research Network Family Medicine (Maastricht)

Registration Network Groningen

Registration Network of General Practitioners Associated

Leiden University

Relative Risk

United Kingdom 
General appendices 


\section{GENERAL APPENDIXA}

Description of the six Dutch primary care network databases.

\begin{tabular}{l} 
JGPN (Utrecht) \\
\hline The Julius General Practitioner's Network (JGPN) database contains free-text and coded information \\
from primary care electronic health records (EHRs) of over 300,000 patients, subscribed to 52 GP \\
practices in a central region of the Netherlands.' \\
ANH VUmc (Amsterdam) \\
The Database of the Academic Network of General Practice, Department of General Practice VU \\
University Medical Centre (ANHVUmc) is a longitudinal database containing pseudonymized coded and \\
free text data extracted from the EHR of around I 97,000 patients enlisted in about 50 practices in the \\
Amsterdam region in the studied time period. Free text data are further anonymized before they are \\
shared with researchers.
\end{tabular}

RNG (Groningen)

The Registration Network Groningen (RNG) comprises of three GP group practices in the northern part of the Netherlands and has a dynamic patient population of approximately 30,000 patients. No free-text is available in the database, medical records were studied on location in the participating GP-practices. Since 2017 this network is known as Academic General Practitioners Network Northern Netherlands (AHON). Nowadays the longitudinal database of this network contains routinely registered primary care data from about 50 GP-practices with approximately 250,000 patients. More information can be found on https://huisartsgeneeskunde-umcg.nl/ahon-database

\section{HAGnet AMC (Amsterdam)}

The general practice registration network database of the Department of General Practice, Academic Medical Center Amsterdam, currently contains routinely collected free text and coded data of more than 500,000 patients of 2010 settled GPs working at 50 primary care centres in a western-central region of the Netherlands. Data obtained for this study were retrieved from a former version of the database containing 46,000 patients of 49 GPs working at six primary care centres.

RNUH-LEO (Leiden)
Registration Network of General Practitioners Associated with Leiden University (RNUH-LEO) is a
longitudinal database containing electronic health records of over 40,000 patients subscribed to I9 GP
practices organised in 4 healthcare centres in the western region of the Netherlands. Since 20I6, RNUH-
LEO is transformed into Extramural Leiden Academic Network (ELAN) with data from GP and patients
in the Leiden and The Hague area.Website: https://www.lumc.nl/elan

\section{RNFM (Maastricht)}

The Research Network Family Medicine (RNFM) is a continuous database in which about 70 GPs working in 22 different practices in the South of the Netherlands are participating. For this study, data of 8 practices with a total population of almost 28,000 patients were included. At the time of data-extraction, no free-text was available in the database; therefore, medical records were studied on location in the participating GP-practices. Website: https://www.rnfm.nl 


\section{GENERAL APPENDIX B}

Duration of symptoms as recorded in primary care records (IP duration): interpretation and rules for date registration.

\begin{tabular}{|c|c|c|c|}
\hline & $\begin{array}{l}\text { GP registry of } \\
\text { duration }\end{array}$ & Interpretation & Rule for date registration \\
\hline Range & $\begin{array}{l}\text { Since } 2-3 \text { months/ } \\
\text { years }\end{array}$ & $\begin{array}{l}\text { Mean; } 2.5 \text { months/ } \\
\text { years }\end{array}$ & $\begin{array}{l}\text { Halfway through month: } 15^{\text {th }} \text { (in February: } 14^{\text {th }} \text { ) } \\
\text { Halfway through year: first of July }\end{array}$ \\
\hline Acute & Since last night & 0 days & Date of consultation \\
\hline \multirow[t]{2}{*}{ Days } & $\begin{array}{l}\text { Couple/few/ } \\
\text { several days }\end{array}$ & 3 days & 3 days before date of consultation \\
\hline & Since last weekend & $\begin{array}{l}\text { Saturday as reference } \\
\text { day }\end{array}$ & Saturday before date of consultation \\
\hline \multirow[t]{5}{*}{ Weeks } & Since last week & 7 days & 7 days before date of consultation \\
\hline & For over a week & 9 days & 9 days before date of consultation \\
\hline & $\begin{array}{l}\text { Since the end of } \\
\text { last week }\end{array}$ & Friday as reference day & Friday before date of consultation \\
\hline & $\begin{array}{l}\text { For a week and } \\
\text { a half }\end{array}$ & II days & II days before date of consultation \\
\hline & $\begin{array}{l}\text { Couple/few/ } \\
\text { several weeks }\end{array}$ & 3 weeks & 21 days before date of consultation \\
\hline \multirow[t]{6}{*}{ Months } & Since one month & I calendar month & Same date, one month before \\
\hline & For over a month & $\begin{array}{l}\text { I month and one } \\
\text { week }\end{array}$ & Same date, one month before, minus 7 days \\
\hline & $\begin{array}{l}\text { For over two } \\
\text { months }\end{array}$ & 2.5 month & Halfway through month: $15^{\text {th }}$ (in February: $\left.14^{\text {th }}\right)$ \\
\hline & Since December & $\begin{array}{l}\text { Halfway through the } \\
\text { month }\end{array}$ & Halfway through month: $15^{\text {th }}$ (in February: $\left.14^{\text {th }}\right)$ \\
\hline & $\begin{array}{l}\text { Since the end of } \\
\text { December }\end{array}$ & $\begin{array}{l}\text { Since the last day of } \\
\text { the month }\end{array}$ & $30^{\text {th }}$ or $31^{\text {th }}$ (in February: $28^{\text {th }}$ or $29^{\text {th }}$ ) \\
\hline & $\begin{array}{l}\text { Couple/few/ } \\
\text { several months }\end{array}$ & 3 calendar months & Same date, three months before \\
\hline \multirow[t]{5}{*}{ Years } & Since years & 3 calendar years & Same date, three years before \\
\hline & $\begin{array}{l}\text { Couple/few/ } \\
\text { several years }\end{array}$ & 3 calendar years & Same date, three years before \\
\hline & Since over a year & $\begin{array}{l}\text { I year and three } \\
\text { months }\end{array}$ & $\begin{array}{l}\text { Same date one year and three calendar months } \\
\text { before }\end{array}$ \\
\hline & $\begin{array}{l}\text { Since the beginning } \\
\text { of the year }\end{array}$ & Since January first & January first of that year \\
\hline & $\begin{array}{l}\text { Since the year ... } \\
(\text { eg 2008) }\end{array}$ & Halfway through year & Halfway through year: first of July \\
\hline \multirow[t]{4}{*}{ Vague } & Since a while & \multirow{4}{*}{$\begin{array}{l}\text { Too vague, no } \\
\text { interpretation }\end{array}$} & \multirow[t]{4}{*}{ None } \\
\hline & For some time & & \\
\hline & For a long time & & \\
\hline & Etc. & & \\
\hline
\end{tabular}




\title{
GENERAL APPENDIX C
}

\author{
Characteristics and methods of collection.
}

\begin{tabular}{ll}
\hline Characteristic & Method of collection \\
\hline Age & $\begin{array}{l}\text { Age was calculated based on birth year as registered in the routine primary care } \\
\text { databases. For all patients, July first was set as their birthdate as only year of } \\
\text { birth was available for analysis. Age at first consultation was then calculated.Age } \\
\text { was categorized as a non-linear association with duration of the primary care } \\
\text { interval was expected }\end{array}$ \\
\hline
\end{tabular}

Socio-economic status score (SES) 2014
SES was retrieved from publicly available data from the Netherlands Institute for Social Research ${ }^{2}$ in which status scores are available according to postal code and based on level of education, income and job status. The scores of 2014 were used. The Dutch mean SES in 2014 was 0.28 (SD I.09). Postal code (4 digits) was available in the primary care databases from 4 out of the 6 primary care network databases (JGPN,ANHVUmc, RNG and RNFM) and transferred to SES by the data managers. Patients were divided in two categories based on the Dutch mean: $S E S<0.28$ and $S E S \geq 0.28$.

Consultation frequency in year before first consultation

We used the consultation frequency in the year preceding first consultation as a measure of how frequent a patients generally visits the general practitioner, in other words: to identify 'frequent visitors'. Number of GP consultations in the year before the first cancer related consultation was determined by counting all registered physical or phone contacts with the practice, except for repeated prescriptions and registered correspondence with secondary care.

Number of registered chronic somatic comorbidities and registered psychiatric comorbidity

Episode lists in the EHRs were used to determine existence of chronic comorbidities by the time of first consultation with cancer related complaints. To decide on relevance and chronicity of registered disease episodes, the list of chronic comorbidities in primary care as provided by O'Halloran et al. was used as guidance ${ }^{3}$. All disease episodes registered in the EHR appearing on this list -whether still active in the EHR or not- were taken into account as they were considered chronic comorbidities. In this list included ICPC-codes starting with a "P" were regarded as relevant, chronic psychiatric comorbidities.

Dominant symptom(s) at first consultation Information on symptoms at first consultation was retrieved from the free text consultation registries in the routine primary care databases. Cancer specific alarm symptoms are defined below per cancer type. Cancer general alarm symptoms were defined as unintended weight loss and anaemia (and ascites, except for ovarian cancer). In case of presence of both cancer specific and cancer general alarm symptoms, cancer specific alarm symptoms were considered dominant.

Cancer specific alarm symptoms

Gastric and oesophageal cancer
Cancer specific alarm symptoms for UGI cancers (oesophageal and gastric cancer) were defined as persistent vomiting, UGI bleeding (hematemesis or melena), dysphagia and a palpable mass in the epigastric region. Cancer general alarm symptoms were defined as unintended weight loss, anaemia and ascites. Other, non-alarming symptoms were all other presenting symptoms that could be related to the UGI-cancer, including abdominal pain, nausea, gastrooesophageal reflux, malaise etc. In case of presence of both cancer specific and cancer general alarm symptoms, cancer specific alarm symptoms were considered dominant. 


\begin{tabular}{ll}
\hline Kidney and bladder & $\begin{array}{l}\text { Cancer specific alarm symptoms for urological cancers (kidney and bladder } \\
\text { cancer }\end{array}$ \\
& $\begin{array}{l}\text { tumour in the abdomen or flank (kidney cancer). Other symptoms were all } \\
\text { other presenting symptoms that could be related to the kidney or bladder } \\
\text { cancer, including dysuria, abdominal and flank/back pain (kidney cancer), non- } \\
\text { visible haematuria etc. In case of presence of both cancer specific and cancer } \\
\text { general alarm symptoms, cancer specific alarm symptoms were considered } \\
\text { dominant. }\end{array}$ \\
\hline Ovarian cancer & $\begin{array}{l}\text { Cancer specific alarm symptoms for ovarian cancer were defined as increased } \\
\text { abdominal size and a palpable abdominal or pelvic mass. Other symptoms were } \\
\text { all other presenting symptoms that could be related to the ovarian cancer, } \\
\text { including abdominal pain, post-menopausal blood loss, defaecation and/or } \\
\text { urinary complaints, malaise etc. }\end{array}$ \\
\hline $\begin{array}{l}\text { Information on symptoms at referral was retrieved from the free text } \\
\text { symptom(s) at } \\
\text { referral }\end{array}$ & $\begin{array}{l}\text { symptoms at referral included the dominant symptom(s) that occurred } \\
\text { somewhere after first consultation and before referral. In case of presence of } \\
\text { both cancer specific and cancer general alarm symptoms, cancer specific alarm } \\
\text { symptoms were considered dominant. }\end{array}$ \\
\hline $\begin{array}{l}\text { Disease stage at } \\
\text { diagnosis and tumour } \\
\text { morphology }\end{array}$ & $\begin{array}{l}\text { Disease stage at diagnosis and tumour morphology were extracted from the } \\
\text { NCR database. }\end{array}$ \\
\hline
\end{tabular}

\section{REFERENCES}

I. Smeets HM, Kortekaas MF, Rutten FH, Bots ML, Kraan WVan Der, Daggelders G, et al. Routine primary care data for scientific research, quality of care programs and educational purposes: the Julius General Practitioners' Network (JGPN). BMC Health Serv Res 20।8; I8: I-9

2. The Netherlands Institute of Social Research. https: //www.scp.nl/ Onderzoek/Lopend_ onderzoek/A_Z_alle_lopende_onderzoeken/Statusscores.Accessed Jun 10, 2015.

3. O'Halloran J, Miller GC, Britt H. Defining chronic conditions for primary care with ICPC-2. Fam Pract 2004;21:381-386. 
Summary 
As prognosis of cancer is highly dependent on disease stage at diagnosis, timely detection of cancer is widely pursued. Evidence is increasing that longer durations to diagnosis are associated with more advanced disease stage at diagnosis, worse prognosis and worse patient experiences. Timeliness of the diagnosis depends on the efficiency of the different intervals of the diagnostic pathway: the patient interval, primary care and secondary care interval. In all these intervals, delays may occur. Differences in cancer outcomes between countries are thought to at least partly reflect differences in diagnostic timeliness and have led to international research exploring the cancer diagnostic process and factors influencing its efficiency. For the Netherlands, the cancer diagnostic process including all its different intervals was not yet explored. The aim of this thesis was therefore to explore the diagnostic pathway of symptomatic cancer patients in the Netherlands and to identify room for improvement. Here we summarize the different parts and chapters of this thesis.

In PART I of this thesis we present the duration of the different intervals of the diagnostic pathway for ten cancer types, including characteristics associated with 'long duration' for a selection of cancer types.

In chapter $\mathbf{2}$ we charted he duration of the different intervals of the diagnostic pathway for the five most common cancer types in the Netherlands; breast cancer, colorectal cancer, prostate cancer, lung cancer and melanoma. Anonymised primary care data of patients with these types of cancer (diagnosed between 2007 and 20II) were linked to the Netherlands Cancer Registry. Median duration was determined of the primary care interval (IPC, from first symptoms to primary care consultation), secondary care interval (ISC, from referral to diagnosis), treatment interval (IT, from diagnosis to start of treatment) and the overarching diagnostic interval (ID, from first consultation to diagnosis) and healthcare interval (IHC, from first consultation to start of treatment). These data showed that median IPC, ISC and ID durations were shortest for breast cancer and melanoma (ID duration 7 and 21 days, respectively), intermediate for lung and colon cancer (ID duration 49 and 54 days) and the longest for prostate cancer (ID duration I 37 days). For all cancers, the majority of symptomatic patients seem to experience timely referral by the GP, diagnostic investigation and treatment. However, duration of intervals increases steeply for the 10-25\% with longest durations. For colorectal cancer, increasing ID durations show increasing proportions of time attributable to primary care, suggesting that reduction of primary care delay seems particularly relevant for colorectal cancer.

In chapter 3, 4 and 5, we explored the diagnostic pathway of less common cancer types, including characteristics associated with long duration ( $\geq 75$ th percentile, $P 75)$ and 
the association between duration and tumour stage at diagnosis. Anonymised electronic health records of symptomatic patients with oesophageal, gastric, kidney, bladder and ovarian cancer (diagnosed between 2010 and 2015) were used, derived from six Dutch routine primary care databases, partly linked to the Netherlands Cancer Registry. Duration of four diagnostic intervals was determined: the patient interval, the primary care interval, the secondary care interval and the diagnostic interval.

In chapter 3, the results are presented for oesophageal and gastric cancer. Median duration of the patient interval was 29 days (interquartile interval 15-73), median duration of the primary care interval was 12 days (interquartile interval 1-43), median duration of the secondary care interval 13 days (interquartile interval 6-29) and median duration of the diagnostic interval was 31 days (interquartile interval II-74). Patient interval duration was comparable for patients with and without alarm symptoms. Based on log-binomial regression analysis, we found that absence of cancer-specific alarm symptoms was associated with 'long duration' of primary care interval and secondary care interval: relative risk 5.0 (95\% confidence interval $2.7-9.1)$ and 2.1 (95\% confidence interval 1.3-3.7), respectively. Median diagnostic interval duration for local stage disease was $5 \mathrm{I}$ days (interquartile interval I3-135) versus 27 days (interquartile interval II-7I) for advanced stage $(p=0.07)$, suggesting faster processing for the sickest patients. Results of this study show that in the diagnostic pathway of upper gastrointestinal cancers, the longest interval is the patient interval. Reducing time to diagnosis may be achieved by improving patients' awareness of alarm symptoms and by additional diagnostic strategies which better identify cancer patients despite low suspicion.

Chapter 4 describes the results for kidney and bladder cancer. Duration of the patient interval, primary care interval, secondary care interval and diagnostic interval was 6, 10, 39 and 56 days respectively. 'Long duration' ( $\geq$ P75) was seen more often in female patients (in the primary care interval) and among patients without cancer alarm symptoms (all intervals). In this study we additionally determined time from referral to initial therapy, to be able to compare its duration with the recommendations of the Dutch quality standard for cancer care. We found that the maximum duration of 49 days for this interval was met in less than half of the patients. Based on these results, for kidney and bladder cancer mainly the secondary care interval shows potential for improvement.

In chapter 5 the results for ovarian cancer are presented. Median durations of these intervals were 15, 6, 22 and 41 days respectively. We found that patients with ovarian cancer specific alarm symptoms (increased abdominal size and/or a palpable abdominal or pelvic mass) showed increased risk of long ( $\geq$ P75) patient interval duration, while patients without these alarming symptoms showed increased risk of long primary 
care interval duration. A lower socioeconomic status score was associated with long secondary care interval duration. We additionally determined time from referral to initial therapy, to be able to compare its duration with the recommendations of the Dutch quality standard for cancer care. We found that the maximum duration of 49 days for this interval was met in $70 \%$ of the patients. This study showed that compared to the other intervals, the primary care interval was relatively short. In general, duration of all intervals seems acceptable, but for a relevant minority (up to $20 \%$ of the patients) intervals are remarkably long. Due to the nonspecific nature of ovarian cancer symptoms, reducing the diagnostic pathway seems very challenging.

In PART II of this thesis we further explored reasons for long duration to referral from primary care.

In chapter $\mathbf{6}$ we aimed to identify potential for reducing time to referral from primary care for colorectal cancer patients. We studied anonymized free-text primary care records from the Julius General Practitioners' Network database, linked to the Netherlands Cancer Registry. The duration of the primary care interval was determined, as well as associations of patient and presentation characteristics with long time to referral $(\geq 75$ th percentile, $\geq 59$ days). Additionally, we explored routes to referral of patients with the longest times to referral ( $\geq 90$ th percentile, $\geq 219$ days) using thematic free-text analyses. Patients who were female, did not have a registered family history of colorectal cancer, had a history of malignancy, lacked alarm symptoms at presentation, or had hemorrhoids at physical examination were at risk for longer time to referral in univariable analyses (longer median durations and or univariable association with the 75th percentile). Only presentation without alarm symptoms showed a statistically significant association with long duration (75th percentile) in multivariable analysis (relative risk $=1.7 ; 95 \% \mathrm{Cl}, \mathrm{I} . \mathrm{I}$ 2.6).Thematic exploration of the diagnostic routes to referral of patients with the longest durations (90th percentile) showed 2 dominating themes: "alternative working diagnosis" and "suboptimal diagnostic strategies," including the subthemes "omitting to reconsider an initial diagnosis" and "lacking follow-up." Based on these data we conclude that long time to referral for CRC in primary care is mainly related to low cancer suspicion. There is at least some potential for reducing the longest times to referral for patients with CRC in primary care, with earlier reconsideration of the initial hypothesis and implementation of strict follow-up consultations.

Chapter 7 presents a thematic analysis of reasons for longest durations from presentation in primary care to referral for nine cancer types. We extensively studied the anonymized electronic heath records of 203 patients with longest durations to referral ( $\geq 90$ th percentile value). The longest primary care intervals took over 16 days for breast 
cancer to over 203 days for gastric cancer.We found that patients with longest durations were often younger (breast-, gastric-, ovarian cancer and melanoma), more often female (gastric- and bladder cancer and melanoma) and less often presented with alarm symptoms for cancer (all cancer types). Ten themes contributing to longest duration were identified, most of the themes reflecting low (initial) cancer suspicion. Both the frequency of theme attribution to long duration, as the relative weight (prominence) of theme attribution, varied per cancer type. For seven of the nine studied cancer types the leading theme was "initial absence of alarm symptoms or non-specific presentations", for the other two (gastric and bladder cancer) this theme ranked second. For gastric cancer,"masking effect of therapy" (antacids and proton pump inhibitors) was the main attributed theme. For bladder cancer, it was "intermittent complaints". These results reflect the diagnostic challenge that gatekeeping GPs face. It also underlines the need to improve diagnostic strategies and tools, to enable the GP to identify cancer in patients presenting without cancer alarm symptoms or signs. As GPs sometimes miss diagnostic opportunities and time to reconsultation is sometimes long, better adherence to diagnostic guidelines and improved safety-netting may at least partially help to prevent delays in diagnosing cancer.

In chapter 8, the main findings and conclusions of this thesis are discussed. In the Netherlands, cancer generally seems to be diagnosed within acceptable time limits. The patient interval and the secondary care interval generally are more time consuming than the primary care interval. In international comparison, the duration of diagnostic interval is generally similar to- or shorter than the duration in other gatekeeper based health care systems. GPs promptly refer the majority of the cancer patients and factors associated with long duration in primary care mainly reflect the diagnostic challenges of the GP. Even though GPs do miss opportunities sometimes, reduction of the primary care interval seems hardly possible without new test strategies and better risk assessment tools. Future focus should be on more detailed exploration of the secondary care interval and the potential for reducing its duration and potential beneficial effects of diagnostic interval reduction on disease outcomes and patient experiences. 
Nederlandse samenvatting 
Vroege opsporing van kanker wordt intensief nagestreefd. Er is steeds meer bewijs dat als de diagnose later wordt gesteld, de ziekte vaak verder gevorderd is, een slechtere prognose heeft en dat de ziektelast voor patiënten groter is. Hoe vlot de diagnose wordt gesteld hangt af van de efficiëntie van het diagnostisch traject. Het diagnostisch traject bestaat uit verschillende fases of intervallen: het patiënt interval, huisartsinterval, tweedelijnsinterval en therapeutisch interval. In al die fases kan (onnodige) vertraging optreden. Er bestaan grote verschillen in overleving bij kanker tussen verschillende landen. Waarschijnlijk wordt in elk geval een deel van die verschillen veroorzaakt door verschillen in het diagnostisch traject en hoe vlot dat verloopt. Er is al behoorlijk wat internationaal onderzoek uitgevoerd dat de duur van diagnostische trajecten beschrijft en factoren die de efficiëntie hiervan beïnvloeden. Voor Nederlandse kankerpatiënten is de duur van het diagnostisch traject en de verschillende fases hiervan echter nog niet in kaart gebracht. Het doel van dit proefschrift is daarom het in kaart brengen van het diagnostisch traject van Nederlandse kankerpatiënten, en het opsporen van ruimte voor verbetering. Hieronder vatten we de inhoud van de verschillende delen en hoofdstukken van het proefschrift samen.

In DEEL I van dit proefschrift presenteren we de duur van de verschillende fases van het diagnostisch traject van tien soorten kanker en onderzochten we voor een deel van die kankersoorten welke karakteristieken geassocieerd zijn met relatief lange duur.

In hoofdstuk 2 onderzochten we de duur van het diagnostisch traject van de vijf meest voorkomende kankersoorten in Nederland; borstkanker, colorectale kanker, prostaatkanker, longkanker en melanoom. We koppelden geanonimiseerde huisartsendossiers van patiënten met deze kankersoorten (gediagnosticeerd tussen 2007 en 20 II) aan gegevens van de Nederlandse Kankerregistratie. We bepaalden de mediane duur van het patient interval (IP, van bemerken van klachten tot eerste consult bij de huisarts), huisartseninterval (IPC, van eerste consult bij de huisarts tot verwijzing), tweedelijnsinterval (ISC, van verwijzing tot diagnose), behandelinterval (IT, van diagnose tot therapie) en het overkoepelende diagnostisch interval (ID, van eerste consult tot diagnose) en zorginterval (IHC, van eerste consult tot de start van therapie). We vonden dat de mediane duur van IPC, ISC en ID het kortst was voor borstkanker en melanoom (duur van ID respectievelijk 7 en 2 I dagen), middellang voor longkanker en colorectale kanker (duur van ID respectievelijk 49 en 54 dagen) en het langst voor prostaatkanker (duur van ID 137 dagen). Hoewel de duur van de diagnostische intervallen bij alle kankersoorten voor het grootste deel van de patiënten beperkt was, was bij 10 tot $25 \%$ van de patiënten de duur opvallend lang. Bij colorectale kanker werd bij stijgende IDduur steeds meer tijd bij de huisarts gespendeerd. Daarom lijkt het vooral voor deze kankersoort relevant om te onderzoeken hoe de lengte van het huisartsinterval kan worden verkort. 
In hoofdstuk 3, 4 en $\mathbf{5}$ exploreerden we het diagnostisch traject van minder vaak voorkomende kankersoorten, onderzochten we karakteristieken geassocieerd met 'lange duur' ( $\geq 75$ e percentiel, P75) en de associatie tussen duur en tumorstadium ten tijde van de diagnose. We gebruikten geanonimiseerde huisartsdossiers van symptomatische patiënten met slokdarm-, maag-, nier-, blaas-en ovariumkanker (gediagnosticeerd tussen 2010 en 2015) afkomstig uit zes Nederlandse routine zorgdatabases. Een deel van deze dossiers koppelden we aan gegevens van de Nederlandse Kankerregistratie. We bepaalden de duur van vier intervallen van het diagnostisch traject: het patiëntinterval (van eerste symptoom tot eerste consult bij de huisarts), het huisartsinterval (van eerste consult bij de huisarts tot verwijzing naar de tweede lijn), het tweedelijnsinterval (van verwijzing tot diagnose) en het diagnostisch interval (van eerste consult tot diagnose).

In hoofdstuk 3 presenteren we de resultaten voor slokdarm- en maagkanker. De mediane duur van het patiëntinterval was 29 dagen (interkwartiel interval 15-73 dagen), van het huisartsinterval 12 dagen (interkwartiel interval I-43 dagen), het tweedelijnsinterval I3 dagen (interkwartiel interval 6-29 dagen) en het diagnostisch interval 31 dagen (interkwartiel interval I I-74 dagen). De duur van het patiëntinterval was vergelijkbaar voor patiënten met en zonder alarmsymptomen. Log-binomiale regressieanalyse liet zien dat de afwezigheid van kankerspecifieke alarmsymptomen geassocieerd was met 'lange duur' van het huisartsinterval en tweedelijnsinterval: relatief risico respectievelijk 5.0 (95\% betrouwbaarheidsinterval 2.7-9.1) en 2.1 ( $95 \%$ betrouwbaarheidsinterval I.3-3.7). De mediane duur van het diagnostisch interval was $5 \mathrm{I}$ dagen (interkwartiel interval I3-I35 dagen) voor patiënten met lokale ziekte (stadium 0, I of II) en 27 dagen (interkwartiel interval II-7I dagen) voor patiënten met gevorderde ziekte (stadium III of IV), wat suggereert dat de ziekste patiënten het snelste traject ondergaan. Deze studie laat zien dat het patiënt interval het langste interval is in het diagnostisch traject van slokdarm- en maagkanker. Betere herkenning van alarmsymptomen door patiënten en aanvullende diagnostische strategieën waarmee kankerpatiënten beter kunnen worden geïdentificeerd zouden kunnen bijdragen aan het terugdringen van de tijd tot diagnose bij slokdarm- en maagkanker.

Hoofdstuk 4 geeft de resultaten weer voor nier- en blaaskanker. De duur van het patiënt interval, huisartsinterval, tweedelijnsinterval en diagnostisch interval was respectievelijk 6, 10, 39 en 56 dagen. 'Lange duur' ( $\geq 75$ th percentiel) werd vaker gezien bij vrouwelijke patiënten (in het huisarts interval) en bij patiënten zonder alarmsymptomen voor kanker (alle intervallen). In deze studie werd aanvullend ook de tijd van verwijzing tot start van de behandeling bepaald, om te kunnen vergelijken met het normeringsrapport van de Stichting Oncologische Samenwerking (SONCOS). De maximaal aanbevolen duur voor dit interval van 49 dagen werd in minder dan de helft van de patiënten gehaald. In het 
diagnostisch traject van nier- en blaaskanker lijkt de ruimte voor verbetering met name in de tweede lijn aanwezig.

In hoofdstuk 5 presenteren we de resultaten voor ovariumkanker. De mediane duur van het patiënt-, huisarts-, tweedelijns- en diagnostisch interval was respectievelijk I5, 6, 22 en 41 dagen. Patiënten met ovariumkanker-specifieke alarm symptomen (een toegenomen buikomvang en/of een palpabele massa in buik of bekken) hadden relatief vaak een lange duur ( $\geq$ P75) van het patiënt interval, terwijl patiënten zonder deze alarm symptomen relatief vaak een lange duur van het huisartsinterval hadden. Een lagere sociaal economische statusscore was geassocieerd met lange duur van het tweedelijnsinterval. Aanvullend bepaalden we de duur van verwijzing tot eerste behandeling, om te kunnen vergelijken met de maximale duur volgens het normeringsrapport van SONCOS. Voor $70 \%$ van de patiënten werd de aanbevolen maximale duur van 49 dagen gehaald. In vergelijking met de overige intervallen was de duur van het huisartsinterval voor patiënten met ovariumkanker relatief kort. In het algemeen lijken de duren van het diagnostisch traject van ovariumkanker acceptabel, maar voor een relevante minderheid (tot $20 \%$ van de patiënten) zijn de duren opmerkelijk lang. Omdat de symptomen van ovariumkanker zo aspecifiek zijn is het terugdringen van de tijd tot diagnose een uitdaging.

In DEEL II van dit proefschrift exploreerden we redenen voor lange duur van het huisartsinterval.

In hoofdstuk $\mathbf{6}$ onderzochten we het huisartsinterval van patiënten met colorectale kanker en de potentie om de duur hiervan terug te dringen. Geanonimiseerde huisartsdossiers van het Julius Huisartsnetwerk werden gekoppeld aan gegevens van de Nederlandse kankerregistratie. Op basis van deze gekoppelde database bepaalden wij de duur van het huisartsinterval en de associatie van patiënt- en presentie karakteristieken met lange duur tot verwijzing ( $\geq 75$ e percentiel, $\geq 59$ dagen). Daarnaast exploreerden we door middel van thematische vrije tekst analyse het huisartsinterval van de patiënten met de langste duur tot verwijzing ( $\geq 90$ e percentiel, $\geq 219$ dagen). Vrouwen, patiënten zonder geregistreerde familie anamnese voor colorectale kanker, met een maligniteit in de voorgeschiedenis, zonder alarmsymptomen bij eerste presentatie en patiënten met hemorroïden bij lichamelijk onderzoek hadden een verhoogd risico op lange duur tot verwijzing, op basis van de univariabele analyses (een langere mediane duur tot verwijzing of een univariable associatie met duur langer dan de 75e percentiel). In de multivariabele analyse was alleen de afwezigheid van alarmsymptomen statistisch significant geassocieerd met lange duur ( $\geq 75$ e percentiel). De thematische analyse van de patiënten met de langste duur tot verwijzing liet twee belangrijke thema's zien, namelijk: 'het hebben van een alternatieve werkdiagnose' en 'suboptimale diagnostische strategieën', waaronder 
het niet heroverwegen van de initiële werkdiagnose en inadequate follow-up. Deze studie liet zien dat lange duur tot verwijzing bij darmkanker vaak een logisch gevolg van relatief lage verdenking op kanker. Mogelijk is er wel winst te behalen wanneer huisartsen initiële werkdiagnoses vaker heroverwegen en huisartsen en patiënten followup afspraken strikter naleven.

Hoofdstuk 7 bestaat uit een thematische analyse van redenen voor de langste duur tot verwijzing bij negen kankersoorten.Van 203 patiënten met een opvallend lange duur tot verwijzing (duur langer dan de 90 e percentiel, variërend van $\geq 16$ dagen voor borstkanker tot $\geq 203$ dagen voor maagkanker) bestudeerden we uitgebreid de vrije teksten uit het geanonimiseerde huisartsdossier. Hierop voerden we een thematische analyse uit. Patiënten waarbij verwijzing lang op zich liet wachten waren vaker jong (borstkanker, maagkanker, ovariumkanker en melanoom), vaker vrouw (maagkanker, blaaskanker en melanoom) en presenteerden zich minder vaak met alarmsymptomen (alle negen kankersoorten). We identificeerden 10 thema's die bijdroegen aan de lange duur tot verwijzing, waarvan de meeste een lage (initiële) verdenking op kanker reflecteerden. Hoe vaak een thema een rol speelde en het 'relatieve gewicht' van het thema varieerde sterk per kankersoort. Voor zeven van de negen kankersoorten was het belangrijkste thema '(initiële) afwezigheid van alarmsymptomen of aspecifieke presentatie'. Voor de andere twee kankersoorten (maagkanker en blaaskanker) was dit het op een na belangrijkste thema. Bij maagkanker was het belangrijkste thema het 'maskerend effect van behandeling' (antacida en protonpomp remmers) en bij blaaskanker was dit 'intermitterende klachten'. De bevindingen van deze studie reflecteren de diagnostische uitdagingen waar de huisarts in de dagelijkse praktijk voor staat. Ook onderstreept deze studie het belang van betere diagnostische strategieën en hulpmiddelen, waarmee de huisarts kankerpatiënten beter kan herkennen, ook als ze zich niet met alarmerende symptomen presenteren. Omdat sommige diagnostische kansen door huisartsen gemist worden en de tijd tot herconsultatie soms lang is, kan het strikter naleven van richtlijnen en betere 'safety-netting' in elk geval deels bijdragen aan het terugdringen van vertraging bij het opsporen van kanker.

In hoofdstuk 8 bediscussiëren we de belangrijkste bevindingen en conclusies van dit proefschrift. In Nederland wordt kanker over het algemeen vlot gediagnosticeerd. Het patiënt interval en het tweedelijns interval nemen daarbij vaak meer tijd in beslag dan het huisartsinterval. In vergelijking met andere landen met een vergelijkbaar zorgsysteem is de duur van het diagnostisch traject in Nederland vergelijkbaar of korter. Huisartsen verwijzen het grootste deel van de patiënten tijdig door naar de tweede lijn, en de factoren die geassocieerd zijn met lange duur van het huisartsinterval reflecteren de diagnostische uitdagingen waar de huisarts in de praktijk voor staat. Hoewel huisartsen 
soms kansen missen, lijkt het terugdringen van de duur van het huisartsinterval haast onmogelijk zonder nieuwe diagnostische strategieën en tools voor betere herkenning van kanker bij de afwezigheid van alarmsymptomen. Toekomstig onderzoek dient zich ook te richten op een meer gedetailleerde analyse van het tweedelijns interval en de ruimte voor verbetering daarin, de ervaring van patiënten met betrekking tot de duur van het diagnostisch traject en de impact van snellere trajecten op verschillende uitkomsten. 
Dankwoord 
Het is af! Heel graag bedank ik iedereen die direct of indirect heeft bijgedragen aan het tot stand komen van dit proefschrift.

Prof. dr. N.J. de Wit, beste Niek, bedankt voor de prettige begeleiding de afgelopen vijf jaar. Jij had altijd oog voor zowel het project als voor hoe het met mij en de afwisseling tussen praktijk en onderzoek ging. Bedankt dat je, ook na de veranderingen in jouw loopbaan, altijd de tijd vond om snel en kritisch te reageren op de Dickens stukken. Dankzij jou zijn de grote lijnen nooit uit het oog verloren.

Prof. dr. P.H.M. Peeters, beste Petra, ik ben je erg dankbaar voor jouw fijne begeleiding en epidemiologische expertise. Het was altijd leuk om voorafgaand aan het overleg even te kletsen en te horen hoe het ging. Je nam altijd alle tijd om met mij de artikelen en analyses door te spreken, ook toen dat voor jou steeds moeilijker werd. Heel veel dank.

Dr. C.W. Helsper, beste Charles, ik waardeer jouw passie en enthousiasme voor de wetenschap enorm. Jij bent het toonbeeld van 'denken in mogelijkheden' en hebt me laten zien hoe ver je daarmee kunt komen. Overleggen werkte voor jou het beste met wat zuurtstof tijdens een rondje wandelen, maar veel vaker heb ik je in kleine overlegruimtes overladen met al mijn schema's en lijstjes; bedankt dat je dat hebt doorstaan. Ook veel dank voor al je slimme ideeën, die je meestal uitwerkte op een hoekje van een papier uit je achterzak: daar kon vaak geen schema tegenop! Heel erg bedankt voor de fijne samenwerking de afgelopen 5 jaar, ik ga het echt missen.

Prof. dr. H.C.P.M. van Weert, prof. dr. C.H. van Gils, prof. dr. R.A.M.J. Damoiseaux, prof. dr. P.O. Witteveen en prof. dr. F.P.Vleggaar, hartelijk dank voor het lezen en beoordelen van mijn manuscript.

Graag dank ik alle patiënten waarvan we de gegevens hebben kunnen gebruiken voor dit onderzoek, alle huisartspraktijken aangesloten bij de registratienetwerken, de registratienetwerken zelf en de Nederlandse Kankerregistratie; de data vormen de basis van dit proefschrift.

Er waren maar liefst 28 wetenschappelijke stages nodig om alle data te kunnen verzamelen. Ik wil alle studenten die hebben bijgedragen enorm bedanken voor de inzet, het enthousiasme en de gezelligheid: Ramon, Charlotte, Bart, Saskia, Amber, Carolien, Margarita, Myrthe, Tessa, Aysenur, Jessika, Eliza, Rinck, Anne, Françoise, Stijn, Lisanne, Stacey, Nanne, Valerie, Liedeke, Sam, Renske, Eva, Nathalie en Wieke: zonder jullie was het niet gelukt! 
Datamanagers van het Julius Centrum en het Julius Huisartsen Netwerk, Julia Velikopolskaia en Nicole Boekema, bedankt voor de tijd en energie die jullie hebben gestoken in het samenstellen van de datasets en het beantwoorden van onze vragen daarover. Nicole, veel dank voor het meedenken over en het uitwerken van de koppeling. Jij was onmisbaar als vraagbaak en korte lijn met de andere netwerken.

Alle data-managers, co-auteurs en betrokkenen vanuit de verschillende registratienetwerken: veel dank voor jullie inspanningen! JHN; Hugo Smeets, dank voor de eerste overleggen over de JGPN data en het meedenken over de mogelijkheden, Marlous Kortekaas, bedankt voor je analyse van de patiënten met de langste duur tot verwijzing en bijdrage aan de artikelen. ANH VUMc Amsterdam; Pauline Slottje en Hanna Joosten, bedankt voor het meedenken, het prepareren van de datasets en het realiseren van de dataverzameling door studenten en mijzelf bij jullie op locatie. HAGnet AMC Amsterdam; Derk Arts en Erna Beers, bedankt voor de eerste oriënterende overleggen en inzicht in jullie data. Erna, dank voor de realisatie van een wetenschappelijke stage bij jullie en de begeleiding van Renske. Kristel van Asselt, bedankt voor je analyse van de patiënten met de langste duur tot verwijzing en je kritische blik op de verschillende artikelen. RNG Groningen; Feikje Groenhof en Daan Brandenbarg; dank voor jullie bijdrage aan de artikelen en de realisatie van een Groningse studentenstage voor Dickens door Wieke. RNUH LEO Leiden: Henk de Jong en Margot de Waal, bedankt voor het meedenken en prepareren van de datasets. Frederieke Buchner, bedankt voor je bijdrage aan de artikelen, het mogelijk maken van de dataverzameling bij jullie op locatie en het samen begeleiden van Stijn. RNFM Maastricht: Marjan van den Akker en Jos Boesten: dankzij jullie konden ook de Limburgse data onderdeel uitmaken van ons onderzoek. Alle betrokken Limburgse huisartspraktijken, bedankt voor het mogelijk maken van dataverzameling bij jullie in de praktijk. Professor J.W.M. Muris, dank voor uw analyse van de patiënten met de langste duur tot verwijzing en het kritisch meelezen van de verschillende artikelen.

Prof. dr. R.P. Zweemer en dr. P.M. Willemse, bedankt voor het sparren over het diagnostisch traject van de kankersoorten binnen jullie expertise gebied, respectievelijk de oncologische gynaecologie en oncologische urologie. Dr. A.P.E. Sachs, hartelijk dank voor uw analyse van de patiënten met de langste duur tot verwijzing en het uitgebreid bespreken daarvan.

Medewerkers van IKNL, Janneke Verloop en Henrike Bretveld - de nodige uitdagingen werden overwonnen en het is gelukt! Bedankt voor al het denkwerk en jullie inspanningen de koppeling van de huisartsdossiers aan de gegevens van de Nederlandse kankerregistratie voor elkaar te krijgen. 
Medewerkers van ZorgTTP, veel dank voor de vlotte realisatie van de koppeling. Ingeborg Sanders, jouw koppelschema was de perfecte basis voor het uitdenken ervan.

Het Julius centrum was een inspirerende omgeving waar ik van veel mensen heb kunnen leren. Julius collega's, waaronder alle leden van de oncologie groep: bedankt voor de goede ideeën en kritische noten. Coby en Henk, bedankt voor de onsteuning met alle praktische zaken, waaronder het op gang helpen van de eerdergenoemde studenten.

Alle (oud)kamergenoten uit het Stratenum en het van Geuns, ganggenoten, medepromovendi en mede AIOTHO's. Bedankt voor de gezelligheid, de koffietjes, writingmornings, minuutjes planken tussendoor, alle andere sportieve uitspattingen, de leuke congresbezoeken, het lachen, het delen van alle frustraties en het sparren over onderzoek en tal van andere zaken. Het was een mooie tijd!

Lieve paranimfen, ik ben heel blij dat jullie tijdens mijn verdediging achter me willen staan! letje, ik waardeer jouw kijk op de dingen en hoe je altijd bij jezelf blijft enorm. Dankje voor de gezelligheid in het van Geuns en tijdens alle congressen, de goede adviezen, je humor en natuurlijk alle drop. Fleur, ik wilde op onze oude zolderkamer nooit met jou een spelletje spelen en vouwde altijd de Donald Duck verkeerd dubbel; gelukkig heb je me dat vergeven! Je bent allang niet meer het kleine zusje, maar een vrouw vol daadkracht en ambitie waar ik supertrots op ben.

Lieve vrienden, bedankt voor de betrokkenheid, gezelligheid en afleiding de afgelopen jaren. Floriek, Suus, len, Pam en Robin; heel fijn altijd weer toe te kunnen leven naar het volgende koffietje, etentje, zomer- of kerstdiner, rondje fietsen of weekendje weg. Laten we dat met de mannen (en kinderen!) erbij nog veel blijven doen. Jiske en Jolien, Beekie en Jo, we drinken allang niet meer wekelijks MooiKaap samen en onze spreiding over het land had niet verder uit elkaar kunnen liggen, maar ik ben blij dat we elkaar nog zo veel als mogelijk zien. Ik kijk terug op een hele mooie geneeskundetijd met jullie en ben trots op wat jullie sindsdien hebben bereikt! Pien, onze middelbare school projecten (biokast, proef met de magneet en ons profielwerkstuk) waren nou niet echt wetenschappelijke hoogstandjes, maar wie weet vormden ze toch de basis tot interesse in onderzoek? Het maakt niet uit hoe lang er tussen heeft gezeten, jou zien, even bellen of een kaartje van jou krijgen maken me altijd heel blij! Boulderbitches, dinnertimers, spirelli's; bedankt voor alle gezelligheid, het is altijd fijn om met jullie te kunnen sparren over het artsen- en onderzoekersbestaan, en al het andere daaromheen.

Lieve Boermannen- en vrouwen, wat bof ik met jullie als schoonfamilie. Bij jullie kan iedereen zichzelf zijn en is het altijd gezellig en ontspannen. Betere momenten van 
ontspanning dan op de boot in Griekenland of Friesland kon ik me niet wensen de afgelopen onderzoeksjaren. Bedankt voor jullie altijd oprechte interesse en betrokkenheid!

Lieve zussen, Francine en Fleur, als ik ergens altijd terecht kan, dan is het bij jullie. Francine, jij bent me in het leven met veel dingen voorgegaan, zo ook met de studie geneeskunde en het promoveren, en ik bewonder hoe goed jij de dingen altijd doet. Jouw wijze raad en luisterend oor betekenen heel veel voor me, dankjewel!

Lieve pap en mam, alle kansen om te komen waar ik wil zijn heb ik aan jullie te danken! Thuiskomen bij jullie, waar dat ook is, is altijd fijn. Bedankt voor jullie onvoorwaardelijke steun.

Charlie, bedankt voor het vrolijke onthaal elke dag en voor al die kilometers langs de Singel; mijn redding in Corona- en proefschrifttijd!

Lieve Bram, bedankt voor je eindeloze energie, optimisme en alle avonturen die we beleven. Ik ben je heel dankbaar dat je er altijd voor me bent en hoop dat we de mooie plannen die we allemaal nog voor ogen hebben samen waar mogen maken. 
About the author 


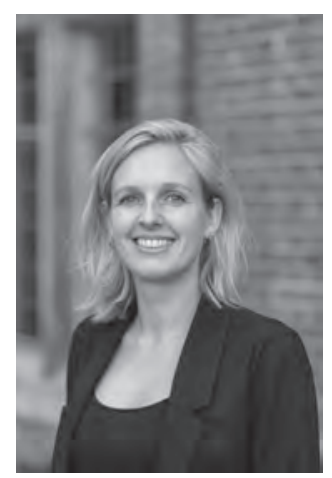

Nicole van Erp was born on January 12th 1988 in Huizen, the Netherlands. After living in Friesland for a few years she grew up in Soest. She graduated from the Baarnsch Lyceum in 2006 and moved to Utrecht to start with the studies Liberal Arts and Sciences.After completion of the first year, she followed her interest in the healthrelated courses and switched to Medicine. During her research internship at the Julius Center for Health Sciences and Primary Care, under supervision of Prof. dr. Th.J.M. Verheij, her interest in scientific research was raised. After obtaining her medical degree in 2013, Nicole worked as a Paediatrics resident at Gelre Hospital, Apeldoorn. As she decided to become a general practitioner and her interest in research sustained, she was happy to get the chance to start a primary care related PhD project: the Dickens studies, of which this thesis is the result. Nicole was supervised by dr. C.W. Helsper, prof. dr. P.H.M. Peeters and prof. dr. N.J. de Wit and combined her work as a PhD student with the training to become a general practitioner (AIOTHO traject). During this AIOTHO traject, she completed the postgraduate Master in Clinical Epidemiology at Utrecht University. Currently, Nicole started her last year of the GP vocational training, which she hopes to complete in the summer of 2021. 

